\title{
How-to Suggestions for Implementing Executive Order 12941 on Seismic Safety of Existing Federal Buildings, A Handbook
}

Ann Bieniawski

Diana Todd

November 1995

Building and Fire Research Laboratory

National Institute of Standards and Technology

Gaithersburg, MD 20899

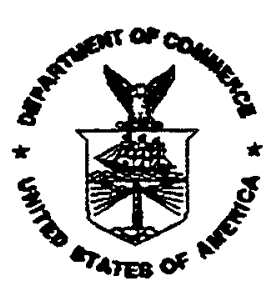

U.S. Department of Commerce

Ronald H. Brown, Secretary

Technology Administration

Mary L. Good, Under Secretary for Technology

National Institute of Standards and Technology

Arati A. Prabhakar, Director
Prepared for:

Federal Emergency

Management Agency

Mitigation Directorate

Washington, DC 20472 


\section{ACKNOWLEDGEMENTS}

The Interagency Committee on Seismic Safety in Construction (ICSSC) Subcommittee 1, Standards for New and Existing Buildings, developed and reviewed this document to accompany ICSSC RP5, ICSSC Guidance on Implementing Executive Order 12941 on Seismic Safety of Existing Federally Owned or Leased Buildings. The following people contributed to the development of this document:

ICSSC Members:

H.S. Lew, chairman

Kharaiti Abrol

Charles Anderson

Krishna Banga

James Binkley

Larry Black

Jack Brynda

Oilda del Castillo

Harish Chander

Tom Chappell

Joseph Corliss

Richard Cutsinger

Mike Davister

Don Denton

Don Evick

Nathaniel Foster

Joe Galetovic

Charles Gutberlet

Lucian Guthrie

Bruce Hall

Walt Hays

Don Heald

James Hill

Sam Hodges

Larry Hultengren

Bill Jacks

Paul Johnson

Howard Kass

Tom Kearns

Jeff Kimball

Jim Lafrenz

Doreen Christian Laroche

Shi-Chi Liu

Robert Madison

Rita Martin

Tom Moran
National Institute of Standards and Technology

Veterans Affairs

Dept. of Interior

Veterans Affairs

US Postal Service

HQ Dept. of Army

Dept. of Interior

US Information Agency

Dept. of Energy

US Dept. of Agriculture

Health and Human Services

Tennessee Valley Authority

Dept. of Energy

Dept. of Energy

US Postal Service

Tennessee Valley Authority

Dept. of Interior

US Army Corps of Engineers

US Army Corps of Engineers

General Services Administration

US Geological Survey

US Dept. of Agriculture

Dept. of Energy

US Dept. of Agriculture

Dept. of State

Tennessee Valley Authority

Dept. of Interior

National Aeronautics and Space Administration

Federal Bureau of Prisons

Dept. of Energy

US Air Force

US Dept. of Agriculture

National Science Foundation

Dept. of Transportation

Dept. of Transportation

Environmental Protection Agency 
Ugo Morelli

Tom Myers

Tom Nelson

Howard Nickerson

Brian Olson

David Perkins

LJ Porter

Fidel Rodriguez

Eufracio Sabay

Erdal Safak

John Scalzi

Mike Schilling

Herbert Schneider

Subir Sen

Charles Smith

Bob Stein

Lance Swanhorst

Steve Sweeney

Terry Wong

Marshall Wright
Federal Emergency Management Agency

Smithsonian Institute

Dept. of Energy

US Navy

Dept. of Interior

US Geological Survey

Dept. of Interior

US Army Corps of Engineers

Dept. of Interior

US Geological Survey

National Science Foundation

Dept. of State

Dept. of Interior

Dept. of Energy

Dept. of Interior

Dept. of Transportation

Environmental Protection Agency

US Army Corps of Engineers

Dept. of Interior

Dept. of Interior

ICSSC Technical Secretariat:

Diana Todd, NIST

Ann Bieniawski, NIST

Structural Engineering Consultants:

Chris Poland, Degenkolb Engineers

William T. Holmes, Rutherford \& Chekene

NIST Consultants

Keith Eberhardt, Engineering Statistics

Terry King, Computer Databases 


\section{PREFACE}

On December 1, 1994, the President signed Executive Order 12941, Seismic Safety of Existing Federally Owned or Leased Buildings. The order adopted minimum technical standards for all future seismic safety evaluation and rehabilitation projects for Federally owned and leased buildings. These standards, Standards of Seismic Safety for Existing Federally Owned or Leased Buildings, are referred to in this document as ICSSC RP4. In addition, the order called for all agencies and departments owning or leasing buildings to develop, by December 1, 1998, a seismic inventory of their owned and leased buildings, and to estimate the costs of mitigating unacceptable seismic risks in that inventory.

The inventory and cost information is being collected in order to develop reliable information upon which to build future public policy. At the time the order was signed, only limited data on the vulnerability of the approximately half-million Federally-owned buildings existed. The government-wide seismic rehabilitation cost estimates that could be generated based on this data were judged to be too uncertain to allow for reliable budget planning.

The order directs the Interagency Committee on Seismic Safety in Construction (ICSSC) to issue guidance on how to develop the inventory and cost estimate. Thirty Federal departments and agencies with an interest in seismic safety participate in the ICSSC. A major role of the ICSSC is to encourage the adoption of consistent and effective seismic safety practices by all entities of the Executive Branch of the Federal government. This is accomplished in part by developing and issuing Recommended Practices. A Recommended Practice (ICSSC RP document) must be approved by at least two thirds of the member departments and agencies before it is issued.

The ICSSC Guidance on how to implement the Executive Order was published as RP5, ICSSC Guidance on Implementing Executive Order 12941 on Seismic Safety of Existing Federally Owned or Leased Buildings. This document, TR-17, is meant to supplement the RP5 document by giving examples of how to put this guidance into practice.

Each agency's inventory and cost estimate is to be forwarded to the Federal Emergency Management Agency (FEMA) by December 1, 1998. FEMA will use the data to examine a wide variety of potential programs to upgrade the seismic safety of existing Federal buildings. The order directs FEMA to submit to Congress, by December 1, 2000, a "comprehensive report on how to achieve an adequate level of seismic safety in federally owned and leased buildings in an economically feasible manner." It is hoped that this effort will lead to the adoption of a proactive program of systematic upgrading of the seismic safety of Federal buildings.

The Technical Secretariat of the ICSSC is maintained by the Building and Fire Research Laboratory at the National Institute of Standards and Technology (NIST). For additional copies of this or other ICSSC documents, write to:

ICSSC Technical Secretariat

NIST/Building and Fire Research Laboratory

Building 226, Room B158

Gaithersburg, MD 20899 


\begin{abstract}
This Handbook supplements ICSSC RP5, ICSSC Guidance on Implementing Executive Order 12941 on Seismic Safety of Existing Federally Owned or Leased Buildings. RP5 describes the approach recommended by the Interagency Committee on Seismic Safety in Construction (ICSSC) to fulfill the inventorying and cost estimating requirements of Executive Order 12941, Seismic Safety of Federally Owned or Leased Buildings. This Handbook describes detailed methodologies for developing inventories, screening for exempt buildings, identifying buildings for evaluation, and developing cost estimate information. These methodologies are not mandatory requirements of the ICSSC recommended program but provide guidance for agencies which do not have agency-specific programs in place and would like a model to follow. The Handbook also outlines the specific fields to be entered into each agency's electronic database for owned buildings as well as the specific items which should be discussed in the supporting documentation. Each agency is required to follow the format outlined in these sections when submitting their information in order to ensure that data received from all agencies is compatible and machine-readable.
\end{abstract}




\section{TABLE OF CONTENTS}

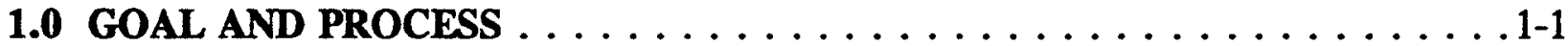

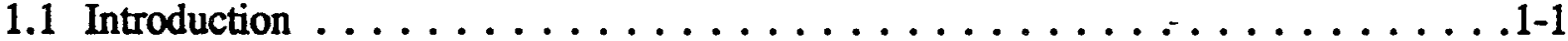

1.2 The Recommended Program: Owned Buildings . . . . . . . . . . . . 1-1

1.3 The Recommended Program: Leased Buildings . . . . . . . . . . . . . 1-1

1.4 Products to be Produced by Each Agency . . . . . . . . . . . . . . 1-2

1.5 Organization of the Handbook . . . . . . . . . . . . . . . 1-3

2.0 OWNED INVENTORY DATABASE . . . . . . . . . . . . . 2-1

2.1 Relationship to Existing Real Property Inventories $\ldots \ldots \ldots \ldots \ldots . \ldots .2-1$

2.2 Scope and Screening of Inventory . . . . . . . . . . . . . . 2-1

2.2.1 Grouped Buildings Versus Building-by-Building Reporting $\ldots \ldots \ldots .2-2$

2.2.2 Identifying Exempt Buildings (Screening the Inventory) $\ldots \ldots \ldots . . .2-3$

2.2.3 One Possible Screening Process . . . . . . . . . . . . . . . 2-4

2.2.4 RP4 Exemptions and How to Identify Them . . . . . . . . . 2-5

2.3 Required Inventory Data . . . . . . . . . . . . . 2-13

2.3.1 Data Needed for All Buildings . . . . . . . . . . . . . 2-13

2.3.2 Additional Data Needed for Exempt Buildings . . . . . . . . . 2-14

2.3.3 Additional Data Needed for Non-Exempt Buildings . . . . . . . . . . 2-14

Non-Exempt Evaluated Buildings . . . . . . . . . . . . . . . 2-20

Non-Exempt Evaluated Buildings Found to be Deficient . . . . . . . 2-21

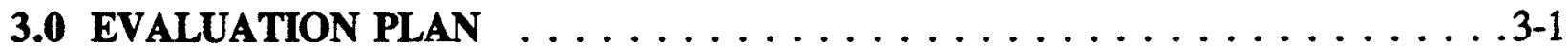

3.1 Selection of Buildings for Evaluation . . . . . . . . . . . . . 3-1

3.1.1 Evaluate All Exceptionally High Risk Buildings . . . . . . . . . . 3-1

Identification of Exceptionally High Risk Buildings . . . . . . . . . 3-2

Prioritization Process Used by the Air Force . . . . . . . . . . . 3-5

Prioritization Process Used by the Department of Energy . . . . . . . . 3-8

3.1.2 Evaluate a Representative Sample of Remaining Non-Exempt Buildings . . 3-12

Option A: Selecting a Random Sample . . . . . . . . . . . 3-13

Option B: Selecting Buildings Based on Seismic Risk . . . . . . . 3-15

Agencies with Very Small Inventories . . . . . . . . . . . . 3-17

3.1.3 Report Results From Previous Evaluations . . . . . . . . . . 3-18

3.2 Performing Evaluations on Selected Buildings . . . . . . . . . . . 3-19

3.2.1 Goal of Evaluation . . . . . . . . . . . . . . . . . . 3-19

3.2.2 Definitely Needing Rehabilitation Buildings $\ldots \ldots \ldots \ldots \ldots . \ldots$ 3-20

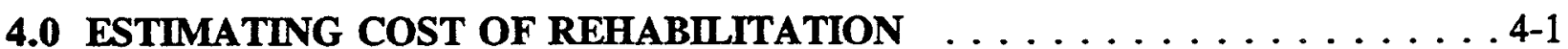

4.1 Cost Estimates for Evaluated and Deficient Buildings $\ldots \ldots \ldots \ldots \ldots$ 4-1

4.1 .1 Cost Categories . . . . . . . . . . . . . . . . . . .4-1

4.1.2 Cost Estimation Methods . . . . . . . . . . . . . . . .4-2

4.2 Cost Estimates for Non-Evaluated Buildings $\ldots \ldots \ldots \ldots \ldots \ldots$. . . . . .

5.0 REPORTING REQUIREMENTS $\ldots \ldots \ldots \ldots \ldots \ldots \ldots \ldots \ldots \ldots$. . . . . . . . .

5.1 Contents and Format of the Submission . . . . . . . . . . . .

5.1 .1 Owned Building Database Information . . . . . . . . . . 
Data Needed for All Buildings . . . . . . . . . . . . 5-2

Data Needed for Non-Exempt Buildings . . . . . . . . . . 5-5

Data Needed for Non-Exempt Evaluated Buildings . . . . . . . . . 5-6

Non-Exempt Evaluated Buildings Found to be Deficient . . . . . . . 5-7

5.1 .2 Supporting Documentation . . . . . . . . . . . . . . 5-12

5.2 Corrections to Submitted Databases $\ldots \ldots \ldots \ldots \ldots \ldots \ldots \ldots$. $\ldots \ldots \ldots$

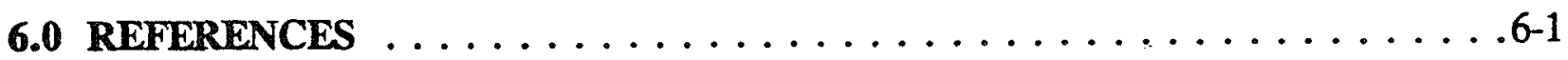

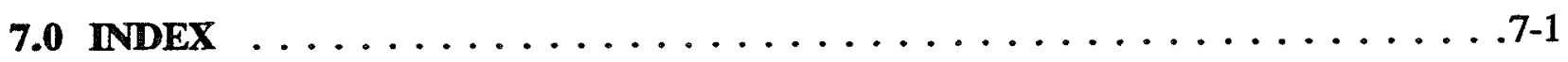

APPENDIX A

APPENDIX B 


\section{LIST OF FIGURES AND TABLES}

Figure 1-1 - Decision Tree for Owned Buildings . . . . . . . . . . . . . 1-4

Table 2-1 - Predominant Building Code Use . . . . . . . . . . . . . . . 2-8

Table 2-2 - Simplified Benchmark Years . . . . . . . . . . . . . . . . 2-9

Table 2-3 - RP4 Table 1: Advisory Benchmark Years . . . . . . . . . . . . . 2-12

Table 2-4 - Required Inventory Data for Owned Buildings . . . . . . . . . . . . . . 2-23

Table 3-1 - Number of Occupants Per 93 Square Meters (1000 Sq Ft) . . . . . . . . . 3-2

Table 3-2 - Indicators of Potential for Higher Seismic Risk . . . . . . . . . . . . 3-3

Table 3-3 - Air Force Performance Objective Categories . . . . . . . . . . . . . . 3-6

Table 3-4 - Air Force Risk Groups . . . . . . . . . . . . . . . . . . . 3-6

Table 3-5 - DOE Definition of Failure Consequences . . . . . . . . . . . . . . 3-9

Table 3-6 - DOE Definition of Building Vulnerability . . . . . . . . . 3-10

Table 3-7 - DOE Building Vulnerability Factor . . . . . . . . . . . . 3-11

Table 3-8 - Suggested Building Characteristics to be Used to Categorize Buildings . . . 3-13

Table 3-9 - Sample Inventory Partitions for Use in Identifying Dominant Characteristics 3-14

Table 3-10 - Sample Inventory Breakdown . . . . . . . . . . . . . . 3-15

Table 3-11 - Sample Inventory Breakdown for Risk Based Method . . . . . . . . . . 3-16

Table 4-1 - Cost Reporting for Non-Evaluated Buildings . . . . . . . . . . . . . 4-5

Table 5-1 - Agency Codes . . . . . . . . . . . . . . . . . . .5-3

Table 5-2 - Reasons for Exemptions . . . . . . . . . . . . . . . 5-4

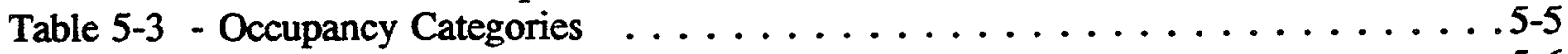

Table 5-4 - Model Building Types $\ldots \ldots \ldots \ldots \ldots \ldots \ldots \ldots \ldots . \ldots \ldots$

Table 5-5 - Sources for Cost Estimates . . . . . . . . . . . . . . . 5-8

Table 5-6 - Example Inventory Using Codes . . . . . . . . . . . . . . 5-10 


\subsection{GOAL AND PROCESS}

\subsection{Introduction}

This document supplements ICSSC Guidance on Implementing Executive Order 12941 on Seismic Safety of Existing Federally Owned or Leased Buildings (RP5) [Todd, 1995]. RP5 presents recommendations of the Interagency Committee on Seismic Safety in Construction (ICSSC) to agencies affected by Section 2 of Executive Order 12941, Seismic Safety of Existing Federally Owned or Leased Buildings. Section 2 states that all Federal departments and agencies that own or lease buildings "shall develop an inventory of their owned and leased buildings and shall estimate the costs of mitigating unacceptable risks in those buildings. . . Cost estimates with supporting documentation shall be submitted to the Director of the Federal Emergency Management Agency (FEMA) no later than four years after the signing of this order."

This Handbook offers two additional levels of guidance beyond that presented in RP5:

1) detailed methodologies for fulfilling the RP5 recommendations for inventorying and cost estimating, which can be followed as default procedures by agencies which do not have agency-specific programs in place and which do not wish to develop agency-specific programs, and

2) detailed specifications for preparing and submitting the cost estimate and supporting documentation called for in the Executive Order. While the first type of guidance, presented in Sections 1-4 of this Handbook, is optional, the second type, presented in Section 5 , is to be considered mandatory in order to ensure uniform reporting.

\subsection{The Recommended Program: Owned Buildings}

The recommended program for owned buildings outlined in the Guidance Document and discussed in detail in this Handbook emphasizes the collection of data based on seismic evaluations on all high risk/high priority buildings and on a representative sample of lower risk/lower priority buildings, as determined by the agency in both cases. This approach will give thorough and accurate information on the population of buildings considered by the agencies to be at the highest risk. The sample information which is collected for the lower risk/lower priority buildings will be used to estimate the extent of necessary rehabilitation in the nonevaluated buildings and the costs of those rehabilitation efforts. All data will eventually be used to examine a wide variety of possible overall Federal seismic rehabilitation programs. The recommended inventorying and cost estimating program for owned buildings is outlined in the decision tree shown in Figure 1-1. The numbers in each block represent Sections of this Handbook which contain guidance related to that particular issue.

\subsection{The Recommended Program: Leased Buildings}

Executive Order 12941 adopts Standards of Seismic Safety for Existing Federally Owned or Leased Buildings (RP4) [Todd, 1994] as a minimum standard for use by Federal departments 
and agencies. RP4 states that existing leases may be held without action (concerning their seismic safety) until the lease expires, but that new leases and lease renewals are not to be made in seismically unsafe space. Through this mechanism, it is expected that the seismic safety of leased space will be gradually, systematically reduced. The ICSSC does not expect that a more aggressive program for reducing seismic risk in leased buildings will be recommended any time in the foreseeable future.

Despite this, the Executive Order does require that an inventory of leased buildings be developed, and that an estimate of the cost of mitigating unacceptable seismic risk in leased buildings be submitted. Agencies may submit any existing inventory of leased buildings to fulfill this requirement. No special formatting or data collection is needed. Note that buildings leased from GSA or another Federal department or agency need not be reported by the leasing agency. Such buildings are to be reported as owned buildings by the owning agency.

Agencies are asked to determine the costs of implementing the RP4 program for reducing risks in leased buildings, and to report their findings in the supporting documentation. This brief report should address, at a minimum, the following issues:

- How are the requirements that leases not be entered into or renewed in seismically unsafe space being implemented in the leasing programs of the department or agency?

- What administrative costs are expected within the agency for including this consideration of seismic safety in the leasing process?

- Are leases in seismically-acceptable space expected to be more costly than leases in seismically-hazardous space?

\subsection{Products to be Produced by Fach Agency}

Each agency is to submit an electronic inventory database of its owned buildings, including the types of information specified in RP5, using the format specified in Section 5 of this Handbook. This database will contain building-by-building specific information as well as seismic hazard mitigation cost estimates for each building selected for evaluation and found to be deficient. An inventory of leased buildings is also to be submitted, in any format that is convenient for the agency but preferably in an electronic format. This inventory should contain any information pertinent to seismic safety that the agency already has regarding leased buildings. Supporting written documentation is to accompany the inventory databases, including an estimate of the rate of attrition of buildings from the agency's inventory, and a record of the costs of performing seismic evaluations completed to fulfill the requirements of the Executive Order. An estimate of mitigation costs for the owned buildings which were not evaluated is to be included in the supporting documentation along with any agency specific definitions and methodologies used in the inventorying and cost estimating process. The minimum content of the supporting documentation is described in Section 5.1.2 of this Handbook. 


\subsection{Organization of the Handbook}

This Handbook is written in parallel with RP5 so that the main section numbers are the same in each. Sections 2 and 3 of this Handbook give suggested methodologies for screening exempt buildings, identifying exceptionally high risk buildings, and establishing a representative sample from the remaining non-exempt buildings. These methodologies are not mandatory; they simply give guidance to agencies which do not have methodologies of their own. Section 4 describes acceptable cost-estimating approaches. Section 5 of this Handbook describes the format for the inventory database of owned buildings which must be followed by all agencies in order to ensure a consistent and machine-readable total database. 
Figure 1-1 - Decision Tree for Owned Buildings

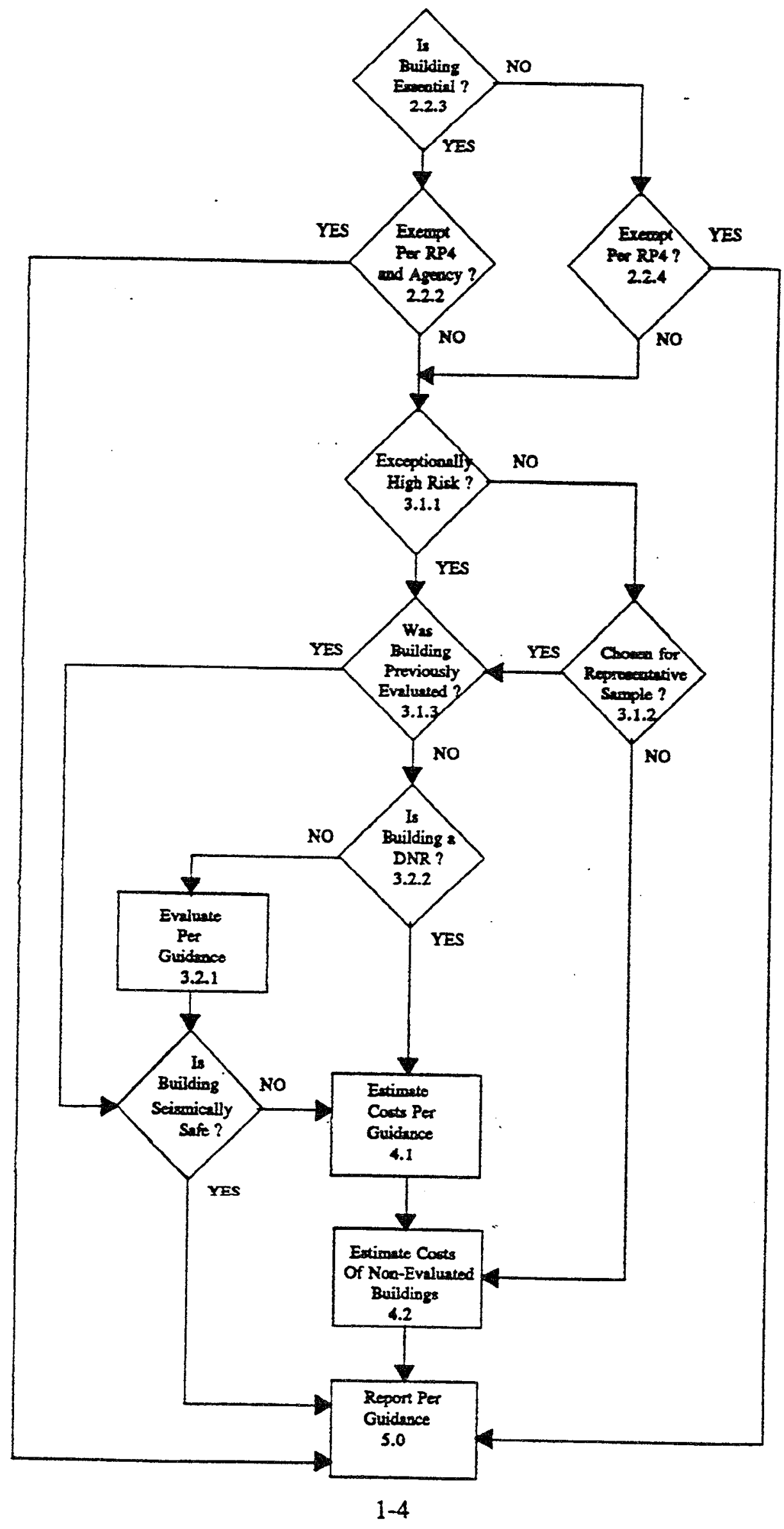




\subsection{OWNED INVENTORY DATABASE}

An inventory database containing information on all buildings owned by the department or agency is to be created and submitted in electronic format. See Section 5 of this Handbook for details of the database reporting format. (The discussion in this section and the detailed format information contained in Section 5 apply only to owned buildings, not leased buildings.)

\subsection{Relationship to Existing Real Property Inventories}

\section{The General Services Administration Real Property Database}

Most Federal agencies currently submit an inventory of their owned and leased real property to the General Services Administration (GSA) annually. The seismic inventory to be produced in response to Executive Order 12941 will use much of the same information already collected for that effort, and many of the same codes. Therefore, for many agencies, it may be time and cost-effective to build their seismic inventory using the GSA-required inventory as a base.

The GSA office which collects and collates the real-property information has informed the ICSSC that most agencies owning large numbers of buildings and other property submit the information electronically. However, there remains a significant number of agencies that submit their inventories on paper (manually). In these cases, GSA enters the manually-submitted data into their electronic database. The GSA database is available at no cost to other Federal agencies, in both electronic and paper formats. Therefore, if an agency typically submits their real-property information to GSA manually, they can get an electronic version to use as the base for the seismic inventory by contacting the GSA Office of Governmentwide Real Property Policy on (202) 219-0077. The GSA database is supplied in a generic form that can be read and manipulated by most PC-based word processing, spreadsheet, and database programs.

\section{Other Databases}

Some agencies have electronic seismic inventories already in place. In most cases, the information already collected will be usable for the Executive Order 12941 inventory. In some instances some translation of data will be needed, for example, translating Uniform Building Code (UBC) seismic zones to NEHRP-based seismicities of High, Moderate, and Low. Algorithms to make this and similar translations automatically can be developed. The ICSSC Technical Secretariat will be available to offer suggestions and ideas for how to address these types of problems.

\subsection{Scope and Screening of Inventory}

All owned buildings are to be listed in the inventory database and screened into "exempt" and "non-exempt" categories. This section of the Handbook gives detailed suggestions on how to identify (screen) exempt buildings. Note that the Executive Order applies only to buildings within the United States, as defined in the Earthquake Hazards Reduction Act of 1977 as amended. That definition, from Public Law 95-124 as amended, is: 
Section 4 (5) - The term "United States" means, when used in a geographical sense, all the States as defined in section 4 (4).

Section 4 (4) - The term "State" means each of the States in the United States, the District of Columbia, the Commonwealth of Puerto Rico, the Virgin Islands, Guam, American Samoa, the Commonwealth of the Mariana Islands, and any other territory or possession of the United States.

\subsubsection{Grouped Buildings Versus Building-by-Building Reporting}

Similar buildings may be reported in the electronic database in groups, rather than as individual entries, if they meet the criteria given below. When buildings are reported in groups, the number of buildings included in the group and the total area in square meters for all buildings must be reported.

Exempt buildings can be reported in the database in groups if they share the same occupancy class, the same state, county and seismicity and the same reason for exemption (e.g. 152 picnic shelters in the same county which collectively total 30,400 square feet, exempted because they are small, single-story, wood-frame structures, may be reported in one entry in the inventory database; reporting details are given in Section 5).

Non-exempt, non-evaluated buildings may be reported in groups only if they have the following characteristics in common:

- all characteristics identified above for groups of exempt buildings, except for "reason for exemption",

- similar $( \pm 10 \%)$ size and number of stories,

- similar date of construction ( \pm 5 years)

- same model building type

- same classification in historic, essential, and exceptionally high risk categories

Non-exempt, evaluated buildings may be reported in groups only if they have the following characteristics in common:

- all characteristics identified above for groups of non-exempt, non-evaluated buildings

- same soil type

- same foundation type

For groups of buildings sharing these characteristics, a representative building may be selected for evaluation rather than evaluating each building in the group individually. In these cases, the same evaluation outcome, reason for deficiency (if any), and cost per square meter for rehabilitation are to be assumed for all buildings in the group.

All characteristics identified above are described in detail in Section 2.3 of this document.

For agencies which choose to use the GSA-required database as a starting base, it is 
important to note that it includes many multiple-building entries. In some cases, some of the buildings in a multiple-building entry will be exempt, and others will be non-exempt. In other cases, all the buildings in a group will be exempt for the same reason (e.g. one- or twofamily dwellings in regions where the expected seismic acceleration is less than $0.15 \mathrm{~g}$ ). Agencies that utilize their GSA-required database as a starting point are encouraged to identify as many exempt groups of buildings as possible before making the effort to reconstitute the database into a building-by-building listing.

\subsubsection{Identifying Exempt Buildings (Screening the Inventory)}

Buildings are to be labeled as exempt if they meet the criteria for exemption given in Section 1.3 of RP4. RP4 exemptions are reprinted below. The codes to be used in reporting the reason for exemption in the inventory database are given in Section 5 of this Handbook.

Buildings are also considered to be exempt if they will no longer be used by any branch of the Federal government in five years because they are scheduled to be abandoned, demolished, sold or otherwise removed from government service. The purpose of adding this exemption is to not include in the cost estimate any building which is already scheduled to be removed from the Federal inventory and hence will not be part of this inventory for any future seismic rehabilitation actions. For purposes of this cost estimating exercise, any building which is scheduled to be given to the private sector within the next five years will be considered exempt. If the Federal government is passing on a facility which it knows to be seismically deficient to the private sector it should identify and/or act upon this information. The five years used in this exemption is not directly tied to any "base" year. The five years will be a "rolling" five years which starts from the time an agency is screening a particular building to identify exemptions.

Agencies are urged to keep in mind that the screening procedure used in developing this seismic inventory is specifically intended for developing a reasonable estimate of the cost of achieving adequate seismic safety. It may be appropriate to make simplifying assumptions in order to minimize the cost of developing the inventory and cost estimate. However, any assumptions made for purposes of this inventory should be verified for any building "triggered" for seismic evaluation and rehabilitation under Section 1 of Executive Order 12941. (Section 1 adopts RP4 seismic standards for evaluation, including specific triggers for action.) Any assumptions made in identifying exempt buildings should be documented in the supporting documentation.

RP4 exemptions are intended to remove from further consideration those buildings that present an extremely low threat to life-safety in the event of an earthquake. Agencies are urged to keep in mind that a "life safe" building may be severely damaged in an earthquake, to the extent that it is not salvageable. Therefore, it may be inappropriate to exempt some buildings that need a performance level higher than life-safety. For the purposes of this inventory and cost estimate, all buildings which require a level of performance higher than life-safety are to be classified as Essential. Agencies are encouraged to identify their Essential buildings prior to screening for exemptions. See Section 2.3.3 for guidance on identifying Essential buildings. 
The most expedient process for identifying exempt buildings will vary from agency to agency, depending on what type of information they already have available. The goal of the screening process is to accurately identify exempt buildings by collecting only the minimum additional amount of information needed. The information needed will vary from agency to agency and building to building. Agencies should exempt first the most readily identifiable buildings. For example, agencies which include expected remaining life in their existing inventories will be quickly able to exempt buildings with fewer than five years of remaining life. Agencies which do not have this data readily available will want to identify as many other exemptions as possible before they start collecting information on expected remaining life.

One suggested screening methodology is given in Sections 2.2.3 and 2.2.4. The order of the exemption checks is given first in Section 2.2.3. The details of how to perform each exemption check follows in Section 2.2.4, in order of RP4 exemption.

\subsubsection{One Possible Screening Process}

1. Be sure the inventory includes only buildings, not other special structures (RP4 exemption c). Remove non-building listings from the inventory database.

2. Be sure the inventory includes only buildings owned by the Federal government, not private buildings on Federal land or buildings held in trust for others by the Federal government (RP4 exemption h). Remove these buildings from the database.

3. Be sure the inventory includes only buildings within the United States (as defined by Executive Order 12941, see first paragraphs of Section 2.2 above), not foreign buildings. Remove foreign buildings from the database.

4. Identify and mark as exempt all buildings with fewer than 5 years of remaining life.

5. Identify and mark as exempt all buildings designed for the Federal government after Jan. 5, 1990 (RP4 exemption h).

6. Identify all buildings less than $280 \mathrm{~m}^{2}(3,000$ square feet) in area; separate them into single-story and multi-story; for single story, determine whether building is wood or light steel frame; if yes, mark building as exempt (RP4 exemption d); all others are non-exempt unless they are exempt for some other reason.

7. Identify and mark as exempt all buildings that have been previously evaluated and judged OK (RP4 exemption $\mathrm{g}$ - agencies are encouraged to review Section 2.2.4 of this Handbook before using this exemption)

8. Identify and mark as exempt all buildings that have been previously rehabilitated (RP4 exemption e).

9. Identify and mark as exempt all one- and two-family dwellings in low seismic areas. In moderate seismic areas, identify and mark as exempt one- and two-family dwellings where $A_{v}<0.15 g$ (RP4 exemption $b-$ See Table A-1 in Appendix A for identification of areas with $A_{v}<0.15 \mathrm{~g}$ ).

10. Identify and mark as exempt agricultural buildings and those with minimal human occupancy (RP4 exemption a).

11. Identify and mark as exempt all buildings designed during or after the benchmark year appropriate for the building structural type and location (RP4 exemption f). 


\subsubsection{RP4 Exemptions and How to Identify Them}

RP4 exemptions are reprinted below in italics. Non-italicized text provides suggestions on how to identify the exempt buildings.

a. buildings classified for agricultural use, or intended only for incidental human occupancy, or occupied by persons for a total of less than 2 hours a day

Most agencies will probably not have this type of information in their existing database in this exact form. However, agencies should, within their GSA-required database, have each building (or group of buildings) identified by occupancy class. (Occupancy classes are described in more detail in Section 2.3.3.) Buildings that will be exempt for the reasons cited above will most likely be classified in the "storage" and "miscellaneous" occupancy classes. Additional information that is already available should be used to identify the exempt buildings within these classes. For example, buildings housing unmanned data-collection instruments or storing infrequently used equipment could be readily identified as intended only for incidental human occupancy. Other buildings will be readily identifiable as not belonging in this category, for example offices, schools, hospitals, and so forth. Once the clearly exempt and clearly non-exempt buildings have been identified, a person at each site who is familiar with their use should be asked to determine whether each of the remaining buildings is exempt for this reason or not.

b. detached one- and two-family dwellings that are located in areas having a governing acceleration coefficient less than 0.15 (within the United States, where $A_{v}$ is less than 0.15 as delineated on Map 4 of the 1991 NEHRP Recommended Provisions for the Development of Seismic Regulations for New Buildings [BSSC, 1992]), (note: Map 4 is identical in the 1991 and 1994 editions of the NEHRP Recommended Provisions).

To be exempt under this criteria, a building must meet three criteria: 1) it must be a residence (a category tracked in the GSA database); 2) it must be a detached one- or two-family dwelling (this information is not available in the GSA database); and 3) it must be located where expected seismic ground accelerations are less than $0.15 \mathrm{~g}$. To eliminate unnecessary effort in distinguishing between multifamily housing units and detached dwellings, the inventory should first be sorted by seismicity. Tables A-1 and A-2 in Appendix A of this document list those states and counties and territories that are mapped on the specified NEHRP map as expecting $A_{v}$ below $0.15 g$. Only those buildings categorized as housing in the $A_{v}<0.15 \mathrm{~g}$ states and counties need be assessed for possible exemption under this category. Housing where $A_{v} \geq 0.15$ is not exempt unless it qualifies as exempt for some other reason.

The GSA-required inventory occupancy class for housing does not require a distinction between one- and two-family dwellings, apartment buildings, barracks, and the like. A reasonable assumption that could be used in making this distinction is that if a building is smaller than $185 \mathrm{~m}^{2}(2,000$ square feet) it is a one-family dwelling (exempt) and if it is larger than $465 \mathrm{~m}^{2}(5,000)$ it houses three or more families or is a barracks (non-exempt for this category). For the in-between size buildings classified as housing (that are in areas of $A_{v}$ less than 0.15), a person familiar with the site should be asked to indicate which are one- or two- 
family dwellings.

Agencies are reminded that the simplifying assumptions made for the purposes of developing the cost estimate required under Section 2 of Executive Order 12941 should be verified for every exempt building which is "triggered" for seismic evaluation under Section 1 of Executive Order 12941 (details listed in Section 2.1 of RP4) to ascertain that the building is indeed exempt from evaluation.

c. special structures including, but not limited to: bridges, transmission towers, industrial towers and equipment, piers and wharves, and hydraulic structures

Within the GSA-required inventory, buildings are identified with the code 30 to differentiate them from land (code 20) and other types of structures (code 40). If agencies have reason to believe that some of the types of structures defined as exempt in RP4 have been labeled with code $\mathbf{3 0}$ for GSA-reporting purposes, an effort should be made to identify the nonbuilding structures and remove them from the inventory database.

d. one-story buildings of steel light frame or wood construction with areas less than 280 $m^{2}$ (3000 square feet)

In order to qualify for this exemption, a building must meet three different criteria: it must be small; it must be one-story; and it must be of steel light frame or wood construction. Agencies that have already collected information on all three of these criteria will have no trouble sorting their inventory to identify these buildings. Many agencies will only have information on size, and will have to collect additional information.

The logical first step is to sort out the small buildings (less than $280 \mathrm{~m}^{2}$ ) for further investigation. In the GSA database, all individual buildings smaller than 3,000 square feet would be potentially eligible for exemption. Groups of buildings with a total collective area of less than 3,000 square feet are also potentially eligible for exemption. Groups with sum total areas larger than 3,000 square feet may have one or more buildings smaller than the minimum and thus eligible for exemption. A precise and complete approach to the effort to exempt buildings would require that all groups of buildings be broken down into their constituent individual building listings. Presumably this could be done by returning to the source of the original data submission. However, it may be possible for some agencies to make reasonable assumptions to limit effort spent at this point in breaking apart groups of buildings. For example, groups of certain occupancy classes, such as hospitals, prisons, and schools, are very unlikely to have any small buildings among them. Agencies should consider the characteristics of their own building population, and, bringing to bear any additional information that may be available, identify those groups with an average size (the total area divided by the number of buildings in the group) of $280 \mathrm{~m}^{2}$ or less that are unlikely to contain any individual large (non-exempt) buildings. These groups need not be broken down into their constituent individual buildings. (Those planning this inventory effort should keep in mind that most non-exempt buildings must be listed on a building-by-building basis, so many groups of buildings will need to be broken down into their individual listings in any case if the agency starts with the GSA database.) 
The next two steps for each potentially exempt small building are probably most efficiently accomplished if done at the same time: determine whether the building is one-story, and whether it is light steel frame or wood construction. The most complete and accurate approach would be to have a person on site make the distinction for all the identified small buildings. However, some reasonable assumptions may be appropriate in order to minimize the level of on-site effort. For example, in some parks it may be reasonable to assume that all picnic shelters, restrooms, and cabins are one-story wood buildings, and thus are exempt. In other parks, the cabins may be one-story and wood (exempt), but the restrooms and picnic shelters may be masonry (non-exempt).

e. fully-rehabilitated buildings which comply with the RP4 seismic safety standards in all four compliance categories (structural, nonstructural, geologic/site hazards, and adjacency)

Some agencies maintain records in a central office of those buildings which have been seismically rehabilitated. For those agencies, identifying buildings exempt for the above reason will be straightforward. The rehabilitation criteria should be briefly reviewed to ascertain that structural, nonstructural, geologic/site hazards, and adjacency issues were reasonably considered at the time of the rehabilitation.

For agencies without a central repository of information on seismic rehabilitation, identifying buildings exempt for this reason may be extremely difficult. Each facility manager should be asked to identify which of the buildings on the site have been rehabilitated.

\section{f. post-benchmark buildings as defined in Table 1 of RP4 which also comply with the nonstructural, geologic/site, and adjacency compliance categories}

Table 1 of RP4 (reproduced at the end of this Section as Table 2-3) tabulates suggested "benchmark years", by code or standard and structural system, for use in identifying exempt buildings. A benchmark year is the year a given code or standard first adopted what is now considered modern seismic design requirements for a particular type of building. Any building designed and built using the requirements of the benchmark year (or more recent) code or standard is assumed to provide adequate seismic resistance for life-safety purposes, and can be exempted.

Benchmark years vary in different regions of the country because the three major model codes (BOCA, SBCCI, and UBC) that serve as the basis for the legally enforceable local codes incorporated seismic design requirements at different points in time. Typically, benchmark years are later in the midwest, south, and east than they are on the west coast because BOCA and SBCCI model codes, which are in dominant use in those areas, adopted improvements in seismic design several years after the UBC. Table 2-1 lists the areas of the country, by state, in which the three major model codes have traditionally been used.

Benchmark years also vary by model building type, because the engineering community understood the particular problems of some types of structures before others. Thus, some parts of the codes became "modern" before others were, because information became available at different points in time. For some types of structural systems, there is no 
benchmark year listed. These are typically systems no longer used in regions of high seismicity; the seismic safety of such systems in regions of moderate and low seismicity is not well understood.

Table 2-1 - Predominant Building Code Use

\begin{tabular}{|c|c|}
\hline Model Code & States and Territories of Predominant use \\
\hline BOCA & $\begin{array}{l}\text { Maine, New Hampshire, Vermont, Massachusetts, Rhode Island, Connecticut, New } \\
\text { Jersey, Delaware, Maryland, Washington DC, Pennsylvania, Virginia, West Virginia, } \\
\text { Ohio, Michigan, Illinois, Missouri, Oklahoma, Kentucky, }\end{array}$ \\
\hline SBCCI & $\begin{array}{l}\text { North Carolina, South Carolina, Georgia, Florida, Alabama, Mississippi, Louisiana, } \\
\text { Arkansas, Tennessee, Southeastern Texas (Beaumont, Brownsville, Bryan, Corpus } \\
\text { Christi, El Paso, Laredo, Temple, Texarkana, Tyler, Waco) }\end{array}$ \\
\hline UBC & $\begin{array}{l}\text { North Dakota, South Dakota, Iowa, Kansas, Nebraska, Wyoming, Montana, Colorado, } \\
\text { New Mexico, Arizona, Utah, Idaho, Washington, Oregon, Nevada, California, } \\
\text { Minnesota, Indiana, Hawaii, Alaska, Guam, Virgin Islands (for public works), } \\
\text { Northwest Texas (Abilene, Amarillo, Arlington, Austin, Dallas, Fort Worth, Garland, } \\
\text { Houston, Irving, Lubbock, Plano, San Antonio) }\end{array}$ \\
\hline $\begin{array}{l}\text { State-written or } \\
\text { Territory-written }\end{array}$ & New York, Wisconsin, Puerto Rico, Virgin Islands \\
\hline
\end{tabular}

The benchmark years given in RP4 are advisory only. Each agency may develop its own list of appropriate benchmark years for the various model building types in various parts of the country. This is especially appropriate for the Defense agencies, for example, that have for many years used their own design procedures and have not used the model building codes. It is also appropriate for agencies such as GSA, that have required for many years that all their buildings, across the country, be designed and built for seismic concerns using the appropriate sections of the UBC, rather than using whichever model building code happened to be in use at that location. Each agency can establish their own benchmark years; those using other than the RP4 benchmark years must report what they used and the rationale behind it in the supporting documentation.

A default procedure for identifying exempt buildings based on RP4 benchmark years is given in this section. The following considerations were taken into account in developing this procedure.

Because it generally takes a year or more for changes in the model codes to be adopted into the locally enforceable code, the date used for allowing exemptions is one year later than the benchmark year in RP4 Table 1. (Note: This is an assumption based on the average amount of time for updated information to be included in a local code. If an agency knows that the code which the agency followed did not meet these benchmark years, it should use agency specific benchmark years).

- No benchmark years are listed in RP4 Table 1 for several structural systems. There are two reasons for this. First some systems represent little risk, such as wood and light metal 
frame. Second, some systems are no longer allowed in regions of high seismicity (where the UBC predominates). For this default exemption procedure, it is reasonable to make the following assumptions:

- for the systems which represent little risk, it is conservative to use the same benchmark year as for the majority of other types of construction.

- for the systems which are disallowed-in-high-seismicity areas, it is reasonable to assume 1) that these construction types were not used in high seismic areas after they became disallowed, therefore there will not be any buildings of these structural types which have a construction date after the benchmark date and 2) that these structural systems provide adequate safety under current design loads in regions of moderate and low seismicity (where BOCA and SBCCI codes predominate). Therefore, the same benchmark year is used for these un-assigned types as for the majority of the other structural systems for a given model code.

- Where recommended benchmark years in RP4 Table 1 for a given model code vary based on model building type, the latest year listed is used for all model building types (steel braced frames excepted). This is a conservative assumption.

For purposes of practical application, the benchmark year table is simplified as follows:

Table 2-2 - Simplified Benchmark Years

\begin{tabular}{|c|c|c|c|c|}
\hline Building Type & Model Code & BOCA & SBCCI & UBC \\
\hline \multicolumn{2}{|c|}{ Steel Braced Frame } & 1991 & 1992 & 1989 \\
\hline \multicolumn{2}{|l|}{ All Other } & 1988 & 1992 & 1977 \\
\hline
\end{tabular}

In order to identify buildings exempt by virtue of benchmark year, the year of design must be known. The GSA-required database includes a year of acquisition. This may be later than the year of design, for either or both of two reasons. 1) Buildings may have been preexisting when acquired by the Federal government. 2) Buildings may have been constructed several years after being designed. Therefore, assuming that the date of acquisition is the same as the date of design is a non-conservative assumption. Each agency should consider whether their population of buildings was acquired primarily as pre-existing buildings or was primarily designed and built specifically for Federal use. If the latter is the case and no ready source of information on date of design is available, it is reasonable to assume that the date of acquisition and the date of design are the same. If this assumption cannot be made, information on actual date of design must be sought out on a building-by-building basis.

To be exempt, the building must not only have been designed after the relevant benchmark year, but must also provide the nonstructural, geologic/site hazard, and adjacency safety levels specified in RP4. For the purposes of this cost estimate, where this information is not 
readily available, it is reasonable to assume that the building meets these requirements if it meets the benchmark year. However, if the agency does have information regarding the geologic/site and adjacency conditions of a building, the agency should include this information in its consideration of this exemption. The effects of geologic conditions and adjacency concerns can have large implications on the seismic safety as well as the cost to rehabilitate a building in many instances.

Again, agencies are reminded that the simplifying assumptions made for the purposes of developing the cost estimate required under Section 2 of Executive Order 12941 should be verified for every exempt building which is "triggered" for seismic evaluation under Section 1 of Executive Order 12941 (Section 2.1 of RP4) to ascertain that the building is indeed exempt from evaluation.

To use this default procedure to identify exempt buildings based on benchmark year, sort the list of buildings by state into the three model code categories. Within SBCCI-controlled buildings, all buildings designed in or after 1992 may be considered exempt. For BOCA- and UBC-controlled buildings, identify those which are steel braced frame buildings. Steel braced frame buildings designed in or after 1991 for BOCA-controlled buildings and in or after 1989 for UBC-controlled buildings are exempt. Other BOCA-controlled buildings designed in or after 1988 are exempt. Other UBC-controlled buildings designed in or after 1977 are exempt.

g. pre-benchmark buildings which have been shown by evaluation to be life-safe in all four compliance categories

If a building has been evaluated for seismic safety prior to the adoption of Executive Order 12941 and found to provide adequate seismic safety, and if the owning agency feels that the previous evaluation adequately addressed nonstructural, geologic/site hazard, and adjacency issues in addition to structural concerns, then there is no need to re-evaluate the building.

However, if an agency reports these buildings as exempt, they will not be included in the sample of buildings evaluated by the agency. It is recommended that agencies consider not reporting these buildings as exempt but instead making a point to include them in the sample of evaluated buildings in order to receive "credit" for work already completed. For further details on reporting previously evaluated buildings see Section 3.1.3 of this Handbook.

For agencies which maintain a central list of buildings which have been evaluated and rehabilitated, identifying these buildings will be relatively easy. Other agencies should contact facility managers and ask them which, if any, buildings on their site have been previously evaluated for seismic safety.

h. buildings constructed for the Federal government whose detailed design was done after the date of the adoption of Executive Order 12699 (January 5, 1990) and that were designed and constructed in accordance with the ICSSC Guidelines and Procedures for Implementation of the Executive Order on Seismic Safety of New Building Construction

Executive Order 12699 requires that buildings newly designed and constructed for the Federal 
government after Jan 5, 1990 use appropriate standards of seismic safety. Unless the agency has reason to believe that they have not followed this policy, all buildings newly built for the agency in 1990 or later may be exempted, regardless of structural system, occupancy, seismicity, or other concern.

\section{i. leased buildings identified in Section 1.3.2 as exempt}

Leased buildings are not to be included in the separate inventory database of owned buildings.

j. Federally permitted or regulated privately owned buildings on Federal land.

Only Federally owned buildings should be included in the inventory database of owned buildings. On the GSA database, some buildings are identified with the code letter " $T$ ". These buildings are held in trust by the Federal government on behalf of private owners. They need not be included in the owned-building inventory, and may be exempted under this provision. 
Table 2-3 - RP4 Table 1: Advisory Benchmark Years

\begin{tabular}{|c|l|c|c|c|c|c|}
\hline \multicolumn{2}{|c|}{ BUILDING TYPE } & \multicolumn{5}{c|}{$\begin{array}{c}\text { Model Building Seismic } \\
\text { Design Provisions }\end{array}$} \\
\hline $\begin{array}{c}\text { FEMA } \\
\mathbf{1 7 8}\end{array}$ & \multicolumn{1}{|c|}{ BOCA } & SBCCI & UBC & ANSI & NEHRP \\
\hline 1,2 & Wood Frame, Wood Shear Panels & $* *$ & $* *$ & 1949 & $* *$ & $* *$ \\
\hline 3 & Steel Moment Resisting Frame (MRF) & 1987 & 1991 & 1976 & 1982 & 1985 \\
\hline 4 & Steel Braced Frame & 1990 & 1991 & 1988 & $*$ & 1991 \\
\hline 5 & Light Metal Frame & $*$ & $*$ & $*$ & $*$ & $*$ \\
\hline 6 & Steel Frame w/ Concrete Shear Walls & 1987 & 1991 & 1976 & 1982 & 1985 \\
\hline 8 & Reinf. Conc. Moment Resisting Frame & 1987 & 1991 & 1976 & 1982 & 1985 \\
\hline 9 & Reinf. Concrete Shear Walls w/o MRF & 1987 & 1991 & 1976 & 1982 & 1985 \\
\hline 10,7 & Steel or Concrete Frame w/ URM Infill & $*$ & $*$ & $*$ & $*$ & $*$ \\
\hline 11 & Tilt-up Concrete & 1987 & 1991 & 1973 & 1982 & 1985 \\
\hline 12 & Precast Concrete Frame & $*$ & $*$ & $*$ & $*$ & $*$ \\
\hline 13,14 & Reinforced Masonry & 1987 & 1991 & 1976 & 1982 & 1985 \\
\hline 15 & Unreinforced Masonry (URM) & $*$ & $*$ & $*$ & $*$ & $*$ \\
\hline
\end{tabular}

1 The tabulated numbers refer to the 15 common building types as they are defined in FEMA 178.

* Indicates no benchmark year (no comprehensive seismic requirements for these buildings exist).

** Local provisions for wood construction need to be compared to 1949 UBC to determine benchmark year.

BOCA - Building Officials and Code Administrators, National Building Code. (BOCA adopted the NEHRP 1991 seismic provisions in a 1992 Addendum to their 1990 edition.)

SBCCI - Southern Building Code Congress, Standard Building Code. (SBCCI adopted the NEHRP 1991 seismic provisions in a 1992 Addendum to their 1991 edition.)

UBC - International Conference of Building Officials, Uniform Building Code.

ANSI - American National Standards Institute, A58.1, Minimum Design Loads for Buildings and Other Structures. (Currently called ASCE 7)

NEHRP - Federal Emergency Management Agency, NEHRP Recommended Provisions for the Development of Seismic Regulations for New Buildings. 


\subsection{Required Inventory Data}

The results of the inventory/screening process are to be reported in the agency inventory database. Table 2-4 (reproduced from RP5) indicates the types of information that are to be reported for each of three categories of buildings: 1) exempt, 2) non-exempt and non-evaluated, and 3) non-exempt and evaluated. Section 3 of this Handbook offers suggestions on selecting buildings for evaluation and discusses evaluation procedures. The required format for the electronic database is described in detail in Section 5 of this Handbook.

\subsubsection{Data Needed for All Buildings}

Regardless of whether a building (or group of buildings) is exempt or not, the following basic information is required in the inventory database.

Agency Code: The agency code is the four digit numerical code used by the GSA Real Property Database to identify which agency owns a specific building(s). See Section 5 for a listing of these codes. (If your agency does not appear on the list of codes in Section 5 please contact the ICSSC Technical Secretariat for assistance.)

Unique Identifier: The unique identifier may be whatever alpha-numeric designation the agency uses to track its buildings in its own real property inventory. It may be an address, a coded number, or some other method of identifying a specific building in the database. If desired, agencies may use a coding system to preserve the anonymity of specific buildings within their inventory database. However, agencies must maintain a record linking each unique identifier to a specific building, should the need ever arise to identify a specific structure. Specific format/reporting requirements are given in Section 5.

Location: Location by state and county is to be reported for each building (or group of buildings). This information already exists in the GSA-required database. The seismic inventory will use the same state and county codes that are used in the GSA database. See Tables A-1 and A-2 in Appendix A of this Handbook for a complete listing of these codes.

Seismicity: Each building (or group of buildings) is to be assigned to one of three seismicity levels: Low, Moderate, or High. Seismicity levels are defined by the Map Areas given on Map 2 ( $\mathrm{A}_{\mathrm{v}}$, county-by-county) in the 1994 NEHRP Recommended Provisions [BSSC, 1995].
Low seismicity
Map Areas $1 \& 2$
Moderate seismicity
Map Areas 3 \& 4
High seismicity
Map Areas 5, 6, \& 7

State and county codes may be used to rapidly assign each building (or group of buildings) to the proper seismicity. See Tables A-1 and A-2 in Appendix A of this Handbook for a tabulation of the appropriate seismicity level given by state and county. 
Persons with moderate computer skills should be able to devise algorithms appropriate to software being used that would automate the process of assigning seismicity level based on state and county codes.

Agencies that wish to make finer distinctions of seismicity than is possible using countyby-county maps are encouraged to use the contour map for acceleration $A_{v}$ (map number 4) from the 1994 NEHRP Recommended Provisions for the Development of Seismic Regulations for New Buildings. The following mapped accelerations are associated with each seismicity level:

$$
\begin{array}{lr}
\text { Low seismicity } & \mathrm{A}_{\mathrm{v}}<0.10 \mathrm{~g} \\
\text { Moderate seismicity } & 0.10 \mathrm{~g} \leq \mathrm{A}_{\mathrm{v}}<0.20 \mathrm{~g} \\
\text { High seismicity } & 0.20 \mathrm{~g} \leq \mathrm{A}_{\mathrm{v}}
\end{array}
$$

If some other method of assigning buildings to seismicity ranges is used, the method is to be described in the supporting documentation.

Area (Size): The size of the building is to be reported in square meters. This includes the area of all stories of the building, not just the footprint area. Existing information on area that is reported in square feet can be converted to square meters by multiplying the entry by 0.0929 . It should be possible to automate this conversion in all spreadsheet programs and some database and word processing programs.

\subsubsection{Additional Data Needed for Exempt Buildings}

For exempt buildings, in addition to agency code, unique identifier, location, seismicity, and area (size), the database is to indicate the reason for exemption. See Section 2.2.2 of this Handbook for suggested methods for identifying exempt buildings; see Section 5 for a list of codes to use in the database to describe the reason for exemption. Note that, for groups of buildings in the same state, county and seismicity with the same reason for exemption that are reported collectively, the number of buildings in the group must also be reported, and the reported area is to be the cumulative total area of all buildings in the group.

The information items tabulated in Table 2-4 for exempt buildings (agency code, unique identifier, location, seismicity, area (size), and reason for exemption) are the minimum amounts of information required to be reported. However, for many exempt buildings, additional information will have been collected during the screening process. Agencies are encouraged to report all the available information for each building or group of buildings, even though the information is not specifically required.

\subsubsection{Additional Data Needed for Non-Exempt Buildings}

Additional information required for all non-exempt buildings includes: occupancy class, whether building is considered essential, whether building is historic, date of construction, 
model building type, and number of stories. Each of these types of information is described in more detail below.

Occupancy Classes are to be the same as those used in creating the real-property inventory for annual submission to GSA. The 12 occupancy classes are:

- offices

- hospitals

- housing

- prisons

- schools

- post offices

- other institutional

- storage

- industrial

- service

- research \& development

- miscellaneous

GSA does not provide standard definitions for these occupancy classes. The GSA codes were used for this category in order to accommodate agencies which are already using these codes. Some agencies, including the defense agencies, have other code systems set up which identify additional buildings categories. The defense agencies have drafted a list of their codes and correlated them to the GSA codes for use with this database. This list is reproduced in Appendix B. Other agencies which need to correlate their existing classifications with the GSA codes can use this as a guide.

Essential buildings are those which, in the judgement of the owning agency, require a level of seismic resistance that is higher than life-safety. (Life-safety is the minimum level of protection required by RP4. After an earthquake, an RP4 "life-safe" building should not have caused any fatalities, but it may be so badly damaged that it is no longer functional or even salvageable.) Examples of buildings which may fall into the essential category are:

- hospitals, fire and police stations, communication and command centers and other buildings that must remain functional in order to respond to an earthquake emergency;

- buildings which must remain operational after an earthquake to maintain critical agency functions;

- buildings housing hazardous materials which, if released as a result of an earthquake, would create an unacceptable risk; and

- buildings housing vulnerable populations or extremely valuable contents.

Some agencies have already established agency-specific definitions of essential buildings. A few of these are published here to provide guidance for agencies which have not yet established their definitions.

a) The Air Force defines essential buildings as any building which must remain occupied and functional during an earthquake as well as any buildings which houses a function necessary for post-disaster recovery. This includes hospitals, fire stations, communications centers, disaster preparedness offices, weapons storage, petroleum storage, chemical storage and buildings housing other hazardous materials. 
b) The Army defines essential buildings as the following:

- Hospitals and other medical facilities having surgery and emergency treatment areas.

- Fire and police stations.

- Tanks or other structures containing, housing, or supporting water or other fire-suppression materials or equipment required for the protection of essential or hazardous facilities, or special occupancy structures.

- Emergency vehicle and equipment shelters and garages.

- Structures and equipment in emergency preparedness centers.

- Stand-by power generating equipment for essential facilities.

- Structures and equipment in communication centers and other facilities required for emergency response.

Buildings which do not require greater than life-safety protection are to be categorized as "other". Section 5 gives details on the codes and format to use in the electronically reported database.

Historic buildings are those which are included on any local, regional, state, national, or other register of historic buildings. If a building is potentially qualified to be on a historic register, but has not been actually listed, it is not to be deemed historic in this inventory.

Date of Construction is not always the same as date of acquisition by the government. The latter is tracked in the GSA database. For non-exempt buildings, an effort should be made to identify, as nearly as possible, the actual year of construction. If the year of design is significantly earlier than the year of construction, the year of design should be the date reported.

Model Building Types reported in this inventory are to be the 15 types identified in FEMA 178, NEHRP Handbook for the Seismic Evaluation of Existing Buildings [BSSC, 1992]. Guidance on how to identify the 15 model building types is given in Rapid Visual Screening [ATC, 1988]. Wherever possible, it is recommended that a civil or structural engineer identify the structural type, because it has been shown that, even with Rapid Visual Screening-type training, non-engineers frequently mis-identify structural type. See Section 5 for codes to use in reporting model building type. The 15 model building types from FEMA 178 are reproduced below:

Building Type 1 - Wood, Light Frame: These buildings are typically single- or multiplefamily dwellings of one or more stories. The essential structural character of this type is repetitive framing by wood joists on wood studs. Loads are light and spans are small. These buildings may have relatively heavy chimneys and may be partially or fully covered with veneer. Most of these buildings are not engineered; however, they usually have the components of a lateral-force-resisting system even though it may be incomplete. Lateral loads are transferred by diaphragms to shear walls. The diaphragms are roof panels and floors. Shear walls are exterior walls sheathed with plank siding, stucco, plywood, gypsum board, particle board, or fiberboard. Interior partitions are sheathed with plaster or gypsum board. 
Building Type 2 - Wood. Commercial and Industrial: These buildings usually are commercial or industrial buildings with a floor area of 465 square meters $(5,000$ square feet) or more and with few, if any, interior walls. The essential structural character is framing by beams on columns. The beams may be glulam beams, steel beams or trusses. Lateral forces usually are resisted by wood diaphragms and exterior walls sheathed with plywood, stucco, plaster, or other paneling. The walls may have rod bracing. Large openings for stores and garages often require post-and-beam framing. Lateral force resistance on those lines can be achieved with rigid steel frames or diagonal bracing.

Building Type 3 - Steel Moment Frame: These buildings have a frame of steel columns and beams. In some cases, the beam-to-column connections have very small moment resisting capacity but, in other cases, some of the beams and columns are fully developed as moment frames to resist lateral forces. Usually the structure is concealed on the outside by exterior walls, which can be of almost any material (curtain walls, brick masonry, or precast concrete panels), and on the inside by ceilings and column furring. Lateral loads are transferred by diaphragms to moment resisting frames. The diaphragms can be of almost any material. The frames develop their stiffness by full or partial moments connections. The frames can be located almost anywhere in the building. Usually the columns have their strong directions oriented so that some columns act primarily in one direction while the others act in the other direction, and the frames consist of lines of strong columns and their intervening beams. Steel moment frame buildings are typically more flexible than shear wall buildings. This low stiffness can result in large interstory drifts that may lead to extensive nonstructural damage.

Building Type 4-Steel Braced Frame: These buildings are similar to Type 3 buildings except that the vertical components of the lateral-force-resisting system are braced frames rather than moment frames.

Building Type 5 - Steel Light Frame: These buildings are pre-engineered and prefabricated with transverse rigid frames. The roof and walls consist of lightweight panels. The frames are designed for maximum efficiency, often with tapered beam and column sections built up of light plates. The frames are built in segments and assembled in the field with bolted joints. Lateral loads in the transverse direction are resisted by the rigid frames with loads distributed to them by shear elements. Loads in the longitudinal direction are resisted entirely by shear elements. The shear elements can be either the roof and wall sheathing panels, an independent system of tension-only rod bracing, or a combination of panels and bracing.

Building Type 6 - Steel Frame with Concrete Shear Walls: The shear walls in these buildings are cast-in-place concrete and may be bearing walls. The steel frame is designed for vertical loads only. Lateral loads are transferred by diaphragms of almost any material to the shear walls. The steel frame may provide a secondary lateral-forceresisting system depending on the stiffness of the frame and the moment capacity of the beam-column connections. In modern "dual" systems, the steel moment frames are designed to work together with the concrete shear walls in proportion to their relative rigidities. In this case, the walls would be evaluated under this building type and the frames would be evaluated under Type 3, Steel Moment Frames. 
Building Type 7 - Steel Frame with Infill Shear Walls: This is one of the older types of building. The infill walls are offset from the exterior frames members, wrap around them, and present a smooth masonry exterior with no indication of the frame. Solidly infilled masonry panels act as a diagonal compression strut between the intersections of the moment frame. If the walls do not fully engage the frame members (i.e., lie in the same plane), the diagonal compression struts will not develop. The peak strength of the diagonal strut is determined by the tensile stress capacity of the masonry panel. The post-cracking strength is determined by an analysis of a moment frame that is partially restrained by the cracked infill. The analysis should be based on published research and should treat the system as a composite of a frame and an infill. An analysis that attempts to treat the system as a frame and shear wall is not capable of assuring compatibility.

Building Type 8 - Concrete Moment Frames: These buildings are similar to Type 3 buildings except that the frames are of concrete. Some older concrete frames may be proportioned and detailed such that brittle failure can occur. There is a large variety of frame systems. Buildings in zones of low seismicity or older buildings in zones of high seismicity can have frame beams that have broad shallow cross sections or are simply the column strips of flat-slabs. Modern frames in zones of high seismicity are detailed for ductile behavior and the beams and columns have definitely regulated proportions.

Building Type 9 - Concrete Shear Walls: The vertical components of the lateral-forceresisting system in these buildings are concrete shear walls that are usually bearing walls. In older buildings, the walls often quite extensive and the wall stresses are low but reinforcing is light. When remodeling calls for enlarging the windows, the strength of the modified walls becomes a critical concern. In newer buildings, the shear walls often are limited in extent, thus generating concerns about boundary members and overturning forces.

Building Type 10 - Concrete Frame with Infill Shear Walls: These buildings are similar to Type 7 buildings except that the frame is of reinforced concrete. The analysis of this building is similar to that recommended for Type 7 except that the shear strength of the concrete columns, after cracking of the infill, may limit the semiductile behavior of the system. Research that is specific to confinement of the infill by reinforced concrete frames should be used for the analysis.

Building Type 11 - Precast/Tilt-Up Concrete Walls with Lightweight Flexible Diaphragm: These buildings have a wood or metal deck roof diaphragm, which often is very large, that distributes lateral forces to precast concrete shear walls. The walls are thin but relatively heavy while the roofs are relatively light. Older buildings often have inadequate connections for anchorage of the walls to the roof for out-of-plane forces, and the panel connections often are brittle. Tilt-up buildings often have more than one story. Walls can have numerous openings for doors and windows of such size that the wall looks more like a frame than a shear wall.

Building Type 12 - Precast Concrete Frames with Concrete Shear Walls: These buildings contain floor and roof diaphragms typically composed of precast concrete elements with or without cast-in-place concrete topping slabs. The diaphragms are 
supported by precast concrete girders and columns. The girders often bear on column corbels. Closure strips between precast floor elements and beam-column joints usually are cast-in-place concrete. Welded steel inserts often are used to interconnect precast elements. Lateral loads are resisted by precast or cast-in-place concrete shear walls. Buildings with precast frames and concrete shear walls should perform well if the details used to connect the structural elements have sufficient strength and displacement capacity; however, in some cases, the connection details between the precast elements have negligible ductility.

Building Type 13 - Reinforced Masonry Bearing Walls with Wood or Metal Deck Diaphragms: These buildings have perimeter bearing walls of reinforced brick or concrete-block masonry. These walls are the vertical elements in the lateral-forceresisting system. The floors and roofs are framed either with wood joists and beams with plywood or straight or diagonal sheathing or with steel beams with metal deck with or without a concrete fill. Wood floor framing is supported by interior wood posts or steel columns; steel beams are supported by steel columns.

Building Type 14 - Reinforced Masonry Bearing Walls with Precast Concrete Diaphragms: These buildings have bearing walls similar to those of Type 13 buildings, but the roof and floors are composed of precast concrete elements such as planks or teebeams and the precast roof and floor elements are supported on interior beams and columns of steel or concrete (cast-in-place or precast). The precast horizontal elements often have a cast-in-place topping.

Building Type 15 - Unreinforced Masonry Bearing Wall Buildings: These buildings include structural elements that vary depending on the building's age and, to a lesser extent, its geographic location. In buildings built before 1900, the majority of floor and roof construction consists of wood sheathing supported by wood subframing. In large multistory buildings, the floors are cast-in-place concrete supported by wood subframing. In large multistory buildings, the floors are cast-in-place concrete supported by the unreinforced masonry walls and/or steel or concrete interior framing. In buildings built after 1950, unreinforced masonry buildings with wood floors usually have plywood rather than board sheathing. In regions of lower seismicity, buildings of this type constructed more recently can include floor and roof framing that consists of metal deck and concrete fill supported by steel framing elements. The perimeter walls, and possibly some interior walls, are unreinforced masonry. The walls may or may not be anchored to the diaphragms. Ties between the walls and diaphragms are more common for the bearing walls than for walls that are parallel to the floor framing. Roof ties usually are less common and more erratically spaced than those at the floor levels. Interior partitions that interconnect the floors and roof can have the effect of reducing diaphragm displacements.

Agencies should attempt to categorize each non-exempt building into one of these 15 model building types. If a building has a dual system which cannot be categorized as predominantly one model building type, or if a building system does not resemble in any way any of these model building types, the building can be entered in the electronic database with a model building type of "other" (see Table 5-4). A brief description of the building 
construction should then be included in the "Comment" field of the database as well as in the supporting documentation.

Number of Stories to be reported is number of above ground stories, not including small penthouse stories such as those that house elevator equipment. For buildings with multiple levels, the number of stories in the highest level is the number to be reported.

\section{Non-Exempt Evaluated Buildings}

The Guidance (RP5) recommends that certain non-exempt buildings be selected for seismic evaluation in order to better estimate the potential cost of achieving adequate seismic safety in existing Federal buildings. Exempt buildings are those which clearly present a very low risk to life-safety in the event of an earthquake. This does not mean that non-exempt buildings automatically present a high risk. Some non-exempt buildings, upon evaluation, will be found to provide adequate seismic safety. At the present time, the ratio of adequate to deficient buildings is unknown. Some evaluations must be done in order to better estimate the percentage of non-exempt buildings which will provide adequate seismic safety without rehabilitation.

Section 3 of this Handbook offers guidance on selecting buildings for evaluation and on performing evaluations. Additional information to be reported for all buildings which are non-exempt and evaluated includes: whether the building is categorized as being an "exceptionally high risk"; the evaluation procedure used; soil type; foundation type; the outcome of the evaluation (OK or deficient); and, if deficient, then why deficient, the cost of rehabilitation, and the source of the cost estimate. Each of these types of information is described in more detail below.

Exceptionally High Risk or Other: RP5 directs agencies to identify all of their buildings which pose an "exceptionally high risk." Under the triggering requirements of RP4, which was adopted by the President in Executive Order 12941, these buildings must be evaluated for seismic safety. RP5 additionally directs agencies to evaluate a representative sample of their remaining non-exempt buildings. For reporting purposes, these two categories are to be distinguished in the inventory database.

Prior to seismic evaluation, the actual level of seismic risk in a building cannot be known with certainty, but reasonable estimates can be made to identify the buildings which are believed to pose the greatest risk. These are the buildings which are to be classified as exceptionally high risk. Exceptionally high risk buildings should not be confused with essential buildings. Essential buildings are those which require greater than life-safety performance in an earthquake. Some, but not all, of these buildings may be judged to pose an exceptionally high risk. Section 3 of this Handbook offers suggestions on how to identify exceptionally high risk buildings.

Evaluation Procedure Used: RP4 evaluation procedures represent a minimum acceptable level of investigation. Section 3.1.1 of this Handbook discusses situations in which other procedures are appropriate. Section 5 lists the codes to be used in the inventory database 
to identify which evaluation procedure was used.

Soil Type: Soil types are to be categorized into one of the four soil categories identified in FEMA 178. These soil types are reproduced from FEMA 178 as follows:

\begin{tabular}{|c|l|c||}
\hline $\begin{array}{c}\text { Soil Profile } \\
\text { Type }\end{array}$ & \multicolumn{1}{|c|}{ Profile with } & $\begin{array}{c}\text { Site } \\
\text { Coefficient, S }\end{array}$ \\
\hline S1 & $\begin{array}{l}\text { Rock of any characteristic, either shale-like or crystalline in nature. Such } \\
\text { material may be characterized by a shear wave velocity greater than 2,500 feet } \\
\text { per second or by any other appropriate means of classification. } \\
\text { OR } \\
\text { Stiff soil conditions where the soil depth is less than 200 feet and the soil types } \\
\text { overlying rock are stable deposits of sands, gravels, or stiff clays. }\end{array}$ & 1.0 \\
\hline S2 & $\begin{array}{l}\text { Deep cohesionless or stiff clay conditions including sites where the soil depth } \\
\text { exceeds 200 feet and the soil types overlying rock are stable deposits of sands, } \\
\text { gravels, or stiff clays. }\end{array}$ & 1.2 \\
\hline S3 & $\begin{array}{l}\text { Soft- to medium-stiff clays and sands characterized by 30 feet or more of soft- } \\
\text { to medium-stiff clays with or without intervening layers of sand or other } \\
\text { cohesionless soils. }\end{array}$ & 1.5 \\
\hline S4 & $\begin{array}{l}\text { More than } 70 \text { feet of soft clays or silts characterized by a shear wave velocity } \\
\text { less than } 400 \text { feet per second. }\end{array}$ & 2.0 \\
\hline
\end{tabular}

Foundation Type: The foundation type is to be categorized into one of the following types: shallow foundations - isolated or continuous spread footings or mats deep foundations - piles or piers

other - intended for older foundation types which do not fall under one of the categories listed above and other non-typical systems

Outcome of Evaluation: OK or Deficient: The goal of the seismic evaluation is to determine whether the building provides adequate seismic safety as is (OK) or whether the building is deficient. Section 5 lists the codes to be used in the inventory database for reporting the outcome of the evaluation.

\section{Non-Exempt Evaluated Buildings Found to be Deficient}

For evaluated buildings found to be deficient, additional information, including an estimate of the cost of rehabilitation, must be collected or calculated and reported.

Why Deficient: According to the RP4 standard of seismic safety that is the minimum for use by Federal agencies, a building can fail the seismic evaluation because of structural or nonstructural deficiencies, site/geologic hazards, adjacency problems, or a combination of these. Agencies should take measures to ensure that the evaluating engineer reports the reason a building is found to be deficient in terms that can be readily related to the RP4 deficiencies. Section 5 lists the codes to be used in reporting the reason a building is found to be deficient in the inventory database. 
Estimated Costs of Rehabilitation: Four different components of rehabilitation cost are to be separately reported. These include:

- structural (changes to the lateral force resisting system)

- nonstructural (changes to other parts of the building and to building equipment, systems, and contents)

- finishing (costs of removing and replacing finishes such as wallboard, paint, carpet, etc.)

- project costs (design, testing, and permit fees, cost of project management, etc.)

Costs of other upgrades triggered by the rehabilitation effort (such as handicapped access, asbestos removal, etc.) are not to be included. Details on what is and is not included in each of the cost components are given in Section 4 of this Handbook. Information on how the calculated costs are to be reported in the inventory database are given in Section 5.

Source of Cost Estimate: Acceptable cost estimation methods include the following:

1) Have the evaluating engineer develop a preliminary rehabilitation scheme appropriate for the specific structure and calculate the cost of the proposed fix. (Note, for this cost estimation method, the agency may use any nationally accepted seismic hazard map or available site-specific study as the source of ground motion acceleration. No specific map is mandated for use.)

2) Use agency-specific cost estimating procedures. Include detailed information on the procedure used in supporting information that is submitted.

3) Use default method: Follow cost estimating Option II in Typical Costs for Seismic Rehabilitation, Volume I (FEMA 156) [FEMA, 1994]. Use Typical Costs for Seismic Rehabilitation of Existing Buildings, Volume II (FEMA 157) [FEMA, 1995] to estimate nonstructural, etc. costs.

4) If, instead of being rehabilitated, the building would be replaced, a replacement cost should be reported instead of a rehabilitation cost, and so noted.

5) If, instead of being rehabilitated, the building would be abandoned and not replaced, the rehabilitation cost should be the cost of disposal. If no disposal cost is anticipated, the rehabilitation costs can be reported as zero.

The codes used to indicate which of these cost estimating methods was used are given in Section 5 of this Handbook. 
Table 2-4 - Required Inventory Data for Owned Buildings

\begin{tabular}{|c|c|c|c|}
\hline Qharactentic & (1) & Non-Exempt. & Non- Exenpl \\
\hline Unique Identifier & $\mathbf{x}$ & $\mathbf{x}$ & $\mathbf{x}$ \\
\hline Location - State \& County & $\mathbf{X}$ & $\mathbf{x}$ & $\mathbf{x}$ \\
\hline Seismicity - High, Moderate or Low & $\mathbf{x}$ & $\mathbf{x}$ & $\mathbf{X}$ \\
\hline Area in Square Meters & $\mathbf{x}$ & $\mathrm{x}$ & $\mathbf{X}$ \\
\hline Reason for Exemption & $\mathbf{X}$ & $\mathbf{X}$ & $\mathbf{X}$ \\
\hline Occupancy Class (by GSA categories) & & $\mathbf{X}$ & $\mathbf{X}$ \\
\hline Essential or Other & & $\mathbf{X}$ & $\mathrm{X}$ \\
\hline Historic or Non-Historic & & $\mathbf{X}$ & $\mathbf{X}$ \\
\hline Date of Construction & & $\mathbf{X}$ & $\mathbf{X}$ \\
\hline Model Building Type & & $\mathbf{X}$ & $\mathbf{X}$ \\
\hline Number of Stories & & $\mathbf{X}$ & $\mathbf{X}$ \\
\hline Exceptionally High Risk or Other & & & $\mathrm{X}$ \\
\hline Evaluation Procedure Used & & & $\mathbf{X}$ \\
\hline Soil Type & & & $\mathbf{X}$ \\
\hline Foundation Type & & & $\mathbf{x}$ \\
\hline Outcome of Evaluation: OK or Deficient & & & $\mathbf{X}$ \\
\hline For Deficient Only: Why Deficient & & & $\mathbf{X}$ \\
\hline For Deficient Only: Estimated Costs of Rehab(4 fields) & & & $\mathbf{X}$ \\
\hline For Deficient Only: Source of Cost Estimate & & & $\mathbf{x}$ \\
\hline
\end{tabular}

NOTE: Each of the characteristics are to be reported in a single field in the electronic database, unless otherwise noted above. Details of reporting (electronic format, codes for categories, field sizes, etc.) are contained in Section $\mathbf{5}$ of this Handbook. 


\subsection{EVALUATION PLAN}

\subsection{Selection of Buildings for Evaluation}

The RP5 document states that agencies should evaluate buildings in two categories. First agencies should evaluate all of their exceptionally high risk buildings. Second, agencies should evaluate a representative sample of their remaining non-exempt buildings in high and moderate seismic areas. This means that once an agency has screened its inventory, identified all exempt buildings, and collected the additional information required for non-exempt buildings, the next step is to identify those buildings considered to be exceptionally high risk. All of these buildings should be evaluated. In addition, agencies should evaluate a representative sample of the nonexempt buildings which remain after the exceptionally high risk buildings are identified. The following sections give guidance for identifying the exceptionally high risk buildings and selecting the additional representative sample.

\subsubsection{Evaluate All Exceptionally High Risk Buildings}

Section 2.1 of RP4 gives conditions which require an agency to evaluate a building and mitigate any unacceptable seismic hazards found in that building. One of these "triggers" is if "the building is deemed by the agency to be an exceptionally high risk to occupants or the public at large." The purpose of this trigger is to identify those buildings which should be the highest priority in an agency's seismic mitigation program.

As part of the ICSSC recommended program, agencies should identify and evaluate all of their buildings perceived to pose an exceptionally high risk. In this way, the highest priority segment of the Federal inventory will be identified and an accurate cost estimate developed for the mitigation of unacceptable seismic risk in these facilities.

In assessing seismic risk, at least two factors must be considered: the probability of a damaging earthquake occurring at a specific location, and the potential consequences that such an earthquake would cause. For instance, a seismically deficient building poses a higher risk in a high seismic area than a similar building in a low seismic area due to the greater probability of an earthquake occurring in a high seismic area. However, a seismically deficient building which houses 2000 people and is located in a moderate seismic area poses a higher seismic risk than a seismically deficient building which stores paper supplies in a high seismic area because of the higher life-safety consequences.

There are several variables which can be used to determine the definition of an exceptionally high risk building, many of which will depend on the specific characteristics of an agency's inventory. The RP4 document does not give a definition of an exceptionally high risk building. This definition is left up to the individual agency in order to allow agencyappropriate definitions to be established. The following sections give guidance on how to identify exceptionally high risk buildings. 


\section{Identification of Exceptionally High Risk Buildings}

Since seismic risk is a function of a combination of two separate variables, the probability of the occurrence of a damaging earthquake and the potential consequences of that earthquake, characteristics of an agency's inventory which relate to these two variables will be useful in this definition. The seismicity category identified in Section 2.3.1 is the best indicator of the chances of an earthquake occurring. A building which is located in a high seismicity area has a greater chance of having a damaging earthquake than a building located in a moderate seismicity area. Likewise, a building which is located in a moderate seismicity area has a greater chance of having a damaging earthquake than a building located in a low seismicity area. This does not mean that all exceptionally high risk buildings will be located in high seismic areas. It is possible that the consequences of having an earthquake in a moderate or low seismic area may be so unacceptable that this outweighs the difference in expected frequency or severity of an earthquake.

Indicators of the potential consequences that an earthquake may have on a building include whether the mission of the building is such that the building must survive an earthquake in order for the agency to use it immediately following an earthquake, how many people occupy the building and hence could be affected by damage to or collapse of the building, whether or not the structure of the building is a type historically shown to perform well or poorly in an earthquake, and whether there are hazardous contents stored in the building which could harm the occupants or the general public if the building were damaged or if it collapsed. These indicators can be summarized by using the occupancy class, the model building type, and a determination as to whether the building is mission essential.

The occupancy class, or usage category, of a building may be used to identify two risk characteristics. First, there are certain occupancies which must be functional after an earthquake occurs in order to be used in an emergency situation. These buildings include hospitals, fire stations, emergency operation centers, and some schools. Second, there are certain occupancies which are likely to hold large populations of people. These may include places of assembly, schools, production facilities, and some office buildings. Although the number of people in a building is not a required field in the inventory database, some agencies have this information for their buildings, or for certain buildings. Table 3-1 indicates an average occupancy for various types of buildings per 93 square meters (1000 sq. $\mathrm{ft}$.) of floor area which can be used to estimate the relative number of occupants in various buildings.

\begin{tabular}{|l|c|}
\hline \multicolumn{2}{|c|}{ Table 3-1 - Number of Occupants Per 93 Square Meters (1000 Sq Ft) } \\
\hline Residential & 3.1 \\
\hline Office & 4.0 \\
\hline Commercial & 10.0 \\
\hline Industrial & $2.5-5.0$ \\
\hline Assembly & 10.0 \\
\hline
\end{tabular}


Numbers in this Table came from Table 4.12 of Earthquake Damage Evaluation Data for California (ATC-13) [ATC, 1985], and Table 6.4-3 of Seismic Retrofitting Alternatives for San Francisco's Unreinforced Masonry Buildings: Estimates of Construction Cost \& Seismic Damage [Rutherford \& Chekene].

The model building type can be an indicator of the expected behavior of the building in an earthquake. Certain building types have been shown to be more vulnerable than others during damaging earthquakes. These types include unreinforced masonry, non-ductile concrete moment frames, tilt-up concrete construction, and pre-cast concrete construction.

Finally, there are certain buildings, designated by the agency, which must remain functional after an earthquake to support mission objectives. These may include buildings which hold key agency personnel, buildings which hold hazardous materials, or buildings which hold expensive equipment. This designation is based on agency-specific reasons. Table 3-2 summarizes many of the indicators which can be used to determine exceptionally high seismic risk in a building.

Table 3-2 - Indicators of Potential for Higher Seismic Risk

Indicator of Higher Probability of Earthquake Occurrence:

Seismicity

High Seismic Areas (NEHRP Map Areas 5-7) Highest Probability

Moderate Seismic Areas (NEHRP Map Areas 3-4)

Low Seismic Areas (NEHRP Map Areas 1-2) Lowest Probability

Indicator of Higher Consequences of Earthquake Occurrence:

\section{Occupancy Categories}

Hospitals

Schools

Fire Stations

Emergency Operations Centers

Some Office Buildings

Places of Assembly

Vulnerable Model Building Types

Unreinforced Masonry

Tilt-Up Concrete Construction

Precast Construction

Non-Ductile Reinforced Concrete Frame

Agency Specific

Mission Essential Building

Buildings Which House Hazardous Materials

Buildings Which House Key Personnel

Buildings Which House Expensive Equipment 
Agencies should use the combination of the indicators listed in Table 3-2 which is most appropriate for their particular inventory in order to identify exceptionally high risk buildings. For example, one appropriate way for an agency to approach their inventory would be as follows. First, the non-exempt inventory could be sorted into the three different seismicity areas, low, moderate and high. The group of buildings in the high seismicity area could be sorted into model building types. The buildings identified in the vulnerable model building types in Table 3-2 would be automatically included in the exceptionally high seismic risk category (it has been assumed that any building with no people in it has been previously exempted). The remaining model building types in the high seismicity group could be sorted into occupancy categories. Any building which is a hospital, fire station, emergency operations center or any otherwise mission essential building could be added to the exceptionally high risk category.

The group of buildings in the moderate seismicity area could be sorted into the model buildings types. These model building types could then each be sorted into occupancy categories. Any building which is one of the vulnerable building types discussed above and also houses an essential function, or also houses a large number of people (say over 300), could be added to the exceptionally high risk category.

The group of buildings in the low seismicity area could be sorted into the same categories as the moderate area. However, there probably will not be any buildings which jump out as definite exceptionally high risks as in the other two seismicity levels. This is because not as much information is available on seismic risks in low seismic areas. It is expected that a few buildings will fall in the exceptionally high risk category because they were not designed for seismic or wind effects and they house particularly important functions or large numbers of people. In examining the building population in the low seismic areas, agencies are urged to keep in mind that buildings which are designated as exceptionally high risk buildings will be the only buildings evaluated from the low seismic areas, since the RP5 guidance does not recommend that any buildings from low seismic areas be chosen for the representative sample. Therefore, agencies may wish to evaluate a few buildings in the low seismic area as part of their exceptionally high risk group to get a feel for the actual seismic risks in those areas. Because of this, an acceptable approach would be to select a few buildings which represent vulnerable model building types, which also house an essential function or a large number of people, and which in addition represent a type of building, such as an office, which is very common in the agency's inventory. This will give the agency some information on what risks may actually exist in this portion of their inventory.

The identification of the exceptionally high risk buildings does not mean that all remaining buildings have no seismic risk. It is meant only to indicate the first priority buildings with the most obvious high risk. If using the example selection procedure identifies too many buildings for the agency to evaluate, the agency could take a smaller subset of this risk group as their priority buildings. As a guideline, it is expected that five to ten percent of each agency's buildings in regions of high seismicity will fall into the exceptionally high risk category, along with one-half to one percent of the buildings in regions of moderate seismicity, and an extremely small percentage of the buildings in regions of low seismicity. Agencies with higher than average numbers of exemptions can expect to find their numbers of exceptionally high risk buildings to be at the low end of the range described. 
As a further guide to identifying exceptionally high risk buildings, the following sections summarize two methodologies for prioritizing buildings prior to seismic evaluation. One was developed by the US Air Force and one by the US Department of Energy. Both are based on characteristics listed in Table 3-2. The Air Force approach also places emphasis on the building configuration. Agencies which do not want to develop their own prioritization method for identifying exceptionally high risk buildings can adopt one of these procedures or the example procedure.

\section{Prioritization Process Used by the Air Force}

The following prioritization process was developed by the Air Force to identify, for each base, the order-in which buildings should be further evaluated and if necessary, have unacceptable hazards mitigated. This methodology introduces the variable of building configuration, which has not been previously discussed in this Handbook. The Air Force defines building configuration as either regular or irregular. Buildings with regular configurations have uniform proportions which retain a compact architectural form. Buildings with irregular configurations include abrupt changes in geometric shape (either plan or profile), are extremely large in plan, have excessive length-to-width proportions, or have a center of mass not coincident with the center of resistance. Large plan buildings, such as aircraft hangars, or warehousing, are considered irregular because the building will respond to earthquake shaking with different modes because of the long spans used in the construction. The more significant of the irregular configurations include the "soft story" (ground level story is less stiff than those above), discontinuous shear walls (location different between floors), and re-entrant corners (L-shape).

The first step of the Air Force process is to divide all buildings into Performance Objective Categories. The categories used by the Air Force are defined in Table 3-3. Within each Performance Objective Category, the Air Force then separates the buildings into the 15 model building types found in FEMA 178.

Buildings are next assigned a Risk Group. The Risk Groups are defined in Table 3-4. The order of evaluation then proceeds starting with the buildings in Risk Group A, Performance Objective Category I, Category III, Category IR, Category IV, Category IIIR, etc. The end result is a prioritization of buildings in the following order within the Risk Groups:

\section{Risk Group A:}

Performance Category I - Buildings are in high seismic areas, buildings have an irregular configuration and buildings must remain functional during or be functional immediately following an earthquake.

Performance Category III - Buildings are in high seismic areas, buildings have an irregular configuration and buildings contain a large number of people, or buildings house a service for a large number of other buildings, or buildings house high-value equipment. 


\section{Table 3-3 - Air Force Performance Objective Categories}

IR Immediate Occupancy, Regular Configuration - The building must remain occupied and functional during an earthquake and/or the building houses a function necessary for postdisaster recovery. This category includes hazardous buildings. Other examples are hospitals, fire stations, communications centers, disaster preparedness offices, weapons storage, petroleum storage, chemical storage, etc.

\section{Immediate Occupancy, Irregular Configuration}

IIIR High Risk, Regular Configuration - This category includes buildings whose primary occupancy is the assembly of a large number of people or the confinement of people (prisons), buildings which house services for a large number of other buildings, or buildings which shelter high-value equipment. Examples of this category include theaters, dormitories, dining halls, aircraft hangars, central heat plants, water treatment plants, etc. This category does not include family housing unless there are more than two families within one building.

\section{High Risk, Irregular Configuration}

IVR Other Buildings, Regular Configuration - Includes all buildings not included in the other categories.

\section{Other Buildings, Irregular Configuration}

V Other Hazards - This category includes buildings which are exempt from a detailed structural evaluation, but which may be subject to other hazards, such as nonstructural damage.

\section{Table 3-4 - Air Force Risk Groups}

Risk Group A: This is the highest priority group of buildings in the seismic risk inventory which may require seismic mitigation. This group contains all buildings in Performance Category I, IR, and III in high seismic areas (NEHRP Map Areas 5-7) and all buildings of the following model building types in high seismic areas: Precast/Tilt-Up Concrete Walls with Lightweight Flexible Diaphragms, Precast Concrete Frames with Concrete Shear Walls, Reinforced Masonry Bearing Walls with Wood or Metal Deck Diaphragms, Reinforced Masonry Bearing Walls with Precast Concrete Diaphragms, and Unreinforced Masonry Bearing Walls.

Risk Group B: This is the second highest priority group of buildings in the seismic risk inventory which may require seismic hazard mitigation. This group shall include any non-exempt buildings in NEHRP Map Areas 5-7 which are not in Risk Group A.

Risk Group C: This is the lowest priority group of buildings in the seismic risk inventory which may require seismic hazard mitigation. This Group includes all buildings in NEHRP Map Areas 4,3,2, and 1 and also includes all post-benchmark buildings which have not been evaluated for seismic hazards other than structural. This Group is further divided into Risk Group $C_{2}$ for buildings in moderate seismic areas (NEHRP Map Areas 3-4) and Risk Group $C_{1}$ for buildings in low seismic areas (NEHRP Map Areas 1-2). 
Performance Category IR - Buildings are the same as listed above under Risk Group A, Performance Category I above but they are of regular configuration rather than irregular configuration.

Remaining Buildings - The remaining buildings in Risk Group A are buildings which are in high seismic areas, which are not in the three Performance Categories listed above but which are in the following model building types: Precast/Tilt-Up Concrete Walls with Lightweight Flexible Diaphragms, Precast Concrete Frames with Concrete Shear Walls, Reinforced Masonry Bearing Walls with Wood or Metal Deck Diaphragms, Reinforced Masonry Bearing Walls with Precast Concrete Diaphragms, and Unreinforced Masonry Bearing Walls.

\section{Risk Group B:}

Performance Category IV - Buildings are in high seismic areas, buildings have an irregular configuration and buildings represent standard life-safety occupancy.

Performance Category IIIR - Buildings are in high seismic areas, buildings have a regular configuration, and buildings contain a large number of people, or buildings house a service for a large number of other buildings, or buildings house high-value equipment.

Performance Category IVR - Buildings are in high seismic areas, buildings have a regular configuration and buildings represent a standard life-safety occupancy.

\section{Risk Group $\mathrm{C}_{2}$ :}

Performance Category I - Buildings are in moderate seismic areas, buildings have an irregular configuration and buildings must remain functional during or be functional immediately following an earthquake.

Performance Category III - Buildings are in moderate seismic areas, buildings have an irregular configuration and buildings contain a large number of people, or buildings house a service for a large number of other buildings, or buildings house high-value equipment.

Performance Category IR - Buildings are the same as listed above under Risk Group $\mathrm{C}_{2}$, Performance Category I but they are of regular configuration rather than irregular configuration.

Performance Category IV - Buildings are in moderate seismic areas and buildings have an irregular configuration and buildings represent standard life-safety occupancy. 
Performance Category IIIR - Buildings are in moderate seismic areas, buildings have a regular configuration, and buildings contain a large number of people, or buildings house a service for a large number of other buildings, or buildings house high-value equipment.

Performance Category IVR - Buildings are in moderate seismic areas, buildings have a regular configuration and buildings represent a standard life-safety occupancy.

\section{Risk Group $\mathrm{C}_{1}$ :}

These buildings proceed through evaluation in the same order as the Risk Group $C_{2}$ buildings except that they are in low seismic areas rather than moderate seismic areas.

Although Risk Group A is considered to be the highest priority for evaluation purposes, if buildings are discovered in Risk Group B which are considered to represent as high a seismic risk as the buildings in Risk Group A, these buildings can be moved up in the prioritization process.

For purposes of the Executive Order effort, the Air Force has defined their Exceptionally High Risk buildings as those buildings which fall into Risk Group A.

\section{Prioritization Process Used by the Department of Energy}

The following prioritization process was developed by the Department of Energy (DOE) to use on all of their buildings in order to screen out buildings of low seismic vulnerability and to direct initial detailed evaluation and mitigation efforts to the buildings which are at greatest potential seismic risk. The process defines two attributes for each building, assigns a numerical value to each attribute, and multiplies the attributes to produce a total score for the individual building. The buildings with the highest final score represent those with the highest seismic vulnerability and therefore those which need a detailed seismic evaluation.

Failure Consequence - The first attribute is the Failure Consequences attribute (FC). The analysis of this attribute considers existing information in the form of hazard category and building occupancy. Numerical scores are assigned for both the hazard category and the building occupancy. The higher of these two scores is used as the FC score. Table 3-5 shows how the numerical scores are assigned.

In the DOE complex, buildings are grouped into various hazard categories as part of the overall safety analysis assessment. These provide an indication of the significance of the failure consequences of the building given the building location and factors such as the on-site and off-site population density. As indicated by the definitions above, the more serious the hazard category, the higher the numerical score. 


\section{Table 3-5 - DOE Definition of Failure Consequences}

\section{$\underline{F C}=$ FAILURE CONSEOUENCES}

Use the greater of the HC - Hazard Category or BO - Building Occupancy

\begin{tabular}{|c|c|c|c|}
\hline$\underline{\mathrm{HC}}$ & SCORE & BO & $\underline{\text { SCORE }}$ \\
\hline HC1 OR HH & 10 & $300+$ PEOPLE & 10 \\
\hline HC2 OR MH & 3 & 51-300 PEOPLE & 6 \\
\hline HC3,LH,EU & 1 & 6-50 PEOPLE & 3 \\
\hline All Others & 0 & $<6$ PEOPLE & 0 \\
\hline
\end{tabular}

HC1 OR HH = usage with potential for significant offsite radiological or chemical hazard.

HC2 OR MH = usage with potential for significant onsite radiological or chemical hazard.

HC3,LH,EU = usage with potential for localized or minor radiological or chemical hazard; or a facility with essential services which must survive the seismic event (e.g. Fire Station).

All Others $=$ general usage facility.

The divisions of occupancy for the Building Occupancy score are based on numbers used in model building codes to define occupancy categories. The higher the number of occupants in a building, the higher the numerical score. The use of 6 people as a lower bound cutoff is consistent with ICSSC RP3 [ICSSC]. A building which has a zero score for both the HC and the BO score would be effectively screened out by receiving a zero score for the FC attribute. This would represent a building with no radiological or chemical hazard, no essential use, and with an occupancy of fewer than 6 people.

Building Vulnerability - The second attribute is the Building Vulnerability (BV) attribute. This attribute is based on the condition of the building in relation to the anticipated seismic hazard at the site of the building. The ranking approach is based on assigning the condition of the building as good, fair, poor, or very poor. This qualification is based as much as possible on existing information. For the case where existing seismic structural analyses have been completed, the ranking is based on the ratio of the seismic capacity to the seismic demand of critical structural members (seismic capacity/demand ratio). The correlation between the seismic capacity/demand ratio and the numerical score is indicated in Table 3-6.

If there is insufficient existing seismic analysis, the condition of the building should be evaluated using data on building behavior from past earthquakes. This includes the use of benchmark years, and the identification of certain building types known to be vulnerable to earthquakes and no longer permitted by the building codes. Table 3-7 shows guidance given in the DOE documentation for determining the numerical score using this type of information. The procedure also allows the use of the preliminary evaluation checklists found in FEMA 178 to establish the condition of the building. 
Table 3-6 - DOE Definition of Building Vulnerability

$\underline{\mathrm{BV}}=\mathrm{BUILDING}$ VULNERABILITY

SEISMIC

CAP/DMD

$\geq 0.9$

CONDITION

GOOD

SCORE

$\geq 0.7<0.9$

$\geq 0.5<0.7$

FAIR

0

POOR

2

$<0.5$

VERY POOR

7

10

Buildings whose seismic C/D ratios are .90 or higher, buildings which have been fully rehabilitated, buildings which show full adherence to adequate seismic codes or buildings which are exempt from seismic design by the model building codes and the NEHRP Provisions will be screened out by receiving a zero in the BV category.

Once the scores for the FC and the BV attributes have been determined, the next step is to compute the overall ranking of the building as follows: $\mathrm{RK}=(\mathrm{FC}) \mathrm{x}(\mathrm{BV})$. This score will range from a 0 for buildings which are screened out of the ranking process, to a maximum score of 100 . The buildings which receive the high scores are the first priority buildings. The DOE has not yet defined a cutoff of the numerical score for which buildings would be determined to be the exceptionally high risk buildings. However, the scores have been assigned nonlinearly in order to cause the worst buildings to get relatively higher scores than the rest.

Although not specifically part of the attributes, the DOE prioritization document allows buildings to be given a higher score if their mission is unique such that the building must not be damaged. Also, buildings may not be exempted based upon a short remaining life unless a budget already exists to demolish or replace the building. 
Table 3-7 - DOE Building Vulnerability Factor

SEISMIC AREAS

UBC - All Zones

NEHRP - All Map Areas

UBC - All Zones

NEHRP - All Map Areas

UBC - All Zones

NEHRP - All Map Zones

UBC - Zones 2B-4

NEHRP - Map Areas 5-7

UBC - Zones 1-2A

NEHRP - Map Areas 3-4

UBC - Zones 2B-4

NEHRP - Map Areas 5-7
Any one-story building of steel light frame or wood construction with areas less than $\mathbf{2 8 0}$ sq. meters (3000 sq. ft.)

Any fully rehabilitated building whose mitigation scheme considered structural, nonstructural, adjacency and geologic/site hazards and was based on an acceptable national seismic code and DOE design criteria.

Post-benchmark buildings whose documentation shows adherence to the seismic design guidelines of accepted national codes and DOE design criteria.

Pre-Benchmark building of any construction not considered above.

Pre-Benchmark building of any construction not considered above.

Masonry shear walls with no reinforcing steel or no verification of acceptable reinforcing steel.

Reinforced concrete moment frames with no detailing for ductile behavior or no verification of acceptable detailing.

UBC - Zones 1-2A

NEHRP - Map Areas 3-4

Masonry shear walls with no reinforcing steel or no verification of acceptable reinforcing steel.

Reinforced concrete moment frames with no detailing for ductile behavior or no verification of acceptable detailing.

UBC - Zones 2B-4

NEHRP - Map Areas 5-7

UBC - Zones 1-2A

NEHRP - Map Areas 3-4

UBC - Zones 2B-4

NEHRP - Map Areas 5-7

UBC - All Zones

NEHRP - All Map Areas

Obvious deterioration of members of the structural system.

Obvious deterioration of members of the structural system.

Potential for soil liquefaction or unknown soil conditions.

Any remaining building not considered above.

Building should be given the lowest score from the applicable categories above.
CONDITION

Good

Good

Good

Very Poor

Poor

Very Poor

Poor

Very Poor

Poor

Poor

Fair 


\subsubsection{Evaluate a Representative Sample of Remaining Non-Exempt Buildings}

After identifying exceptionally high risk buildings for evaluation, agencies are also asked to identify for evaluation a representative sample of the remaining non-exempt buildings in regions of moderate and high seismicity. This means that an agency has taken its total inventory, it has identified its exempt buildings and set these aside for no further effort, it has then identified its exceptionally high risk buildings and set them aside for definite evaluation. The remaining group of buildings should then be divided into the three seismicity levels: high, moderate and low. The buildings in the low seismicity area can now be set aside since no further evaluation effort is required for these buildings. The buildings which are left are the remaining non-exempt buildings in high and moderate seismic areas. RP5 recommends that agencies evaluate a representative sample of this group of buildings. It is expected that evaluations of about one to two percent of the non-exempt buildings in the high and moderate areas will provide an adequately representative sample.

A representative sample is a group of buildings which are typical of the types of buildings found in an agency's inventory. In the development of a representative sample, an agency should examine its particular inventory and identify the dominant characteristics. These characteristics may be such things as seismicity, the occupancy categories of the buildings, the height and/or size of the buildings, and the dominant model building types. Agencies may select their representative sample from those buildings which represent the inventory's dominant characteristics (those categories which collectively represent over $85 \%$ of the remaining non-exempt inventory). By evaluating buildings in such categories, information will be developed on all non-unique building types in the Federal inventory and cost estimates will be available for buildings at several levels of seismic risk. Table 3-8 shows suggested building characteristics to be considered in establishing dominant characteristics.

The purpose of evaluating a representative sample is to gain information about the population of buildings remaining after those buildings which are exceptionally high risks have been identified. This remaining population still contains buildings with potentially high seismic risks, although these risks may be difficult to determine, as well as buildings with various lower levels of seismic risk. The information collected for the representative sample will be used to determine how many buildings in the population which was not evaluated are expected to be seismically deficient, and to estimate what the costs of fixing those buildings would be. This includes an estimate for the buildings in the low seismic areas.

There is not one correct way to choose a representative sample. The sample will depend on the specific inventory of an agency and the specific needs of an agency. However, it is important to note here the relationship between the buildings selected for evaluation and the development of cost estimates for buildings which are not evaluated. As mentioned previously, the information from the evaluations of the representative sample will be extrapolated to the remaining population of non-evaluated buildings to develop cost estimates for the seismic rehabilitation of these buildings. In Section 4.2 of RP5, there are requirements for reporting these cost estimates using the characteristics of essential designation, historic designation, and model building types. Therefore, these characteristics should be considered when an agency is developing their representative sample in order to make the extrapolation process easier. 
Table 3-8 - Suggested Building Characteristics to be Used to Categorize Buildings

\begin{tabular}{|c|c|c|c|c|}
\hline Seismicity: & Occupancy: & Model Building Type: & Size: & Other: \\
\hline $\begin{array}{l}\text { High } \\
\text { Moderate } \\
\text { Low }\end{array}$ & $\begin{array}{l}\text { Offices } \\
\text { Post Offices } \\
\text { Hospitals } \\
\text { Prisons } \\
\text { Schools } \\
\text { Other } \\
\text { Institutional } \\
\text { Housing } \\
\text { Storage } \\
\text { Industrial } \\
\text { Service } \\
\text { Res. \& Dev. } \\
\text { Other (Misc) }\end{array}$ & $\begin{array}{l}\text { Wood, Light Frame } \\
\text { Wood, Commercial and Industrial } \\
\text { Steel Moment Frame } \\
\text { Steel Braced Frame } \\
\text { Steel Light Frame } \\
\text { Steel Frame/Concrete Shear Walls } \\
\text { Steel Frame/Infill Shear Walls } \\
\text { Concrete Moment Frame } \\
\text { Concrete Shear Walls } \\
\text { Concrete Frame/Infill Shear Walls } \\
\text { Precast/Tilt-Up Concrete Walls } \\
\text { Precast Concrete Frames/Concrete } \\
\text { Shear Walls } \\
\text { Reinforced Masonry Bearing } \\
\text { Walls/Wood or Metal Deck } \\
\text { Diaphragms } \\
\text { Reinforced Masonry Bearing } \\
\text { Walls/Precast Concrete } \\
\text { Diaphragms } \\
\text { Unreinforced Masonry Bearing Wall }\end{array}$ & $\begin{array}{l}<4645 \mathrm{~m}^{2} \\
4645-9290 \mathrm{~m}^{2} \\
>9290 \mathrm{~m}^{2}\end{array}$ & $\begin{array}{l}\text { Historic } \\
\text { Mission } \\
\text { Essential }\end{array}$ \\
\hline
\end{tabular}

Two different approaches to identifying the representative sample of buildings are illustrated in the following sections. One is a random sample approach, and one is a risk based approach. These are not required approaches, only suggested approaches. An agency may wish to identify their representative sample based on agency specific needs. The method used to identify the representative sample is to be described in the supporting documentation.

\section{Option A: Selecting a Random Sample}

One way to choose the buildings to be evaluated is to randomly select buildings from the dominant categories. In this way, the agency can focus on a sample which is largely representative of its entire population. The first step in this process would be to determine what dominant building characteristics exist within the inventory. For example, an agency could first divide the buildings into high and moderate seismicities. The buildings could then be divided into key occupancy categories, depending on the types of buildings owned by the agency. The categories may include hospitals, schools, offices, and all other buildings. Within these subsets the buildings could then be divided by model building type. If not all 15 model building types are well represented, a subset of the model building types can be used. For instance, an agency may own buildings which are mostly steel moment frames, concrete moment frames, concrete shear walls, concrete frame with infill shear walls, and reinforced masonry bearing walls with wood diaphragms. 
Table 3-9 shows how this breakdown would look. Each of the smaller boxes in this table would contain a number of buildings. Buildings could be chosen for evaluation from the subsets that represent in total about $85 \%$ of the remaining non-exempt population. This

\begin{tabular}{|c|c|c|c|c|}
\hline & Hospitals & Schools & Offices & All Other \\
\hline \multirow{5}{*}{$\begin{array}{l}\text { Moderate } \\
\text { Seismic } \\
\text { Areas }\end{array}$} & $\begin{array}{l}\text { Steel Moment } \\
\text { Frame }\end{array}$ & $\begin{array}{l}\text { Steel Moment } \\
\text { Frame }\end{array}$ & $\begin{array}{l}\text { Steel Moment } \\
\text { Frame }\end{array}$ & $\begin{array}{l}\text { Steel Moment } \\
\text { Frame }\end{array}$ \\
\hline & $\begin{array}{l}\text { Concrete Moment } \\
\text { Frame }\end{array}$ & $\begin{array}{l}\text { Concrete Moment } \\
\text { Frame }\end{array}$ & $\begin{array}{l}\text { Concrete Moment } \\
\text { Frame }\end{array}$ & $\begin{array}{l}\text { Concrete Moment } \\
\text { Frame }\end{array}$ \\
\hline & $\begin{array}{l}\text { Concrete Shear } \\
\text { Walls }\end{array}$ & $\begin{array}{l}\text { Concrete Shear } \\
\text { Walls }\end{array}$ & $\begin{array}{l}\text { Concrete Shear } \\
\text { Walls }\end{array}$ & $\begin{array}{l}\text { Concrete Shear } \\
\text { Walls }\end{array}$ \\
\hline & $\begin{array}{l}\text { Concrete Frame } \\
\text { with Infill Shear } \\
\text { Walls }\end{array}$ & $\begin{array}{l}\text { Concrete Frame } \\
\text { with Infill Shear } \\
\text { Walls }\end{array}$ & $\begin{array}{l}\text { Concrete Frame } \\
\text { with Infill Shear } \\
\text { Walls }\end{array}$ & $\begin{array}{l}\text { Concrete Frame } \\
\text { with Infill Shear } \\
\text { Walls }\end{array}$ \\
\hline & $\begin{array}{l}\text { Reinforced } \\
\text { Masonry Bearing } \\
\text { Walls - Wood } \\
\text { Diaphragms }\end{array}$ & $\begin{array}{l}\text { Reinforced } \\
\text { Masonry Bearing } \\
\text { Walls - Wood } \\
\text { Diaphragms }\end{array}$ & $\begin{array}{l}\text { Reinforced } \\
\text { Masonry Bearing } \\
\text { Walls - Wood } \\
\text { Diaphragms }\end{array}$ & $\begin{array}{l}\text { Reinforced } \\
\text { Masonry Bearing } \\
\text { Walls - Wood } \\
\text { Diaphragms }\end{array}$ \\
\hline \multirow{5}{*}{$\begin{array}{l}\text { High } \\
\text { Seismic } \\
\text { Areas }\end{array}$} & $\begin{array}{l}\text { Steel Moment } \\
\text { Frame }\end{array}$ & $\begin{array}{l}\text { Steel Moment } \\
\text { Frame }\end{array}$ & $\begin{array}{l}\text { Steel Moment } \\
\text { Frame }\end{array}$ & $\begin{array}{l}\text { Steel Moment } \\
\text { Frame }\end{array}$ \\
\hline & $\begin{array}{l}\text { Concrete Moment } \\
\text { Frame }\end{array}$ & $\begin{array}{l}\text { Concrete Moment } \\
\text { Frame }\end{array}$ & $\begin{array}{l}\text { Concrete Moment } \\
\text { Frame }\end{array}$ & $\begin{array}{l}\text { Concrete Moment } \\
\text { Frame }\end{array}$ \\
\hline & $\begin{array}{l}\text { Concrete Shear } \\
\text { Walls }\end{array}$ & $\begin{array}{l}\text { Concrete Shear } \\
\text { Walls }\end{array}$ & $\begin{array}{l}\text { Concrete Shear } \\
\text { Walls }\end{array}$ & $\begin{array}{l}\text { Concrete Shear } \\
\text { Walls }\end{array}$ \\
\hline & $\begin{array}{l}\text { Concrete Frame } \\
\text { with Infill Shear } \\
\text { Walls }\end{array}$ & $\begin{array}{l}\text { Concrete Frame } \\
\text { with Infill Shear } \\
\text { Walls }\end{array}$ & $\begin{array}{l}\text { Concrete Frame } \\
\text { with Infill Shear } \\
\text { Walls }\end{array}$ & $\begin{array}{l}\text { Concrete Frame } \\
\text { with Infill Shear } \\
\text { Walls }\end{array}$ \\
\hline & $\begin{array}{l}\text { Reinforced } \\
\text { Masonry Bearing } \\
\text { Walls - Wood } \\
\text { Diaphragms }\end{array}$ & $\begin{array}{l}\text { Reinforced } \\
\text { Masonry Bearing } \\
\text { Walls - Wood } \\
\text { Diaphragms }\end{array}$ & $\begin{array}{l}\text { Reinforced } \\
\text { Masonry Bearing } \\
\text { Walls - Wood } \\
\text { Diaphragms }\end{array}$ & $\begin{array}{l}\text { Reinforced } \\
\text { Masonry Bearing } \\
\text { Walls - Wood } \\
\text { Diaphragms }\end{array}$ \\
\hline
\end{tabular}

means that every subset need not be included in the evaluation sample. If a subset contains only a few buildings, this subset is not representative of the population and can be ignored. The exact number of buildings chosen from each subset can be determined by the agency. More buildings should be chosen from the categories which contain more buildings. As stated before, the total number of buildings to be evaluated in the representative sample is expected to be about one to two percent of the non-exempt buildings in high and moderate areas, or, in other words, one to two percent of the total number of buildings in all of the boxes. 
There is no one correct way for an agency to break down its inventory. Dividing the inventory is meant to be a tool to assist the agency in determining the dominant characteristics of its inventory. It is of no advantage to sub-divide the inventory into so many categories that the number of buildings in each category is too small to indicate any helpful information. Inventories should be subdivided only into a number of categories which shows where the majority of the buildings lie.

There are many agencies whose inventories contain buildings which for the most part have the same characteristics. These agencies will need a relatively small number of divisions to determine their inventory characteristics. For example, it is anticipated that many agencies will end up with an inventory of non-exempt buildings which are all relatively the same size, and are mainly office and storage buildings. These buildings can first be divided into areas of moderate and high seismicity. The buildings can then be divided by usage category, such as office, storage and other. Any further division of the buildings can be based on the fifteen model building types, or some smaller subset of these building types. For instance, the buildings may be mostly of concrete moment frame or concrete shear wall construction. Table 3-10 shows how a such a subdivision would look. The majority of the buildings would fall into the boxes which are not part of "other" categories. Therefore, the buildings to be evaluated would be selected from the eight boxes in Table 3-10 which are shaded. An agency need not evaluate every building in the box, only a representative sample.

\begin{tabular}{|c|c|c|c|}
\hline & Office & Storage & Other \\
\hline \multirow{3}{*}{$\begin{array}{c}\text { Moderate } \\
\text { Seismic } \\
\text { Areas }\end{array}$} & ratrit: & 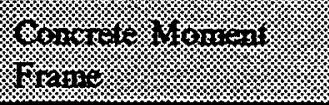 & $\begin{array}{l}\text { Concrete Moment } \\
\text { Frame }\end{array}$ \\
\hline & 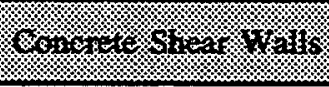 & E & Concrete Shear Walls \\
\hline & Other & Other & Other \\
\hline \multirow{3}{*}{$\begin{array}{l}\text { High } \\
\text { Seismic } \\
\text { Areas }\end{array}$} & 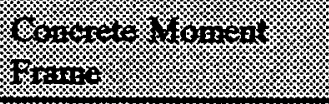 & 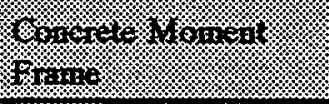 & $\begin{array}{l}\text { Concrete Moment } \\
\text { Frame }\end{array}$ \\
\hline & 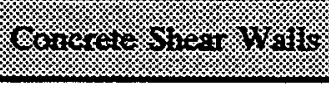 & 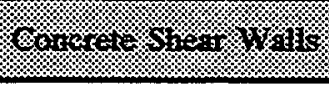 & Concrete Shear Walls \\
\hline & Other & Other & Other \\
\hline
\end{tabular}

\section{Option B: Selecting Buildings Based on Seismic Risk}

Rather than randomly selecting buildings from dominant groups, an agency may instead choose to continue to emphasize the potentially higher risk buildings. In using this method, an agency should continue to define its highest risks using the same methods utilized in the identification of its exceptionally high risk buildings. The main building characteristics to 
be used are listed in Table 3-2 and include the seismicity, the model building type, and the occupancy category of the building.

The specific buildings to be evaluated can also be determined using the approach of dividing the buildings into dominant characteristics as discussed in the previous section. However, instead of selecting randomly from each subset of buildings, an agency can choose to evaluate only buildings from those subsets of buildings which represent the highest potential seismic risk of the remaining non-exempt buildings in the moderate and high seismic areas.

\begin{tabular}{|c|c|c|c|c|c|}
\hline & Hospitals & Schools & $\begin{array}{l}\text { Other Mission } \\
\text { Essential }\end{array}$ & Offices & Other \\
\hline \multirow{6}{*}{$\begin{array}{c}\text { Moderate } \\
\text { Seismic } \\
\text { Areas }\end{array}$} & $\begin{array}{l}\text { Steel Moment } \\
\text { Frame }\end{array}$ & $\begin{array}{l}\text { Steel Moment } \\
\text { Frame }\end{array}$ & (s) & $\begin{array}{l}\text { Steel Moment } \\
\text { Frame }\end{array}$ & $\begin{array}{l}\text { Steel Moment } \\
\text { Frame }\end{array}$ \\
\hline & $\begin{array}{l}\text { Concrete } \\
\text { Moment } \\
\text { Frame } \\
\end{array}$ & $\begin{array}{l}\text { Concrete } \\
\text { Moment } \\
\text { Frame } \\
\end{array}$ & 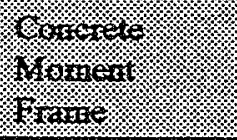 & $\begin{array}{l}\text { Concrete } \\
\text { Moment } \\
\text { Frame }\end{array}$ & $\begin{array}{l}\text { Concrete } \\
\text { Moment } \\
\text { Frame }\end{array}$ \\
\hline & $\begin{array}{l}\text { Concrete } \\
\text { Shear Walls }\end{array}$ & $\begin{array}{l}\text { Concrete } \\
\text { Shear Walls }\end{array}$ & 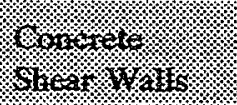 & $\begin{array}{l}\text { Concrete } \\
\text { Shear Walls }\end{array}$ & $\begin{array}{l}\text { Concrete } \\
\text { Shear Walls }\end{array}$ \\
\hline & $\begin{array}{l}\text { Unreinforced } \\
\text { Masonry } \\
\text { Bearing Walls }\end{array}$ & $\begin{array}{l}\text { Unreinforced } \\
\text { Masonry } \\
\text { Bearing Walls }\end{array}$ & 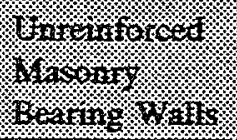 & $\begin{array}{l}\text { Unreinforced } \\
\text { Masonry } \\
\text { Bearing Walls }\end{array}$ & $\begin{array}{l}\text { Unreinforced } \\
\text { Masonry } \\
\text { Bearing Walls }\end{array}$ \\
\hline & $\begin{array}{l}\text { Precast/Tilt- } \\
\text { Up Concrete } \\
\text { Walls }\end{array}$ & 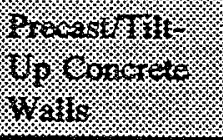 & 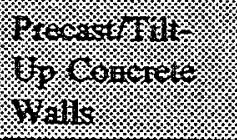 & 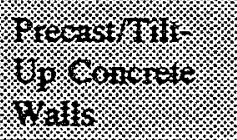 & 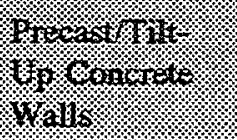 \\
\hline & Other & Other & ortank & Other & Other \\
\hline \multirow{6}{*}{$\begin{array}{c}\text { High } \\
\text { Seismic } \\
\text { Areas }\end{array}$} & rir & $\begin{array}{l}\text { Steel Moment } \\
\text { Frame }\end{array}$ & 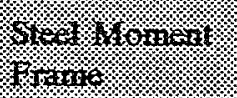 & $\begin{array}{l}\text { Steel Moment } \\
\text { Frame }\end{array}$ & $\begin{array}{l}\text { Steel Moment } \\
\text { Frame }\end{array}$ \\
\hline & 1010) & 8.t. & 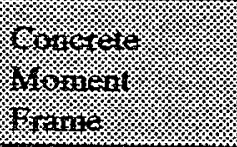 & 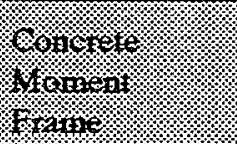 & 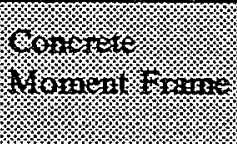 \\
\hline & 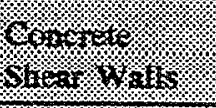 & $\begin{array}{l}\text { Concrete } \\
\text { Shear Walls }\end{array}$ & (y) & $\begin{array}{l}\text { Concrete } \\
\text { Shear Walls }\end{array}$ & $\begin{array}{l}\text { Concrete } \\
\text { Shear Walls }\end{array}$ \\
\hline & 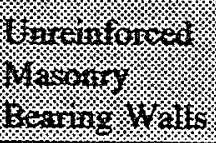 & 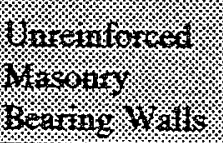 & 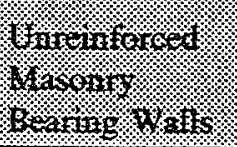 & 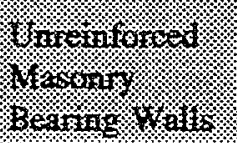 & 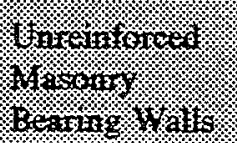 \\
\hline & 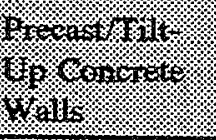 & 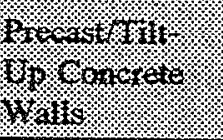 & 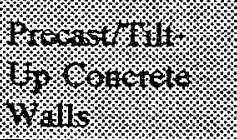 & 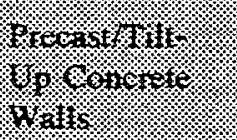 & 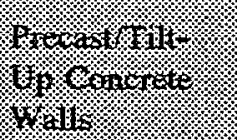 \\
\hline & Filisey & Other & (6) & Other & Other \\
\hline
\end{tabular}


For example, one approach would be for an agency to divide its remaining non-exempt inventory into moderate, and high seismic areas. It could then divide each of these subsets into the following occupancy and/or mission groups: hospitals, - schools, other mission essential buildings, offices, and other usage facilities. It could further divide these groups into the following model buildings types based on the characteristics of the inventory: Steel Moment Frame, Concrete Moment Frame, Concrete Shear Walls, Unreinforced Masonry Bearing Walls, Precast/Tilt-Up Concrete Walls and Other. After placing each building into these categories, the agency decides to evaluate a sample of, or all of, the buildings in the groups which represent the highest relative risk. This could include hospitals in high seismic areas, unreinforced masonry and concrete moment frames in the high seismic areas, as well as precast tilt-ups and mission essential buildings. The agency chooses these buildings because the agency feels that these represent their highest risks in this non-evaluated population. Table 3-11 shows what this inventory breakdown would look like. The agency will evaluate a sample of buildings from the shaded boxes.

Note that, if a risk-based methodology is used to select the representative sample, the results may not be easily extrapolated to the remaining non-evaluated population in order to estimate total costs. In a truly random sample, the ratio of deficient to acceptable buildings will be the same in the evaluated sample as in the population as a whole. For a risk-based sample, this will not be the case. If a risk-based sample is chosen, careful attention must be paid to the methodology used to estimate the vulnerability of the non-evaluated population for costestimating purposes, so that estimates are not unrealistically high.

\section{Agencies with Very Small Inventories}

There are a number of agencies which own fewer than 1000 non-exempt buildings. It will be difficult for these agencies to divide their inventory into a large number of dominant characteristics due to the small number of buildings. These agencies may still be able to divide their buildings into two or three main characteristics, such as just seismicity or seismicity and two or three key occupancies or model building types. Other agencies may be forced to leave all of their buildings in one group and simply evaluate a few of these buildings. It is not useful to divide the buildings into so many groups that there are only three or four buildings in each group. There may be no dominant characteristic of the buildings, therefore dividing them into groups does not make the effort of selecting representative buildings easier.

As an example of the methodology involved for an agency with few buildings, this discussion will focus on the imaginary inventory of the Department of Science. Assume that according to the 1993 GSA Real Property Database, the imaginary Department of Science owns 650 buildings within the United States and its territories. If the exempt buildings are subtracted from this number, there are 179 buildings remaining. Of these 179 buildings, 101 are in low seismic areas, 37 are in moderate seismic areas, and 41 are in high seismic areas. When the Department of Science identifies exceptionally high risk buildings, it identifies fifteen in the high seismic areas, 2 in the moderate seismic areas and 2 in the low seismic areas. Therefore, the Department evaluates these 19 buildings. (It is possible that a Department may have no buildings which they consider to represent an exceptionally high risk. The 
number of buildings evaluated in this category would then be zero.)

Subtracting those 19 buildings from the Department of Science non-exempt inventory, and placing aside the buildings in the low seismic areas leaves 61 non-exempt buildings in the high and moderate seismic areas. If the Department of Science were to evaluate 1-2\% of these buildings, they would evaluate only 1-2 additional buildings. All of these 61 buildings fall into approximately the same size group. Most of these buildings represent offices, research and development facilities, and storage facilities. A reasonable approach would be to evaluate one office and one research and development facility. An alternate approach would be to evaluate two buildings which are most important to the agency. It becomes obvious that the amount of time and effort spent dividing the sample into representative groups is not advantageous to agencies with small inventories of buildings.

\subsubsection{Report Results From Previous Evaluations}

A building which has already been evaluated for seismic safety will fall into one of the following situations:

1) A building has been previously evaluated to criteria substantially equivalent to the RP4 minimum evaluation procedure and has been found to be seismically adequate. According to RP4 exemption g, this building could be reported as exempt. However, it is recommended that the agency not report this building as exempt but instead make a point to include this building in its evaluated sample in order to "take credit" for work already completed. No further evaluation would be needed for this building. An evaluation outcome of "OK" would be reported for this building in the database and the results of this evaluation could possibly be extrapolated to other similar buildings.

2) A building has been previously evaluated to the acceptable criteria described above but has been found to be seismically inadequate. This building should be included in the evaluated sample. An evaluation outcome of "NG" would be reported. No further evaluation would be needed but a cost estimate would need to be developed.

3) A building has been previously evaluated to the acceptable criteria described above, has been found to be seismically inadequate, and has been rehabilitated to standards deemed appropriate by the agency. This building should be categorized as exempt.

4) A building has been previously evaluated to criteria substantially less stringent than the minimum evaluation requirements in RP4. This building should be considered a non-exempt, non-evaluated building which would need a new evaluation if it were chosen as part of the evaluated sample.

Many previously evaluated buildings are likely to be categorized as "exceptionally high risk". Agencies should report the information from those buildings as such. Agencies are encouraged to include previously evaluated buildings which are not "exceptionally high risk" buildings as part of their representative sample of remaining non-exempt buildings in order to utilize available data as much as possible. 


\subsection{Performing Evaluations on Selected Buildings}

Upon reaching this point in the process, the agency will have identified the buildings which it intends to evaluate. If a building in this group has already been evaluated, it is not necessary to redo this process as long as the evaluation performed was sufficiently close to an RP4 evaluation. Otherwise, the evaluation of each building must be done by a civil/structural engineer. This evaluation will determine whether or not the building poses a seismic risk. If an evaluation is performed on a building and the evaluation shows that the building is seismically acceptable, no further work will be done on the building. If an evaluation is done and the evaluation shows the building to be seismically vulnerable, a cost estimate must be developed for achieving adequate seismic safety in that building. The cost estimate will show how much it will cost to mitigate the unacceptable risk, either through upgrading the building, or by abandoning, demolishing, replacing, or reducing the use of the building.

The minimum evaluation methodology which can be used for this effort is the preliminary evaluation procedure outlined in RP4, which in turn references FEMA 178. This evaluation is for a life-safety level only. The detailed evaluation may be used if the building fails the preliminary checklist in an attempt to more precisely differentiate between the potential hazards identified in the preliminary procedure and actual unacceptable risks. An agency may use an evaluation procedure for life-safety which is different from that in RP4 if it results in a similar level of safety. This evaluation procedure must be summarized in the written supporting documentation. If an agency is evaluating a building for a level higher than life-safety, that agency will have to use an alternate evaluation procedure because RP4 is for life-safety only. Such procedures should also be summarized in the written supporting documentation.

If the RP4 procedure is used, the expected ground acceleration determined from the maps cited in RP4 shall be considered the minimum allowable level for use in the evaluation. Acceleration values from other nationally accepted seismic hazard maps and codes may be used as long as they are not lower than the RP4 value. However, if a site specific value is used, this value may be lower than the RP4 value.

\subsubsection{Goal of Evaluation}

The goal of the evaluation is to determine whether the building is seismically acceptable or seismically deficient. If the building is acceptable, this should be reported in the database with an outcome of evaluation of "OK". If the building is seismically deficient in any way, it should be reported in the database with an outcome of evaluation of "NG". For buildings reported as "NG", a cost estimate for the seismic rehabilitation necessary to make the building seismically acceptable should be developed and reported in the database.

There are several reasons why a building may be found to be deficient. Causes of deficiency include:

- $\quad$ structural deficiency

- nonstructural deficiency

- geologic/site hazard 
- adjacency problems

- combination of above reasons

- $\quad$ building is categorized as a DNR (See section 3.2.2 below)

Section 5 lists the codes to be used when reporting each of these causes of deficiency.

\subsubsection{Definitely Needing Rehabilitation Buildings}

There are some buildings which are so obviously in need of rehabilitation that they do not need an evaluation to determine that rehabilitation efforts are needed. These buildings are referred to as Definitely Needing Rehabilitation (DNR) Buildings. These buildings may be deemed deficient without any further evaluation. Agencies are cautioned that an overly liberal use of the DNR designation may result in an unrealistically high estimate of the cost of rehabilitating their buildings.

Once an agency has determined its group of exceptionally high risk buildings, this group of buildings can be examined for DNR buildings. If any DNR buildings are identified in this group, the DNR buildings would need no further evaluation. In most cases a building will be designated a DNR because of structural deficiency. Therefore, the reason for deficiency would be reported as such. A cost estimate must still be developed and submitted for each of these buildings.

Guidelines included in RP5 for which buildings can be designated as DNR buildings are as follows:

- unreinforced masonry buildings in areas of high seismicity

- concrete frame buildings without shear walls built before 1960 in areas of high seismicity

- pre-cast frame buildings in moderate and high seismic areas

Agencies may identify buildings with certain other characteristics which they deem to be DNR buildings. The rationale used to develop additional agency-specific DNR definitions must be based on documented performance of the structural system, in either laboratory tests or actual earthquakes. Any such definitions must be summarized in the written supporting documentation. 


\subsection{ESTIMATING COST OF REHABILITATION}

\subsection{Cost Estimates for Evaluated and Deficient Buildings}

\subsubsection{Cost Categories}

For each evaluated building found to be deficient, the following categories of cost are to be calculated and separately reported in the inventory database:

- structural (changes to the lateral force resisting system)

- nonstructural (changes to other parts of the building and to building equipment, systems, and contents)

- finishing (costs of removing and replacing finishes such as wallboard, paint, carpet, etc.)

- project costs (design, testing, and permit fees, cost of project management, etc.)

The definitions of these categories of costs are to be the same as those used in Typical Costs, FEMA 156. These are described below.

Structural Costs are to include the cost of construction materials and labor (contractor overhead and profit included) for seismic structural rehabilitation of the building. These structural costs are the only components of the "typical" cost tabulated in Typical Costs, FEMA 156. This value should not include the cost of removing and replacing finishes; upgrading nonstructural portions of the building such as ceilings, interior partitions, mechanical, or electrical systems; or design, testing and management fees. This component of cost is of interest because it represents the cost of including a seismic upgrade concurrent with some other already planned renovation project. Any rehabilitation costs which are associated with adjacency issues or geologic/site issues should be reported in the database under structural costs as well.

Nonstructural Costs should include construction and materials costs associated with seismically upgrading the nonstructural architectural features of the building, such as cladding, exterior non-load-bearing facades, parapets, interior partitions, decorative elements; and building operating systems such as mechanical, electrical and plumbing systems.

Finishing Costs should include costs of removing and replacing architectural finishes such as floors, walls, and ceilings (wallboard, paint, wallpaper, carpeting, etc.). Removal and reinstallation of electrical and mechanical equipment and removal and replacement of roofing systems is also to be included in this category. Note that if the systems themselves are seismically upgraded, the cost should be included under Nonstructural Costs. If the system merely needs to be removed and replaced in order to gain access to the structural system, the cost is to be included in Finishing Costs. 
Project Costs should include design fees, testing and permitting costs, and project management costs.

If an estimated cost is developed without the specific breakdowns identified above, an attempt should be made to either break down the cost into these areas, if it known that they were included in the estimate, or to estimate the amounts of the costs which were not included.

The following costs are NOT to be reported: other upgrades triggered by the rehabilitation effort (such as handicapped access, asbestos removal, etc.), repair of existing damage, relocation of occupants, business loss or interruption. Agencies interested in estimating these costs for their own use will find guidance in Volume II of Typical Costs, FEMA 157. Although none of these costs are to be reported for this effort, it is recognized that these can be costs encountered during seismic rehabilitation. The potential effects of these "triggered" and additional costs will be addressed in the final report written by FEMA.

Reported costs are to be total costs for the building, not costs per square meter. Section 5 of this Handbook provides formatting details.

\subsubsection{Cost Estimation Methods}

Acceptable cost estimation methods include the following:

1) Have the evaluating engineer develop a preliminary rehabilitation scheme appropriate for the specific structure, not less stringent than the RP4 life-safety criteria, and calculate the cost of the proposed fix. (Note, for this cost estimation method, the agency may use any nationally accepted seismic hazard map or available site-specific study as the source of ground acceleration values. No specific map is mandated for use.)

2) Use agency-specific cost estimating procedures. Include detailed information on the procedure used in the supporting information that is submitted.

3) Use the recommended default method: Follow cost estimating Option II in Volume I of Typical Costs, FEMA 156 to obtain structural (typical) costs. Use the guidance provided in Chapter 1 of Volume II of Typical Costs, FEMA 157 to estimate nonstructural, finishing, and project costs.

4) If, instead of being rehabilitated, the building would be replaced, a replacement cost should be reported instead of a rehabilitation cost, and so noted.

5) If, instead of being rehabilitated, the building would be abandoned and not replaced, the reported rehabilitation cost should be the cost of disposal. If no disposal cost is anticipated, the rehabilitation costs can be reported as zero.

Section 5 of this Handbook lists the codes to be used in reporting which cost estimation method was used.

\subsection{Cost Estimates for Non-Evaluated Buildings}

Agencies are to use the information gathered from the evaluations performed and the cost 
estimates developed to estimate 1) how many of the non-exempt, non-evaluated buildings are expected to be seismically deficient; and 2) what would the cost of achieving seismic safety in these seismically deficient buildings be.

The development of these estimates will be highly dependent on the criteria used by the agency to identify its "exceptionally high risk buildings" and on the number and distribution of buildings selected for evaluation in the "representative sample." The following suggestions may be useful in developing an agency-specific cost estimate for non-evaluated buildings.

Random sampling - If the "representative sample" was chosen randomly, and if the sample was large enough, the results of the evaluations can be used to directly extrapolate back to the non-exempt population as a whole. In these situations, the percent of non-evaluated buildings that are expected to be deficient will be the same as the percent of the evaluated buildings that were found to be deficient. Note - do not combine the results of the evaluations of "exceptionally high risk buildings" with those in the representative (random) sample in calculating this percentage.

Prioritized sampling - If an agency chose to build its "representative sample" around high risk buildings, rather than using a random selection scheme, the estimate of the vulnerability of the non-evaluated buildings will have to be based on significant engineering judgement. For each of the sub-categories considered by the agency in their sample, an estimate must be made concerning how representative the sample was. Do the evaluated buildings include the vast majority of at-risk buildings in the category or do they represent only the very tip of an enormous iceberg of at-risk buildings? The assumptions made in estimating the total number of buildings that will require rehabilitation must be documented and reported in the supporting documentation.

Low seismicity - Buildings in regions of low seismicity need not be included in the representative sample. It is possible that the agency will not identify any "exceptionally high risk buildings" in the regions of low seismicity. Therefore, it is conceivable that an agency will have no information available about the potential seismic vulnerability of its buildings in regions of low seismicity. Nevertheless, the cost estimate should include the potential costs of any necessary seismic upgrades for buildings in these regions.

One possible way to consider the problem would be to compare some measure of deficiency in high seismicity regions to the same measure in moderate seismicity regions. An example of such a measure might be the ratio of deficient "exceptionally high risk" buildings to the total population in a region. It is expected that the ratio will be lower in regions of moderate seismicity than in regions of high seismicity. That trend could be extrapolated to regions of low seismicity to come up with an estimate of vulnerability of buildings in those areas.

Any procedures used for establishing the number of deficient buildings as well as the cost estimates for non-evaluated buildings in the various seismic areas should be described in the supporting documentation.

Agencies should also consider the following when developing their cost estimates for nonevaluated buildings: 
- Existing studies (such as Typical Costs, FEMA 156) have shown that rehabilitation costs for essential buildings exceed costs for non-essential buildings. Similarly, rehabilitation costs for historic buildings typically exceed costs for non-historic buildings. Estimated rehabilitation costs for these subcategories of non-evaluated buildings (essential and historic) should be calculated separately from estimates for other building types.

- Cost estimates for non-evaluated buildings should be based on the 15 model building types (specified in Section 2.3) that represent at least 85 percent of the non-exempt, nonevaluated building stock in regions of moderate and high seismicity.

The cost estimate which is reported will not be a building-by-building cost. Instead, a cost estimate in each of the four cost categories should be calculated and reported for each of the groups of non-evaluated buildings sharing dominant characteristics by seismicity group. The RP5 guidance states that the dominant characteristics should be mission essential buildings, historic buildings, and all others. The "all others" category should be further divided into those model building types that represent at least $85 \%$ of the non-exempt, non-evaluated building stock in regions of high and moderate seismicity.

All required information is to be reported in tabular form in the supporting documentation. This table should indicate how many buildings in each of these dominant characteristic groups are expected to be deficient, the expected total area in square meters these building represent, and the estimated rehabilitation costs in each of the four cost categories in both costs per square meter and the total cost for the expected population. Table 4-1 illustrates this reporting format. In addition, a detailed explanation should be provided in the supporting documentation on any estimating methodology which was used. 
Table 4-1 - Cost Reporting for Non-Evaluated Buildings

PART 1 - ESSENTIAL AND HISTORIC BUILDINGS

\begin{tabular}{|c|c|c|c|c|c|c|c|c|}
\hline \multirow[t]{3}{*}{ Seismicity Area } & \multicolumn{4}{|c|}{ Essential Buildings } & \multicolumn{4}{|c|}{ Historic Buildings } \\
\hline & \multirow[t]{2}{*}{ No. of Bldgs. } & \multirow{2}{*}{$\begin{array}{l}\text { Total } \\
\text { Square } \\
\text { Meters }\end{array}$} & \multicolumn{2}{|c|}{ Estimated Costs } & \multirow[t]{2}{*}{ No. of Bldgs. } & \multirow{2}{*}{$\begin{array}{l}\text { Total } \\
\text { Square } \\
\text { Meters }\end{array}$} & \multicolumn{2}{|c|}{ Estimated Costs ${ }^{*}$} \\
\hline & & & $\begin{array}{c}\text { Cost Per" } \\
\text { Square } \\
\text { Meter } \\
\end{array}$ & Total Cost & & & $\begin{array}{c}\text { Cost Per" } \\
\text { Square } \\
\text { Meter } \\
\end{array}$ & Total Cost \\
\hline Low & & & & & & & & \\
\hline Medium & & & & & & & & \\
\hline High & & & & & & & & \\
\hline
\end{tabular}

Note: All estimated costs should be reported as four separate costs: A. Structural Costs, B. Nonstructural Costs, C. Finishing Costs, and D. Project Costs. 
Table 4-1 - Cost Reporting for Non-Evaluated Buildings (Continued)

PART 2 - ALL OTHER BUILDINGS

\begin{tabular}{|c|c|c|c|c|c|c|c|c|c|c|c|c|}
\hline Bldg & \multicolumn{12}{|c|}{ Seismicity Area } \\
\hline & \multicolumn{4}{|c|}{ Low } & \multicolumn{4}{|c|}{ Moderate } & \multicolumn{4}{|c|}{ High } \\
\hline & \multirow{2}{*}{$\begin{array}{l}\text { No. of } \\
\text { Bldgs } \\
\end{array}$} & \multirow{2}{*}{$\begin{array}{c}\text { Total Sq. } \\
\text { Meters } \\
\end{array}$} & \multicolumn{2}{|c|}{ Estimated Costs } & \multirow{2}{*}{$\begin{array}{c}\text { No. of } \\
\text { Bldgs } \\
\end{array}$} & \multirow{2}{*}{$\begin{array}{c}\text { Total Sq. } \\
\text { Meters }\end{array}$} & \multicolumn{2}{|c|}{ Estimated Costs* } & \multirow{2}{*}{$\begin{array}{l}\text { No. of } \\
\text { Bldgs }\end{array}$} & \multirow{2}{*}{$\begin{array}{c}\text { Total Sq. } \\
\text { Meters }\end{array}$} & \multicolumn{2}{|c|}{ Estimated Costs ${ }^{*}$} \\
\hline & & & $\begin{array}{l}\text { Cost Per } \\
\text { Sq. Meter }\end{array}$ & $\begin{array}{l}\text { Total } \\
\text { Cost }\end{array}$ & & & $\begin{array}{l}\text { Cost Per } \\
\text { Sq. Meter }\end{array}$ & $\begin{array}{l}\text { Total } \\
\text { Cost }\end{array}$ & & & $\begin{array}{l}\text { Cost Per" } \\
\text { Sq. Meter }\end{array}$ & $\begin{array}{l}\text { Total } \\
\text { Cost }\end{array}$ \\
\hline MB01 & & & & & & & & & & & & \\
\hline MB02 & & & & & & & & & & & & \\
\hline MB03 & & & & & & & & & & & & \\
\hline MB04 & & & & & & & & & & & & \\
\hline MB05 & & & & & & & & & & & & \\
\hline MB06 & & & & & & & & & & & & \\
\hline MB07 & & & & & & & & & & & & \\
\hline MB08 & & & & & & & & & & & & \\
\hline MB09 & & & & & & & & & & & & \\
\hline MB10 & & & & & & & & & & & & \\
\hline MB11 & & & & & & & & & & & ' & \\
\hline MB12 & & & & & & & & & & & & \\
\hline MB13 & & & & & & & & & & & & \\
\hline MB14 & & & & & & & & & & & & \\
\hline MB15 & & & & & & & & & & & & \\
\hline MB16 & & & & & & & & & & & & \\
\hline
\end{tabular}

Notes: 1. All estimated costs should be reported as four separate costs: A. Structural Costs, B. Nonstructural Costs, C. Finishing Costs, and D. Project Costs.

2. Model Building Types and corresponding codes are given in Section 5 of this Handbook under Field 10. 


\subsection{REPORTING REQUIREMENTS}

\subsection{Contents and Format of the Submission}

The final submission to FEMA is to consist of two electronic databases, one for owned buildings and one for leased buildings, and one volume of supporting documentation. The leased building data need only be information which the agency already has available; no new data collection need be undertaken for this project. The available information will, in many cases, be the information which is reported to GSA as part of the Real Property Inventory Database effort. The leased building information can be reported in any format. However, the information on owned buildings must be reported in the electronic database and the supporting documentation as outlined in this section in order to assure consistency and readability. If an agency submits information which does not conform to this format, it will be returned for corrections. (The ICSSC Technical Secretariat is available to assist agencies with the use of this format. Please call with any questions). Section 5.1.1 outlines the format for the database of owned buildings. The detailed fields described in that section are for owned buildings only. Section 5.1.2 describes the requirements for the supporting documentation.

Early submissions of portions of the owned building database are not required, but would be helpful to FEMA and the ICSSC. This may also be a useful exercise for the agency if they would like assistance in choosing which buildings to evaluate. Suggested milestones which are appropriate for early submission include:

1. Completion of screening for exempt/non-exempt status.

2. Completion of identification of "exceptionally high risk" buildings.

3. Completion of identification of representative sample of non-exempt buildings.

4. Completion of evaluations.

If an agency chooses to make partial submissions, the agency is asked to resubmit the entire database when it is complete (no later than Dec. 1, 1998).

\subsubsection{Owned Building Database Information}

Agencies may develop their databases on any software they currently have available. Many agencies already have some sort of electronic inventory database system. Agencies which have this may use this as a starting point and add any additional needed information to the system, as needed to fulfill the requirements of the Executive Order. Agencies which do not yet have any inventory database may use any database, spreadsheet, or word processing program. The choice of this software may depend on the size of the agency's inventory.

The database software to be used by FEMA and the ICSSC to tabulate all agencies' data has not yet been determined. It is anticipated that whatever database software is used by each agency, it will be possible to convert this information into a form which is readable by the FEMA/ICSSC database. As soon as detailed information on what software package will be used by FEMA/ICSSC is available, this information will be distributed to ICSSC members. In the meantime, agencies are encouraged to utilize whatever software package is most 
convenient for their internal use. The ICSSC Technical Secretariat is available for further consultation on this issue. The Technical Secretariat will also be available to work with agencies to establish the easiest way to enter their information into the FEMA/ICSSC database when the time is appropriate.

In order to streamline the effort of entering all of the agencies' information into the FEMA/ICSSC database, all agencies must record each piece of required inventory data using the same format. The following sections and tables give the type of information and corresponding codes for each piece of inventory data. For a more detailed explanation of each category, refer to Section 2.3. Data for each owned building is to be reported in the order and format described below.

\section{Data Needed for All Buildings}

Field 1A. Agency Code: The name of the agency is to be identified using the four digit numerical codes used by the GSA Real Property Database. Table 5-1 lists the appropriate codes. If the code for your agency is not shown in this table, please contact the ICSSC Technical Secretariat for assistance.

Field 1B. Unique Identifier: A unique identifier is to be given for each building or group of buildings. This will be entered as an alpha-numeric string of any length. The identifier should contain as few blank spaces as possible.

Field 2A. Location - State: The state code (or territory code) is to be listed using the two digit code used by the GSA Real Property Database. Tables A-1 and A-2 in Appendix A list all state and territory codes.

Field 2B. Location - County: The county code is to be listed after the state code using the three digit code specified in the GSA Real Property database. Table A-1 in Appendix A lists all county codes by state. (If a building is located in a US territory with no county code, simply enter 00 for the county code.)

Field 3. Seismicity: The seismicity code is to be entered as the letter $L$ (for Low), $M$ (for Moderate), or $\mathbf{H}$ (for High). These designations correspond to the areas on Map 2 of the 1994 NEHRP Recommended Provisions and to acceleration levels as follows:

$\begin{array}{lll}\text { Low } & \text { Map Areas 1 \& } & \text { Av } \leq 0.10 \mathrm{~g} \\ \text { Moderate } & \text { Map Areas 3 \& 4 } & 0.10 \mathrm{~g} \leq \mathrm{Av}<0.20 \mathrm{~g} \\ \text { High } & \text { Map Areas 5,6 \& } 7 & 0.20 \mathrm{~g} \leq \mathrm{Av}\end{array}$

Table A-1 in Appendix A gives the seismicity designation by county for each state.

Field 4A. Area: The size of each building is to be reported in square meters. This is to be reported as a whole number. There should be NO COMMAS used to separate thousands, 


\begin{tabular}{|c|c|}
\hline Code to be Entered & Agency \\
\hline 1200 & Department of Agriculture \\
\hline 1300 & Department of Commerce \\
\hline 1400 & Department of the Interior \\
\hline 1407 & U.S. Geological Survey \\
\hline 1423 & Bureau of Reclamation \\
\hline 1500 & Department of Justice \\
\hline 1519 & Bureau of Prisons \\
\hline 1600 & Department of Labor \\
\hline 1700 & Department of the Navy \\
\hline 1800 & U.S. Postal Service \\
\hline 1900 & Department of State \\
\hline 2000 & Treasury Department \\
\hline 2100 & Department of the Army \\
\hline 3300 & Smithsonian Institution \\
\hline 3600 & Veterans Affairs \\
\hline 4700 & General Services Administration \\
\hline 4900 & National Science Foundation \\
\hline 5700 & Department of the Air Force \\
\hline 5800 & Federal Emergency Management Agency \\
\hline 6400 & Tennessee Valley Authority \\
\hline 6800 & Environmental Protection Agency \\
\hline 6900 & Department of Transportation \\
\hline 7500 & Department of Health and Human Services \\
\hline 8000 & National Aeronautics and Space Administration \\
\hline 8600 & Department of Housing and Urban Development \\
\hline 8900 & Department of Energy \\
\hline 9100 & Department of Education \\
\hline 9600 & Corps of Engineers \\
\hline 9700 & U.S. Information Agency \\
\hline
\end{tabular}

NOTE: If your agency code is not shown above, please contact the ICSSC Technical Secretariat for assistance. 
millions etc. For buildings being reported in a group, only the total additive size of all the buildings in the group should be reported.

Field 4B. Number of Buildings: This field represents the number of buildings in the entry. For the majority of cases, this will be 1 , and is to be entered as such. However, for buildings being reported in a group, the number of buildings in that group is to be recorded as that number.

Field 5. Reason for Exemption: If the building is exempt, the numerical code corresponding to the reason for exemption is to be entered according to Table 5-2. If a building is not exempt, the code (E0) is to be entered. If an agency identifies an agency specific reason for exemption (code E9), the agency is to give the justification for this exemption in the written supporting documentation.

\begin{tabular}{|c|l||}
\hline \multicolumn{2}{|c|}{ Table 5-2 - Reasons for Exemptions } \\
\hline Code to be Entered & \multicolumn{1}{|c|}{ Exemption } \\
\hline E0 & Building is not exempt. \\
\hline E1 & $\begin{array}{l}\text { Building is classified for agricultural use, or intended only for incidental human } \\
\text { occupancy, or occupied by persons for a total of less than 2 hours a day. (RP4 } \\
\text { exemption a) }\end{array}$ \\
\hline E2 & $\begin{array}{l}\text { Building is a detached one- or two- family dwelling located in an area having a } \\
\text { governing acceleration coefficients less than 0.15. (RP4 exemption b) }\end{array}$ \\
\hline E3 & $\begin{array}{l}\text { Building is a one-story building of steel light frame or wood construction with } \\
\text { an area of less than 280 m } \text { (3000 square feet). (RP4 exemption d) }\end{array}$ \\
\hline E4 & $\begin{array}{l}\text { The building has been fully rehabilitated to comply with the RP4 seismic safety } \\
\text { standards in all four compliance categories (structural, nonstructural, } \\
\text { geologic/site hazards, and adjacency) (RP4 exemption e) }\end{array}$ \\
\hline E5 & $\begin{array}{l}\text { The building is a post-benchmark building as defined in Table 1 of RP4 which } \\
\text { also complies with the nonstructural, geologic/site, and adjacency categories. } \\
\text { (RP4 exemption f) }\end{array}$ \\
\hline E9 & $\begin{array}{l}\text { The building is a pre-benchmark building which has been shown by evaluation } \\
\text { to be life-safe in all four compliance categories. (RP4 exemption g) }\end{array}$ \\
\hline E6 & $\begin{array}{l}\text { The building was constructed for the Federal government and the detailed } \\
\text { design was done after the date of the adoption of Executive Order 12699 } \\
\text { (January 5, 1990) and the building was designed and constructed in accordance } \\
\text { with the ICSSC Guidelines and Procedures for Implementation of the Executive } \\
\text { Order on Seismic Safety of New Building Construction. (RP4 exemption h) }\end{array}$ \\
\hline $\begin{array}{l}\text { The remaining useful life of the building has been identified as being less than } \\
\text { five years. }\end{array}$ \\
\hline \begin{tabular}{l} 
Other - describe briefly in Field 23 and in the supporting documentation. \\
\hline
\end{tabular}
\end{tabular}




\section{Data Needed for Non-Exempt Buildings}

Field 6. Occupancy Class: The occupancy class is to be entered as a numerical code corresponding to the occupancy classes used in the GSA Real Property Inventory. Table 5-3 lists the appropriate codes to be entered. These are the same codes used for GSA reporting purposes.

\begin{tabular}{|c|l|}
\hline \multicolumn{2}{|c|}{ Table 5-3 - Occupancy Categories } \\
\hline \hline Code to be Entered & \multicolumn{1}{|c|}{ Occupancy Classification } \\
\hline 10 & Office \\
\hline 14 & Post Office \\
\hline 21 & Hospital \\
\hline 22 & Prison \\
\hline 23 & School \\
\hline 29 & Other Institutional \\
\hline 30 & Housing \\
\hline 40 & Storage \\
\hline 50 & Industrial \\
\hline 60 & Service \\
\hline 70 & Research and Development \\
\hline 80 & All Other \\
\hline
\end{tabular}

Field 7. Essential Designation : Essential buildings are to be identified with the alphanumeric code of $\mathbf{Z 1}$. Any non-exempt building which is not designated as essential is to be designated as other and the numerical code $\mathbf{Z 2}$ is to be entered.

Field 8. Historic Designation : Each building which is known to be designated as an historic building is to be identified with the alpha-numeric code H1. Any building which has not been designated as an historic building is to be identified with the alpha-numeric code $\mathbf{H 2}$.

Field 9. Date of Construction : The date of actual construction is to be reported for each building as the four digit numerical year i.e., 1984. If the year of design is significantly earlier than the year of construction, then the year of design is to be entered instead.

Field 10. Model Building Type : The model building type is to be entered as an alphanumerical code corresponding to the 15 types identified in FEMA 178 (See Section 2.3.3 for a detailed explanation of these building types). Table 5-4 lists the appropriate codes to be entered. 


\begin{tabular}{||l|l||}
\hline \multicolumn{2}{|c|}{ Table 5-4 - Model Building Types } \\
\hline Code to be Entered & \multicolumn{1}{|c|}{ Model Building Type } \\
\hline MB01 & Wood, Light Frame \\
\hline MB02 & Wood, Commercial and Industrial \\
\hline MB03 & Steel Moment Frame \\
\hline MB04 & Steel Braced Frame \\
\hline MB05 & Steel Light Frame \\
\hline MB06 & Steel Frame with Concrete Shear Walls \\
\hline MB07 & Steel Frame with Infill Shear Walls \\
\hline MB08 & Concrete Moment Frame \\
\hline MB09 & Concrete Shear Walls \\
\hline MB10 & Concrete Frame with Infill Shear Walls \\
\hline MB11 & Precast/Tilt-Up Concrete Walls with Lightweight Flexible Diaphragm \\
\hline MB12 & Precast Concrete Frames with Concrete Shear Walls \\
\hline MB13 & Reinforced Masonry Bearing Walls with Wood or Metal Deck Diaphragms \\
\hline MB14 & Reinforced Masonry Bearing Walls with Precast Concrete Diaphragms \\
\hline MB15 & Unreinforced Masonry Bearing Wall Buildings \\
\hline MB16 & Other - describe briefly in Field 23 and in the supporting documentation. \\
\hline
\end{tabular}

Field 11. Number of Stories : The number of above ground stories in the building is to be recorded as the letter $N$ followed directly (without a space) by the two-digit numerical code representing that number. For example, if a building has two stories, the appropriate entry would be N02.

\section{Data Needed for Non-Exempt Evaluated Buildings}

Field 12. Exceptionally High Risk Designation : Exceptionally high risk buildings are to be identified with the alpha-numeric code R1. All non-exempt evaluated buildings not designated as exceptionally high risk are to be identified as Other with the code $\mathbf{R 2}$.

Field 13. Evaluation Procedure Used : The minimum acceptable level of evaluation is the procedures given in RP4. If a building is evaluated using RP4 the alpha-numeric code P1 is to be entered for this field. If the engineer who evaluated the building used a procedure other than what is outlined in RP4, the alpha-numeric code P2 is to be entered for this field. All P2 codes must be explained and justified in the written supporting documentation. If a building is designated as a DNR and therefore is determined to be deficient without an actual evaluation, the alpha-numeric code P3 is to be entered for this field. A short statement of why the building is a DNR should be given in the Comments Field (Field 20). 
Field 14. Soil Type : The soil type is to be entered as the code which identifies one of the four soil types in FEMA 178: S1, S2, S3, or S4.

Field 15. Foundation Type : The foundation type is to be entered as one of the following three codes:

FT1 = shallow foundations (isolated or continuous spread footings or mats)

FT2 = deep foundations (piles or piers)

FT3 $=$ other

An explanation of the FT3 code should be given in the comment field as well as in the supporting documentation.

Field 16. Outcome of Evaluation : If the evaluation of a building indicates that the building provides an acceptable level of seismic safety and no rehabilitation is needed, the alphanumeric code $\mathbf{O K}$ is to be entered for this category. If the evaluation indicates that the building is deficient, the alpha-numeric code NG is to be entered for this category. A building which has been designated as a DNR should be given a NG code for this field.

\section{Non-Exempt Evaluated Buildings Found to be Deficient}

Field 17. Why Deficient : The reason a building was found to be deficient is to be entered as four separate codes which correspond to the four compliance categories in RP4.

Field 17A. Structural : There are three possible codes for this field. PS if the building passes in this category, FS if the building failed in this category and NCS if the building was not checked in this category.

Field 17B. Nonstructural : There are three possible codes for this field. PN if the building passes in this category, FN if the building failed in this category and NCN if the building was not checked in this category.

Field 17C. Geologic/Site Hazard : There are three possible codes for this field. PG if the building passes in this category, FG if the building failed in this category and NCG if the building was not checked in this category. (Note that failure in this category refers to site issues such as landslides and liquefaction. If a building fails because the soil conditions amplify the motion past the point where the structure is adequate, this is a structural failure, not a geologic one.)

Field 17D. Adjacency Problems : There are three possible codes for this field. PA if the building passes in this category, FA if the building failed in this category and NCA if the building was not checked in this category.

\section{Field 18. Estimated Costs of Rehabilitation :}

The estimated cost of rehabilitation is to be reported as four separate costs. Each is to be a dollar amount, expressed in whole numbers and using NO COMMAS between any numbers. 
Each entry is to be preceded by a dollar sign. For example, $\$ 10000$ is the correct entry for a cost of ten thousand dollars. Costs of other upgrades triggered by the rehabilitation effort are NOT to be included. If a replacement cost, or disposal cost, is to be entered rather than a rehabilitation cost, it is to be entered as the structural cost entry. When a replacement cost or disposal cost is entered, this should be indicated in the "Comments" Field (Field 20).

Field 18A. Structural Costs : This cost is to be reported in the format described above. Field 18A is to be the Structural Costs for buildings to be rehabilitated as well as any costs associated with adjacency issues or geologic/site issues. Costs associated with the replacement or disposal cost are to be reported here for buildings which would not be rehabilitated.

Field 18B. Nonstructural Costs: This cost is to be reported in the same format as described above. Field $18 \mathrm{~B}$ is to be the Nonstructural Costs only.

Field 18C. Finishing Costs : This cost is to be reported in the same format as described above. Field $18 \mathrm{C}$ is to be the Finishing Costs only.

Field 18D. Project Costs : This cost is to be reported in the same format as described above. Field $18 \mathrm{D}$ is to be the associated Project Costs only.

Field 19. Source of Cost Estimate : The method used to develop the cost estimate for a building is to be identified using a numerical code corresponding to the appropriate source. Table 5-5 shows the codes to be used.

Field 20. Comments : This field is for any brief comments necessary to explain designations made in the other fields. These comments are to be described in further detail in the written supporting documentation. This field is to be entered as an alpha-numeric string of any length and should not contain any commas or hard returns. The comment could simply repeat a code and give a short description i.e., MB16 mobile home.

\begin{tabular}{|c|l||}
\hline \multicolumn{2}{|c|}{ Table 5-5 - Sources for Cost Estimates } \\
\hline \hline Code to be Entered & \multicolumn{1}{|c|}{ Sources of Cost Estimates } \\
\hline C1 & $\begin{array}{l}\text { Engineer developed a preliminary rehabilitation scheme appropriate for the } \\
\text { specific structure and calculated the cost of the proposed fix. }\end{array}$ \\
\hline C2 & $\begin{array}{l}\text { An agency-specific cost estimating procedure was used to develop the cost } \\
\text { estimate. }\end{array}$ \\
\hline C3 & $\begin{array}{l}\text { The estimate was developed using cost estimate Option II in Typical Costs, } \\
\text { FEMA 156 document. Volume II of Typical Costs, FEMA 157 was used to } \\
\text { estimate nonstructural, etc. costs. }\end{array}$ \\
\hline C4 & $\begin{array}{l}\text { Instead of being rehabilitated, the building would be replaced. Therefore, } \\
\text { the cost reported is a replacement cost and not a rehabilitation cost. }\end{array}$ \\
\hline C5 & $\begin{array}{l}\text { Instead of being rehabilitated, the building would be abandoned and not } \\
\text { replaced. Therefore, the cost reported is the demolition cost. }\end{array}$ \\
\hline
\end{tabular}


Table 5-6 shows an example of data compiled for a small sample inventory. As stated at the beginning of this section, this kind of inventory can be developed using any database software. The first example entry shows a storage facility which was found to be exempt because it is intended for only incidental human occupancy. Because it is an exempt building, no information after the "Reason for Exemption Code" is required to be submitted in the inventory. The next example building entry shows an office building which is not exempt. Data was reported on this building up to the point where it was determined that this building would not be evaluated. No data was entered after this point.

The third example building entry shows a Laboratory which was chosen for evaluation but upon evaluation was shown to be seismically acceptable. Therefore there are no rehabilitation costs entered for this building. The next Laboratory building entry shows a building which was found to be seismically deficient. Therefore a code of NG was entered under Outcome of Evaluation. In the evaluation, the building was found to be both structurally and nonstructurally deficient but it passed in the geologic and adjacency areas. The appropriate deficiency codes were therefore entered. Costs were then developed to rehabilitate the building. The four costs entered represent the structural cost, the nonstructural cost, the finishing cost and the project cost.

The final example building entry shows a Picnic Area which was found to exempt because it a wood frame building less than $280 \mathrm{~m}^{2}$ (3000 sq. $\mathrm{ft}$.). Even though this building is exempt, additional information was reported beyond what is required. This is because the agency happened to have additional information in a few categories and passed this information on in the inventory. Agencies are encouraged to report any information they have available since all information is useful to FEMA and the ICSSC.

This example illustrates that each building entry is a separate line containing each field for that building. Hard returns should only be used at the end of the last field for a particular building. 
Table 5-6 - Example Inventory Using Codes

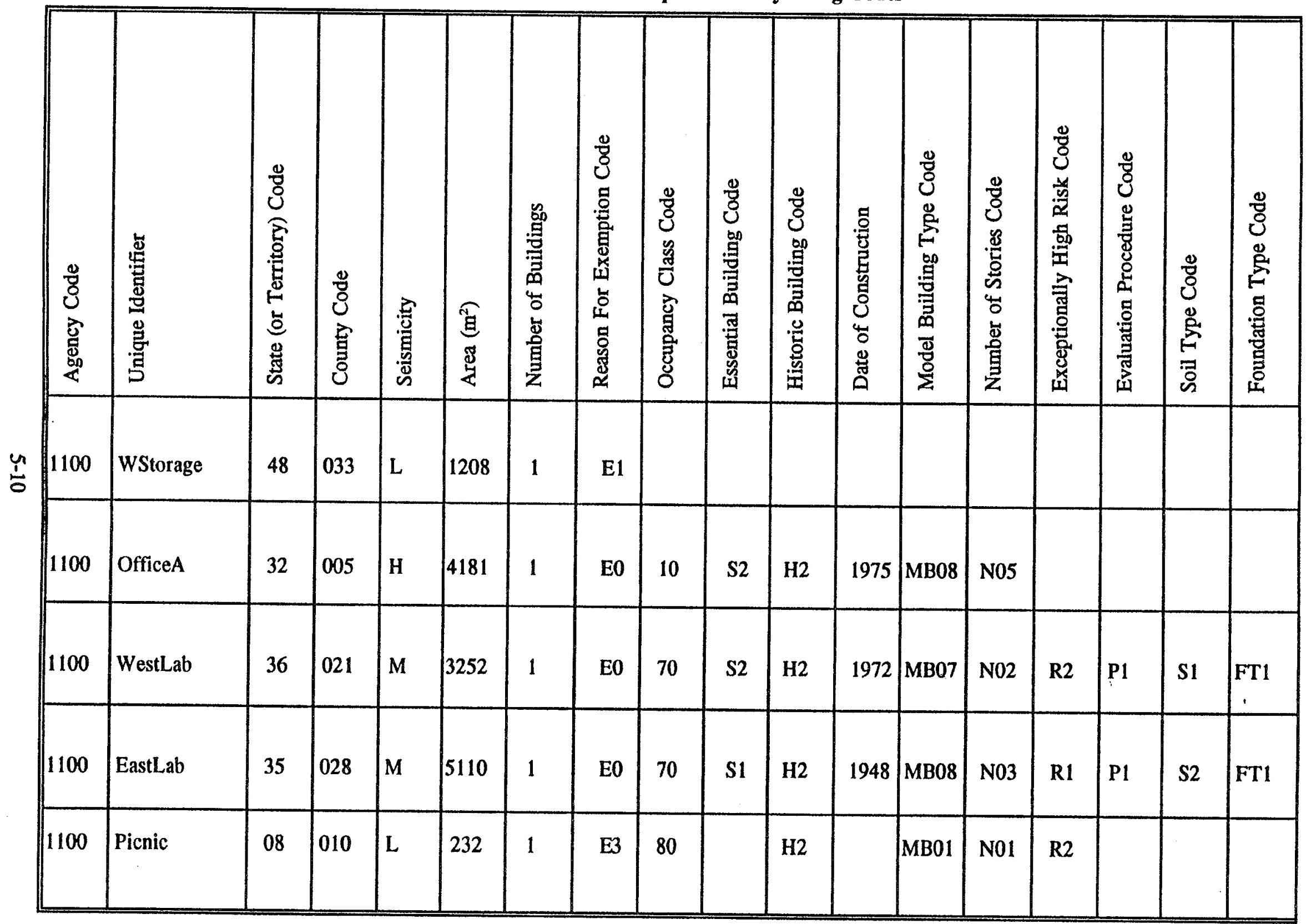


Table 5-6 - Example Inventory Using Codes (Continued)

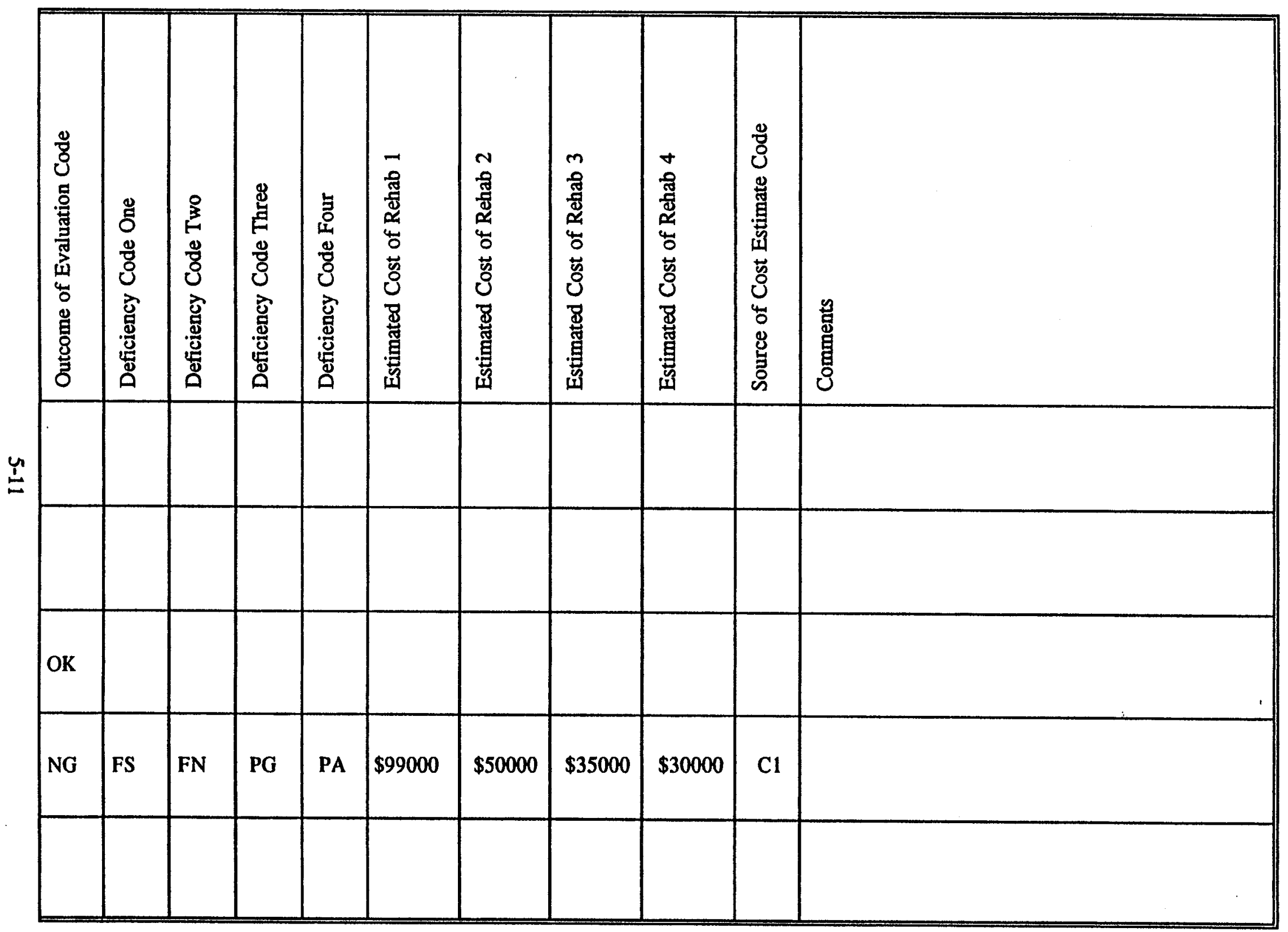




\subsubsection{Supporting Documentation}

The written documentation to be submitted with the database information is intended to explain any agency-specific methodologies used and to justify any deviation from the category entries specified in Section 5.1.1.

The written documentation should be brief but will contain sufficient detail to clearly explain any agency-specific procedures. All agencies will submit some written documentation, although some will need to submit more information than others. The sections of the written documentation shall correspond with the sections given below. If an agency has no information which needs to be reported in a particular section, this will be stated under that section heading.

\section{Section 1 - Agency Screening Process}

Any assumptions made in the identification of exempt buildings which is specific to the agency and not outlined in this Handbook will be discussed in this Section of the written documentation. This Section will also describe any criteria used for exempting a building which is not listed in Table 5-2. This would pertain to any building which received an "E9" code for the Reason for Exemption. If more than one criteria was used for the "E9" code, each of these will be explained.

This Section will also describe and justify any benchmark years used which differ from those given in RP4, reproduced as Table 2-3, or in the simplified RP4 Table shown as Table 2-2.

Section 2 -Inventory Data

This section will describe any agency specific method of assigning buildings to seismicity categories (see Field 3).

This section will describe any building types which did not fit into the 15 model building types described in Field 10 (any building which received a MB16 code for Field 10.)

This section will explain any foundation type which was given a foundation code of "other" (any building which received a FT3 code for Field 15).

Section 3 - Selection of Buildings to be Evaluated

This Section will describe the criteria or methodology used to identify "exceptionally high risk" buildings. All agencies must report this information.

This Section will also describe procedures used to designate buildings for evaluation from the representative sample of non-exempt buildings. All agencies must report this information.

Section 4 - Evaluation Process

This Section will describe any evaluation procedure used which is different from those 
evaluation procedures outlined in RP4. This applies to any building which received a "P2" code in the Evaluation Process Used category (Field 13). Any methodology used to evaluate buildings at a level higher than life-safety will also be described here-since RP4 only outlines evaluation for life-safety.

This Section will describe any agency-specific definitions of buildings definitely needing rehabilitation (DNR), and the justifications for those definitions. The DNR categories given by this Handbook are in Section 3.2.2.

\section{Section 5 - Cost-Estimating Process}

This Section will report the costs of performing the seismic evaluations needed to fulfill the cost-estimating requirements. These costs can be reported in any form which is convenient for the agency. The costs can be separate for each evaluation, costs for a group of evaluations, or an average cost for all of the evaluations.

This Section will describe any agency-specific cost-estimating methods used to develop building-by-building rehabilitation cost estimates. This corresponds to any building which was assigned a "C2" for the Source of Cost-Estimate category in Table 5-5.

\section{Section 6 - Costs of Rehabilitating Non-Evaluated Buildings}

This Section will report the estimated cost, calculated by the agency, of achieving seismic safety in the non-evaluated buildings. This information will be given in a tabular format which divides the non-evaluated buildings expected to need seismic rehabilitation into the categories of essential buildings, historic buildings, and other buildings. The "other buildings" category will be further divided into the model building types which make up $85 \%$ of the non-evaluated building stock. Each category in the table should contain the estimated number of deficient buildings in that category, the estimated total area (in square meters) which these buildings represent, and an estimated cost reported in the four cost categories in both cost per square meter and total cost for the subgroup. See Section 4.2, Table 4-1, of this document for a sample table.

This Section will describe the methods which the agency used to estimate the costs of rehabilitating the buildings which were not evaluated.

\section{Section 7 - Costs of Rehabilitating Leased Buildings}

This Section will estimate the cost impact of reducing seismic risk in leased buildings. If a program other than that recommended in RP4 (allowing existing leases to expire without action, and not entering into new leases in inadequate space) will be used, the agency will describe the program. See Section 1.3 of this document for more detail.

Section 8 - Additional Information

This Section will report any additional information which the agency feels that FEMA and the ICSSC should know about its inventory, or any of the procedures used to develop the 
information submitted. Discussion in this Section should be kept brief.

This Section will also report an estimated average annual attrition rate (rate at which existing owned buildings are removed from the inventory). The source or methodology used to develop the attrition rate will be included here.

\subsection{Corrections to Submitted Databases}

The ICSSC recommended program outlined in RP5 and in this Handbook leaves much flexibility for agencies to choose which and how many buildings will be evaluated. It also allows agencies to choose how they wish to develop cost estimates for these buildings if they are found to be seismically deficient. Because of this, FEMA and the ICSSC will not examine and find error with the procedures used by the agencies in these areas once the information is submitted.

However, the format outlined in Section 5 of this Handbook for the submission of electronic inventory data must be followed to best allow FEMA and the ICSSC to combine all of the data into one large Federal inventory database. Therefore, if your agency electronic database submissions do not follow the format outlined here, or if the data presented are unintelligible, the information will be returned to your agency for corrections to the format. When the electronic database is submitted, each agency should include the name, address, and phone number (an e-mail address would also be helpful) of the person who should be contacted by FEMA or the ICSSC if such corrections are necessary. This person should be someone who would be best able to correct the computer database format as well as verify the information which was submitted. 


\subsection{REFERENCES}

Applied Technology Council (1988). Rapid Visual Screening of Buildings for Potential Seismic Hazards: A Handbook, FEMA 154, Federal Emergency Management Agency, Washington, DC, 1988.

Applied Technology Council (1985). Earthquake Damage Evaluation Data for California, ATC-13, Redwood City, CA, 1985.

Building Seismic Safety Council (1995). NEHRP Recommended Provisions for the Development of Seismic Regulations for New Buildings, Provisions and Commentary, 1994 edition, FEMA 222A \& 223A, Federal Emergency Management Agency, Washington, DC, 1995.

Building Seismic Safety Council (1992). NEHRP Recommended Provisions for the Development of Seismic Regulations for New Buildings, Provisions and Commentary, 1991 edition, FEMA 222 \& 223, Federal Emergency Management Agency, Washington, DC, 1992.

Building Seismic Safety Council (1992). NEHRP Handbook for the Seismic Evaluation of Existing Buildings, FEMA 178, Federal Emergency Management Agency, Washington, DC, 1992.

Federal Emergency Management Agency (1995). Second Edition Typical Costs for Seismic Rehabilitation of Existing Buildings, Volume II - Supporting Documentation, FEMA 157, Washington, DC, October 1995.

Federal Emergency Management Agency (1994). Second Edition Typical Costs for Seismic Rehabilitation of Existing Buildings, Volume I - Summary, FEMA 156, Washington, DC, December, 1994.

Interagency Committee on Seismic Safety in Construction. Guidelines for Identification and Mitigation of Seismically Hazardous Existing Federal Buildings, NISTIR 89-4062, ICSSC RP3, National Institute of Standards and Technology, Gaithersburg, MD, March 1989.

Todd, Diana, and Ann Bieniawski, editors (1995). ICSSC Guidance on Implementing Executive Order 12941 on Seismic Safety of Existing Federally Owned or Leased Buildings, NISTIR 5734, ICSSC RP5, National Institute of Standards and Technology, Gaithersburg, MD, October 1995.

Todd, Diana, editor (1994). Standards of Seismic Safety for Existing Federally Owned or Leased Buildings, NISTIR 5382, ICSSC RP4, National Institute of Standards and Technology, Gaithersburg, MD, February, 1994.

Rutherford and Chekene. Seismic Retrofitting Alternatives for San Francisco's Unreinforced Masonry Buildings: Estimates of Construction Cost \& Seismic Damage, Rutherford \& Chekene, San Francisco, CA, 1990. 


\subsection{INDEX}

Agency Code . . . 2-13, 2-14, 5-2, 5-3

Attrition Rate . . . 5-14

Benchmark Year . . 2-4, 2-7, 2-8, 2-9, 2-10, 2-12

Cost Estimate . . . 1-1, 2-3, 2-6, 2-9, 2-10, 2-20, 2-22, 2-23, 3-1, 3-18, 3-19, 3-20, 4-3, 4-4, 5-8

Database . . . . . 1-2, 1-3, 2-1, 2-2, 2-3, 2-4, 2-5, 2-6, 2-9, 2-11, 2-13, 2-14, 2-15, $2-16,2-19,2-20,2-21,2-22,2-23,3-2,3-17,3-18,3-19,4-1,5-1,5-2$, $5-9,5-12,5-14$

Date of Construction 2-2, 2-14, 2-16, 2-23, 5-5

Deficient $\ldots . . .1-2,2-3,2-20,2-21,2-23,3-1,3-12,3-17,3-19,3-20,4-1,4-3,4-4$, $5-6,5-7,5-9,5-13,5-14$

Disposal Cost . . . 2-22, 4-2, 5-8

DNR Buildings . . 3 3-20

Dominant

Characteristics .. 3-12, 3-14, 3-15, 3-16, 3-17, 4-4

Early Submissions . 5-1

Electronic Database 2-1, 2-2, 2-13, 2-19, 2-23, 5-1, 5-14

Essential Buildings 2-3, 2-15, 2-16, 2-20, 3-17, 4-4, 4-5, 5-5, 5-13

Estimated Costs of

Rehabilitation .. 2 2-22, 5-7

Evaluation

Procedure . . . . 2-20, 2-21, 2-23, 3-18, 3-19, 5-6, 5-12

Exceptionally

High Risk . . . . 1-3, 2-2, 2-20, 2-23, 3-1, 3-2, 3-4, 3-5, 3-8, 3-10, 3-12, 3-15, 3-17, 3-18, 3-20, 4-3, 5-1, 5-6, 5-12

Exempt Buildings . 1-3, 2-1, 2-2, 2-3, 2-4, 2-5, 2-6, 2-7, 2-8, 2-10, 2-14, 2-16, 2-20, 3-1, $3-6,3-12,3-14,3-15,3-16,3-17,3-18,5-1,5-5,5-12$

Exemptions . . . 2-3, 2-4, 2-5, 2-8, 3-4, 5-4

Expensive

Equipmen . . . 3-3

FEMA $178 \ldots . .2-12,2-16,2-21,3-5,3-9,3-19,5-5,5-7,6-1$

Finishing Costs ... 4-1, 4-5, 4-6, 5-8

Foundation Type . . 2-2, 2-20, 2-21, 2-23, 5-7, 5-12

GSA Database ... 2-1, 2-5, 2-6, 2-11, 2-13, 2-16

Hazardous Materials 2-15, 3-3

Historic Buildings . 2-16, 4-4, 4-5, 5-13

Inventory Data . . 2 2-13, 2-23, 5-2, 5-12, 5-14

Key Agency

Personnel ... . 3-3

Leased Buildings . . 1-1, 1-2, 2-1, 2-11, 5-1, 5-13, 6-1

Location . . . . . 2-4, 2-8, 2-13, 2-14, 2-19, 2-23, 3-1, 3-5, 3-8, 5-2

Mandatory $\ldots \ldots 1-1,1-3$

Maps ...... 2-14, 3-19

Model Building

Type $\ldots \ldots .2-2,2-7,2-9,2-15,2-16,2-19,2-23,3-2,3-3,3-13,3-16,5-5,5-6$ 


\section{Non-Evaluated}

Buildings $\ldots \ldots 1-1,2-2,3-12,4-2,4-3,4-4,4-5,4-6,5-13$

Non-Exempt

Buildings $\ldots . .1-3,2-5,2-6,2-14,2-16,2-20,3-1,3-6,3-12,3-14,3-15,3-16,3-17$, $3-18,5-1,5-5,5-12$

Nonstructural Costs $4-1,4-5,4-6,5-8$

Number of

Occupants . . . . 3-2, 3-9

Number of Stories . 2-2, 2-15, 2-20, 2-23, 5-6

Occupancy Class . . 2-2, 2-5, 2-14, 2-23, 3-2, 5-5

Outcome of

Evaluation . . . . 2-21, 2-23, 3-19, 5-7, 5-9

Owned Buildings . 1-1, 1-2, 1-3, 1-4, 2-1, 2-11, 2-23, 5-1, 5-14

Previously Evaluated

Buildings . . . 2-10, 3-18

Prioritization ... 3-5, 3-8, 3-10

Project Costs ... 2-22, 4-1, 4-2, 4-5, 4-6, 5-8

Random Sample . . 3-13, 3-17

Reason for

Exemption $\ldots .2-2,2-3,2-14,2-23,5-4,5-9,5-12$

Representative

Sample . . . . . 1-1, 1-3, 2-20, 3-1, 3-4, 3-12, 3-13, 3-14, 3-15, 3-17, 3-18, 4-3, 5-1, 5-12

RP4 ....... 1-1, 1-2, 2-3, 2-4, 2-5, 2-6, 2-7, 2-8, 2-9, 2-10, 2-12, 2-15, 2-20, $2-21,3-1,3-18,3-19,4-2,5-4,5-6,5-7,5-12,5-13,6-1$

Screening $\ldots . . .1-3,2-1,2-3,2-4,2-13,2-14,2-16,5-1,5-12,6-1$

Seismic Risk . . . 1-2, 2-20, 3-1, 3-2, 3-3, 3-4, 3-6, 3-8, 3-12, 3-15, 3-16, 3-19, 5-13

Seismicity . . . . 2-2, 2-5, 2-8, 2-9, 2-11, 2-13, 2-14, 2-18, 2-19, 2-23, 3-2, 3-3, 3-4, $3-12,3-13,3-15,3-16,3-17,3-20,4-3,4-4,4-5,4-6,5-2,5-12$

Small Inventories . 3-17, 3-18

Software . . . 2 2-14, 5-1, 5-9

Soil Type .... 2-2, 2-20, 2-21, 2-23, 5-7

Source of Cost

Estimate . . . 2-22, 2-23, 5-8

Structural Costs . . 4-1, 4-5, 4-6, 5-8

Supporting

Documentation . . 1-1, 1-2, 2-3, 2-8, 2-14, 2-20, 3-13, 3-19, 3-20, 4-3, 4-4, 5-1, 5-4, 5-6, $5-7,5-8,5-12,6-1$

Typical Costs . . . 2-22, 4-1, 4-2, 4-4, 5-8, 6-1

Unique Identifier . . 2-13, 2-14, 2-23, 5-2 


\section{APPENDIX A \\ STATE, COUNTY, AND TERRITORY CODES SEISMICITY CODES}




\begin{tabular}{||l|l|l|c|c|c|}
\hline \multicolumn{5}{|c|}{ Table A-1 - Location and Seismicity Data } & Page A-1 \\
\hline \hline State Code & State & County Code & County Name & Seismicity & $A_{\mathrm{v}}<0.15$ \\
\hline
\end{tabular}

\begin{tabular}{|c|c|c|c|c|}
\hline \multirow[t]{2}{*}{01} & \multicolumn{2}{|c|}{ ALABAMA } & \multirow{2}{*}{$\frac{\text { ALL LOW }}{\text { Low }}$} & \multirow{2}{*}{$\frac{\text { ALL YES }}{\text { Yes }}$} \\
\hline & 001 & Autauga & & \\
\hline & 003 & Baldwin & Low & Yes \\
\hline & 005 & Barbour & Low & Yes \\
\hline & 007 & Bibb & Low & Yes \\
\hline & 009 & Blount & Low & Yes \\
\hline & 011 & Bullock & Low & Yes \\
\hline & 013 & Butler & Low & Yes \\
\hline & 015 & Calhoun & Low & Yes \\
\hline & 017 & Chambers & Low & Yes \\
\hline & 019 & Cherokee & Low & Yes \\
\hline & 021 & Chilton & Low & Yes \\
\hline & 023 & Choctaw & Low & Yes \\
\hline & 025 & Clarke & Low & Yes \\
\hline & 027 & Clay & Low & Yes \\
\hline & 029 & Cleburne & Low & Yes \\
\hline & 031 & Coffee & Low & Yes \\
\hline & 033 & Colbert & Low & Yes \\
\hline & 035 & Conecuh & Low & Yes \\
\hline & 037 & Coosa & Low & Yes \\
\hline & 039 & Covington & Low & Yes \\
\hline & 041 & Crenshaw & Low & Yes \\
\hline & 043 & Cullman & Low & Yes \\
\hline & 045 & Dale & Low & Yes \\
\hline & 047 & Dallas & Low & Yes \\
\hline & 049 & De Kalb & Low & Yes \\
\hline & 051 & Elmore & Low & Yes \\
\hline & 053 & Escambia & Low & Yes \\
\hline & 055 & Etowah & Low & Yes \\
\hline
\end{tabular}




\begin{tabular}{|c|c|c|c|c|c|}
\hline \multicolumn{5}{|c|}{ Table A-1 - Location and Seismicity Data } & Page A-2 \\
\hline State Code & State & County Code & County Name & Seismicity & $A_{v}<0.15$ \\
\hline
\end{tabular}

\begin{tabular}{|c|c|c|c|c|c|}
\hline 01 & Alabama & 057 & Fayette & Low & Yes \\
\hline & & 059 & Franklin & Low & Yes \\
\hline & & 061 & Geneva & Low & Yes \\
\hline & & 063 & Greene & Low & Yes \\
\hline & & 065 & Hale & Low & Yes \\
\hline & & 067 & Henry & Low & Yes \\
\hline & & 069 & Houston & Low & Yes \\
\hline & & 071 & Jackson & Low & Yes \\
\hline & & 073 & Jefferson & Low & Yes \\
\hline & & 075 & Lamar & Low & Yes \\
\hline & & 077 & Lauderdale & Low & Yes \\
\hline & & 079 & Lawrence & Low & Yes \\
\hline & & 081 & Lee & Low & Yes \\
\hline & & 083 & Limestone & Low & Yes \\
\hline & & 085 & Lowndes & Low & Yes \\
\hline & & 087 & Macon & Low & Yes \\
\hline & & 089 & Madison & Low & Yes \\
\hline & & 091 & Marengo & Low & Yes \\
\hline & & 093 & Marion & Low & Yes \\
\hline & & 095 & Marshall & Low & Yes \\
\hline & & 097 & Mobile & Low & Yes \\
\hline & & 099 & Monroe & Low & Yes \\
\hline & & 101 & Montgomery & Low & Yes \\
\hline & & 103 & Morgan & Low & Yes \\
\hline & & 105 & Perry & Low & Yes \\
\hline & & 107 & Pickens & Low & Yes \\
\hline & & 109 & Pike & Low & Yes \\
\hline & & 111 & Randolph & Low & Yes \\
\hline & & 113 & Russell & Low & Yes \\
\hline & & 115 & St Clair & Low & Yes \\
\hline
\end{tabular}




\begin{tabular}{|l|c|c|c|c|c|}
\hline \multicolumn{5}{|c|}{ Table A-1 - Location and Seismicity Data } & Page A-3 \\
\hline \hline State Code & State & County Code & County Name & Seismicity & Av $_{\mathrm{v}}<\mathbf{0 . 1 5}$ \\
\hline
\end{tabular}

\begin{tabular}{|c|c|c|c|c|c|}
\hline 01 & Alabama & 117 & Shelby & Low & Yes \\
\hline & & 119 & Sumter & Low & Yes \\
\hline & & 121 & Talladega & Low & Yes \\
\hline & & 123 & Tallapoosa & Low & Yes \\
\hline & & 125 & Tuscaloosa & Low & Yes \\
\hline & & 127 & Walker & Low & Yes \\
\hline & & 129 & Washington & Low & Yes \\
\hline & & 131 & Wilcox & Low & Yes \\
\hline & & 133 & Winston & Low & Yes \\
\hline 02 & \multicolumn{3}{|c|}{ ALASKA } & MIXED & MIXED \\
\hline & & 013 & Aleutians East & High & No \\
\hline & & 016 & Aleutians West & High & No \\
\hline & & 020 & Anchorage & High & No \\
\hline & & 050 & Bethel & High & No \\
\hline & & 060 & Bristol Bay & High & No \\
\hline & & 070 & Dillingham & High & No \\
\hline & & 090 & Fairbanks North Star & High & No \\
\hline & & 100 & Haines & High & No \\
\hline & & 110 & Juneau & High & No \\
\hline & & 122 & Kenai Peninsula & High & No \\
\hline & & 130 & Ketchikan Gateway & High & No \\
\hline & & 150 & Kodiak Island & High & No \\
\hline & & 164 & Lake and Peninsula & High & No \\
\hline & & 170 & Matanuska-Susitna & High & No \\
\hline & & 180 & Nome & Low & Yes \\
\hline & & 185 & North Slope & Low & Yes \\
\hline & & 188 & Northwest Arctic & Low & Yes \\
\hline & & 201 & $\begin{array}{l}\text { Prince of Wales-Outer } \\
\text { Ketchikan }\end{array}$ & High & No \\
\hline
\end{tabular}




\begin{tabular}{|l|c|c|c|c|c|}
\hline \multicolumn{5}{|c|}{ Table A-1 - Location and Seismicity Data } & Page A-4 \\
\hline \hline State Code & State & County Code & County Name & Seismicity & Av $_{\mathrm{v}}<0.15$ \\
\hline
\end{tabular}

\begin{tabular}{|c|c|c|c|c|c|}
\hline 02 & Alaska & 220 & Sitka & High & No \\
\hline & & 232 & $\begin{array}{l}\text { Skagway-Yakutat- } \\
\text { Angoon }\end{array}$ & High & No \\
\hline & & 240 & Southeast Fairbanks & High & No \\
\hline & & 261 & Valdez-Cordova & High & No \\
\hline & & 270 & Wade Hampton & Low & Yes \\
\hline & & 280 & Wrangell-Petersburg & High & No \\
\hline & & 290 & Yukon-Koyukuk & High & No \\
\hline 04 & \multicolumn{3}{|c|}{ ARIZONA } & MIXED & MIXED \\
\hline & & 001 & Apache & Low & Yes \\
\hline & & 003 & Cochise & Moderate & Yes \\
\hline & & 005 & Coconino & Low & Yes \\
\hline & & 007 & Gila & Low & Yes \\
\hline & & 009 & Graham & Moderate & Yes \\
\hline & & 011 & Greenlee & Moderate & Yes \\
\hline & & 012 & $\mathrm{LaPaz}$ & High & No \\
\hline & & 013 & Maricopa & Moderate & No \\
\hline & & 015 & Mohave & Moderate & Yes \\
\hline & & 017 & Navajo & Low & Yes \\
\hline & & 019 & Pima & Moderate & No \\
\hline & & 021 & Pinal & Low & Yes \\
\hline & & 023 & Santa Cruz & Low & Yes \\
\hline & & 025 & Yavapai & Moderate & Yes \\
\hline & & 027 & Yuma & High & No \\
\hline 05 & \multicolumn{3}{|c|}{ ARKANSAS } & MIXED & MIXED \\
\hline & & 001 & Arkansas & Moderate & Yes \\
\hline & & 003 & Ashley & Low & Yes \\
\hline & & 005 & Baxter & Moderate & Yes \\
\hline
\end{tabular}




\begin{tabular}{|l|l|l|l|l|c|}
\hline \multicolumn{5}{|c|}{ Table A-1 - Location and Seismicity Data } & Page A-5 \\
\hline \hline State Code & State & County Code & County Name & Seismicity & Av $_{\mathrm{v}}<0.15$ \\
\hline
\end{tabular}

\begin{tabular}{|c|c|c|c|c|c|}
\hline 05 & Arkansas & 007 & Benton & Low & Yes \\
\hline & & 009 & Boone & Low & Yes \\
\hline & & 011 & Bradley & Low & Yes \\
\hline & & 013 & Calhoun & Low & Yes \\
\hline & & 015 & Carroll & Low & Yes \\
\hline & & 017 & Chicot & Low & Yes \\
\hline & & 019 & Clark & Low & Yes \\
\hline & & 021 & Clay & High & No \\
\hline & & 023 & Cleberne & Moderate & Yes \\
\hline & & 025 & Cleveland & Low & Yes \\
\hline & & 027 & Columbia & Low & Yes \\
\hline & & 029 & Conway & Low & Yes \\
\hline & & 031 & Craighead & High & No \\
\hline & & 033 & Crawford & Low & Yes \\
\hline & & 035 & Crittenden & High & No \\
\hline & & 037 & Cross & High & No \\
\hline & & 039 & Dallas & Low & Yes \\
\hline & & 041 & Desha & Moderate & Yes \\
\hline & & 043 & Drew & Low & Yes \\
\hline & & 045 & Faulkner & Moderate & Yes \\
\hline & & 047 & Franklin & Low & Yes \\
\hline & & 049 & Fulton & Moderate & No \\
\hline & & 051 & Garland & Low & Yes \\
\hline & & 053 & Grant & Low & Yes \\
\hline & & 055 & Greene & High & No \\
\hline & & 057 & Hempstead & Low & Yes \\
\hline & & 059 & Hot Spring & Low & Yes \\
\hline & & 061 & Howard & Low & Yes \\
\hline & & 063 & Independence & Moderate & No \\
\hline & & 065 & Izard & Moderate & Yes \\
\hline
\end{tabular}




\begin{tabular}{|l|c|c|c|c|c|}
\hline \multicolumn{5}{|c|}{ Table A-1 - Location and Seismicity Data } & Page A-6 \\
\hline \hline State Code & State & County Code & County Name & Seismicity & Av $_{\mathrm{v}}<0.15$ \\
\hline
\end{tabular}

\begin{tabular}{|c|c|c|c|c|c|}
\hline 05 & Arkansas & 067 & Jackson & High & No \\
\hline & & 069 & Jefferson & Low & Yes \\
\hline & & 071 & Johnson & Low & Yes \\
\hline & & 073 & Lafayette & Low & Yes \\
\hline & & 075 & Lawrence & High & No \\
\hline & & 077 & Lee & Moderate & No \\
\hline & & 079 & Lincoln & Low & Yes \\
\hline & & 081 & Little River & Low & Yes \\
\hline & & 083 & Logan & Low & Yes \\
\hline & & 085 & Lonoke & Moderate & Yes \\
\hline & & 087 & Madison & Low & Yes \\
\hline & & 089 & Marion & Low & Yes \\
\hline & & 091 & Miller & Low & Yes \\
\hline & & 093 & Mississippi & High & No \\
\hline & & 095 & Monroe & Moderate & No \\
\hline & & 097 & Montgomery & Low & Yes \\
\hline & & 099 & Nevada & Low & Yes \\
\hline & & 101 & Newton & Low & Yes \\
\hline & & 103 & Ouachita & Low & Yes \\
\hline & & 105 & Perry & Low & Yes \\
\hline & & 107 & Phillips & Moderate & No \\
\hline & & 109 & Pike & Low & Yes \\
\hline & & 111 & Poinsett & High & No \\
\hline & & 113 & Polk & Moderate & Yes \\
\hline & & 115 & Pope & Low & Yes \\
\hline & & 117 & Prairie & Moderate & No \\
\hline & & 119 & Pulaski & Low & Yes \\
\hline & & 121 & Randolph & High & No \\
\hline & & 123 & St Francis & High & No \\
\hline & & 125 & Saline & Low & Yes \\
\hline
\end{tabular}




\begin{tabular}{||l|l|l|c|c|c|}
\hline \multicolumn{5}{|c|}{ Table A-1 - Location and Seismicity Data } & Page A-7 \\
\hline \hline State Code & State & County Code & County Name & Seismicity & A. $<$ 0.15 \\
\hline
\end{tabular}

\begin{tabular}{|c|c|c|c|c|c|}
\hline 05 & Arkansas & 127 & Scott & Low & Yes \\
\hline & & 129 & Searcy & Low & Yes \\
\hline & & 131 & Sebastian & Low & Yes \\
\hline & & 133 & Sevier & Low & Yes \\
\hline & & 135 & Sharp & Moderate & No \\
\hline & & 137 & Stone & Moderate & Yes \\
\hline & & 139 & Union & Low & Yes \\
\hline & & 141 & Van Buren & Low & Yes \\
\hline & & 143 & Washington & Low & Yes \\
\hline & & 145 & White & Moderate & No \\
\hline & & 147 & Woodruff & High & No \\
\hline & & 149 & Yell & Low & Yes \\
\hline 06 & \multicolumn{3}{|c|}{ CAIIFORNIA } & MIXED & MIXED \\
\hline & & 001 & Alameda & High & No \\
\hline & & 003 & Alpine & High & No \\
\hline & & 005 & Amador & High & No \\
\hline & & 007 & Butte & High & No \\
\hline & & 009 & Calaveras & High & No \\
\hline & & 011 & Colusa & High & No \\
\hline & & 013 & Contra Costa & High & No \\
\hline & & 015 & Del Norte & High & No \\
\hline & & 017 & El Dorado & High & No \\
\hline & & 019 & Fresno & High & No \\
\hline & & 021 & Glenn & High & No \\
\hline & & 023 & Humboldt & High & No \\
\hline & & 025 & Imperial & High & No \\
\hline & & 027 & Inyo & High & No \\
\hline & & 029 & Kern & High & No \\
\hline
\end{tabular}




\begin{tabular}{|l|c|c|c|c|c|}
\hline \multicolumn{5}{|c|}{ Table A-1 - Location and Seismicity Data } & Page A-8 \\
\hline \hline State Code & State & County Code & County Name & Seismicity & $A_{v}<0.15$ \\
\hline
\end{tabular}

\begin{tabular}{|c|c|c|c|c|c|}
\hline 06 & California & 031 & Kings & High & No \\
\hline & & 033 & Lake & High & No \\
\hline & & 035 & Lassen & High & No \\
\hline & & 037 & Los Angeles & High & No \\
\hline & & 039 & Madera & High & No \\
\hline & & 041 & Marin & High & No \\
\hline & & 043 & Mariposa & High & No \\
\hline & & 045 & Mendocino & High & No \\
\hline & & 047 & Merced & High & No \\
\hline & & 049 & Modoc & Moderate & Yes \\
\hline & & 051 & Mono & High & No \\
\hline & & 053 & Monterey & High & No \\
\hline & & 055 & Napa & High & No \\
\hline & & 057 & Nevada & High & No \\
\hline & & 059 & Orange & High & No \\
\hline & & 061 & Placer & High & No \\
\hline & & 063 & Plumas & High & No \\
\hline & & 065 & Riverside & High & No \\
\hline & & 067 & Sacramento & High & No \\
\hline & & 069 & San Benito & High & No \\
\hline & & 071 & San Bernardino & High & No \\
\hline & & 073 & San Diego & High & No \\
\hline & & 075 & San Francisco & High & No \\
\hline & & 077 & San Joaquin & High & No \\
\hline & & 079 & San Luis Obispo & High & No \\
\hline & & 081 & San Mateo & High & No \\
\hline & & 083 & Santa Barbara & High & No \\
\hline & & 085 & Santa Clara & High & No \\
\hline & & 087 & Santa Cruz & High & No \\
\hline & & 089 & Shasta & High & No \\
\hline
\end{tabular}


Table A-1 - Location and Seismicity Data

Page A-9

\begin{tabular}{|l|l|l|l|l|l|}
\hline State Code & State & County Code & County Name & Seismicity & $A_{v}<0.15$ \\
\hline
\end{tabular}

\begin{tabular}{|c|c|c|c|c|c|}
\hline 06 & California & 091 & Sierra & High & No \\
\hline & & 093 & Siskiyou & Moderate & No \\
\hline & & 095 & Solano & High & No \\
\hline & & 097 & Sonoma & High & No \\
\hline & & 099 & Stanislaus & High & No \\
\hline & & 101 & Sutter & High & No \\
\hline & & 103 & Tehama & High & No \\
\hline & & 105 & Trinity & High & No \\
\hline & & 107 & Tulare & High & No \\
\hline & & 109 & Tuolumne & High & No \\
\hline & & 111 & Ventura & High & No \\
\hline & & 113 & Yolo & High & No \\
\hline & & 115 & Yuba & High & No \\
\hline 08 & \multicolumn{3}{|c|}{ COLORADO } & MIXED & ALL YES \\
\hline & & 001 & Adams & Low & Yes \\
\hline & & 003 & Alamosa & Low & Yes \\
\hline & & 005 & Arapahoe & Low & Yes \\
\hline & & 007 & Archuleta & Moderate & Yes \\
\hline & & 009 & Baca & Low & Yes \\
\hline & & 011 & Bent & Low & Yes \\
\hline & & 013 & Boulder & Low & Yes \\
\hline & & 015 & Chaffee & Low & Yes \\
\hline & & 017 & Cheyenne & Low & Yes \\
\hline & & 019 & Clear Creek & Low & Yes \\
\hline & & 021 & Conejos & Moderate & Yes \\
\hline & & 023 & Costilla & Low & Yes \\
\hline & & 025 & Crowley & Low & Yes \\
\hline & & 027 & Custer & Low & Yes \\
\hline
\end{tabular}




\begin{tabular}{|l|c|c|c|c|c|}
\hline \multicolumn{5}{|c|}{ Table A-1 - Location and Seismicity Data } & Page A-10 \\
\hline State Code & State & County Code & County Name & Seismicity & $A_{\mathrm{v}}<0.15$ \\
\hline
\end{tabular}

\begin{tabular}{|c|c|c|c|c|c|}
\hline 08 & Colorado & 029 & Delta & Low & Yes \\
\hline & & 031 & Denver & Low & Yes \\
\hline & & 033 & Dolores & Low & Yes \\
\hline & & 035 & Douglas & Low & Yes \\
\hline & & 037 & Eagle & Low & Yes \\
\hline & & 039 & Elbert & Low & Yes \\
\hline & & 041 & El Paso & Low & Yes \\
\hline & & 043 & Fremont & Low & Yes \\
\hline & & 045 & Garfield & Low & Yes \\
\hline & & 047 & Gilpin & Low & Yes \\
\hline & & 049 & Grand & Low & Yes \\
\hline & & 051 & Gunnison & Low & Yes \\
\hline & & 053 & Hinsdale & Moderate & Yes \\
\hline & & 055 & Huerfano & Low & Yes \\
\hline & & 057 & Jackson & Low & Yes \\
\hline & & 059 & Jefferson & Low & Yes \\
\hline & & 061 & Kiowa & Low & Yes \\
\hline & & 063 & Kit Carson & Low & Yes \\
\hline & & 065 & Lake & Low & Yes \\
\hline & & 067 & La Plata & Low & Yes \\
\hline & & 069 & Larimer & Low & Yes \\
\hline & & 071 & Las Animas & Low & Yes \\
\hline & & 073 & Lincoln & Low & Yes \\
\hline & & 075 & Logan & Low & Yes \\
\hline & & 077 & Mesa & Low & Yes \\
\hline & & 079 & Mineral & Moderate & Yes \\
\hline & & 081 & Moffat & Low & Yes \\
\hline & & 083 & Montezuma & Low & Yes \\
\hline & & 085 & Montrose & Low & Yes \\
\hline & & 087 & Morgan & Low & Yes \\
\hline
\end{tabular}




\begin{tabular}{|l|c|c|c|c|c|}
\hline \multicolumn{5}{|c|}{ Table A-1 - Location and Seismicity Data } & Page A-11 \\
\hline \hline State Code & State & County Code & County Name & Seismicity & Av $<0.15$ \\
\hline
\end{tabular}

\begin{tabular}{|c|c|c|c|c|c|}
\hline 08 & Colorado & 089 & Otero & Low & Yes \\
\hline & & 091 & Ouray & Low & Yes \\
\hline & & 093 & Park & Low & Yes \\
\hline & & 095 & Phillips & Low & Yes \\
\hline & & 097 & Pitkin & Low & Yes \\
\hline & & 099 & Prowers & Low & Yes \\
\hline & & 101 & Pueblo & Low & Yes \\
\hline & & 103 & Rio Blanco & Low & Yes \\
\hline & & 105 & Rio Grande & Moderate & Yes \\
\hline & & 107 & Routt & Low & Yes \\
\hline & & 109 & Saguache & Moderate & Yes \\
\hline & & 111 & San Juan & Low & Yes \\
\hline & & 113 & San Miguel & Low & Yes \\
\hline & & 115 & Sedgwick & Low & Yes \\
\hline & & 117 & Summit & Low & Yes \\
\hline & & 119 & Teller & Low & Yes \\
\hline & & 121 & Washington & Low & Yes \\
\hline & & 123 & Weld & Low & Yes \\
\hline & & 125 & Yuma & Low & Yes \\
\hline 09 & \multicolumn{3}{|c|}{ CONNECTICUT } & ALL MOD & ALL YES \\
\hline & & 001 & Fairfield & Moderate & Yes \\
\hline & & 003 & Hartford & Moderate & Yes \\
\hline & & 005 & Litchfield & Moderate & Yes \\
\hline & & $\infty 07$ & Middlesex & Moderate & Yes \\
\hline & & 009 & New Haven & Moderate & Yes \\
\hline & & 011 & New London & Moderate & Yes \\
\hline & & 013 & Tolland & Moderate & Yes \\
\hline & & 015 & Windham & Moderate & Yes \\
\hline
\end{tabular}




\begin{tabular}{|l|l|l|c|c|c|}
\hline \multicolumn{5}{|c|}{ Table A-1 - Location and Seismicity Data } & Page A-12 \\
\hline \hline State Code & State & County Code & County Name & Seismicity & $\mathbf{A}_{v}<0.15$ \\
\hline
\end{tabular}

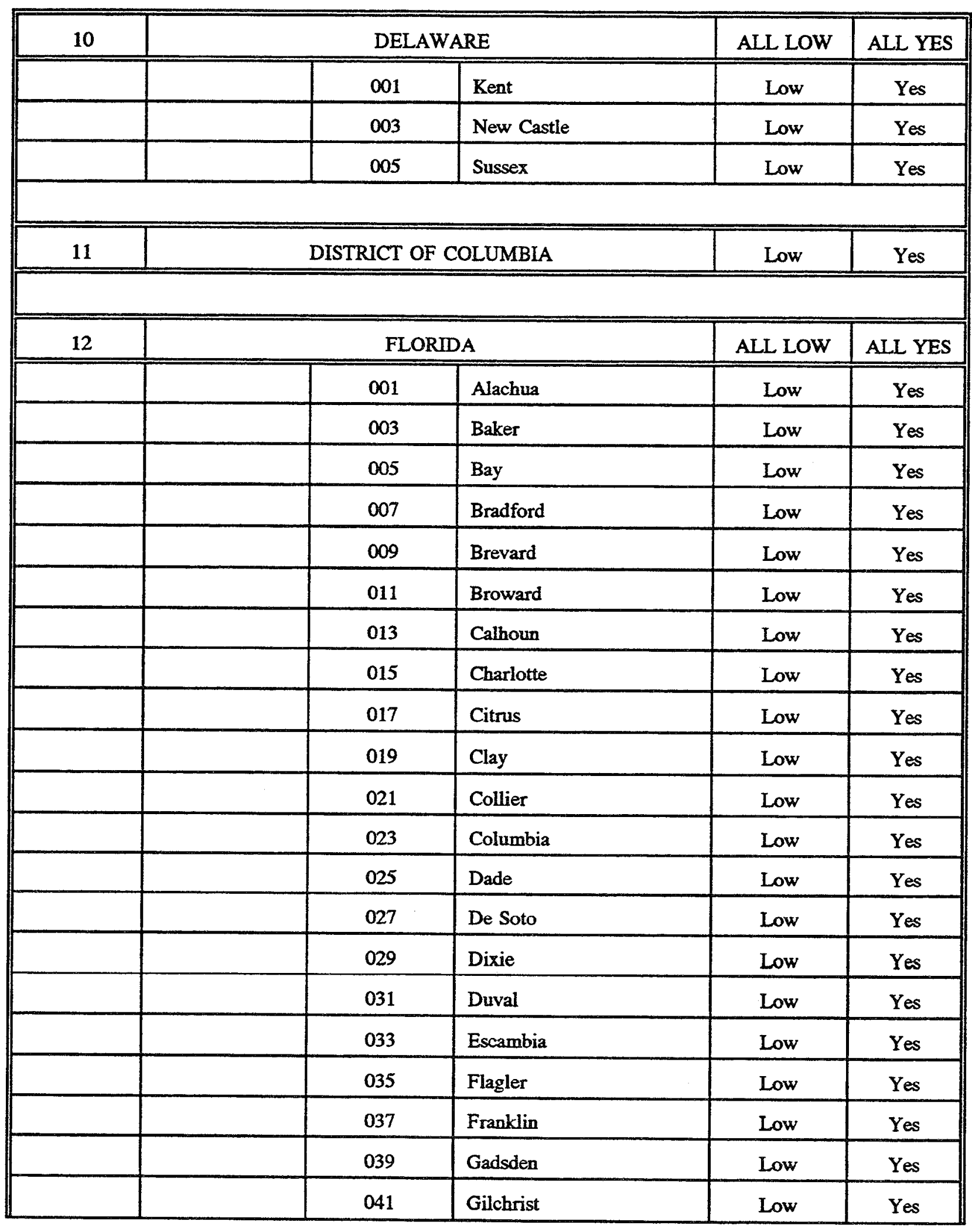




\begin{tabular}{|l|l|l|l|c|c|}
\hline \multicolumn{5}{|c|}{ Table A-1 - Location and Seismicity Data } & Page A-13 \\
\hline \hline State Code & State & County Code & County Name & Seismicity & Av $<0.15$ \\
\hline
\end{tabular}

\begin{tabular}{|c|c|c|c|c|c|}
\hline 12 & Florida & 043 & Glades & Low & Yes \\
\hline & & 045 & Gulf & Low & Yes \\
\hline & & 047 & Hamilton & Low & Yes \\
\hline & & 049 & Hardee & Low & Yes \\
\hline & & 051 & Hendry & Low & Yes \\
\hline & & 053 & Hernando & Low & Yes \\
\hline & & 055 & Highlands & Low & Yes \\
\hline & & 057 & Hillsborough & Low & Yes \\
\hline & & 059 & Holmes & Low & Yes \\
\hline & & 061 & Indian River & Low & Yes \\
\hline & & 063 & Jackson & Low & Yes \\
\hline & & 065 & Jefferson & Low & Yes \\
\hline & & 067 & Lafayette & Low & Yes \\
\hline & & 069 & Lake & Low & Yes \\
\hline & & 071 & Lee & Low & Yes \\
\hline & & 073 & Leon & Low & Yes \\
\hline & & 075 & Levy & Low & Yes \\
\hline & & 077 & Liberty & Low & Yes \\
\hline & & 079 & Madison & Low & Yes \\
\hline & & 081 & Manatee & Low & Yes \\
\hline & & 083 & Marion & Low & Yes \\
\hline & & 085 & Martin & Low & Yes \\
\hline & & 087 & Monroe & Low & Yes \\
\hline & & 089 & Nassau & Low & Yes \\
\hline & & 091 & Okaloosa & Low & Yes \\
\hline & & 093 & Okeechobee & Low & Yes \\
\hline & & 095 & Orange & Low & Yes \\
\hline & & 097 & Osceola & Low & Yes \\
\hline & & 099 & Palm Beach & Low & Yes \\
\hline & & 101 & Pasco & Low & Yes \\
\hline
\end{tabular}




\begin{tabular}{|l|l|l|c|c|c|}
\hline \multicolumn{5}{|c|}{ Table A-1 - Location and Seismicity Data } & Page A-14 \\
\hline \hline State Code & State & County Code & County Name & Seismicity & Av $_{\mathrm{v}}<0.15$ \\
\hline
\end{tabular}

\begin{tabular}{|c|c|c|c|c|c|}
\hline 12 & Florida & 103 & Pinellas & Low & Yes \\
\hline & & 105 & Polk & Low & Yes \\
\hline & & 107 & Putnam & Low & Yes \\
\hline & & 109 & St Johns & Low & Yes \\
\hline & & 111 & St Lucie & Low & Yes \\
\hline & & 113 & Santa Rosa & Low & Yes \\
\hline & & 115 & Sarasota & Low & Yes \\
\hline & & 117 & Seminole & Low & Yes \\
\hline & & 119 & Sumter & Low & Yes \\
\hline & & 121 & Suwannee & Low & Yes \\
\hline & & 123 & Taylor & Low & Yes \\
\hline & & 125 & Union & Low & Yes \\
\hline & & 127 & Volusia & Low & Yes \\
\hline & & 129 & Wakulla & Low & Yes \\
\hline & & 131 & Walton & Low & Yes \\
\hline & & 133 & Washington & Low & Yes \\
\hline 13 & \multicolumn{3}{|c|}{ GEORGIA } & MLXED & ALL YES \\
\hline & & 001 & Appling & Low & Yes \\
\hline & & 003 & Atkinson & Low & Yes \\
\hline & & 005 & Bacon & Low & Yes \\
\hline & & 007 & Baker & Low & Yes \\
\hline & & 009 & Baldwin & Low & Yes \\
\hline & & 011 & Banks & Moderate & Yes \\
\hline & & 013 & Barrow & Moderate & Yes \\
\hline & & 015 & Bartow & Moderate & Yes \\
\hline & & 017 & Ben Hill & Low & Yes \\
\hline & & 019 & Berrien & Low & Yes \\
\hline & & 021 & Bibb & Low & Yes \\
\hline
\end{tabular}




\begin{tabular}{|l|c|c|c|c|c|}
\hline \multicolumn{5}{|c|}{ Table A-1 - Location and Seismicity Data } & Page A-15 \\
\hline \hline State Code & State & County Code & County Name & Seismicity & Av $_{\mathbf{v}}<0.15$ \\
\hline
\end{tabular}

\begin{tabular}{|c|c|c|c|c|c|}
\hline 13 & Georgia & 023 & Bleckley & Low & Yes \\
\hline & & 025 & Brantley & Low & Yes \\
\hline & & 027 & Brooks & $\frac{\text { Lain }}{\text { Ancterate }}$ & Yes \\
\hline & & 029 & Bryan & Moderate & Yes \\
\hline & & 031 & Bulloch & Moderate & Yes \\
\hline & & 033 & Burke & Moderate & Yes \\
\hline & & 035 & Butts & Low & Yes \\
\hline & & 037 & Calhoun & Low & Yes \\
\hline & & 039 & Camden & Low & Yes \\
\hline & & 043 & Candler & Moderate & Yes \\
\hline & & 045 & Carroll & Low & Yes \\
\hline & & 047 & Catoosa & Moderate & Yes \\
\hline & & 049 & Charlton & Low & Yes \\
\hline & & 051 & Chatham & Moderate & Yes \\
\hline & & 053 & Chattahoochee & Low & Yes \\
\hline & & 055 & Chattooga & Moderate & Yes \\
\hline & & 057 & Cherokee & Moderate & Yes \\
\hline & & 059 & Clarke & Moderate & Yes \\
\hline & & 061 & Clay & Low & Yes \\
\hline & & 063 & Clayton & Low & Yes \\
\hline & & 065 & Clinch & Low & Yes \\
\hline & & 067 & Cobb & Moderate & Yes \\
\hline & & 069 & Coffee & Low & Yes \\
\hline & & 071 & Colquitt & Low & Yes \\
\hline & & 073 & Columbia & Moderate & Yes \\
\hline & & 075 & Cook & Low & Yes \\
\hline & & 077 & Coweta & Low & Yes \\
\hline & & 079 & Crawford & Low & Yes \\
\hline & & 081 & Crisp & Low & Yes \\
\hline & & 083 & Cawson & Moderate & Yes \\
\hline
\end{tabular}




\begin{tabular}{|l|c|c|c|c|c|}
\hline \multicolumn{5}{|c|}{ Table A-1 - Location and Seismicity Data } & Page A-16 \\
\hline \hline State Code & State & County Code & County Name & Seismicity & $A_{v}<0.15$ \\
\hline
\end{tabular}

\begin{tabular}{|c|c|c|c|c|c|}
\hline 13 & Georgia & 085 & Dade & Moderate & Yes \\
\hline & & 087 & Decatur & Low & Yes \\
\hline & & 089 & De Kalb & Moderate & Yes \\
\hline & & 091 & Dodge & Low & Yes \\
\hline & & 093 & Dooly & Low & Yes \\
\hline & & 095 & Dougherty & Low & Yes \\
\hline & & 097 & Douglas & Low & Yes \\
\hline & & 099 & Early & Low & Yes \\
\hline & & 101 & Echols & Low & Yes \\
\hline & & 103 & Effingham & Moderate & Yes \\
\hline & & 105 & Elbert & Moderate & Yes \\
\hline & & 107 & Emanuel & Moderate & Yes \\
\hline & & 109 & Evans & Low & Yes \\
\hline & & 111 & Fannin & Moderate & Yes \\
\hline & & 113 & Fayette & Low & Yes \\
\hline & & 115 & Floyd & Moderate & Yes \\
\hline & & 117 & Forsyth & Moderate & Yes \\
\hline & & 119 & Franklin & Moderate & Yes \\
\hline & & 121 & Fulton & Moderate & Yes \\
\hline & & 123 & Gilmer & Moderate & Yes \\
\hline & & 125 & Glascock & Moderate & Yes \\
\hline & & 127 & Glynn & Low & Yes \\
\hline & & 129 & Gordon & Moderate & Yes \\
\hline & & 131 & Grady & Low & Yes \\
\hline & & 133 & Greene & Moderate & Yes \\
\hline & & 135 & Gwinnett & Moderate & Yes \\
\hline & & 137 & Habersham & Moderate & Yes \\
\hline & & 139 & Hall & Moderate & Yes \\
\hline & & 141 & Hancock & Moderate & Yes \\
\hline & & 143 & Haralson & Low & Yes \\
\hline
\end{tabular}




\begin{tabular}{||c|c|c|c|c|c|}
\hline \multicolumn{5}{|c|}{ Table A-1 - Location and Seismicity Data } & Page A-17 \\
\hline State Code & State & County Code & County Name & Seismicity & $\mathbf{A}_{\mathbf{v}}<\mathbf{0 . 1 5}$ \\
\hline
\end{tabular}

\begin{tabular}{|c|c|c|c|c|c|}
\hline 13 & Georgia & 145 & Harris & Low & Yes \\
\hline & & 147 & Hart & Moderate & Yes \\
\hline & & 149 & Heard & - Low & Yes \\
\hline & & 151 & Henry & Low & Yes \\
\hline & & 153 & Houston & Low & Yes \\
\hline & & 155 & Irwin & Low & Yes \\
\hline & & 157 & Jackson & Moderate & Yes \\
\hline & & 159 & Jasper & Moderate & Yes \\
\hline & & 161 & Jeff Davis & Low & Yes \\
\hline & & 163 & Jefferson & Moderate & Yes \\
\hline & & 165 & Jenkins & Moderate & Yes \\
\hline & & 167 & Johnson & Moderate & Yes \\
\hline & & 169 & Jones & Low & Yes \\
\hline & & 171 & Lamar & Low & Yes \\
\hline & & 173 & Lanier & Low & Yes \\
\hline & & 175 & Laurens & Low & Yes \\
\hline & & 177 & Lee & Low & Yes \\
\hline & & 179 & Liberty & Low & Yes \\
\hline & & 181 & Lincoln & Moderate & Yes \\
\hline & & 183 & Long & Low & Yes \\
\hline & & 185 & Lowndes & Low & Yes \\
\hline & & 187 & Lumpkin & Moderate & Yes \\
\hline & & 189 & McDuffie & Moderate & Yes \\
\hline & & 191 & McIntosh & Low & Yes \\
\hline & & 193 & Macon & Low & Yes \\
\hline & & 195 & Madison & Moderate & Yes \\
\hline & & 197 & Marion & Low & Yes \\
\hline & & 199 & Meriwether & Low & Yes \\
\hline & & 201 & Miller & Low & Yes \\
\hline & & 205 & Mitchell & Low & Yes \\
\hline
\end{tabular}


Table A-1 - Location and Seismicity Data

Page A-18

\begin{tabular}{|l|l|l|l|l|l|}
\hline State Code & State & County Code & County Name & Seismicity & $A_{v}<0.15$ \\
\hline
\end{tabular}

\begin{tabular}{|c|c|c|c|c|c|}
\hline 13 & Georgia & 207 & Monroe & Low & Yes \\
\hline & & 209 & Montgomery & Low & Yes \\
\hline & & 211 & Morgan & Moderate & Yes \\
\hline & & 213 & Murray & Moderate & Yes \\
\hline & & 215 & Muscogee & Low & Yes \\
\hline & & 217 & Newton & Moderate & Yes \\
\hline & & 219 & Oconee & Moderate & Yes \\
\hline & & 221 & Oglethorpe & Moderate & Yes \\
\hline & & 223 & Paulding & Low & Yes \\
\hline & & 225 & Peach & Low & Yes \\
\hline & & 227 & Pickens & Moderate & Yes \\
\hline & & 229 & Pierce & Low & Yes \\
\hline & & 231 & Pike & Low & Yes \\
\hline & & 233 & Polk & Low & Yes \\
\hline & & 235 & Pulaski & Low & Yes \\
\hline & & 237 & Putnam & Moderate & Yes \\
\hline & & 239 & Quitman & Low & Yes \\
\hline & & 241 & Rabun & Moderate & Yes \\
\hline & & 243 & Randolph & Low & Yes \\
\hline & & 245 & Richmond & Moderate & Yes \\
\hline & & 247 & Rockdale & Moderate & Yes \\
\hline & & 249 & Schley & Low & Yes \\
\hline & & 251 & Screven & Moderate & Yes \\
\hline & & 253 & Seminole & Low & Yes \\
\hline & & 255 & Spalding & Low & Yes \\
\hline & & 257 & Stephens & Moderate & Yes \\
\hline & & 259 & Stewart & Low & Yes \\
\hline & & 261 & Sumter & Low & Yes \\
\hline & & 263 & Talbot & Low & Yes \\
\hline & & 265 & Taliaferro & Moderate & Yes \\
\hline
\end{tabular}




\begin{tabular}{|l|c|c|c|c|c|}
\hline \multicolumn{5}{|c|}{ Table A-1 - Location and Seismicity Data } & Page A-19 \\
\hline \hline State Code & State & County Code & County Name & Seismicity & Av $_{v}<0.15$ \\
\hline
\end{tabular}

\begin{tabular}{|c|c|c|c|c|c|}
\hline 13 & Georgia & 267 & Tattnall & Low & Yes \\
\hline & & 269 & Taylor & Low & Yes \\
\hline & & 271 & Telfair & Low & Yes \\
\hline & & 273 & Terrell & Low & Yes \\
\hline & & 275 & Thomas & Low & Yes \\
\hline & & 277 & Tift & Low & Yes \\
\hline & & 279 & Toombs & Low & Yes \\
\hline & & 281 & Towns & Moderate & Yes \\
\hline & & 283 & Treutlen & Moderate & Yes \\
\hline & & 285 & Troup & Low & Yes \\
\hline & & 287 & Turner & Low & Yes \\
\hline & & 289 & Twiggs & Low & Yes \\
\hline & & 291 & Union & Moderate & Yes \\
\hline & & 293 & Upson & Low & Yes \\
\hline & & 295 & Walker & Moderate & Yes \\
\hline & & 297 & Waltoon & Moderate & Yes \\
\hline & & 299 & Ware & Low & Yes \\
\hline & & 301 & Warren & Moderate & Yes \\
\hline & & 303 & Washington & Moderate & Yes \\
\hline & & 305 & Wayne & Low & Yes \\
\hline & & 307 & Webster & Low & Yes \\
\hline & & 309 & Wheeler & Low & Yes \\
\hline & & 311 & White & Moderate & Yes \\
\hline & & 313 & Whitfield & Moderate & Yes \\
\hline & & 315 & Wilcox & Low & Yes \\
\hline & & 317 & Wilkes & Moderate & Yes \\
\hline & & 319 & Wilkinson & Low & Yes \\
\hline & & 321 & Worth & Low & Yes \\
\hline
\end{tabular}




\begin{tabular}{|l|c|c|c|c|c|}
\hline \multicolumn{5}{|c|}{ Table A-1 - Location and Seismicity Data } & Page A-20 \\
\hline State Code & State & County Code & County Name & Seismicity & A. $_{\mathbf{r}}<0.15$ \\
\hline
\end{tabular}

\begin{tabular}{|c|c|c|c|c|}
\hline \multirow[t]{2}{*}{15} & \multicolumn{2}{|c|}{ HAWAII } & \multirow{2}{*}{$\frac{\text { MIXED }}{\text { High }}$} & \multirow{2}{*}{$\frac{\text { MIXED }}{\text { No }}$} \\
\hline & 001 & Hawaii & & \\
\hline & 003 & Honolulu & Moderate & Yes \\
\hline & 005 & Kalawao & Moderate & No \\
\hline & 007 & Kauai & Low & Yes \\
\hline & 009 & Maui & Moderate & No \\
\hline \multirow[t]{22}{*}{16} & \multicolumn{2}{|c|}{ IDAHO } & MIXED & MIXED \\
\hline & 001 & Ada & Low & Yes \\
\hline & 003 & Adams & Low & Yes \\
\hline & 005 & Bannock & High & No \\
\hline & 007 & Bear Lake & High & No \\
\hline & 009 & Benewah & Low & Yes \\
\hline & 011 & Bingham & High & No \\
\hline & 013 & Blaine & Moderate & Yes \\
\hline & 015 & Boise & Low & Yes \\
\hline & 017 & Bonner & Low & Yes \\
\hline & 019 & Bonneville & High & No \\
\hline & 021 & Boundary & Low & Yes \\
\hline & 023 & Butte & Moderate & No \\
\hline & 025 & Camas & Low & Yes \\
\hline & 027 & Canyon & Low & Yes \\
\hline & 029 & Caribou & High & No \\
\hline & 031 & Cassia & Moderate & No \\
\hline & 033 & Clark & High & No \\
\hline & 035 & Clearwater & Moderate & Yes \\
\hline & 037 & Custer & Moderate & Yes \\
\hline & 039 & Elmore & Low & Yes \\
\hline & 041 & Franklin & High & No \\
\hline
\end{tabular}




\begin{tabular}{|l|l|l|l|l|l|}
\hline \multicolumn{5}{|c|}{ Table A-1 - Location and Seismicity Data } & Page A-21 \\
\hline \hline State Code & State & County Code & County Name & Seismicity & $\mathbf{A}_{\mathbf{v}}<\mathbf{0 . 1 5}$ \\
\hline
\end{tabular}

\begin{tabular}{|c|c|c|c|c|c|}
\hline 16 & Idaho & 043 & Fremont & High & No \\
\hline & & 045 & Gem & Low & Yes \\
\hline & & 047 & Gooding & Low & Yes \\
\hline & & 049 & Idaho & Moderate & Yes \\
\hline & & 051 & Jefferson & High & No \\
\hline & & 053 & Jerome & Low & Yes \\
\hline & & 055 & Kootenai & Low & Yes \\
\hline & & 057 & Latah & Low & Yes \\
\hline & & 059 & Lemhi & Moderate & No \\
\hline & & 061 & Lewis & Low & Yes \\
\hline & & 063 & Lincoln & Moderate & Yes \\
\hline & & 065 & Madison & High & No \\
\hline & & 067 & Minidoka & Moderate & Yes \\
\hline & & 069 & Nez Perce & Low & Yes \\
\hline & & 071 & Oneida & High & No \\
\hline & & 073 & Owyhee & Moderate & Yes \\
\hline & & 075 & Payette & Low & Yes \\
\hline & & 077 & Power & Moderate & No \\
\hline & & 079 & Shoshone & Moderate & Yes \\
\hline & & 081 & Teton & High & No \\
\hline & & 083 & Twin Falls & Moderate & Yes \\
\hline & & 085 & Valley & Moderate & Yes \\
\hline & & 087 & Washington & Low & Yes \\
\hline 17 & \multicolumn{3}{|c|}{ ILLINOIS } & MIXED & MIXED \\
\hline & & 001 & Adams & Low & Yes \\
\hline & & 003 & Alexander & High & No \\
\hline & & 005 & Bond & Moderate & Yes \\
\hline & & 007 & Boone & Low & Yes \\
\hline
\end{tabular}




\begin{tabular}{|l|c|c|c|c|c|}
\hline \multicolumn{5}{|c|}{ Table A-1 - Location and Seismicity Data } & Page A-22 \\
\hline \hline State Code & State & County Code & County Name & Seismicity & Av $_{\mathrm{v}}<0.15$ \\
\hline
\end{tabular}

\begin{tabular}{|c|c|c|c|c|c|}
\hline 17 & Illinois & 009 & Brown & Low & Yes \\
\hline & & 011 & Bureau & Low & Yes \\
\hline & & 013 & Calhoun & Low & Yes \\
\hline & & 015 & Carroll & Low & Yes \\
\hline & & 017 & Cass & Low & Yes \\
\hline & & 019 & Champaign & Low & Yes \\
\hline & & 021 & Christian & Moderate & Yes \\
\hline & & 023 & Clark & Moderate & Yes \\
\hline & & 025 & Clay & Moderate & Yes \\
\hline & & 027 & Clinton & Moderate & No \\
\hline & & 029 & Coles & Moderate & Yes \\
\hline & & 031 & Cook & Low & Yes \\
\hline & & 033 & Crawford & Moderate & Yes \\
\hline & & 035 & Cumberland & Moderate & Yes \\
\hline & & 037 & De Kalb & Low & Yes \\
\hline & & 039 & De Witt & Low & Yes \\
\hline & & 041 & Douglas & Moderate & Yes \\
\hline & & 043 & Du Page & Low & Yes \\
\hline & & 045 & Edgar & Moderate & Yes \\
\hline & & 047 & Edwards & Moderate & Yes \\
\hline & & 049 & Effingham & Moderate & Yes \\
\hline & & 051 & Fayette & Moderate & Yes \\
\hline & & 053 & Ford & Low & Yes \\
\hline & & 055 & Franklin & Moderate & No \\
\hline & & 057 & Fulton & Low & Yes \\
\hline & & 059 & Gallatin & Moderate & No \\
\hline & & 061 & Greene & Low & Yes \\
\hline & & 063 & Grundy & Low & Yes \\
\hline & & 065 & Hamilton & Moderate & No \\
\hline & & 067 & Hancock & Low & Yes \\
\hline
\end{tabular}


Table A-1 - Location and Seismicity Data

Page A-23

\begin{tabular}{|l|l|l|l|l|l|}
\hline State Code & State & County Code & County Name & Seismicity & $A_{\mathbf{v}}<0.15$ \\
\hline
\end{tabular}

\begin{tabular}{|c|c|c|c|c|c|}
\hline 17 & Illinois & 069 & Hardin & Moderate & No \\
\hline & & 071 & Henderson & Low & Yes \\
\hline & & 073 & Henry & Low & Yes \\
\hline & & 075 & Iroquois & Low & Yes \\
\hline & & 077 & Jackson & Moderate & No \\
\hline & & 079 & Jasper & Moderate & Yes \\
\hline & & 081 & Jefferson & Moderate & No \\
\hline & & 083 & Jersey & Low & Yes \\
\hline & & 085 & Jo Daviess & Low & Yes \\
\hline & & 087 & Johnson & Moderate & No \\
\hline & & 089 & Kane & Low & Yes \\
\hline & & 091 & Kankakee & Low & Yes \\
\hline & & 093 & Kendall & Low & Yes \\
\hline & & 095 & Knox & Low & Yes \\
\hline & & 097 & Lake & Low & Yes \\
\hline & & 099 & La Salle & Low & Yes \\
\hline & & 101 & Lawrence & Moderate & Yes \\
\hline & & 103 & Lee & Low & Yes \\
\hline & & 105 & Livingston & Low & Yes \\
\hline & & 107 & Logan & Low & Yes \\
\hline & & 109 & McDonough & Low & Yes \\
\hline & & 111 & McHenry & Low & Yes \\
\hline & & 113 & McLean & Low & Yes \\
\hline & & 115 & Macon & Low & Yes \\
\hline & & 117 & Macoupin & Moderate & Yes \\
\hline & & 119 & Madison & Moderate & Yes \\
\hline & & 121 & Marion & Moderate & No \\
\hline & & 123 & Marshall & Low & Yes \\
\hline & & 125 & Mason & Low & Yes \\
\hline & & 127 & Massac & Moderate & No \\
\hline
\end{tabular}




\begin{tabular}{|l|l|l|l|l|l|}
\hline \multicolumn{5}{|c|}{ Table A-1 - Location and Seismicity Data } & Page A-24 \\
\hline State Code & State & County Code & County Name & Seismicity & A $_{\mathrm{r}}<0.15$ \\
\hline
\end{tabular}

\begin{tabular}{|c|c|c|c|c|c|}
\hline 17 & Illinois & 129 & Menard & Low & Yes \\
\hline & & 131 & Mercer & Low & Yes \\
\hline & & 133 & Monroe & Moderate & No \\
\hline & & 135 & Montgomery & Moderate & Yes \\
\hline & & 137 & Morgan & Low & Yes \\
\hline & & 139 & Moultrie & Moderate & Yes \\
\hline & & 141 & Ogle & Low & Yes \\
\hline & & 143 & Peoria & Low & Yes \\
\hline & & 145 & Perry & Moderate & No \\
\hline & & 147 & Piatt & Low & Yes \\
\hline & & 149 & Pike & Low & Yes \\
\hline & & 151 & Pope & Moderate & No \\
\hline & & 153 & Pulaski & High & No \\
\hline & & 155 & Putnam & Low & Yes \\
\hline & & 157 & Randolph & Moderate & No \\
\hline & & 159 & Richland & Moderate & Yes \\
\hline & & 161 & Rock Island & Low & Yes \\
\hline & & 163 & St Clair & Moderate & No \\
\hline & & 165 & Saline & Moderate & No \\
\hline & & 167 & Sangamon & Low & Yes \\
\hline & & 169 & Schuyler & Low & Yes \\
\hline & & 171 & Scott & Low & Yes \\
\hline & & 173 & Shelby & Moderate & Yes \\
\hline & & 175 & Stark & Low & Yes \\
\hline & & 177 & Stephenson & Low & Yes \\
\hline & & 179 & Tazewell & Low & Yes \\
\hline & & 181 & Union & High & No \\
\hline & & 183 & Vermilion & Low & Yes \\
\hline & & 185 & Wabash & Moderate & Yes \\
\hline & & 187 & Warren & Low & Yes \\
\hline
\end{tabular}




\begin{tabular}{|l|l|c|c|c|c|}
\hline \multicolumn{5}{|c|}{ Table A-1 - Location and Seismicity Data } & Page A-25 \\
\hline \hline State Code & State & County Code & County Name & Seismicity & $\mathbf{A}_{\mathbf{v}}<0.15$ \\
\hline
\end{tabular}

\begin{tabular}{|c|c|c|c|c|c|}
\hline 17 & Illinois & 189 & Washington & Moderate & No \\
\hline & & 191 & Wayne & Moderate & No \\
\hline & & 193 & White & Moderate & No \\
\hline & & 195 & Whiteside & Low & Yes \\
\hline & & 197 & Will & Low & Yes \\
\hline & & 199 & Williamson & Moderate & No \\
\hline & & 201 & Winnebago & Low & Yes \\
\hline & & 203 & Woodford & Low & Yes \\
\hline 18 & \multicolumn{3}{|c|}{ INDIANA } & MIXED & ALL YES \\
\hline & & 001 & Adams & Low & Yes \\
\hline & & 003 & Allen & Low & Yes \\
\hline & & 005 & Bartholomew & Low & Yes \\
\hline & & 007 & Benton & Low & Yes \\
\hline & & 009 & Blackford & Low & Yes \\
\hline & & 011 & Boone & Low & Yes \\
\hline & & 013 & Brown & Low & Yes \\
\hline & & 015 & Carroll & Low & Yes \\
\hline & & 017 & Cass & Low & Yes \\
\hline & & 019 & Clark & Low & Yes \\
\hline & & 021 & Clay & Low & Yes \\
\hline & & 023 & Clinton & Low & Yes \\
\hline & & 025 & Crawford & Low & Yes \\
\hline & & 027 & Daviess & Low & Yes \\
\hline & & 029 & Dearborn & Low & Yes \\
\hline & & 031 & Decatur & Low & Yes \\
\hline & & 033 & De Kalb & Low & Yes \\
\hline & & 035 & Delaware & Low & Yes \\
\hline & & 037 & Dubois & Low & Yes \\
\hline
\end{tabular}


Table A-1 - Location and Seismicity Data

Page A-26

\begin{tabular}{|l|l|l|l|l|l|}
\hline State Code & State & County Code & County Name & Seismicity & $\mathbf{A}_{v}<0.15$ \\
\hline
\end{tabular}

\begin{tabular}{|c|c|c|c|c|c|}
\hline 18 & Indiana & 039 & Elkhart & Low & Yes \\
\hline & & 041 & Fayette & Low & Yes \\
\hline & & 043 & Floyd & Low & Yes \\
\hline & & 045 & Fountain & Low & Yes \\
\hline & & 047 & Franklin & Low & Yes \\
\hline & & 049 & Fulton & Low & Yes \\
\hline & & 051 & Gibson & Moderate & Yes \\
\hline & & 053 & Grant & Low & Yes \\
\hline & & 055 & Greene & Low & Yes \\
\hline & & 057 & Hamilton & Low & Yes \\
\hline & & 059 & Hancock & Low & Yes \\
\hline & & 061 & Harrison & Low & Yes \\
\hline & & 063 & Hendricks & Low & Yes \\
\hline & & 065 & Henry & Low & Yes \\
\hline & & 067 & Howard & Low & Yes \\
\hline & & 069 & Huntington & Low & Yes \\
\hline & & 071 & Jackson & Low & Yes \\
\hline & & 073 & Jasper & Low & Yes \\
\hline & & 075 & Jay & Low & Yes \\
\hline & & 077 & Jefferson & Low & Yes \\
\hline & & 079 & Jennings & Low & Yes \\
\hline & & 081 & Johnson & Low & Yes \\
\hline & & 083 & Knox & Moderate & Yes \\
\hline & & 085 & Kosciusko & Low & Yes \\
\hline & & 087 & LaGrange & Low & Yes \\
\hline & & 089 & Lake & Low & Yes \\
\hline & & 091 & La Porte & Low & Yes \\
\hline & & 093 & Lawrence & Low & Yes \\
\hline & & 095 & Madison & Low & Yes \\
\hline & & 097 & Marion & Low & Yes \\
\hline
\end{tabular}




\begin{tabular}{|l|c|c|c|c|c|}
\hline \multicolumn{5}{|c|}{ Table A-1 - Location and Seismicity Data } & Page A-27 \\
\hline \hline State Code & State & County Code & County Name & Seismicity & A $_{\mathrm{V}}<\mathbf{0 . 1 5}$ \\
\hline
\end{tabular}

\begin{tabular}{|c|c|c|c|c|c|}
\hline 18 & Indiana & 099 & Marshall & Low & Yes \\
\hline & & 101 & Martin & Low & Yes \\
\hline & & 103 & Miami & Low & Yes \\
\hline & & 105 & Monroe & Low & Yes \\
\hline & & 107 & Montgomery & Low & Yes \\
\hline & & 109 & Morgan & Low & Yes \\
\hline & & 111 & Newton & Low & Yes \\
\hline & & 113 & Noble & Low & Yes \\
\hline & & 115 & Ohio & Low & Yes \\
\hline & & 117 & Orange & Low & Yes \\
\hline & & 119 & Owen & Low & Yes \\
\hline & & 121 & Parke & Low & Yes \\
\hline & & 123 & Perry & Low & Yes \\
\hline & & 125 & Pike & Low & Yes \\
\hline & & 127 & Porter & Low & Yes \\
\hline & & 129 & Posey & Moderate & Yes \\
\hline & & 131 & Pulaski & Low & Yes \\
\hline & & 133 & Putnam & Low & Yes \\
\hline & & 135 & Randolph & Low & Yes \\
\hline & & 137 & Ripley & Low & Yes \\
\hline & & 139 & Rush & Low & Yes \\
\hline & & 141 & St Joseph & Low & Yes \\
\hline & & 143 & Scott & Low & Yes \\
\hline & & 145 & Shelby & Low & Yes \\
\hline & & 147 & Spencer & Low & Yes \\
\hline & & 149 & Starke & Low & Yes \\
\hline & & 151 & Steuben & Low & Yes \\
\hline & & 153 & Sullivan & Moderate & Yes \\
\hline & & 155 & Switzerland & Low & Yes \\
\hline & & 157 & Tippecanoe & Low & Yes \\
\hline
\end{tabular}




\begin{tabular}{|l|c|c|c|c|c|}
\hline \multicolumn{5}{|c|}{ Table A-1 - Location and Seismicity Data } & Page A-28 \\
\hline State Code & State & County Code & County Name & Seismicity & $A_{\mathrm{v}}<0.15$ \\
\hline
\end{tabular}

\begin{tabular}{|c|c|c|c|c|c|}
\hline 18 & Indiana & 159 & Tipton & Low & Yes \\
\hline & & 161 & Union & Low & Yes \\
\hline & & 163 & Vanderburgh & Moderate & Yes \\
\hline & & 165 & Vermillion & Moderate & Yes \\
\hline & & 167 & Vigo & Moderate & Yes \\
\hline & & 169 & Wabash & Low & Yes \\
\hline & & 171 & Warren & Low & Yes \\
\hline & & 173 & Warrick & Low & Yes \\
\hline & & 175 & Washington & Low & Yes \\
\hline & & 177 & Wayne & Low & Yes \\
\hline & & 179 & Wells & Low & Yes \\
\hline & & 181 & White & Low & Yes \\
\hline & & 183 & Whitley & Low & Yes \\
\hline 19 & \multicolumn{3}{|c|}{ IOWA } & MIXED & ALL YES \\
\hline & & 001 & Adair & Low & Yes \\
\hline & & 003 & Adams & Low & Yes \\
\hline & & 005 & Allamakee & Low & Yes \\
\hline & & 007 & Appanoose & Low & Yes \\
\hline & & 009 & Audubon & Low & Yes \\
\hline & & 011 & Benton & Low & Yes \\
\hline & & 013 & Black Hawk & Low & Yes \\
\hline & & 015 & Boone & Low & Yes \\
\hline & & 017 & Bremer & Low & Yes \\
\hline & & 019 & Buchanan & Low & Yes \\
\hline & & 021 & Buena Vista & Low & Yes \\
\hline & & 023 & Butler & Low & Yes \\
\hline & & 025 & Calhoun & Low & Yes \\
\hline & & 027 & Carroll & Low & Yes \\
\hline
\end{tabular}




\begin{tabular}{|l|l|l|c|c|c|}
\hline \multicolumn{5}{|c|}{ Table A-1 - Location and Seismicity Data } & Page A-29 \\
\hline State Code & State & County Code & County Name & Seismicity & Av $<0.15$ \\
\hline
\end{tabular}

\begin{tabular}{|c|c|c|c|c|c|}
\hline 19 & Iowa & 029 & Cass & Low & Yes \\
\hline & & 031 & Cedar & Low & Yes \\
\hline & & 033 & Cerro Gordo & Low & Yes \\
\hline & & 035 & Cherokee & Low & Yes \\
\hline & & 037 & Chickasaw & Low & Yes \\
\hline & & 039 & Clarke & Low & Yes \\
\hline & & 041 & Clay & Low & Yes \\
\hline & & 043 & Clayton & Low & Yes \\
\hline & & 045 & Clinton & Low & Yes \\
\hline & & 047 & Crawford & Low & Yes \\
\hline & & 049 & Dallas & Low & Yes \\
\hline & & 051 & Davis & Low & Yes \\
\hline & & 053 & Decatur & Low & Yes \\
\hline & & 055 & Delaware & Low & Yes \\
\hline & & 057 & Des Moines & Low & Yes \\
\hline & & 059 & Dickinson & Low & Yes \\
\hline & & 061 & Dubuque & Low & Yes \\
\hline & & 063 & Emmet & Low & Yes \\
\hline & & 065 & Fayette & Low & Yes \\
\hline & & 067 & Floyd & Low & Yes \\
\hline & & 069 & Franklin & Low & Yes \\
\hline & & 071 & Fremont & Moderate & Yes \\
\hline & & 073 & Greene & Low & Yes \\
\hline & & 075 & Grundy & Low & Yes \\
\hline & & 077 & Guthrie & Low & Yes \\
\hline & & 079 & Hamilton & Low & Yes \\
\hline & & 081 & Hancock & Low & Yes \\
\hline & & 083 & Hardin & Low & Yes \\
\hline & & 085 & Harrison & Low & Yes \\
\hline & & 087 & Henry & Low & Yes \\
\hline
\end{tabular}




\begin{tabular}{|l|l|l|l|c|c|}
\hline \multicolumn{5}{|c|}{ Table A-1 - Location and Seismicity Data } & Page A-30 \\
\hline \hline State Code & State & County Code & County Name & Seismicity & $A_{\mathrm{v}}<0.15$ \\
\hline
\end{tabular}

\begin{tabular}{|c|c|c|c|c|c|}
\hline 19 & Iowa & 089 & Howard & Low & Yes \\
\hline & & 091 & Humboldt & Low & Yes \\
\hline & & 093 & Ida & Low & Yes \\
\hline & & 095 & lowa & Low & Yes \\
\hline & & 097 & Jackson & Low & Yes \\
\hline & & 099 & Jasper & Low & Yes \\
\hline & & 101 & Jefferson & Low & Yes \\
\hline & & 103 & Johnson & Low & Yes \\
\hline & & 105 & Jones & Low & Yes \\
\hline & & 107 & Keokuk & Low & Yes \\
\hline & & 109 & Kossuth & Low & Yes \\
\hline & & 111 & Lee & Low & Yes \\
\hline & & 113 & Linn & Low & Yes \\
\hline & & 115 & Louisa & Low & Yes \\
\hline & & 117 & Lucas & Low & Yes \\
\hline & & 119 & Lyon & Low & Yes \\
\hline & & 121 & Madison & Low & Yes \\
\hline & & 123 & Mahaska & Low & Yes \\
\hline & & 125 & Marion & Low & Yes \\
\hline & & 127 & Marshall & Low & Yes \\
\hline & & 129 & Mills & Moderate & Yes \\
\hline & & 131 & Mitchell & Low & Yes \\
\hline & & 133 & Monona & Low & Yes \\
\hline & & 135 & Monroe & Low & Yes \\
\hline & & 137 & Montgomery & Low & Yes \\
\hline & & 139 & Muscatine & Low & Yes \\
\hline & & 141 & O Brien & Low & Yes \\
\hline & & 143 & Osceola & Low & Yes \\
\hline & & 145 & Page & Moderate & Yes \\
\hline & & 147 & Palo Alto & Low & Yes \\
\hline
\end{tabular}




\begin{tabular}{|l|c|c|c|c|c|}
\hline \multicolumn{5}{|c|}{ Table A-1 - Location and Seismicity Data } & Page A-31 \\
\hline \hline State Code & State & County Code & County Name & Seismicity & Av $_{\mathrm{v}}<\mathbf{0 . 1 5}$ \\
\hline
\end{tabular}

\begin{tabular}{|c|c|c|c|c|c|}
\hline 19 & Iowa & 149 & Plymouth & Low & Yes \\
\hline & & 151 & Pocahontas & Low & Yes \\
\hline & & 153 & Polk & Low & Yes \\
\hline & & 155 & Pottawattamie & Low & Yes \\
\hline & & 157 & Poweshiek & Low & Yes \\
\hline & & 159 & Ringgold & Low & Yes \\
\hline & & 161 & Sac & Low & Yes \\
\hline & & 163 & Scott & Low & Yes \\
\hline & & 165 & Shelby & Low & Yes \\
\hline & & 167 & Sioux & Low & Yes \\
\hline & & 169 & Story & Low & Yes \\
\hline & & 171 & Tama & Low & Yes \\
\hline & & 173 & Taylor & Low & Yes \\
\hline & & 175 & Union & Low & Yes \\
\hline & & 177 & Van Buren & Low & Yes \\
\hline & & 179 & Wapello & Low & Yes \\
\hline & & 181 & Warren & Low & Yes \\
\hline & & 183 & Washington & Low & Yes \\
\hline & & 185 & Wayne & Low & Yes \\
\hline & & 187 & Webster & Low & Yes \\
\hline & & 189 & Winnebago & Low & Yes \\
\hline & & 191 & Winneshiek & Low & Yes \\
\hline & & 193 & Woodbury & Low & Yes \\
\hline & & 195 & Worth & Low & Yes \\
\hline & & 197 & Wright & Low & Yes \\
\hline 20 & \multicolumn{3}{|c|}{ KANSAS } & MIXED & ALL YES \\
\hline & & 001 & Allen & Low & Yes \\
\hline & & 003 & Anderson & Moderate & Yes \\
\hline
\end{tabular}




\begin{tabular}{|l|c|c|c|c|c|}
\hline \multicolumn{5}{|c|}{ Table A-1 - Location and Seismicity Data } & Page A-32 \\
\hline \hline State Code & State & County Code & County Name & Seismicity & $\mathbf{A}_{\mathrm{v}}<\mathbf{0 . 1 5}$ \\
\hline
\end{tabular}

\begin{tabular}{|c|c|c|c|c|c|}
\hline 20 & Kansas & 005 & Atchison & Moderate & Yes \\
\hline & & $\infty 07$ & Barber & Low & Yes \\
\hline & & 009 & Barton & Low & Yes \\
\hline & & 011 & Bourbon & Low & Yes \\
\hline & & 013 & Brown & Moderate & Yes \\
\hline & & 015 & Butler & Low & Yes \\
\hline & & 017 & Chase & Low & Yes \\
\hline & & 019 & Chautauqua & Low & Yes \\
\hline & & 021 & Cherokee & Low & Yes \\
\hline & & 023 & Cheyenne & Low & Yes \\
\hline & & 025 & Clark & Low & Yes \\
\hline & & 027 & Clay & Low & Yes \\
\hline & & 029 & Cloud & Low & Yes \\
\hline & & 031 & Coffey & Moderate & Yes \\
\hline & & 033 & Comanche & Low & Yes \\
\hline & & 035 & Cowley & Low & Yes \\
\hline & & 037 & Crawford & Low & Yes \\
\hline & & 039 & Decatur & Low & Yes \\
\hline & & 041 & Dickinson & Low & Yes \\
\hline & & 043 & Doniphan & Moderate & Yes \\
\hline & & 045 & Douglas & Moderate & Yes \\
\hline & & 047 & Edwards & Low & Yes \\
\hline & & 049 & Elk & Low & Yes \\
\hline & & 051 & Ellis & Low & Yes \\
\hline & & 053 & Ellsworth & Low & Yes \\
\hline & & 055 & Finney & Low & Yes \\
\hline & & 057 & Ford & Low & Yes \\
\hline & & 059 & Franklin & Moderate & Yes \\
\hline & & 061 & Geary & Moderate & Yes \\
\hline & & 063 & Gove & Low & Yes \\
\hline
\end{tabular}




\begin{tabular}{|l|l|l|c|c|c|}
\hline \multicolumn{5}{|c|}{ Table A-1 - Location and Seismicity Data } & Page A-33 \\
\hline State Code & State & County Code & County Name & Seismicity & Av $_{\mathrm{v}}<\mathbf{0 . 1 5}$ \\
\hline
\end{tabular}

\begin{tabular}{|c|c|c|c|c|c|}
\hline 20 & Kansas & 065 & Graham & Low & Yes \\
\hline & & 067 & Grant & Low & Yes \\
\hline & & 069 & Gray & $\therefore$ Low & Yes \\
\hline & & 071 & Greeley & Low & Yes \\
\hline & & 073 & Greenwood & Low & Yes \\
\hline & & 075 & Hamilton & Low & Yes \\
\hline & & 077 & Harper & Low & Yes \\
\hline & & 079 & Harvey & Low & Yes \\
\hline & & 081 & Haskell & Low & Yes \\
\hline & & 083 & Hodgeman & Low & Yes \\
\hline & & 085 & Jackson & Moderate & Yes \\
\hline & & 087 & Jefferson & Moderate & Yes \\
\hline & & 089 & Jewell & Low & Yes \\
\hline & & 091 & Johnson & Moderate & Yes \\
\hline & & 093 & Kearny & Low & Yes \\
\hline & & 095 & Kingman & Low & Yes \\
\hline & & 097 & Kiowa & Low & Yes \\
\hline & & 099 & Labette & Low & Yes \\
\hline & & 101 & Lane & Low & Yes \\
\hline & & 103 & Leavenworth & Moderate & Yes \\
\hline & & 105 & Lincoln & Low & Yes \\
\hline & & 107 & Linn & Moderate & Yes \\
\hline & & 109 & Logan & Low & Yes \\
\hline & & 111 & Lyon & Moderate & Yes \\
\hline & & 113 & McPherson & Low & Yes \\
\hline & & 115 & Marion & Low & Yes \\
\hline & & 117 & Marshall & Moderate & Yes \\
\hline & & 119 & Meade & Low & Yes \\
\hline & & 121 & Miami & Moderate & Yes \\
\hline & & 123 & Mitchell & Low & Yes \\
\hline
\end{tabular}




\begin{tabular}{|l|c|c|c|c|c|}
\hline \multicolumn{5}{|c|}{ Table A-1 - Location and Seismicity Data } & Page A-34 \\
\hline \hline State Code & State & County Code & County Name & Seismicity & Av $_{v}<0.15$ \\
\hline
\end{tabular}

\begin{tabular}{|c|c|c|c|c|c|}
\hline 20 & Kansas & 125 & Montgomery & Low & Yes \\
\hline & & 127 & Morris & Moderate & Yes \\
\hline & & 129 & Morton & Low & Yes \\
\hline & & 131 & Nemaha & Moderate & Yes \\
\hline & & 133 & Neosho & Low & Yes \\
\hline & & 135 & Ness & Low & Yes \\
\hline & & 137 & Norton & Low & Yes \\
\hline & & 139 & Osage & Moderate & Yes \\
\hline & & 141 & Osborne & Low & Yes \\
\hline & & 143 & Ottawa & Low & Yes \\
\hline & & 145 & Pawnee & Low & Yes \\
\hline & & 147 & Phillips & Low & Yes \\
\hline & & 149 & Pottawatomie & Moderate & Yes \\
\hline & & 151 & Pratt & Low & Yes \\
\hline & & 153 & Rawlins & Low & Yes \\
\hline & & 155 & Reno & Low & Yes \\
\hline & & 157 & Republic & Low & Yes \\
\hline & & 159 & Rice & Low & Yes \\
\hline & & 161 & Riley & Moderate & Yes \\
\hline & & 163 & Rooks & Low & Yes \\
\hline & & 165 & Rush & Low & Yes \\
\hline & & 167 & Russell & Low & Yes \\
\hline & & 169 & Saline & Low & Yes \\
\hline & & 171 & Scott & Low & Yes \\
\hline & & 173 & Sedgwick & Low & Yes \\
\hline & & 175 & Seward & Low & Yes \\
\hline & & 177 & Shawnee & Moderate & Yes \\
\hline & & 179 & Sheridan & Low & Yes \\
\hline & & 181 & Sherman & Low & Yes \\
\hline & & 183 & Smith & Low & Yes \\
\hline
\end{tabular}


Table A-1 - Location and Seismicity Data

Page A-35

\begin{tabular}{|l|l|l|l|l|l|}
\hline State Code & State & County Code & County Name & Seismicity & $\mathbf{A}_{\mathbf{v}}<0.15$ \\
\hline
\end{tabular}

\begin{tabular}{|c|c|c|c|c|c|}
\hline 20 & Kansas & 185 & Stafford & Low & Yes \\
\hline & & 187 & Stanton & Low & Yes \\
\hline & & 189 & Stevens & Low & Yes \\
\hline & & 191 & Sumner & Low & Yes \\
\hline & & 193 & Thomas & Low & Yes \\
\hline & & 195 & Trego & Low & Yes \\
\hline & & 197 & Wabaunsee & Moderate & Yes \\
\hline & & 199 & Wallace & Low & Yes \\
\hline & & 201 & Washington & Moderate & Yes \\
\hline & & 203 & Wichita & Low & Yes \\
\hline & & 205 & Wilson & Low & Yes \\
\hline & & 207 & Woodson & Low & Yes \\
\hline & & 209 & Wyandotte & Moderate & Yes \\
\hline 21 & \multicolumn{3}{|c|}{ KENTUCKY } & MIXED & MIXED \\
\hline & & 001 & Adair & Low & Yes \\
\hline & & 003 & Allen & Low & Yes \\
\hline & & 005 & Anderson & Low & Yes \\
\hline & & 007 & Ballard & High & No \\
\hline & & 009 & Barren & Low & Yes \\
\hline & & 011 & Bath & Low & Yes \\
\hline & & 013 & Bell & Moderate & Yes \\
\hline & & 015 & Boone & Low & Yes \\
\hline & & 017 & Bourbon & Low & Yes \\
\hline & & 019 & Boyd & Low & Yes \\
\hline & & 021 & Boyle & Low & Yes \\
\hline & & 023 & Bracken & Low & Yes \\
\hline & & 025 & Breathitt & Low & Yes \\
\hline & & 027 & Breckinridge & Low & Yes \\
\hline
\end{tabular}




\begin{tabular}{|l|l|l|c|c|c|}
\hline \multicolumn{5}{|c|}{ Table A-1 - Location and Seismicity Data } & Page A-36 \\
\hline \hline State Code & State & County Code & County Name & Seismicity & Av $<0.15$ \\
\hline
\end{tabular}

\begin{tabular}{|c|c|c|c|c|c|}
\hline 21 & Kentucky & 029 & Bullitt & Low & Yes \\
\hline & & 031 & Butler & Low & Yes \\
\hline & & 033 & Caldwell & Moderate & Yes \\
\hline & & 035 & Calloway & Moderate & Yes \\
\hline & & 037 & Campbell & Low & Yes \\
\hline & & 039 & Carlisle & High & No \\
\hline & & 041 & Carroll & Low & Yes \\
\hline & & 043 & Carter & Low & Yes \\
\hline & & 045 & Casey & Low & Yes \\
\hline & & 047 & Christian & Low & Yes \\
\hline & & 049 & Clark & Low & Yes \\
\hline & & 051 & Clay & Low & Yes \\
\hline & & 053 & Clinton & Low & Yes \\
\hline & & 055 & Crittenden & Moderate & Yes \\
\hline & & 057 & Cumberland & Low & Yes \\
\hline & & 059 & Daviess & Low & Yes \\
\hline & & 061 & Edmonson & Low & Yes \\
\hline & & 063 & Elliott & Low & Yes \\
\hline & & 065 & Estill & Low & Yes \\
\hline & & 067 & Fayette & Low & Yes \\
\hline & & 069 & Fleming & Low & Yes \\
\hline & & 071 & Floyd & Low & Yes \\
\hline & & 073 & Franklin & Low & Yes \\
\hline & & 075 & Fulton & High & No \\
\hline & & 077 & Gallatin & Low & Yes \\
\hline & & 079 & Garrard & Low & Yes \\
\hline & & 081 & Grant & Low & Yes \\
\hline & & 083 & Graves & Moderate & No \\
\hline & & 085 & Grayson & Low & Yes \\
\hline & & 087 & Green & Low & Yes \\
\hline
\end{tabular}




\begin{tabular}{|l|l|l|l|c|c|}
\hline \multicolumn{5}{|c|}{ Table A-1 - Location and Seismicity Data } & Page A-37 \\
\hline State Code & State & County Code & County Name & Seismicity & $A_{v}<0.15$ \\
\hline
\end{tabular}

\begin{tabular}{|c|c|c|c|c|c|}
\hline 21 & Kentucky & 089 & Greenup & Low & Yes \\
\hline & & 091 & Hancock & Low & Yes \\
\hline & & 093 & Hardin & Low & Yes \\
\hline & & 095 & Harlan & Moderate & Yes \\
\hline & & 097 & Harrison & Low & Yes \\
\hline & & 099 & Hart & Low & Yes \\
\hline & & 101 & Henderson & Moderate & Yes \\
\hline & & 103 & Henry & Low & Yes \\
\hline & & 105 & Hickman & High & No \\
\hline & & 107 & Hopkins & Moderate & Yes \\
\hline & & 109 & Jackson & Low & Yes \\
\hline & & 111 & Jefferson & Low & Yes \\
\hline & & 113 & Jessamine & Low & Yes \\
\hline & & 115 & Johnson & Low & Yes \\
\hline & & 117 & Kenton & Low & Yes \\
\hline & & 119 & Knott & Low & Yes \\
\hline & & 121 & Knox & Low & Yes \\
\hline & & 123 & Larue & Low & Yes \\
\hline & & 125 & Laurel & Low & Yes \\
\hline & & 127 & Lawrence & Low & Yes \\
\hline & & 129 & Lee & Low & Yes \\
\hline & & 131 & Leslie & Low & Yes \\
\hline & & 133 & Letcher & Moderate & Yes \\
\hline & & 135 & Lewis & Low & Yes \\
\hline & & 137 & Lincoln & Low & Yes \\
\hline & & 139 & Livingston & Moderate & No \\
\hline & & 141 & Logan & Low & Yes \\
\hline & & 143 & Lyon & Moderate & Yes \\
\hline & & 145 & McCracken & Moderate & No \\
\hline & & 147 & McCreary & Low & Yes \\
\hline
\end{tabular}




\begin{tabular}{|l|c|c|c|c|c|}
\hline \multicolumn{5}{|c|}{ Table A-1 - Location and Seismicity Data } & Page A-38 \\
\hline \hline State Code & State & County Code & County Name & Seismicity & $A_{v}<0.15$ \\
\hline
\end{tabular}

\begin{tabular}{|c|c|c|c|c|c|}
\hline 21 & Kentucky & 149 & McLean & Low & Yes \\
\hline & & 151 & Madison & Low & Yes \\
\hline & & 153 & Magoffin & Low & Yes \\
\hline & & 155 & Marion & Low & Yes \\
\hline & & 157 & Marshall & Moderate & No \\
\hline & & 159 & Martin & Low & Yes \\
\hline & & 161 & Mason & Low & Yes \\
\hline & & 163 & Meade & Low & Yes \\
\hline & & 165 & Menifee & Low & Yes \\
\hline & & 167 & Mercer & Low & Yes \\
\hline & & 169 & Metcalfe & Low & Yes \\
\hline & & 171 & Monroe & Low & Yes \\
\hline & & 173 & Montgomery & Low & Yes \\
\hline & & 175 & Morgan & Low & Yes \\
\hline & & 177 & Muhlenberg & Low & Yes \\
\hline & & 179 & Nelson & Low & Yes \\
\hline & & 181 & Nicholas & Low & Yes \\
\hline & & 183 & Ohio & Low & Yes \\
\hline & & 185 & Oldham & Low & Yes \\
\hline & & 187 & Owen & Low & Yes \\
\hline & & 189 & Owsley & Low & Yes \\
\hline & & 191 & Pendleton & Low & Yes \\
\hline & & 193 & Perry & Low & Yes \\
\hline & & 195 & Pike & Low & Yes \\
\hline & & 197 & Powell & Low & Yes \\
\hline & & 199 & Pulaski & Low & Yes \\
\hline & & 201 & Robertson & Low & Yes \\
\hline & & 203 & Rockcastle & Low & Yes \\
\hline & & 205 & Rowan & Low & Yes \\
\hline & & 207 & Russell & Low & Yes \\
\hline
\end{tabular}




\begin{tabular}{||c|c|c|c|c|c|}
\hline \multicolumn{5}{|c|}{ Table A-1 - Location and Seismicity Data } & Page A-39 \\
\hline \hline State Code & State & County Code & County Name & Seismicity & Av $_{\mathrm{v}}<\mathbf{0 . 1 5}$ \\
\hline
\end{tabular}

\begin{tabular}{|c|c|c|c|c|c|}
\hline 21 & Kentucky & 209 & Scott & Low & Yes \\
\hline & & 211 & Shelby & Low & Yes \\
\hline & & 213 & Simpson & Low & Yes \\
\hline & & 215 & Spencer & Low & Yes \\
\hline & & 217 & Taylor & Low & Yes \\
\hline & & 219 & Todd & Low & Yes \\
\hline & & 221 & Trigg & Moderate & Yes \\
\hline & & 223 & Trimble & Low & Yes \\
\hline & & 225 & Union & Moderate & Yes \\
\hline & & 227 & Warren & Low & Yes \\
\hline & & 229 & Washington & Low & Yes \\
\hline & & 231 & Wayne & Low & Yes \\
\hline & & 233 & Webster & Moderate & Yes \\
\hline & & 235 & Whitley & Low & Yes \\
\hline & & 237 & Wolfe & Low & Yes \\
\hline & & 239 & Woodford & Low & Yes \\
\hline 22 & \multicolumn{3}{|c|}{ LOUISIANA } & ALI LOW & ALL YES \\
\hline & & 001 & Acadia & Low & Yes \\
\hline & & 003 & Allen & Low & Yes \\
\hline & & 005 & Ascension & Low & Yes \\
\hline & & 007 & Assumption & Low & Yes \\
\hline & & 009 & Avoyelles & Low & Yes \\
\hline & & 011 & Beauregard & Low & Yes \\
\hline & & 013 & Bienville & Low & Yes \\
\hline & & 015 & Bossier & Low & Yes \\
\hline & & 017 & Caddo & Low & Yes \\
\hline & & 019 & Calcasieu & Low & Yes \\
\hline & & 021 & Caldwell & Low & Yes \\
\hline
\end{tabular}




\begin{tabular}{|l|c|c|c|c|c|}
\hline \multicolumn{5}{|c|}{ Table A-1 - Location and Seismicity Data } & Page A-40 \\
\hline State Code & State & County Code & County Name & Seismicity & $A_{v}<0.15$ \\
\hline
\end{tabular}

\begin{tabular}{|c|c|c|c|c|c|}
\hline 22 & Louisiana & 023 & Cameron & Low & Yes \\
\hline & & 025 & Catahoula & Low & Yes \\
\hline & & 027 & Claiborne & Low & Yes \\
\hline & & 029 & Concordia & Low & Yes \\
\hline & & 031 & De Soto & Low & Yes \\
\hline & & 033 & East Baton Rouge & Low & Yes \\
\hline & & 035 & East Carroll & Low & Yes \\
\hline & & 037 & East Feliciana & Low & Yes \\
\hline & & 039 & Evangeline & Low & Yes \\
\hline & & 041 & Franklin & Low & Yes \\
\hline & & 043 & Grant & Low & Yes \\
\hline & & 045 & Iberia & Low & Yes \\
\hline & & 047 & Iberville & Low & Yes \\
\hline & & 049 & Jackson & Low & Yes \\
\hline & & 051 & Jefferson & Low & Yes \\
\hline & & 053 & Jefferson Davis & Low & Yes \\
\hline & & 055 & Lafayette & Low & Yes \\
\hline & & 057 & LaFourche & Low & Yes \\
\hline & & 059 & La Salle & Low & Yes \\
\hline & & 061 & Lincoln & Low & Yes \\
\hline & & 063 & Livingston & Low & Yes \\
\hline & & 065 & Madison & Low & Yes \\
\hline & & 067 & Morehouse & Low & Yes \\
\hline & & 069 & Natchitoches & Low & Yes \\
\hline & & 071 & Orleans & Low & Yes \\
\hline & & 073 & Ouachita & Low & Yes \\
\hline & & 075 & Plaquemines & Low & Yes \\
\hline & & 077 & Pointe Coupee & Low & Yes \\
\hline & & 079 & Rapides & Low & Yes \\
\hline & & 081 & Red River & Low & Yes \\
\hline
\end{tabular}




\begin{tabular}{|l|c|c|c|c|c|}
\hline \multicolumn{5}{|c|}{ Table A-1 - Location and Seismicity Data } & Page A-41 \\
\hline \hline State Code & State & County Code & County Name & Seismicity & $A_{v}<0.15$ \\
\hline
\end{tabular}

\begin{tabular}{|c|c|c|c|c|c|}
\hline 22 & Louisiana & 083 & Richland & Low & Yes \\
\hline & & 085 & Sabine & Low & Yes \\
\hline & & 087 & St Bernard & Low & Yes \\
\hline & & 089 & St Charles & Low & Yes \\
\hline & & 091 & St Helena & Low & Yes \\
\hline & & 093 & St James & Low & Yes \\
\hline & & 095 & St John the Baptist & Low & Yes \\
\hline & & 097 & St Landry & Low & Yes \\
\hline & & 099 & St Martin & Low & Yes \\
\hline & & 101 & St Mary & Low & Yes \\
\hline & & 103 & St Tammany & Low & Yes \\
\hline & & 105 & Tangipahoa & Low & Yes \\
\hline & & 107 & Tensas & Low & Yes \\
\hline & & 109 & Terrebonne & Low & Yes \\
\hline & & 111 & Union & Low & Yes \\
\hline & & 113 & Vermilion & Low & Yes \\
\hline & & 115 & Vernon & Low & Yes \\
\hline & & 117 & Washington & Low & Yes \\
\hline & & 119 & Webster & Low & Yes \\
\hline & & 121 & West Baton Rouge & Low & Yes \\
\hline & & 123 & West Carroll & Low & Yes \\
\hline & & 125 & West Feliciana & Low & Yes \\
\hline & & 127 & Winn & Low & Yes \\
\hline 23 & \multicolumn{3}{|c|}{ MAINE } & ALL MOD & ALL YES \\
\hline & & 001 & Androscoggin & Moderate & Yes \\
\hline & & 003 & Aroostook & Moderate & Yes \\
\hline & & 005 & Cumberland & Moderate & Yes \\
\hline & & 007 & Franklin & Moderate & Yes \\
\hline
\end{tabular}




\begin{tabular}{|l|c|c|c|c|c|}
\hline \multicolumn{5}{|c|}{ Table A-1 - Location and Seismicity Data } & Page A-42 \\
\hline \hline State Code & State & County Code & County Name & Seismicity & $\mathbf{A}_{\mathrm{v}}<0.15$ \\
\hline
\end{tabular}

\begin{tabular}{|c|c|c|c|c|c|}
\hline 23 & Maine & 009 & Hancock & Moderate & Yes \\
\hline & & 011 & Kennebec & Moderate & Yes \\
\hline & & 013 & Knox & Moderate & Yes \\
\hline & & 015 & Lincoln & Moderate & Yes \\
\hline & & 017 & Oxford & Moderate & Yes \\
\hline & & 019 & Penobscot & Moderate & Yes \\
\hline & & 021 & Piscataquis & Moderate & Yes \\
\hline & & 023 & Sagadahoc & Moderate & Yes \\
\hline & & 025 & Somerset & Moderate & Yes \\
\hline & & 027 & Waldo & Moderate & Yes \\
\hline & & 029 & Washington & Moderate & Yes \\
\hline & & 031 & York & Moderate & Yes \\
\hline 24 & \multicolumn{3}{|c|}{ MARYLAND } & ALL LOW & ALL YES \\
\hline & & 001 & Allegany & Low & Yes \\
\hline & & 003 & Anne Arundel & Low & Yes \\
\hline & & 005 & Baltimore & Low & Yes \\
\hline & & 009 & Calvert & Low & Yes \\
\hline & & 011 & Caroline & Low & Yes \\
\hline & & 013 & Carroll & Low & Yes \\
\hline & & 015 & Cecil & Low & Yes \\
\hline & & 017 & Charles & Low & Yes \\
\hline & & 019 & Dorchester & Low & Yes \\
\hline & & 021 & Frederick & Low & Yes \\
\hline & & 023 & Garrett & Low & Yes \\
\hline & & 025 & Harford & Low & Yes \\
\hline & & 027 & Howard & Low & Yes \\
\hline & & 029 & Kent & Low & Yes \\
\hline & & 031 & Montgomery & Low & Yes \\
\hline
\end{tabular}




\begin{tabular}{|l|c|c|c|c|c|}
\hline \multicolumn{5}{|c|}{ Table A-1 - Location and Seismicity Data } & Page A-43 \\
\hline \hline State Code & State & County Code & County Name & Seismicity & $\mathbf{A}_{\mathrm{v}}<\mathbf{0 . 1 5}$ \\
\hline
\end{tabular}

\begin{tabular}{|c|c|c|c|c|c|}
\hline 24 & Maryland & 033 & Prince George's & Low & Yes \\
\hline & & 035 & Queen Anne's & Low & Yes \\
\hline & & 037 & St. Mary's & Low & Yes \\
\hline & & 039 & Somerset & Low & Yes \\
\hline & & 041 & Talbot & Low & Yes \\
\hline & & 043 & Washington & Low & Yes \\
\hline & & 045 & Wicomico & Low & Yes \\
\hline & & 047 & Worcester & Low & Yes \\
\hline & & 510 & City of Baltimore & Low & Yes \\
\hline 25 & \multicolumn{3}{|c|}{ MASSACHUSETTS } & ALL MOD & ALL YES \\
\hline & & 001 & Barnstable & Moderate & Yes \\
\hline & & 003 & Berkshire & Moderate & Yes \\
\hline & & 005 & Bristol & Moderate & Yes \\
\hline & & 007 & Dukes & Moderate & Yes \\
\hline & & 009 & Essex & Moderate & Yes \\
\hline & & 011 & Franklin & Moderate & Yes \\
\hline & & 013 & Hampden & Moderate & Yes \\
\hline & & 015 & Hampshire & Moderate & Yes \\
\hline & & 017 & Middlesex & Moderate & Yes \\
\hline & & 019 & Nantucket & Moderate & Yes \\
\hline & & 021 & Norfolk & Moderate & Yes \\
\hline & & 023 & Plymouth & Moderate & Yes \\
\hline & & 025 & Suffolk & Moderate & Yes \\
\hline & & 027 & Worchester & Moderate & Yes \\
\hline \multirow[t]{3}{*}{26} & \multicolumn{3}{|c|}{ MICHIGAN } & ALL LOW & ALL YES \\
\hline & & 001 & Alcona & Low & Yes \\
\hline & & 003 & Alger & Low & Yes \\
\hline
\end{tabular}




\begin{tabular}{|l|c|c|c|c|c|}
\hline \multicolumn{5}{|c|}{ Table A-1 - Location and Seismicity Data } & Page A-44 \\
\hline \hline State Code & State & County Code & County Name & Seismicity & $A_{v}<0.15$ \\
\hline
\end{tabular}

\begin{tabular}{|c|c|c|c|c|c|}
\hline 26 & Michigan & 005 & Allegan & Low & Yes \\
\hline & & 007 & Alpena & Low & Yes \\
\hline & & 009 & Antrim & Low & Yes \\
\hline & & 011 & Arenac & Low & Yes \\
\hline & & 013 & Baraga & Low & Yes \\
\hline & & 015 & Barry & Low & Yes \\
\hline & & 017 & Bay & Low & Yes \\
\hline & & 019 & Benzie & Low & Yes \\
\hline & & 021 & Berrien & Low & Yes \\
\hline & & 023 & Branch & Low & Yes \\
\hline & & 025 & Calhoun & Low & Yes \\
\hline & & 027 & Cass & Low & Yes \\
\hline & & 029 & Charlevoix & Low & Yes \\
\hline & & 031 & Cheboygan & Low & Yes \\
\hline & & 033 & Chippewa & Low & Yes \\
\hline & & 035 & Clare & Low & Yes \\
\hline & & 037 & Clinton & Low & Yes \\
\hline & & 039 & Crawford & Low & Yes \\
\hline & & 041 & Delta & Low & Yes \\
\hline & & 043 & Dickinson & Low & Yes \\
\hline & & 045 & Eaton & Low & Yes \\
\hline & & 047 & Emmet & Low & Yes \\
\hline & & 049 & Genesee & Low & Yes \\
\hline & & 051 & Gladwin & Low & Yes \\
\hline & & 053 & Gogebic & Low & Yes \\
\hline & & 055 & Grand Traverse & Low & Yes \\
\hline & & 057 & Gratiot & Low & Yes \\
\hline & & 059 & Hillsdale & Low & Yes \\
\hline & & 061 & Houghton & Low & Yes \\
\hline & & 063 & Huron & Low & Yes \\
\hline
\end{tabular}




\begin{tabular}{|l|l|l|c|c|c|}
\hline \multicolumn{5}{|c|}{ Table A-1 - Location and Seismicity Data } & Page A-45 \\
\hline State Code & State & County Code & County Name & Seismicity & Av $_{\mathrm{v}}<0.15$ \\
\hline
\end{tabular}

\begin{tabular}{|c|c|c|c|c|c|}
\hline 26 & Michigan & 065 & Ingham & Low & Yes \\
\hline & & 067 & Ionia & Low & Yes \\
\hline & & 069 & Iosco & Low & Yes \\
\hline & & 071 & Iron & Low & Yes \\
\hline & & 073 & Isabella & Low & Yes \\
\hline & & 075 & Jackson & Low & Yes \\
\hline & & 077 & Kalamazoo & Low & Yes \\
\hline & & 079 & Kalkaska & Low & Yes \\
\hline & & 081 & Kent & Low & Yes \\
\hline & & 083 & Keweenaw & Low & Yes \\
\hline & & 085 & Lake & Low & Yes \\
\hline & & 087 & Lapeer & Low & Yes \\
\hline & & 089 & Leelanau & Low & Yes \\
\hline & & 091 & Lenawee & Low & Yes \\
\hline & & 093 & Livingston & Low & Yes \\
\hline & & 095 & Luce & Low & Yes \\
\hline & & 097 & Mackinac & Low & Yes \\
\hline & & 099 & Macomb & Low & Yes \\
\hline & & 101 & Manistee & Low & Yes \\
\hline & & 103 & Marquette & Low & Yes \\
\hline & & 105 & Mason & Low & Yes \\
\hline & & 107 & Mecosta & Low & Yes \\
\hline & & 109 & Menominee & Low & Yes \\
\hline & & 111 & Midland & Low & Yes \\
\hline & & 113 & Missaukee & Low & Yes \\
\hline & & 115 & Monroe & Low & Yes \\
\hline & & 117 & Montcalm & Low & Yes \\
\hline & & 119 & Montmorency & Low & Yes \\
\hline & & 121 & Muskegon & Low & Yes \\
\hline & & 123 & Newaygo & Low & Yes \\
\hline
\end{tabular}




\begin{tabular}{|l|c|c|c|c|c|}
\hline \multicolumn{5}{|c|}{ Table A-1 - Location and Seismicity Data } & Page A-46 \\
\hline \hline State Code & State & County Code & County Name & Seismicity & A. $<0.15$ \\
\hline
\end{tabular}

\begin{tabular}{|c|c|c|c|c|c|}
\hline 26 & Michigan & 125 & Oakland & Low & Yes \\
\hline & & 127 & Oceana & Low & Yes \\
\hline & & 129 & Ogemaw & Low & Yes \\
\hline & & 131 & Ontonagon & Low & Yes \\
\hline & & 133 & Osceola & Low & Yes \\
\hline & & 135 & Oscoda & Low & Yes \\
\hline & & 137 & Otsego & Low & Yes \\
\hline & & 139 & Ottawa & Low & Yes \\
\hline & & 141 & Presque Isle & Low & Yes \\
\hline & & 143 & Roscommon & Low & Yes \\
\hline & & 145 & Saginaw & Low & Yes \\
\hline & & 147 & St Clair & Low & Yes \\
\hline & & 149 & St Joseph & Low & Yes \\
\hline & & 151 & Sanilac & Low & Yes \\
\hline & & 153 & Schoolcraft & Low & Yes \\
\hline & & 155 & Shiawassee & Low & Yes \\
\hline & & 157 & Tuscola & Low & Yes \\
\hline & & 159 & Van Buren & Low & Yes \\
\hline & & 161 & Washtenaw & Low & Yes \\
\hline & & 163 & Wayne & Low & Yes \\
\hline & & 165 & Wexford & Low & Yes \\
\hline 27 & \multicolumn{3}{|c|}{ MINNESOTA } & ALL LOW & ALL YES \\
\hline & & 001 & Aitkin & Low & Yes \\
\hline & & 003 & Anoka & Low & Yes \\
\hline & & 005 & Becker & Low & Yes \\
\hline & & 007 & Beltrami & Low & Yes \\
\hline & & 009 & Benton & Low & Yes \\
\hline & & 011 & Big Stone & Low & Yes \\
\hline
\end{tabular}




\begin{tabular}{|l|l|l|l|l|c|}
\hline \multicolumn{5}{|c|}{ Table A-1 - Location and Seismicity Data } & Page A-47 \\
\hline \hline State Code & State & County Code & County Name & Seismicity & $A_{v}<0.15$ \\
\hline
\end{tabular}

\begin{tabular}{|c|c|c|c|c|c|}
\hline 27 & Minnesota & 013 & Blue Earth & Low & Yes \\
\hline & & 015 & Brown & Low & Yes \\
\hline & & 017 & Carlton & Low & Yes \\
\hline & & 019 & Carver & Low & Yes \\
\hline & & 021 & Cass & Low & Yes \\
\hline & & 023 & Chippewa & Low & Yes \\
\hline & & 025 & Chisago & Low & Yes \\
\hline & & 027 & Clay & Low & Yes \\
\hline & & 029 & Clearwater & Low & Yes \\
\hline & & 031 & Cook & Low & Yes \\
\hline & & 033 & Cottonwood & Low & Yes \\
\hline & & 035 & Crow Wing & Low & Yes \\
\hline & & 037 & Dakota & Low & Yes \\
\hline & & 039 & Dodge & Low & Yes \\
\hline & & 041 & Douglas & Low & Yes \\
\hline & & 043 & Fairbault & Low & Yes \\
\hline & & 045 & Fillmore & Low & Yes \\
\hline & & 047 & Freeborn & Low & Yes \\
\hline & & 049 & Goodhue & Low & Yes \\
\hline & & 051 & Grant & Low & Yes \\
\hline & & 053 & Hennepin & Low & Yes \\
\hline & & 055 & Houston & Low & Yes \\
\hline & & 057 & Hubbard & Low & Yes \\
\hline & & 059 & Isanti & Low & Yes \\
\hline & & 061 & Itasca & Low & Yes \\
\hline & & 063 & Jackson & Low & Yes \\
\hline & & 065 & Kanabec & Low & Yes \\
\hline & & 067 & Kandiyohi & Low & Yes \\
\hline & & 069 & Kittson & Low & Yes \\
\hline & & 071 & Koochiching & Low & Yes \\
\hline
\end{tabular}




\begin{tabular}{|l|c|c|c|c|c|}
\hline \multicolumn{5}{|c|}{ Table A-1 - Location and Seismicity Data } & Page A-48 \\
\hline \hline State Code & State & County Code & County Name & Seismicity & $A_{v}<0.15$ \\
\hline
\end{tabular}

\begin{tabular}{|c|c|c|c|c|c|}
\hline 27 & Minnesota & 073 & Lac Qui Parle & Low & Yes \\
\hline & & 075 & Lake & Low & Yes \\
\hline & & 077 & Lake of the Woods & Low & Yes \\
\hline & & 079 & Le Sueur & Low & Yes \\
\hline & & 081 & Lincoln & Low & Yes \\
\hline & & 083 & Lyon & Low & Yes \\
\hline & & 085 & McLeod & Low & Yes \\
\hline & & 087 & Mahnomen & Low & Yes \\
\hline & & 089 & Marshall & Low & Yes \\
\hline & & 091 & Martin & Low & Yes \\
\hline & & 093 & Meeker & Low & Yes \\
\hline & & 095 & Mille Lacs & Low & Yes \\
\hline & & 097 & Morrison & Low & Yes \\
\hline & & 099 & Mower & Low & Yes \\
\hline & & 101 & Murray & Low & Yes \\
\hline & & 103 & Nicollet & Low & Yes \\
\hline & & 105 & Nobles & Low & Yes \\
\hline & & 107 & Norman & Low & Yes \\
\hline & & 109 & Olmsted & Low & Yes \\
\hline & & 111 & Otter Tail & Low & Yes \\
\hline & & 113 & Pennington & Low & Yes \\
\hline & & 115 & Pine & Low & Yes \\
\hline & & 117 & Pipestone & Low & Yes \\
\hline & & 119 & Polk & Low & Yes \\
\hline & & 121 & Pope & Low & Yes \\
\hline & & 123 & Ramsey & Low & Yes \\
\hline & & 125 & Red Lake & Low & Yes \\
\hline & & 127 & Redwood & Low & Yes \\
\hline & & 129 & Renville & Low & Yes \\
\hline & & 131 & Rice & Low & Yes \\
\hline
\end{tabular}




\begin{tabular}{|l|l|l|l|l|c|}
\hline \multicolumn{5}{|c|}{ Table A-1 - Location and Seismicity Data } & Page A-49 \\
\hline \hline State Code & State & County Code & County Name & Seismicity & Av $_{\mathrm{v}}<0.15$ \\
\hline
\end{tabular}

\begin{tabular}{|c|c|c|c|c|c|}
\hline 27 & Minnesota & 133 & Rock & Low & Yes \\
\hline & & 135 & Roseau & Low & Yes \\
\hline & & 137 & St Louis & - Low & Yes \\
\hline & & 139 & Scott & Low & Yes \\
\hline & & 141 & Sherburne & Low & Yes \\
\hline & & 143 & Sibley & Low & Yes \\
\hline & & 145 & Stearns & Low & Yes \\
\hline & & 147 & Steele & Low & Yes \\
\hline & & 149 & Stevens & Low & Yes \\
\hline & & 151 & Swift & Low & Yes \\
\hline & & 153 & Todd & Low & Yes \\
\hline & & 155 & Traverse & Low & Yes \\
\hline & & 157 & Wabasha & Low & Yes \\
\hline & & 159 & Wadena & Low & Yes \\
\hline & & 161 & Waseca & Low & Yes \\
\hline & & 163 & Washington & Low & Yes \\
\hline & & 165 & Watonwan & Low & Yes \\
\hline & & 167 & Wilkin & Low & Yes \\
\hline & & 169 & Winona & Low & Yes \\
\hline & & 171 & Wright & Low & Yes \\
\hline & & 173 & Yellow Medicine & Low & Yes \\
\hline 28 & \multicolumn{3}{|c|}{ MISSISSIPPI } & MIXED & MIXED \\
\hline & & 001 & Adams & Low & Yes \\
\hline & & 003 & Alcorn & Low & Yes \\
\hline & & 005 & Amite & Low & Yes \\
\hline & & 007 & Attala & Low & Yes \\
\hline & & 009 & Benton & Moderate & Yes \\
\hline & & 011 & Bolivar & Moderate & Yes \\
\hline
\end{tabular}




\begin{tabular}{|l|c|c|c|c|c|}
\hline \multicolumn{5}{|c|}{ Table A-1 - Location and Seismicity Data } & Page A-50 \\
\hline \hline State Code & State & County Code & County Name & Seismicity & A $_{1}<0.15$ \\
\hline
\end{tabular}

\begin{tabular}{|c|c|c|c|c|c|}
\hline 28 & Mississippi & 013 & Calhoun & Low & Yes \\
\hline & & 015 & Carroll & Low & Yes \\
\hline & & 017 & Chicksaw & Low & Yes \\
\hline & & 019 & Choctaw & Low & Yes \\
\hline & & 021 & Claiborne & Low & Yes \\
\hline & & 023 & Clarke & Low & Yes \\
\hline & & 025 & Clay & Low & Yes \\
\hline & & 027 & Coaboma & Moderate & Yes \\
\hline & & 029 & Copiah & Low & Yes \\
\hline & & 031 & Covington & Low & Yes \\
\hline & & 033 & De Soto & Moderate & No \\
\hline & & 035 & Forrest & Low & Yes \\
\hline & & 037 & Franklin & Low & Yes \\
\hline & & 039 & George & Low & Yes \\
\hline & & 041 & Greene & Low & Yes \\
\hline & & 043 & Grenada & Low & Yes \\
\hline & & 045 & Hancock & Low & Yes \\
\hline & & 047 & Harrison & Low & Yes \\
\hline & & 049 & Hinds & Low & Yes \\
\hline & & 051 & Holmes & Low & Yes \\
\hline & & 053 & Humphreys & Low & Yes \\
\hline & & 055 & Issaquena & Low & Yes \\
\hline & & 057 & Itawamba & Low & Yes \\
\hline & & 059 & Jackson & Low & Yes \\
\hline & & 061 & Jasper & Low & Yes \\
\hline & & 063 & Jefferson & Low & Yes \\
\hline & & 065 & Jefferson Davis & Low & Yes \\
\hline & & 067 & Jones & Low & Yes \\
\hline & & 069 & Kemper & Low & Yes \\
\hline & & 071 & Lafayette & Moderate & Yes \\
\hline
\end{tabular}


Table A-1 - Location and Seismicity Data

Page A-51

\begin{tabular}{|l|l|l|l|l|l|}
\hline State Code & State & County Code & County Name & Seismicity & $\mathbf{A}_{\mathbf{v}}<0.15$ \\
\hline
\end{tabular}

\begin{tabular}{|c|c|c|c|c|c|}
\hline 28 & Mississippi & 073 & Lamar & Low & Yes \\
\hline & & 075 & Lauderdale & Low & Yes \\
\hline & & 077 & Lawrence & Low & Yes \\
\hline & & 079 & Leake & Low & Yes \\
\hline & & 081 & Lee & Low & Yes \\
\hline & & 083 & Leflore & Low & Yes \\
\hline & & 085 & Lincoln & Low & Yes \\
\hline & & 087 & Lowndes & Low & Yes \\
\hline & & 089 & Madison & Low & Yes \\
\hline & & 091 & Marion & Low & Yes \\
\hline & & 093 & Marshall & Moderate & No \\
\hline & & 095 & Monroe & Low & Yes \\
\hline & & 097 & Montgomery & Low & Yes \\
\hline & & 099 & Neshoba & Low & Yes \\
\hline & & 101 & Newton & Low & Yes \\
\hline & & 103 & Noxubee & Low & Yes \\
\hline & & 105 & Oktibbeha & Low & Yes \\
\hline & & 107 & Panola & Moderate & Yes \\
\hline & & 109 & Pearl River & Low & Yes \\
\hline & & 111 & Perry & Low & Yes \\
\hline & & 113 & Pike & Low & Yes \\
\hline & & 115 & Pontotoc & Low & Yes \\
\hline & & 117 & Prentiss & Low & Yes \\
\hline & & 119 & Quitman & Moderate & Yes \\
\hline & & 121 & Rankin & Low & Yes \\
\hline & & 123 & Scott & Low & Yes \\
\hline & & 125 & Sharkey & Low & Yes \\
\hline & & 127 & Simpson & Low & Yes \\
\hline & & 129 & Smith & Low & Yes \\
\hline & & 131 & Stone & Low & Yes \\
\hline
\end{tabular}




\begin{tabular}{|l|c|c|c|c|c|}
\hline \multicolumn{5}{|c|}{ Table A-1 - Location and Seismicity Data } & Page A-52 \\
\hline State Code & State & County Code & County Name & Seismicity & $\mathbf{A}_{\mathrm{v}}<0.15$ \\
\hline
\end{tabular}

\begin{tabular}{|c|c|c|c|c|c|}
\hline 28 & Mississippi & 133 & Sunflower & Low & Yes \\
\hline & & 135 & Tallahatchie & Low & Yes \\
\hline & & 137 & Tate & Moderate & No \\
\hline & & 139 & Tippah & Moderate & Yes \\
\hline & & 143 & Tunica & Moderate & No \\
\hline & & 145 & Union & Moderate & Yes \\
\hline & & 147 & Walthall & Low & Yes \\
\hline & & 149 & Warren & Low & Yes \\
\hline & & 151 & Washington & Low & Yes \\
\hline & & 153 & Wayne & Low & Yes \\
\hline & & 155 & Webster & Low & Yes \\
\hline & & 157 & Wilkinson & Low & Yes \\
\hline & & 159 & Winston & Low & Yes \\
\hline & & 161 & Yalobusha & Low & Yes \\
\hline & & 163 & Yazoo & Low & Yes \\
\hline 29 & \multicolumn{3}{|c|}{ MISSOURI } & MIXED & MIXED \\
\hline & & 001 & Adair & Low & Yes \\
\hline & & 003 & Andrew & Moderate & Yes \\
\hline & & 005 & Atchison & Moderate & Yes \\
\hline & & 007 & Audrain & Low & Yes \\
\hline & & 009 & Barry & Low & Yes \\
\hline & & 011 & Barton & Low & Yes \\
\hline & & 013 & Bates & Low & Yes \\
\hline & & 015 & Benton & Low & Yes \\
\hline & & 017 & Bollinger & High & No \\
\hline & & 019 & Boone & Low & Yes \\
\hline & & 021 & Buchanan & Moderate & Yes \\
\hline & & 023 & Butler & High & No \\
\hline
\end{tabular}




\begin{tabular}{|l|c|c|c|c|c|}
\hline \multicolumn{5}{|c|}{ Table A-1 - Location and Seismicity Data } & Page A-53 \\
\hline \hline State Code & State & County Code & County Name & Seismicity & $A_{v}<0.15$ \\
\hline
\end{tabular}

\begin{tabular}{|c|c|c|c|c|c|}
\hline 29 & Missouri & 025 & Caldwell & Low & Yes \\
\hline & & 027 & Callaway & Low & Yes \\
\hline & & 029 & Camden & Low & Yes \\
\hline & & 031 & Cape Girardeau & High & No \\
\hline & & 033 & Carroll & Low & Yes \\
\hline & & 035 & Carter & Moderate & No \\
\hline & & 037 & Cass & Moderate & Yes \\
\hline & & 039 & Cedar & Low & Yes \\
\hline & & 041 & Chariton & Low & Yes \\
\hline & & 043 & Christian & Low & Yes \\
\hline & & 045 & Clark & Low & Yes \\
\hline & & 047 & Clay & Moderate & Yes \\
\hline & & 049 & Clinton & Moderate & Yes \\
\hline & & 051 & Cole & Low & Yes \\
\hline & & 053 & Cooper & Low & Yes \\
\hline & & 055 & Crawford & Moderate & Yes \\
\hline & & 057 & Dade & Low & Yes \\
\hline & & 059 & Dallas & Low & Yes \\
\hline & & 061 & Daviess & Low & Yes \\
\hline & & 063 & De Kalb & Low & Yes \\
\hline & & 065 & Dent & Moderate & Yes \\
\hline & & 067 & Douglas & Moderate & Yes \\
\hline & & 069 & Dunklin & High & No \\
\hline & & 071 & Franklin & Moderate & Yes \\
\hline & & 073 & Gasconade & Low & Yes \\
\hline & & 075 & Gentry & Low & Yes \\
\hline & & 077 & Greene & Low & Yes \\
\hline & & 079 & Grundy & Low & Yes \\
\hline & & 081 & Harrison & Low & Yes \\
\hline & & 083 & Henry & Low & Yes \\
\hline
\end{tabular}


Table A-1 - Location and Seismicity Data

Page A-54

\begin{tabular}{|l|l|l|l|l|l|}
\hline State Code & State & County Code & County Name & Seismicity & $A_{v}<0.15$ \\
\hline
\end{tabular}

\begin{tabular}{|c|c|c|c|c|c|}
\hline 29 & Missouri & 085 & Hickory & Low & Yes \\
\hline & & 087 & Holt & Moderate & Yes \\
\hline & & 089 & Howard & Low & Yes \\
\hline & & 091 & Howell & Moderate & Yes \\
\hline & & 093 & Iron & Moderate & No \\
\hline & & 095 & Jackson & Moderate & Yes \\
\hline & & 097 & Jasper & Low & Yes \\
\hline & & 099 & Jefferson & Moderate & Yes \\
\hline & & 101 & Johnson & Low & Yes \\
\hline & & 103 & Knox & Low & Yes \\
\hline & & 105 & Laclede & Low & Yes \\
\hline & & 107 & Lafayette & Low & Yes \\
\hline & & 109 & Lawrence & Low & Yes \\
\hline & & 111 & Lewis & Low & Yes \\
\hline & & 113 & Lincoln & Low & Yes \\
\hline & & 115 & Linn & Low & Yes \\
\hline & & 117 & Livingston & Low & Yes \\
\hline & & 119 & McDonald & Low & Yes \\
\hline & & 121 & Macon & Low & Yes \\
\hline & & 123 & Madison & High & No \\
\hline & & 125 & Maries & Low & Yes \\
\hline & & 127 & Marion & Low & Yes \\
\hline & & 129 & Mercer & Low & Yes \\
\hline & & 131 & Miller & Low & Yes \\
\hline & & 133 & Mississippi & High & No \\
\hline & & 135 & Moniteau & Low & Yes \\
\hline & & 137 & Monroe & Low & Yes \\
\hline & & 139 & Montgomery & Low & Yes \\
\hline & & 141 & Morgan & Low & Yes \\
\hline & & 143 & New Madrid & High & No \\
\hline
\end{tabular}


Table A-1 - Location and Seismicity Data

Page A-55

State Code

State

County Code

County Name

Seismicity $\quad A_{v}<0.15$

\begin{tabular}{|c|c|c|c|c|c|}
\hline 29 & Missouri & 145 & Newton & Low & Yes \\
\hline & & 147 & Nodaway & Moderate & Yes \\
\hline & & 149 & Oregon & Moderate & No \\
\hline & & 151 & Osage & Low & Yes \\
\hline & & 153 & Ozark & Moderate & Yes \\
\hline & & 155 & Pemiscot & High & No \\
\hline & & 157 & Perry & Moderate & No \\
\hline & & 159 & Pettis & Low & Yes \\
\hline & & 161 & Phelps & Low & Yes \\
\hline & & 163 & Pike & Low & Yes \\
\hline & & 165 & Platte & Moderate & Yes \\
\hline & & 167 & Polk & Low & Yes \\
\hline & & 169 & Pulaski & Low & Yes \\
\hline & & 171 & Putnam & Low & Yes \\
\hline & & 173 & Ralls & Low & Yes \\
\hline & & 175 & Randolph & Low & Yes \\
\hline & & 177 & Ray & Low & Yes \\
\hline & & 179 & Reynolds & Moderate & No \\
\hline & & 181 & Ripley & High & No \\
\hline & & 183 & St Charles & Moderate & Yes \\
\hline & & 185 & St Clair & Low & Yes \\
\hline & & 186 & Ste Genevieve & Moderate & No \\
\hline & & 187 & St Francois & Moderate & No \\
\hline & & 189 & St Louis & Moderate & Yes \\
\hline & & 510 & St Louis City & Moderate & Yes \\
\hline & & 195 & Saline & Low & Yes \\
\hline & & 197 & Schuyler & Low & Yes \\
\hline & & 199 & Scotiand & Low & Yes \\
\hline & & 201 & Scott & High & No \\
\hline & & 203 & Shannon & Moderate & Yes \\
\hline
\end{tabular}




\begin{tabular}{|l|c|c|c|c|c|}
\hline \multicolumn{5}{|c|}{ Table A-1 - Location and Seismicity Data } & Page A-56 \\
\hline State Code & State & County Code & County Name & Seismicity & $A_{\mathrm{v}}<0.15$ \\
\hline
\end{tabular}

\begin{tabular}{|c|c|c|c|c|c|}
\hline 29 & Missouri & 205 & Shelby & Low & Yes \\
\hline & & 207 & Stoddard & High & No \\
\hline & & 209 & Stone & Low & Yes \\
\hline & & 211 & Sullivan & Low & Yes \\
\hline & & 213 & Taney & Low & Yes \\
\hline & & 215 & Texas & Moderate & Yes \\
\hline & & 217 & Vernon & Low & Yes \\
\hline & & 219 & Warren & Low & Yes \\
\hline & & 221 & Washington & Moderate & Yes \\
\hline & & 223 & Wayne & High & No \\
\hline & & 225 & Webster & Moderate & Yes \\
\hline & & 227 & Worth & Moderate & Yes \\
\hline & & 229 & Wright & Moderate & Yes \\
\hline 30 & \multicolumn{3}{|c|}{ MONTANA } & MIXED & MIXED \\
\hline & & 001 & Beaverhead & High & No \\
\hline & & 003 & Big Horn & Moderate & Yes \\
\hline & & 005 & Blaine & Low & Yes \\
\hline & & 007 & Broadwater & High & No \\
\hline & & 009 & Carbon & Moderate & No \\
\hline & & 011 & Carter & Low & Yes \\
\hline & & 013 & Cascade & Moderate & Yes \\
\hline & & 015 & Chouteau & Low & Yes \\
\hline & & 017 & Custer & Low & Yes \\
\hline & & 019 & Daniels & Low & Yes \\
\hline & & 021 & Dawson & Low & Yes \\
\hline & & 023 & Deer Lodge & Moderate & No \\
\hline & & 025 & Fallon & Low & Yes \\
\hline & & 027 & Fergus & Moderate & Yes \\
\hline
\end{tabular}


Table A-1 - Location and Seismicity Data

Page A-57

\begin{tabular}{|l|l|l|l|l|l|}
\hline State Code & State & County Code & County Name & Seismicity & $A_{\mathrm{v}}<0.15$ \\
\hline
\end{tabular}

\begin{tabular}{|c|c|c|c|c|c|}
\hline 30 & Montana & 029 & Flathead & Moderate & Yes \\
\hline & & 031 & Gallatin & High & No \\
\hline & & 033 & Garfield & Low & Yes \\
\hline & & 035 & Glacier & Low & Yes \\
\hline & & 037 & Golden Valley & Moderate & Yes \\
\hline & & 039 & Granite & Moderate & No \\
\hline & & 041 & Hill & Low & Yes \\
\hline & & 043 & Jefferson & High & No \\
\hline & & 045 & Judith Basin & Moderate & Yes \\
\hline & & 047 & Lake & Moderate & Yes \\
\hline & & 049 & Lewis and Clark & Moderate & No \\
\hline & & 051 & Liberty & Low & Yes \\
\hline & & 053 & Lincoln & Low & Yes \\
\hline & & 055 & McCone & Low & Yes \\
\hline & & 057 & Madison & High & No \\
\hline & & 059 & Meagher & Moderate & No \\
\hline & & 061 & Mineral & Moderate & Yes \\
\hline & & 063 & Missoula & Moderate & No \\
\hline & & 065 & Musselshell & Moderate & Yes \\
\hline & & 067 & Park & High & No \\
\hline & & 069 & Petroleum & Low & Yes \\
\hline & & 071 & Phillips & Low & Yes \\
\hline & & 073 & Pondera & Moderate & Yes \\
\hline & & 075 & Powder River & Low & Yes \\
\hline & & 077 & Powell & Moderate & No \\
\hline & & 079 & Prairie & Low & Yes \\
\hline & & 081 & Ravalli & Moderate & No \\
\hline & & 083 & Richland & Low & Yes \\
\hline & & 085 & Roosevelt & Low & Yes \\
\hline & & 087 & Rosebud & Low & Yes \\
\hline
\end{tabular}




\begin{tabular}{|l|c|c|c|c|c|}
\hline \multicolumn{5}{|c|}{ Table A-1 - Location and Seismicity Data } & Page A-58 \\
\hline \hline State Code & State & County Code & County Name & Seismicity & $\mathbf{A}_{\mathrm{v}}<0.15$ \\
\hline
\end{tabular}

\begin{tabular}{|c|c|c|c|c|c|}
\hline 30 & Montana & 089 & Sanders & Moderate & Yes \\
\hline & & 091 & Sheridan & Low & Yes \\
\hline & & 093 & Silver Bow & High & No \\
\hline & & 095 & Stillwater & High & No \\
\hline & & 097 & Sweet Grass & High & No \\
\hline & & 099 & Teton & Moderate & Yes \\
\hline & & 101 & Toole & Low & Yes \\
\hline & & 103 & Treasure & Low & Yes \\
\hline & & 105 & Valley & Low & Yes \\
\hline & & 107 & Wheatland & Moderate & No \\
\hline & & 109 & Wibaux & Low & Yes \\
\hline & & 111 & Yellowstone & Moderate & Yes \\
\hline & & 113 & Yellowstone National Park & High & No \\
\hline 31 & \multicolumn{3}{|c|}{ NEBRASKA } & MIXED & ALL YES \\
\hline & & 001 & Adams & Low & Yes \\
\hline & & 003 & Antelope & Low & Yes \\
\hline & & 005 & Arthur & Low & Yes \\
\hline & & 007 & Banner & Low & Yes \\
\hline & & 009 & Blaine & Low & Yes \\
\hline & & 011 & Boone & Low & Yes \\
\hline & & 013 & Box Butte & Low & Yes \\
\hline & & 015 & Boyd & Low & Yes \\
\hline & & 017 & Brown & Low & Yes \\
\hline & & 019 & Buffalo & Low & Yes \\
\hline & & 021 & Burt & Low & Yes \\
\hline & & 023 & Butler & Low & Yes \\
\hline & & 025 & Cass & Moderate & Yes \\
\hline & & 027 & Cedar & Low & Yes \\
\hline
\end{tabular}


Table A-1 - Location and Seismicity Data

Page A-59

\begin{tabular}{|l|l|l|l|l|l|}
\hline \hline State Code & State & County Code & County Name & Seismicity & $A_{v}<0.15$ \\
\hline
\end{tabular}

\begin{tabular}{|c|c|c|c|c|c|}
\hline 31 & Nebraska & 029 & Chase & Low & Yes \\
\hline & & 031 & Cherry & Low & Yes \\
\hline & & 033 & Cheyenne & Low & Yes \\
\hline & & 035 & Clay & Low & Yes \\
\hline & & 037 & Colfax & Low & Yes \\
\hline & & 039 & Cuming & Low & Yes \\
\hline & & 041 & Custer & Low & Yes \\
\hline & & 043 & Dakota & Low & Yes \\
\hline & & 045 & Dawes & Low & Yes \\
\hline & & 047 & Dawson & Low & Yes \\
\hline & & 049 & Deuel & Low & Yes \\
\hline & & 051 & Dixon & Low & Yes \\
\hline & & 053 & Dodge & Low & Yes \\
\hline & & 055 & Douglas & Low & Yes \\
\hline & & 057 & Dundy & Low & Yes \\
\hline & & 059 & Fillmore & Low & Yes \\
\hline & & 061 & Franklin & Low & Yes \\
\hline & & 063 & Frontier & Low & Yes \\
\hline & & 065 & Furnas & Low & Yes \\
\hline & & 067 & Gage & Moderate & Yes \\
\hline & & 069 & Garden & Low & Yes \\
\hline & & 071 & Garfield & Low & Yes \\
\hline & & 073 & Gosper & Low & Yes \\
\hline & & 075 & Grant & Low & Yes \\
\hline & & 077 & Greeley & Low & Yes \\
\hline & & 079 & Hall & Low & Yes \\
\hline & & 081 & Hamilton & Low & Yes \\
\hline & & 083 & Harlan & Low & Yes \\
\hline & & 085 & Hayes & Low & Yes \\
\hline & & 087 & Hitchcock & Low & Yes \\
\hline
\end{tabular}


Table A-1 - Location and Seismicity Data

Page A-60

\begin{tabular}{|l|l|l|l|l|l|}
\hline \hline State Code & State & County Code & County Name & Seismicity & $A_{r}<0.15$ \\
\hline
\end{tabular}

\begin{tabular}{|c|c|c|c|c|c|}
\hline 31 & Nebraska & 089 & Holt & Low & Yes \\
\hline & & 091 & Hooker & Low & Yes \\
\hline & & 093 & Howard & Low & Yes \\
\hline & & 095 & Jefferson & Moderate & Yes \\
\hline & & 097 & Johnson & Moderate & Yes \\
\hline & & 099 & Keamey & Low & Yes \\
\hline & & 101 & Keith & Low & Yes \\
\hline & & 103 & Keya Paha & Low & Yes \\
\hline & & 105 & Kimball & Low & Yes \\
\hline & & 107 & Knox & Low & Yes \\
\hline & & 109 & Lancaster & Moderate & Yes \\
\hline & & 111 & Lincoln & Low & Yes \\
\hline & & 113 & Logan & Low & Yes \\
\hline & & 115 & Loup & Low & Yes \\
\hline & & 117 & McPherson & Low & Yes \\
\hline & & 119 & Madison & Low & Yes \\
\hline & & 121 & Merrick & Low & Yes \\
\hline & & 123 & Morrill & Low & Yes \\
\hline & & 125 & Nance & Low & Yes \\
\hline & & 127 & Nemaha & Moderate & Yes \\
\hline & & 129 & Nuckolls & Low & Yes \\
\hline & & 131 & Otoe & Moderate & Yes \\
\hline & & 133 & Pawnee & Moderate & Yes \\
\hline & & 135 & Perkins & Low & Yes \\
\hline & & 137 & Phelps & Low & Yes \\
\hline & & 139 & Pierce & Low & Yes \\
\hline & & 141 & Platte & Low & Yes \\
\hline & & 143 & Polk & Low & Yes \\
\hline & & 145 & Red Willow & Low & Yes \\
\hline & & 147 & Richardson & Moderate & Yes \\
\hline
\end{tabular}




\begin{tabular}{|l|c|c|c|c|c|}
\hline \multicolumn{5}{|c|}{ Table A-1 - Location and Seismicity Data } & Page A-61 \\
\hline State Code & State & County Code & County Name & Seismicity & $A_{v}<0.15$ \\
\hline
\end{tabular}

\begin{tabular}{|c|c|c|c|c|c|}
\hline 31 & Nebraska & 149 & Rock & Low & Yes \\
\hline & & 151 & Saline & Low & Yes \\
\hline & & 153 & Sarpy & Moderate & Yes \\
\hline & & 155 & Saunders & Low & Yes \\
\hline & & 157 & Scotts Bluff & Low & Yes \\
\hline & & 159 & Seward & Low & Yes \\
\hline & & 161 & Sheridan & Low & Yes \\
\hline & & 163 & Sherman & Low & Yes \\
\hline & & 165 & Sioux & Low & Yes \\
\hline & & 167 & Stanton & Low & Yes \\
\hline & & 169 & Thayer & Low & Yes \\
\hline & & 171 & Thomas & Low & Yes \\
\hline & & 173 & Thurston & Low & Yes \\
\hline & & 175 & Valley & Low & Yes \\
\hline & & 177 & Washington & Low & Yes \\
\hline & & 179 & Wayne & Low & Yes \\
\hline & & 181 & Webster & Low & Yes \\
\hline & & 183 & Wheeler & Low & Yes \\
\hline & & 185 & York & Low & Yes \\
\hline 32 & \multicolumn{3}{|c|}{ NEVADA } & MIXED & ALL NO \\
\hline & & 510 & Carson City & High & No \\
\hline & & 001 & Churchill & High & No \\
\hline & & 003 & Clark & Moderate & No \\
\hline & & 005 & Douglas & High & No \\
\hline & & 007 & Elko & High & No \\
\hline & & 009 & Esmeralda & High & No \\
\hline & & 011 & Eureka & High & No \\
\hline & & 013 & Humboldt & High & No \\
\hline
\end{tabular}




\begin{tabular}{|l|c|c|c|c|c|}
\hline \multicolumn{5}{|c|}{ Table A-1 - Location and Seismicity Data } & Page A-62 \\
\hline \hline State Code & State & County Code & County Name & Seismicity & $A_{v}<0.15$ \\
\hline
\end{tabular}

\begin{tabular}{|c|c|c|c|c|c|}
\hline 32 & Nevada & 015 & Lander & High & No \\
\hline & & 017 & Lincoln & Moderate & No \\
\hline & & 019 & Lyon & High & No \\
\hline & & 021 & Mineral & High & No \\
\hline & & 023 & Nye & High & No \\
\hline & & 025 & Ormsby & High & No \\
\hline & & 027 & Pershing & High & No \\
\hline & & 029 & Storey & High & No \\
\hline & & 031 & Washoe & High & No \\
\hline & & 033 & White Pine & Moderate & No \\
\hline 33 & \multicolumn{3}{|c|}{ NEW HAMPSHIRE } & ALL MOD & ALL YES \\
\hline & & 001 & Belknap & Moderate & Yes \\
\hline & & 003 & Carroll & Moderate & Yes \\
\hline & & 005 & Cheshire & Moderate & Yes \\
\hline & & 007 & Coos & Moderate & Yes \\
\hline & & 009 & Grafton & Moderate & Yes \\
\hline & & 011 & Hillsborough & Moderate & Yes \\
\hline & & 013 & Merrimack & Moderate & Yes \\
\hline & & 015 & Rockingham & Moderate & Yes \\
\hline & & 017 & Strafford & Moderate & Yes \\
\hline & & 019 & Sullivan & Moderate & Yes \\
\hline 34 & \multicolumn{3}{|c|}{ NEW JERSEY } & MIXED & ALL YES \\
\hline & & 001 & Atlantic & Low & Yes \\
\hline & & 003 & Bergen & Moderate & Yes \\
\hline & & 005 & Burlington & Low & Yes \\
\hline & & 007 & Camden & Low & Yes \\
\hline & & 009 & Cape May & Low & Yes \\
\hline
\end{tabular}




\begin{tabular}{|l|l|l|c|c|c|}
\hline \multicolumn{5}{|c|}{ Table A-1 - Location and Seismicity Data } & Page A-63 \\
\hline \hline State Code & State & County Code & County Name & Seismicity & Av $_{\mathbf{v}}<0.15$ \\
\hline
\end{tabular}

\begin{tabular}{|c|c|c|c|c|c|}
\hline 34 & New Jersey & 011 & Cumberland & Low & Yes \\
\hline & & 013 & Essex & Moderate & Yes \\
\hline & & 015 & Gloucester & Low & Yes \\
\hline & & 017 & Hudson & Moderate & Yes \\
\hline & & 019 & Hunterdon & Moderate & Yes \\
\hline & & 021 & Mercer & Moderate & Yes \\
\hline & & 023 & Middlesex & Moderate & Yes \\
\hline & & 025 & Monmouth & Moderate & Yes \\
\hline & & 027 & Morris & Moderate & Yes \\
\hline & & 029 & Ocean & Low & Yes \\
\hline & & 031 & Passaic & Moderate & Yes \\
\hline & & 033 & Salem & Low & Yes \\
\hline & & 035 & Somerset & Moderate & Yes \\
\hline & & 037 & Sussex & Moderate & Yes \\
\hline & & 039 & Union & Moderate & Yes \\
\hline & & 041 & Warren & Moderate & Yes \\
\hline 35 & \multicolumn{3}{|c|}{ NEW MEXICO } & MIXED & ALL YES \\
\hline & & 001 & Bernalillo & Moderate & Yes \\
\hline & & 003 & Catron & Moderate & Yes \\
\hline & & 005 & Chaves & Low & Yes \\
\hline & & 006 & Cibola & Moderate & Yes \\
\hline & & 007 & Colfax & Low & Yes \\
\hline & & 009 & Curry & Low & Yes \\
\hline & & 011 & De Baca & Low & Yes \\
\hline & & 013 & Dona Ana & Low & Yes \\
\hline & & 015 & Eddy & Low & Yes \\
\hline & & 017 & Grant & Moderate & Yes \\
\hline & & 019 & Guadalupe & Low & Yes \\
\hline
\end{tabular}




\begin{tabular}{||l|l|l|c|c|c|}
\hline \multicolumn{5}{|c|}{ Table A-1 - Location and Seismicity Data } & Page A-64 \\
\hline \hline State Code & State & County Code & County Name & Seismicity & $A_{v}<0.15$ \\
\hline
\end{tabular}

\begin{tabular}{|c|c|c|c|c|c|}
\hline 35 & New Mexico & 021 & Harding & Low & Yes \\
\hline & & 023 & Hidalgo & Moderate & Yes \\
\hline & & 025 & Lea & Low & Yes \\
\hline & & 027 & Lincoln & Low & Yes \\
\hline & & 028 & Los Alamos & Moderate & Yes \\
\hline & & 029 & Luna & Low & Yes \\
\hline & & 031 & McKinley & Low & Yes \\
\hline & & 033 & Mora & Low & Yes \\
\hline & & 035 & Otero & Low & Yes \\
\hline & & 037 & Quay & Low & Yes \\
\hline & & 039 & Rio Arriba & Moderate & Yes \\
\hline & & 041 & Roosevelt & Low & Yes \\
\hline & & 043 & Sandoval & Moderate & Yes \\
\hline & & 045 & San Juan & Low & Yes \\
\hline & & 047 & San Miguel & Low & Yes \\
\hline & & 049 & Santa $\mathrm{Fe}$ & Moderate & Yes \\
\hline & & 051 & Sierra & Moderate & Yes \\
\hline & & 053 & Socorro & Moderate & Yes \\
\hline & & 055 & Taos & Moderate & Yes \\
\hline & & 057 & Torrance & Moderate & Yes \\
\hline & & 059 & Union & Low & Yes \\
\hline & & 061 & Valencia & Moderate & Yes \\
\hline 36 & \multicolumn{3}{|c|}{ NEW YORK } & MIXED & ALL YES \\
\hline & & $\infty 01$ & Albany & Moderate & Yes \\
\hline & & $\infty 03$ & Allegany & Low & Yes \\
\hline & & 005 & Bronx & Moderate & Yes \\
\hline & & 007 & Broome & Low & Yes \\
\hline & & $\infty 09$ & Cattaraugus & Low & Yes \\
\hline
\end{tabular}




\begin{tabular}{|l|l|l|c|c|c|}
\hline \multicolumn{5}{|c|}{ Table A-1 - Location and Seismicity Data } & Page A-65 \\
\hline State Code & State & County Code & County Name & Seismicity & Av $<0.15$ \\
\hline
\end{tabular}

\begin{tabular}{|c|c|c|c|c|c|}
\hline 36 & New York & 011 & Cayuga & Low & Yes \\
\hline & & 013 & Chautauqua & Moderate & Yes \\
\hline & & 015 & Chemung & Low & Yes \\
\hline & & 017 & Chenango & Low & Yes \\
\hline & & 019 & Clinton & Moderate & Yes \\
\hline & & 021 & Columbia & Moderate & Yes \\
\hline & & 023 & Cortland & Low & Yes \\
\hline & & 025 & Delaware & Moderate & Yes \\
\hline & & 027 & Dutchess & Moderate & Yes \\
\hline & & 029 & Erie & Moderate & Yes \\
\hline & & 031 & Essex & Moderate & Yes \\
\hline & & 033 & Franklin & Moderate & Yes \\
\hline & & 035 & Fulton & Moderate & Yes \\
\hline & & 037 & Genesee & Moderate & Yes \\
\hline & & 039 & Greene & Moderate & Yes \\
\hline & & 041 & Hamilton & Moderate & Yes \\
\hline & & 043 & Herkimer & Moderate & Yes \\
\hline & & 045 & Jefferson & Moderate & Yes \\
\hline & & 047 & Kings & Moderate & Yes \\
\hline & & 049 & Lewis & Moderate & Yes \\
\hline & & 051 & Livingston & Low & Yes \\
\hline & & 053 & Madison & Low & Yes \\
\hline & & 055 & Monroe & Low & Yes \\
\hline & & 057 & Montgomery & Moderate & Yes \\
\hline & & 059 & Nassau & Moderate & Yes \\
\hline & & 061 & New York & Moderate & Yes \\
\hline & & 063 & Niagara & Moderate & Yes \\
\hline & & 065 & Oneida & Moderate & Yes \\
\hline & & 067 & Onondaga & Low & Yes \\
\hline & & 069 & Ontario & Low & Yes \\
\hline
\end{tabular}




\begin{tabular}{|l|l|c|c|c|c|}
\hline \multicolumn{5}{|c|}{ Table A-1 - Location and Seismicity Data } & Page A-66 \\
\hline \hline State Code & State & County Code & County Name & Seismicity & $\mathbf{A}_{\mathbf{v}}<0.15$ \\
\hline
\end{tabular}

\begin{tabular}{|c|c|c|c|c|c|}
\hline 36 & New York & 071 & Orange & Moderate & Yes \\
\hline & & 073 & Orleans & Moderate & Yes \\
\hline & & 075 & Oswego & Low & Yes \\
\hline & & 077 & Otsego & Moderate & Yes \\
\hline & & 079 & Putnam & Moderate & Yes \\
\hline & & 081 & Queens & Moderate & Yes \\
\hline & & 083 & Rensselaer & Moderate & Yes \\
\hline & & 085 & Richmond & Moderate & Yes \\
\hline & & 087 & Rockland & Moderate & Yes \\
\hline & . & 089 & St Lawrence & Moderate & Yes \\
\hline & & 091 & Saratoga & Moderate & Yes \\
\hline & & 093 & Schenectady & Moderate & Yes \\
\hline & & 095 & Schoharie & Moderate & Yes \\
\hline & & 097 & Schuyler & Low & Yes \\
\hline & & 099 & Seneca & Low & Yes \\
\hline & & 101 & Steuben & Low & Yes \\
\hline & & 103 & Suffolk & Moderate & Yes \\
\hline & & 105 & Sullivan & Moderate & Yes \\
\hline & & 107 & Tioga & Low & Yes \\
\hline & & 109 & Tompkins & Low & Yes \\
\hline & & 111 & Ulster & Moderate & Yes \\
\hline & & 113 & Warren & Moderate & Yes \\
\hline & & 115 & Washington & Moderate & Yes \\
\hline & & 117 & Wayne & Low & Yes \\
\hline & & 119 & Westchester & Moderate & Yes \\
\hline & & 121 & Wyoming & Moderate & Yes \\
\hline & & 123 & Yates & Low & Yes \\
\hline
\end{tabular}


Table A-1 - Location and Seismicity Data

Page A-67

\begin{tabular}{|l|l|l|l|l|l|}
\hline State Code & State & County Code & County Name & Seismicity & $A_{v}<0.15$ \\
\hline
\end{tabular}

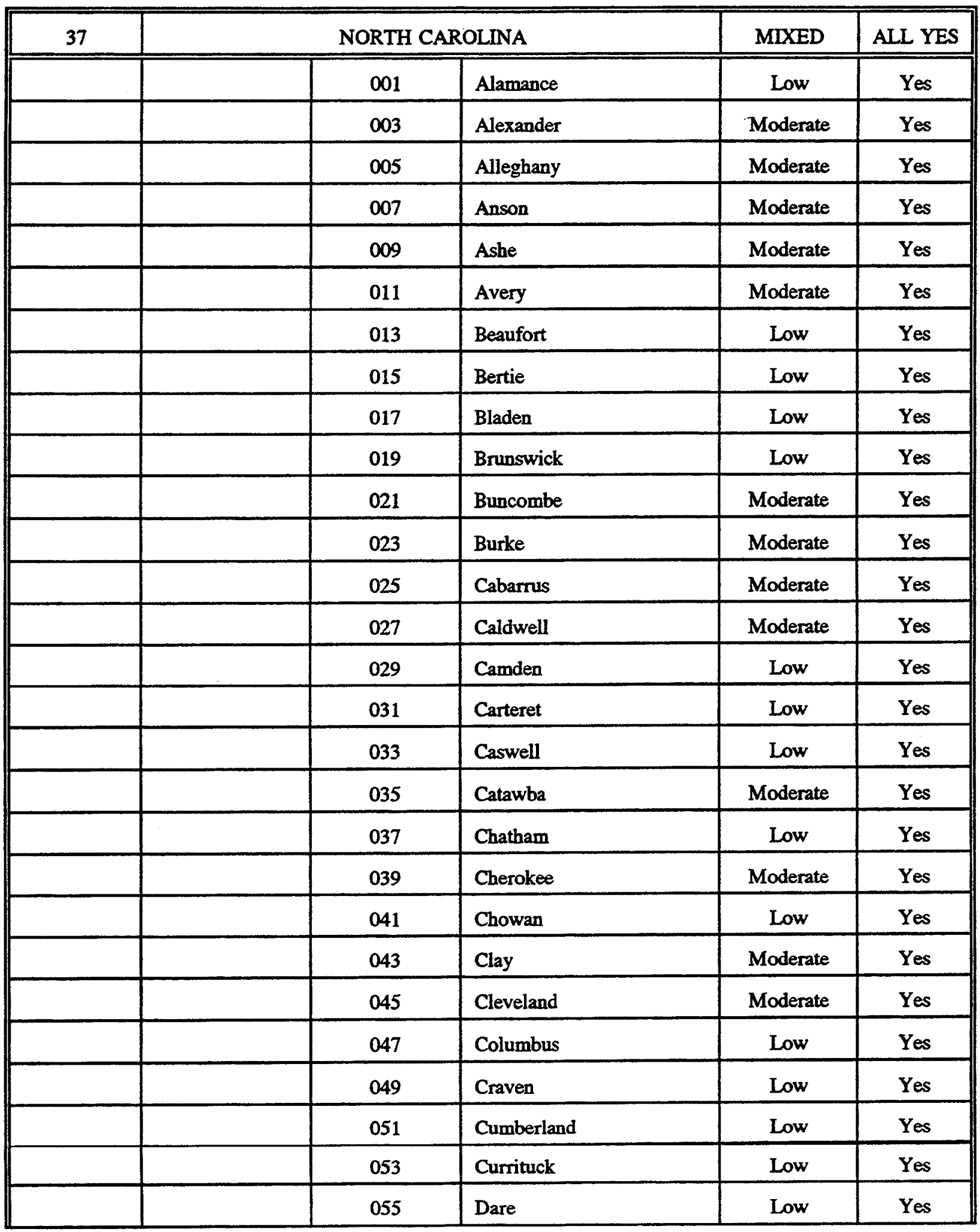




\begin{tabular}{|l|l|l|c|c|c|}
\hline \multicolumn{5}{|c|}{ Table A-1 - Location and Seismicity Data } & Page A-68 \\
\hline \hline State Code & State & County Code & County Name & Seismicity & $\mathbf{A}_{v}<0.15$ \\
\hline
\end{tabular}

\begin{tabular}{|c|c|c|c|c|c|}
\hline 37 & North Carolina & 057 & Davidson & Low & Yes \\
\hline & & 059 & Davie & Low & Yes \\
\hline & & 061 & Duplin & Low & Yes \\
\hline & & 063 & Durham & Low & Yes \\
\hline & & 065 & Edgecombe & Low & Yes \\
\hline & & 067 & Forsyth & Low & Yes \\
\hline & & 069 & Franklin & Low & Yes \\
\hline & & 071 & Gaston & Moderate & Yes \\
\hline & & 073 & Gates & Low & Yes \\
\hline & & 075 & Graham & Moderate & Yes \\
\hline & & 077 & Granville & Low & Yes \\
\hline & & 079 & Greene & Low & Yes \\
\hline & & 081 & Guilford & Low & Yes \\
\hline & & 083 & Halifax & Low & Yes \\
\hline & & 085 & Harnett & Low & Yes \\
\hline & & 087 & Haywood & Moderate & Yes \\
\hline & & 089 & Henderson & Moderate & Yes \\
\hline & & 091 & Hertford & Low & Yes \\
\hline & & 093 & Hoke & Low & Yes \\
\hline & & 095 & Hyde & Low & Yes \\
\hline & & 097 & Iredell & Moderate & Yes \\
\hline & & 099 & Jackson & Moderate & Yes \\
\hline & & 101 & Johnston & Low & Yes \\
\hline & & 103 & Jones & Low & Yes \\
\hline & & 105 & Lee & Low & Yes \\
\hline & & 107 & Lenoir & Low & Yes \\
\hline & & 109 & Lincoln & Moderate & Yes \\
\hline & & 111 & McDowell & Moderate & Yes \\
\hline & & 113 & Macon & Moderate & Yes \\
\hline & & 115 & Madison & Moderate & Yes \\
\hline
\end{tabular}




\begin{tabular}{|l|l|l|l|c|c|}
\hline \multicolumn{5}{|c|}{ Table A-1 - Location and Seismicity Data } & Page A-69 \\
\hline \hline State Code & State & County Code & County Name & Seismicity & $\mathbf{A}_{\mathrm{v}}<0.15$ \\
\hline
\end{tabular}

\begin{tabular}{|c|c|c|c|c|c|}
\hline 37 & North Carolina & 117 & Martin & Low & Yes \\
\hline & & 119 & Mecklenburg & Moderate & Yes \\
\hline & & 121 & Mitchell & Moderate & Yes \\
\hline & & 123 & Montgomery & Low & Yes \\
\hline & & 125 & Moore & Low & Yes \\
\hline & & 127 & Nash & Low & Yes \\
\hline & & 129 & New Hanover & Low & Yes \\
\hline & & 131 & Northampton & Low & Yes \\
\hline & & 133 & Onslow & Low & Yes \\
\hline & & 135 & Orange & Low & Yes \\
\hline & & 137 & Pamlico & Low & Yes \\
\hline & & 139 & Pasquotank & Low & Yes \\
\hline & & 141 & Pender & Low & Yes \\
\hline & & 143 & Perquimans & Low & Yes \\
\hline & & 145 & Person & Low & Yes \\
\hline & & 147 & Pitt & Low & Yes \\
\hline & & 149 & Polk & Moderate & Yes \\
\hline & & 151 & Randolph & Low & Yes \\
\hline & & 153 & Richmond & Moderate & Yes \\
\hline & & 155 & Robeson & Low & Yes \\
\hline & & 157 & Rockingham & Low & Yes \\
\hline & & 159 & Rowan & Moderate & Yes \\
\hline & & 161 & Rutherford & Moderate & Yes \\
\hline & & 163 & Sampson & Low & Yes \\
\hline & & 165 & Scotland & Low & Yes \\
\hline & & 167 & Stanly & Moderate & Yes \\
\hline & & 169 & Stokes & Low & Yes \\
\hline & & 171 & Surry & Moderate & Yes \\
\hline & & 173 & Swain & Moderate & Yes \\
\hline & & 175 & Transylvania & Moderate & Yes \\
\hline
\end{tabular}




\begin{tabular}{|l|l|l|l|c|c|}
\hline \multicolumn{5}{|c|}{ Table A-1 - Location and Seismicity Data } & Page A-70 \\
\hline State Code & State & County Code & County Name & Seismicity & $\mathbf{A}_{\mathrm{v}}<0.15$ \\
\hline
\end{tabular}

\begin{tabular}{|c|c|c|c|c|c|}
\hline 37 & North Carolina & 177 & Tyrrell & Low & Yes \\
\hline & & 179 & Union & Moderate & Yes \\
\hline & & 181 & Vance & Low & Yes \\
\hline & & 183 & Wake & Low & Yes \\
\hline & & 185 & Warren & Low & Yes \\
\hline & & 187 & Washington & Low & Yes \\
\hline & & 189 & Watauga & Moderate & Yes \\
\hline & & 191 & Wayne & Low & Yes \\
\hline & & 193 & Wilkes & Moderate & Yes \\
\hline & & 195 & Wilson & Low & Yes \\
\hline & & 197 & Yadkin & Low & Yes \\
\hline & & 199 & Yancey & Moderate & Yes \\
\hline 38 & \multicolumn{3}{|c|}{ NORTH DAKOTA } & ALL LOW & ALL YES \\
\hline & & 001 & Adams & Low & Yes \\
\hline & & 003 & Barnes & Low & Yes \\
\hline & & 005 & Benson & Low & Yes \\
\hline & & 007 & Billings & Low & Yes \\
\hline & & 009 & Bottineau & Low & Yes \\
\hline & & 011 & Bowman & Low & Yes \\
\hline & & 013 & Burke & Low & Yes \\
\hline & & 015 & Burleigh & Low & Yes \\
\hline & & 017 & Cass & Low & Yes \\
\hline & & 019 & Cavalier & Low & Yes \\
\hline & & 021 & Dickey & Low & Yes \\
\hline & & 023 & Divide & Low & Yes \\
\hline & & 025 & Dunn & Low & Yes \\
\hline & & 027 & Eddy & Low & Yes \\
\hline & & 029 & Emmons & Low & Yes \\
\hline
\end{tabular}




\begin{tabular}{|l|c|c|c|c|c|}
\hline \multicolumn{5}{|c|}{ Table A-1 - Location and Seismicity Data } & Page A-71 \\
\hline \hline State Code & State & County Code & County Name & Seismicity & $A_{\mathrm{v}}<0.15$ \\
\hline
\end{tabular}

\begin{tabular}{|c|c|c|c|c|c|}
\hline 38 & North Dakota & 031 & Foster & Low & Yes \\
\hline & & 033 & Golden Valley & Low & Yes \\
\hline & & 035 & Grand Forks & Low & Yes \\
\hline & & 037 & Grant & Low & Yes \\
\hline & & 039 & Griggs & Low & Yes \\
\hline & & 041 & Hettinger & Low & Yes \\
\hline & & 043 & Kidder & Low & Yes \\
\hline & & 045 & La Moure & Low & Yes \\
\hline & & 047 & Logan & Low & Yes \\
\hline & & 049 & McHenry & Low & Yes \\
\hline & & 051 & McIntosh & Low & Yes \\
\hline & & 053 & McKenzie & Low & Yes \\
\hline & & 055 & McLean & Low & Yes \\
\hline & & 057 & Mercer & Low & Yes \\
\hline & & 059 & Morton & Low & Yes \\
\hline & & 061 & Mountrail & Low & Yes \\
\hline & & 063 & Nelson & Low & Yes \\
\hline & & 065 & Oliver & Low & Yes \\
\hline & & 067 & Pembina & Low & Yes \\
\hline & & 069 & Pierce & Low & Yes \\
\hline & & 071 & Ramsey & Low & Yes \\
\hline & & 073 & Ransom & Low & Yes \\
\hline & & 075 & Renville & Low & Yes \\
\hline & & 077 & Richland & Low & Yes \\
\hline & & 079 & Rolette & Low & Yes \\
\hline & & 081 & Sargent & Low & Yes \\
\hline & & 083 & Sheridan & Low & Yes \\
\hline & & 085 & Sioux & Low & Yes \\
\hline & & 087 & Slope & Low & Yes \\
\hline & & 089 & Stark & Low & Yes \\
\hline
\end{tabular}




\begin{tabular}{|l|l|l|l|c|c|}
\hline \multicolumn{5}{|c|}{ Table A-1 - Location and Seismicity Data } & Page A-72 \\
\hline State Code & State & County Code & County Name & Seismicity & Av $_{\mathrm{v}}<0.15$ \\
\hline
\end{tabular}

\begin{tabular}{|c|c|c|c|c|c|}
\hline 38 & North Dakota & 091 & Steele & Low & Yes \\
\hline & & 093 & Stutsman & Low & Yes \\
\hline & & 095 & Towner & Low & Yes \\
\hline & & 097 & Traill & Low & Yes \\
\hline & & 099 & Walsh & Low & Yes \\
\hline & & 101 & Ward & Low & Yes \\
\hline & & 103 & Wells & Low & Yes \\
\hline & & 105 & Williams & Low & Yes \\
\hline \multirow[t]{20}{*}{39} & \multicolumn{3}{|c|}{ OHIO } & ALL LOW & ALL YES \\
\hline & & 001 & Adams & Low & Yes \\
\hline & & 003 & Allen & Low & Yes \\
\hline & & 005 & Ashland & Low & Yes \\
\hline & & 007 & Ashtabuka & Low & Yes \\
\hline & & 009 & Athens & Low & Yes \\
\hline & & 011 & Auglaize & Low & Yes \\
\hline & & 013 & Belmont & Low & Yes \\
\hline & & 015 & Brown & Low & Yes \\
\hline & & 017 & Butler & Low & Yes \\
\hline & & 019 & Carroll & Low & Yes \\
\hline & & 021 & Champaign & Low & Yes \\
\hline & & 023 & Clark & Low & Yes \\
\hline & & 025 & Clermont & Low & Yes \\
\hline & & 027 & Clinton & Low & Yes \\
\hline & & 029 & Columbiana & Low & Yes \\
\hline & & 031 & Coshocton & Low & Yes \\
\hline & & 033 & Crawford & Low & Yes \\
\hline & & 035 & Cuyahoga & Low & Yes \\
\hline & & 037 & Darke & Low & Yes \\
\hline
\end{tabular}




\begin{tabular}{|l|c|c|c|c|c|}
\hline \multicolumn{5}{|c|}{ Table A-1 - Location and Seismicity Data } & Page A-73 \\
\hline \hline State Code & State & County Code & County Name & Seismicity & A $_{\mathrm{r}}<\mathbf{0 . 1 5}$ \\
\hline
\end{tabular}

\begin{tabular}{|c|c|c|c|c|c|}
\hline 39 & Ohio & 039 & Defiance & Low & Yes \\
\hline & & 041 & Delaware & Low & Yes \\
\hline & & 043 & Erie & Low & Yes \\
\hline & & 045 & Fairfield & Low & Yes \\
\hline & & 047 & Fayette & Low & Yes \\
\hline & & 049 & Franklin & Low & Yes \\
\hline & & 051 & Fulton & Low & Yes \\
\hline & & 053 & Gallia & Low & Yes \\
\hline & & 055 & Geauga & Low & Yes \\
\hline & & 057 & Greene & Low & Yes \\
\hline & & 059 & Guernsey & Low & Yes \\
\hline & & 061 & Hamilton & Low & Yes \\
\hline & & 063 & Hancock & Low & Yes \\
\hline & & 065 & Hardin & Low & Yes \\
\hline & & 067 & Harrison & Low & Yes \\
\hline & & 069 & Henry & Low & Yes \\
\hline & & 071 & Highland & Low & Yes \\
\hline & & 073 & Hocking & Low & Yes \\
\hline & & 075 & Holmes & Low & Yes \\
\hline & & 077 & Huron & Low & Yes \\
\hline & & 079 & Jackson & Low & Yes \\
\hline & & 081 & Jefferson & Low & Yes \\
\hline & & 083 & Knox & Low & Yes \\
\hline & & 085 & Lake & Low & Yes \\
\hline & & 087 & Lawrence & Low & Yes \\
\hline & & 089 & Licking & Low & Yes \\
\hline & & 091 & Logan & Low & Yes \\
\hline & & 093 & Lorain & Low & Yes \\
\hline & & 095 & Lucas & Low & Yes \\
\hline & & 097 & Madison & Low & Yes \\
\hline
\end{tabular}




\begin{tabular}{|l|l|c|c|c|c|}
\hline \multicolumn{5}{|c|}{ Table A-1 - Location and Seismicity Data } & Page A-74 \\
\hline \hline State Code & State & County Code & County Name & Seismicity & $A_{\mathrm{v}}<0.15$ \\
\hline
\end{tabular}

\begin{tabular}{|c|c|c|c|c|c|}
\hline 39 & Ohio & 099 & Mahoning & Low & Yes \\
\hline & & 101 & Marion & Low & Yes \\
\hline & & 103 & Medina & Low & Yes \\
\hline & & 105 & Meigs & Low & Yes \\
\hline & & 107 & Mercer & Low & Yes \\
\hline & & 109 & Miami & Low & Yes \\
\hline & & 111 & Monroe & Low & Yes \\
\hline & & 113 & Montgomery & Low & Yes \\
\hline & & 115 & Morgan & Low & Yes \\
\hline & & 117 & Morrow & Low & Yes \\
\hline & & 119 & Muskingum & Low & Yes \\
\hline & & 121 & Noble & Low & Yes \\
\hline & & 123 & Ottawa & Low & Yes \\
\hline & & 125 & Paulding & Low & Yes \\
\hline & & 127 & Perry & Low & Yes \\
\hline & & 129 & Pickaway & Low & Yes \\
\hline & & 131 & Pike & Low & Yes \\
\hline & & 133 & Portage & Low & Yes \\
\hline & & 135 & Preble & Low & Yes \\
\hline & & 137 & Putnam & Low & Yes \\
\hline & & 139 & Richland & Low & Yes \\
\hline & & 141 & Ross & Low & Yes \\
\hline & & 143 & Sandusky & Low & Yes \\
\hline & & 145 & Scioto & Low & Yes \\
\hline & & 147 & Seneca & Low & Yes \\
\hline & & 149 & Shelby & Low & Yes \\
\hline & & 151 & Stark & Low & Yes \\
\hline & & 153 & Summit & Low & Yes \\
\hline & & 155 & Trumbull & Low & Yes \\
\hline & & 157 & Tuscarawas & Low & Yes \\
\hline
\end{tabular}




\begin{tabular}{||l|l|l|c|c|c|}
\hline \multicolumn{5}{|c|}{ Table A-1 - Location and Seismicity Data } & Page A-75 \\
\hline State Code & State & County Code & County Name & Seismicity & A $_{\mathbf{v}}<0.15$ \\
\hline
\end{tabular}

\begin{tabular}{|c|c|c|c|c|c|}
\hline 39 & Ohio & 159 & Union & Low & Yes \\
\hline & & 161 & Van Wert & Low & Yes \\
\hline & & 163 & Vinton & Low & Yes \\
\hline & & 165 & Warren & Low & Yes \\
\hline & & 167 & Washington & Low & Yes \\
\hline & & 169 & Wayne & Low & Yes \\
\hline & & 171 & Williams & Low & Yes \\
\hline & & 173 & Wood & Low & Yes \\
\hline & & 175 & Wyandot & Low & Yes \\
\hline 40 & & \multicolumn{2}{|c|}{ OKLAHOMA } & MIXED & ALL YES \\
\hline & & 001 & Adair & Low & Yes \\
\hline & & 003 & Alfalfa & Low & Yes \\
\hline & & 005 & Atoka & Moderate & Yes \\
\hline & & 007 & Beaver & Low & Yes \\
\hline & & 009 & Beckham & Low & Yes \\
\hline & & 011 & Blaine & Low & Yes \\
\hline & & 013 & Bryan & Moderate & Yes \\
\hline & & 015 & Caddo & Low & Yes \\
\hline & & 017 & Canadian & Low & Yes \\
\hline & & 019 & Carter & Moderate & Yes \\
\hline & & 021 & Cherokee & Low & Yes \\
\hline & & 023 & Choctaw & Moderate & Yes \\
\hline & & 025 & Cimarron & Low & Yes \\
\hline & & 027 & Cleveland & Moderate & Yes \\
\hline & & 029 & Coal & Moderate & Yes \\
\hline & & 031 & Comanche & Low & Yes \\
\hline & & 033 & Cotton & Low & Yes \\
\hline & & 035 & Craig & Low & Yes \\
\hline
\end{tabular}




\begin{tabular}{|l|c|c|c|c|c|}
\hline \multicolumn{5}{|c|}{ Table A-1 - Location and Seismicity Data } & Page A-76 \\
\hline \hline State Code & State & County Code & County Name & Seismicity & A $_{\mathrm{v}}<\mathbf{0 . 1 5}$ \\
\hline
\end{tabular}

\begin{tabular}{|c|c|c|c|c|c|}
\hline 40 & Oklahoma & 037 & Creek & Moderate & Yes \\
\hline & & 039 & Custer & Low & Yes \\
\hline & & 041 & Delaware & Low & Yes \\
\hline & & 043 & Dewey & Low & Yes \\
\hline & & 045 & Ellis & Low & Yes \\
\hline & & 047 & Garfield & Low & Yes \\
\hline & & 049 & Garvin & Moderate & Yes \\
\hline & & 051 & Grady & Moderate & Yes \\
\hline & & 053 & Grant & Low & Yes \\
\hline & & 055 & Greer & Low & Yes \\
\hline & & 057 & Harmon & Low & Yes \\
\hline & & 059 & Harper & Low & Yes \\
\hline & & 061 & Haskell & Moderate & Yes \\
\hline & & 063 & Hughes & Moderate & Yes \\
\hline & & 065 & Jackson & Low & Yes \\
\hline & & 067 & Jefferson & Low & Yes \\
\hline & & 069 & Johnston & Moderate & Yes \\
\hline & & 071 & Kay & Low & Yes \\
\hline & & 073 & Kingfisher & Low & Yes \\
\hline & & 075 & Kiowa & Low & Yes \\
\hline & & 077 & Latimer & Moderate & Yes \\
\hline & & 079 & Le Flore & Moderate & Yes \\
\hline & & 081 & Lincoln & Moderate & Yes \\
\hline & & 083 & Logan & Low & Yes \\
\hline & & 085 & Love & Low & Yes \\
\hline & & 087 & McClain & Moderate & Yes \\
\hline & & 089 & McCurtain & Moderate & Yes \\
\hline & & 091 & McIntosh & Moderate & Yes \\
\hline & & 093 & Major & Low & Yes \\
\hline & & 095 & Marshall & Moderate & Yes \\
\hline
\end{tabular}




\begin{tabular}{||c|c|c|c|c|c|}
\hline \multicolumn{5}{|c|}{ Table A-1 - Location and Seismicity Data } & Page A-77 \\
\hline \hline State Code & State & County Code & County Name & Seismicity & $\mathbf{A}_{\mathrm{v}}<\mathbf{0 . 1 5}$ \\
\hline
\end{tabular}

\begin{tabular}{|c|c|c|c|c|c|}
\hline 40 & Oklahoma & 097 & Mayes & Low & Yes \\
\hline & & 099 & Murray & Moderate & Yes \\
\hline & & 101 & Muskogee & Moderate & Yes \\
\hline & & 103 & Noble & Low & Yes \\
\hline & & 105 & Nowata & Low & Yes \\
\hline & & 107 & Okfuskee & Moderate & Yes \\
\hline & & 109 & Oklahoma & Moderate & Yes \\
\hline & & 111 & Okmulgee & Moderate & Yes \\
\hline & & 113 & Osage & Low & Yes \\
\hline & & 115 & Ottawa & Low & Yes \\
\hline & & 117 & Pawnee & Low & Yes \\
\hline & & 119 & Payne & Low & Yes \\
\hline & & 121 & Pittsburg & Moderate & Yes \\
\hline & & 123 & Pontotoc & Moderate & Yes \\
\hline & & 125 & Pottawatomie & Moderate & Yes \\
\hline & & 127 & Pushmataha & Moderate & Yes \\
\hline & & 129 & Roger Mills & Low & Yes \\
\hline & & 131 & Rogers & Low & Yes \\
\hline & & 133 & Seminole & Moderate & Yes \\
\hline & & 135 & Sequoyah & Low & Yes \\
\hline & & 137 & Stephens & Moderate & Yes \\
\hline & & 139 & Texas & Low & \\
\hline & & 141 & Tillman & Low & Yes \\
\hline & & 143 & Tulsa & Moderate & Yes \\
\hline & & 145 & Wagoner & Low & Yes \\
\hline & & 147 & Washington & Low & Yes \\
\hline & & 149 & Washita & Low & Yes \\
\hline & & 151 & Woods & Low & Yes \\
\hline & & 153 & Woodward & Low & Yes \\
\hline
\end{tabular}


Table A-1 - Location and Seismicity Data

Page A-78

\begin{tabular}{|l|l|l|l|l|l|}
\hline State Code & State & County Code & County Name & Seismicity & $A_{v}<0.15$ \\
\hline
\end{tabular}

\begin{tabular}{|c|c|c|c|c|}
\hline \multirow[t]{2}{*}{41} & \multicolumn{2}{|c|}{ OREGON } & \multirow{2}{*}{$\frac{\text { MIXED }}{\text { Low }}$} & \multirow{2}{*}{ MIXED } \\
\hline & 001 & Baker & & \\
\hline & 003 & Benton & Low & Yes \\
\hline & 005 & Clackamas & Low & Yes \\
\hline & 007 & Clatsop & Low & Yes \\
\hline & 009 & Columbia & Low & Yes \\
\hline & 011 & Coos & Moderate & Yes \\
\hline & 013 & Crook & Low & Yes \\
\hline & 015 & Curry & Moderate & No \\
\hline & 017 & Deschutes & Low & Yes \\
\hline & 019 & Douglas & Low & Yes \\
\hline & 021 & Gilliam & Low & Yes \\
\hline & 023 & Grant & Low & Yes \\
\hline & 025 & Harney & Low & Yes \\
\hline & 027 & Hood River & Low & Yes \\
\hline & 029 & Jackson & Moderate & Yes \\
\hline & 031 & Jefferson & Low & Yes \\
\hline & 033 & Josephine & Moderate & Yes \\
\hline & 035 & Klamath & Low & Yes \\
\hline & 037 & Lake & Low & Yes \\
\hline & 039 & Lane & Low & Yes \\
\hline & 041 & Lincoln & Low & Yes \\
\hline & 043 & Linn & Low & Yes \\
\hline & 045 & Malheur & Moderate & Yes \\
\hline & 047 & Marion & Low & Yes \\
\hline & 049 & Morrow & Low & Yes \\
\hline & 051 & Multnomah & Low & Yes \\
\hline & 053 & Polk & Low & Yes \\
\hline & 055 & Sherman & Low & Yes \\
\hline
\end{tabular}




\begin{tabular}{||c|c|c|c|c|c|}
\hline \multicolumn{5}{|c|}{ Table A-1 - Location and Seismicity Data } & Page A-79 \\
\hline \hline State Code & State & County Code & County Name & Seismicity & A $_{\mathrm{v}}<0.15$ \\
\hline
\end{tabular}

\begin{tabular}{|c|c|c|c|c|c|}
\hline 41 & Oregon & 057 & Tillamook & Low & Yes \\
\hline & & 059 & Umatilla & Low & Yes \\
\hline & & 061 & Union & Low & Yes \\
\hline & & 063 & Wallowa & Low & Yes \\
\hline & & 065 & Wasco & Low & Yes \\
\hline & & 067 & Washington & Low & Yes \\
\hline & & 069 & Wheeler & Low & Yes \\
\hline & & 071 & Yambill & Low & Yes \\
\hline 42 & \multicolumn{3}{|c|}{ PENNSYLVANIA } & MIXED & AlL YES \\
\hline & & 001 & Adams & Low & Yes \\
\hline & & 003 & Allegheny & Low & Yes \\
\hline & & 005 & Armstrong & Low & Yes \\
\hline & & 007 & Beaver & Low & Yes \\
\hline & & 009 & Bedford & Low & Yes \\
\hline & & 011 & Berks & Moderate & Yes \\
\hline & & 013 & Blair & Low & Yes \\
\hline & & 015 & Bradford & Low & Yes \\
\hline & & 017 & Bucks & Moderate & Yes \\
\hline & & 019 & Butler & Low & Yes \\
\hline & & 021 & Cambria & Low & Yes \\
\hline & & 023 & Cameron & Low & Yes \\
\hline & & 025 & Carbon & Moderate & Yes \\
\hline & & 027 & Centre & Low & Yes \\
\hline & & 029 & Chester & Moderate & Yes \\
\hline & & 031 & Clarion & Low & Yes \\
\hline & & 033 & Clearfield & Low & Yes \\
\hline & & 035 & Clinton & Low & Yes \\
\hline & & 037 & Columbia & Low & Yes \\
\hline
\end{tabular}




\begin{tabular}{|l|c|c|c|c|c|}
\hline \multicolumn{5}{|c|}{ Table A-1 - Location and Seismicity Data } & Page A-80 \\
\hline State Code & State & County Code & County Name & Seismicity & Av $_{\mathrm{v}}<0.15$ \\
\hline
\end{tabular}

\begin{tabular}{|c|c|c|c|c|c|}
\hline 42 & Pennsylvania & 039 & Crawford & Low & Yes \\
\hline & & 041 & Cumberland & Low & Yes \\
\hline & & 043 & Dauphin & Low & Yes \\
\hline & & 045 & Delaware & Moderate & Yes \\
\hline & & 047 & Elk & Low & Yes \\
\hline & & 049 & Erie & Low & Yes \\
\hline & & 051 & Fayette & Low & Yes \\
\hline & & 053 & Forest & Low & Yes \\
\hline & & 055 & Franklin & Low & Yes \\
\hline & & 057 & Fulton & Low & Yes \\
\hline & & 059 & Greene & Low & Yes \\
\hline & & 061 & Huntingdon & Low & Yes \\
\hline & & 063 & Indiana & Low & Yes \\
\hline & & 065 & Jefferson & Low & Yes \\
\hline & & 067 & Juniata & Low & Yes \\
\hline & & 069 & Lackawanna & Moderate & Yes \\
\hline & & 071 & Lancaster & Moderate & Yes \\
\hline & & 073 & Lawrence & Low & Yes \\
\hline & & 075 & Lebanon & Moderate & Yes \\
\hline & & 077 & Lehigh & Moderate & Yes \\
\hline & & 079 & Luzerne & Moderate & Yes \\
\hline & & 081 & Lycoming & Low & Yes \\
\hline & & 083 & McKean & Low & Yes \\
\hline & & 085 & Mercer & Low & Yes \\
\hline & & 087 & Mifflin & Low & Yes \\
\hline & & 089 & Monroe & Moderate & Yes \\
\hline & & 091 & Montgomery & Moderate & Yes \\
\hline & & 093 & Montour & Low & Yes \\
\hline & & 095 & Northhampton & Moderate & Yes \\
\hline & & 097 & Northumberland & Low & Yes \\
\hline
\end{tabular}




\begin{tabular}{|l|l|c|c|c|c|}
\hline \multicolumn{5}{|c|}{ Table A-1 - Location and Seismicity Data } & Page A-81 \\
\hline \hline State Code & State & County Code & County Name & Seismicity & Av $_{v}<0.15$ \\
\hline
\end{tabular}

\begin{tabular}{|c|c|c|c|c|c|}
\hline 42 & Pennsylvania & 099 & Perry & Low & Yes \\
\hline & & 101 & Philadelphia & Moderate & Yes \\
\hline & & 103 & Pike & Moderate & Yes \\
\hline & & 105 & Potter & Low & Yes \\
\hline & & 107 & Schuylkill & Moderate & Yes \\
\hline & & 109 & Snyder & Low & Yes \\
\hline & & 111 & Somerset & Low & Yes \\
\hline & & 113 & Sullivan & Low & Yes \\
\hline & & 115 & Susquehanna & Moderate & Yes \\
\hline & & 117 & Tioga & Low & Yes \\
\hline & & 119 & Union & Low & Yes \\
\hline & & 121 & Venango & Low & Yes \\
\hline & & 123 & Warren & Low & Yes \\
\hline & & 125 & Washington & Low & Yes \\
\hline & & 127 & Wayne & Moderate & Yes \\
\hline & & 129 & Westmoreland & Low & Yes \\
\hline & & 131 & Wyoming & Moderate & Yes \\
\hline & & 133 & York & Low & Yes \\
\hline 44 & \multicolumn{3}{|c|}{ RHODE ISLAND } & ALL MOD & ALL YES \\
\hline & & 001 & Bristol & Moderate & Yes \\
\hline & & 003 & Kent & Moderate & Yes \\
\hline & & 005 & Newport & Moderate & Yes \\
\hline & & $\infty 07$ & Providence & Moderate & Yes \\
\hline & & 009 & Washington & Moderate & Yes \\
\hline 45 & \multicolumn{3}{|c|}{ SOUTH CAROLINA } & ALL MOD & ALL YES \\
\hline & & 001 & Abbeville & Moderate & Yes \\
\hline & & 003 & Aiken & Moderate & Yes \\
\hline
\end{tabular}




\begin{tabular}{|c|c|c|c|c|c|}
\hline \multicolumn{5}{|c|}{ Table A-1 - Location and Seismicity Data } & Page A-82 \\
\hline State Code & State & County Code & County Name & Seismicity & $A_{v}<0.15$ \\
\hline
\end{tabular}

\begin{tabular}{|c|c|c|c|c|c|}
\hline 45 & South Carolina & 005 & Allendale & Moderate & Yes \\
\hline & & 007 & Anderson & Moderate & Yes \\
\hline & & 009 & Bamberg & Moderate & Yes \\
\hline & & 011 & Barnwell & Moderate & Yes \\
\hline & & 013 & Beaufort & Moderate & Yes \\
\hline & & 015 & Berkeley & Moderate & Yes \\
\hline & & 017 & Calhoun & Moderate & Yes \\
\hline & & 019 & Charleston & Moderate & Yes \\
\hline & & 021 & Cherokee & Moderate & Yes \\
\hline & & 023 & Chester & Moderate & Yes \\
\hline & & 025 & Chesterfield & Moderate & Yes \\
\hline & & 027 & Clarendon & Moderate & Yes \\
\hline & & 029 & Colleton & Moderate & Yes \\
\hline & & 031 & Darlington & Moderate & Yes \\
\hline & & 033 & Dillon & Moderate & Yes \\
\hline & & 035 & Dorchester & Moderate & Yes \\
\hline & & 037 & Edgefield & Moderate & Yes \\
\hline & & 039 & Fairfield & Moderate & Yes \\
\hline & & 041 & Florence & Moderate & Yes \\
\hline & & 043 & Georgetown & Moderate & Yes \\
\hline & & 045 & Greenville & Moderate & Yes \\
\hline & & 047 & Greenwood & Moderate & Yes \\
\hline & & 049 & Hampton & Moderate & Yes \\
\hline & & 051 & Horry & Moderate & Yes \\
\hline & & 053 & Jasper & Moderate & Yes \\
\hline & & 055 & Kershaw & Moderate & Yes \\
\hline & & 057 & Lancaster & Moderate & Yes \\
\hline & & 059 & Laurens & Moderate & Yes \\
\hline & & 061 & Lee & Moderate & Yes \\
\hline & & 063 & Lexington & Moderate & Yes \\
\hline
\end{tabular}


Table A-1 - Location and Seismicity Data

Page A-83

\begin{tabular}{|l|l|l|l|l|l|}
\hline State Code & State & County Code & County Name & Seismicity & $A_{v}<0.15$ \\
\hline
\end{tabular}

\begin{tabular}{|c|c|c|c|c|c|}
\hline 45 & South Carolina & 065 & McCormick & Moderate & Yes \\
\hline & & 067 & Marion & Moderate & Yes \\
\hline & & 069 & Marlboro & Moderate & Yes \\
\hline & & 071 & Newberry & Moderate & Yes \\
\hline & & 073 & Oconee & Moderate & Yes \\
\hline & & 075 & Orangeburg & Moderate & Yes \\
\hline & & 077 & Pickens & Moderate & Yes \\
\hline & & 079 & Richland & Moderate & Yes \\
\hline & & 081 & Saluda & Moderate & Yes \\
\hline & & 083 & Spartanburg & Moderate & Yes \\
\hline & & 085 & Sumter & Moderate & Yes \\
\hline & & 087 & Union & Moderate & Yes \\
\hline & & 089 & Williamsburg & Moderate & Yes \\
\hline & & 091 & York & Moderate & Yes \\
\hline 46 & \multicolumn{3}{|c|}{ SOUTH DAKOTA } & ALL LOW & ALL YES \\
\hline & & 003 & Aurora & Low & Yes \\
\hline & & 005 & Beadle & Low & Yes \\
\hline & & 007 & Bennett & Low & Yes \\
\hline & & 009 & Bon Homme & Low & Yes \\
\hline & & 011 & Brookings & Low & Yes \\
\hline & & 013 & Brown & Low & Yes \\
\hline & & 015 & Brule & Low & Yes \\
\hline & & 017 & Buffalo & Low & Yes \\
\hline & & 019 & Butte & Low & Yes \\
\hline & & 021 & Campbell & Low & Yes \\
\hline & & 023 & Charles Mix & Low & Yes \\
\hline & & 025 & Clark & Low & Yes \\
\hline & & 027 & Clay & Low & Yes \\
\hline
\end{tabular}




\begin{tabular}{|l|l|c|c|c|c|}
\hline \multicolumn{5}{|c|}{ Table A-1 - Location and Seismicity Data } & Page A-84 \\
\hline \hline State Code & State & County Code & County Name & Seismicity & A $_{\mathrm{v}}<0.15$ \\
\hline
\end{tabular}

\begin{tabular}{|c|c|c|c|c|c|}
\hline 46 & South Dakota & 029 & Codington & Low & Yes \\
\hline & & 031 & Corson & Low & Yes \\
\hline & & 033 & Custer & Low & Yes \\
\hline & & 035 & Davison & Low & Yes \\
\hline & & 037 & Day & Low & Yes \\
\hline & & 039 & Deuel & Low & Yes \\
\hline & & 041 & Dewey & Low & Yes \\
\hline & & 043 & Douglas & Low & Yes \\
\hline & & 045 & Edmunds & Low & Yes \\
\hline & & 047 & Fall River & Low & Yes \\
\hline & & 049 & Faulk & Low & Yes \\
\hline & & 051 & Grant & Low & Yes \\
\hline & & 053 & Gregory & Low & Yes \\
\hline & & 055 & Haakon & Low & Yes \\
\hline & & 057 & Hamlin & Low & Yes \\
\hline & & 059 & Hand & Low & Yes \\
\hline & & 061 & Hanson & Low & Yes \\
\hline & & 063 & Harding & Low & Yes \\
\hline & & 065 & Hughes & Low & Yes \\
\hline & & 067 & Hutchinson & Low & Yes \\
\hline & & 069 & Hyde & Low & Yes \\
\hline & & 071 & Jackson & Low & Yes \\
\hline & & 073 & Jerauld & Low & Yes \\
\hline & & 075 & Jones & Low & Yes \\
\hline & & 077 & Kingsbury & Low & Yes \\
\hline & & 079 & Lake & Low & Yes \\
\hline & & 081 & Lawrence & Low & Yes \\
\hline & & 083 & Lincoln & Low & Yes \\
\hline & & 085 & Lyman & Low & Yes \\
\hline & & 087 & McCook & Low & Yes \\
\hline
\end{tabular}




\begin{tabular}{|l|c|c|c|c|c|}
\hline \multicolumn{5}{|c|}{ Table A-1 - Location and Seismicity Data } & Page A-85 \\
\hline \hline State Code & State & County Code & County Name & Seismicity & Av $<0.15$ \\
\hline
\end{tabular}

\begin{tabular}{|c|c|c|c|c|c|}
\hline 46 & South Dakota & 089 & McPherson & Low & Yes \\
\hline & & 091 & Marshall & Low & Yes \\
\hline & & 093 & Meade & Low & Yes \\
\hline & & 095 & Mellette & Low & Yes \\
\hline & & 097 & Miner & Low & Yes \\
\hline & & 099 & Minnebaha & Low & Yes \\
\hline & & 101 & Moody & Low & Yes \\
\hline & & 103 & Pennington & Low & Yes \\
\hline & & 105 & Perkins & Low & Yes \\
\hline & & 107 & Potter & Low & Yes \\
\hline & & 109 & Roberts & Low & Yes \\
\hline & & 111 & Sanborn & Low & Yes \\
\hline & & 113 & Shannon & Low & Yes \\
\hline & & 115 & Spink & Low & Yes \\
\hline & & 117 & Stanley & Low & Yes \\
\hline & & 119 & Sully & Low & Yes \\
\hline & & 121 & Todd & Low & Yes \\
\hline & & 123 & Tripp & Low & Yes \\
\hline & & 125 & Turner & Low & Yes \\
\hline & & 127 & Union & Low & Yes \\
\hline & & 129 & Walworth & Low & Yes \\
\hline & & 135 & Yankton & Low & Yes \\
\hline & & 137 & Ziebach & Low & Yes \\
\hline & & 130 & Washaba & Low & jes \\
\hline 47 & \multicolumn{3}{|c|}{ TENNESSEE } & MIXED & MIXED \\
\hline & & 001 & Anderson & Moderate & Yes \\
\hline & & 003 & Bedford & Low & Yes \\
\hline & & 005 & Benton & Moderate & Yes \\
\hline & & 007 & Bledsoe & Moderate & Yes \\
\hline
\end{tabular}




\begin{tabular}{|l|l|l|l|l|c|}
\hline \multicolumn{5}{|c|}{ Table A-1 - Location and Seismicity Data } & Page A-86 \\
\hline \hline State Code & State & County Code & County Name & Seismicity & Av $_{\mathbf{v}}<0.15$ \\
\hline
\end{tabular}

\begin{tabular}{|c|c|c|c|c|c|}
\hline 47 & Tennessee & 009 & Blount & Moderate & Yes \\
\hline & & 011 & Bradley & Moderate & Yes \\
\hline & & 013 & Campbell & Moderate & Yes \\
\hline & & 015 & Cannon & Low & Yes \\
\hline & & 017 & Carroll & Moderate & Yes \\
\hline & & 019 & Carter & Moderate & Yes \\
\hline & & 021 & Cheatham & Low & Yes \\
\hline & & 023 & Chester & Moderate & Yes \\
\hline & & 025 & Claiborne & Moderate & Yes \\
\hline & & 027 & Clay & Low & Yes \\
\hline & & 029 & Cocke & Moderate & Yes \\
\hline & & 031 & Coffee & Low & Yes \\
\hline & & 033 & Crockett & Moderate & No \\
\hline & & 035 & Cumberland & Moderate & Yes \\
\hline & & 037 & Davidson & Low & Yes \\
\hline & & 039 & Decatur & Low & Yes \\
\hline & & 041 & De Kalb & Low & Yes \\
\hline & & 043 & Dickson & Low & Yes \\
\hline & & 045 & Dyer & High & No \\
\hline & & 047 & Fayette & Moderate & No \\
\hline & & 049 & Fentress & Low & Yes \\
\hline & & 051 & Franklin & Low & Yes \\
\hline & & 053 & Gibson & Moderate & No \\
\hline & & 055 & Giles & Low & Yes \\
\hline & & 057 & Grainger & Moderate & Yes \\
\hline & & 059 & Greene & Moderate & Yes \\
\hline & & 061 & Grundy & Low & Yes \\
\hline & & 063 & Hamblen & Moderate & Yes \\
\hline & & 065 & Hamilton & Moderate & Yes \\
\hline & & 067 & Hancock & Moderate & Yes \\
\hline
\end{tabular}




\begin{tabular}{|c|c|c|c|c|c|}
\hline \multicolumn{5}{|c|}{ Table A-1 - Location and Seismicity Data } & Page A-87 \\
\hline State Code & State & County Code & County Name & Seismicity & $A_{V}<0.15$ \\
\hline
\end{tabular}

\begin{tabular}{|c|c|c|c|c|c|}
\hline 47 & Tennessee & 069 & Hardeman & Moderate & Yes \\
\hline & & 071 & Hardin & Low & Yes \\
\hline & & 073 & Hawkins & Moderate & Yes \\
\hline & & 075 & Haywood & Moderate & No \\
\hline & & 077 & Herderson & Moderate & Yes \\
\hline & & 079 & Henry & Moderate & Yes \\
\hline & & 081 & Hickman & Low & Yes \\
\hline & & 083 & Houston & Low & Yes \\
\hline & & 085 & Humphreys & Low & Yes \\
\hline & & 087 & Jackson & Low & Yes \\
\hline & & 089 & Jefferson & Moderate & Yes \\
\hline & & 091 & Johnson & Moderate & Yes \\
\hline & & 093 & Knox & Moderate & Yes \\
\hline & & 095 & Lake & High & No \\
\hline & & 097 & Lauderdale & High & No \\
\hline & & 099 & Lawrence & Low & Yes \\
\hline & & 101 & Lewis & Low & Yes \\
\hline & & 103 & Lincoln & Low & Yes \\
\hline & & 105 & Loudon & Moderate & Yes \\
\hline & & 107 & McMinn & Moderate & Yes \\
\hline & & 109 & McNairy & Moderate & Yes \\
\hline & & 111 & Macon & Low & Yes \\
\hline & & 113 & Madison & Moderate & No \\
\hline & & 115 & Marion & Low & Yes \\
\hline & & 117 & Marshall & Low & Yes \\
\hline & & 119 & Maury & Low & Yes \\
\hline & & 121 & Meigs & Moderate & Yes \\
\hline & & 123 & Monroe & Moderate & Yes \\
\hline & & 125 & Montgomery & Low & Yes \\
\hline & & 127 & Moore & Low & Yes \\
\hline
\end{tabular}




\begin{tabular}{|l|l|l|l|c|c|}
\hline \multicolumn{5}{|c|}{ Table A-1 - Location and Seismicity Data } & Page A-88 \\
\hline State Code & State & County Code & County Name & Seismicity & A $_{v}<0.15$ \\
\hline
\end{tabular}

\begin{tabular}{|c|c|c|c|c|c|}
\hline 47 & Tennessee & 129 & Morgan & Moderate & Yes \\
\hline & & 131 & Obion & High & No \\
\hline & & 133 & Overton & Low & Yes \\
\hline & & 135 & Perry & Low & Yes \\
\hline & & 137 & Pickett & Low & Yes \\
\hline & & 139 & Polk & Moderate & Yes \\
\hline & & 141 & Putnam & Low & Yes \\
\hline & & 143 & Rhea & Moderate & Yes \\
\hline & & 145 & Roane & Moderate & Yes \\
\hline & & 147 & Robertson & Low & Yes \\
\hline & & 149 & Rutherford & Low & Yes \\
\hline & & 151 & Scott & Moderate & Yes \\
\hline & & 153 & Sequatchie & Moderate & Yes \\
\hline & & 155 & Sevier & Moderate & Yes \\
\hline & & 157 & Shelby & High & No \\
\hline & & 159 & Smith & Low & Yes \\
\hline & & 161 & Stewart & Moderate & Yes \\
\hline & & 163 & Sullivan & Moderate & Yes \\
\hline & & 165 & Sumner & Low & Yes \\
\hline & & 167 & Tipton & High & No \\
\hline & & 169 & Trousdale & Low & Yes \\
\hline & & 171 & Unicoi & Moderate & Yes \\
\hline & & 173 & Union & Moderate & Yes \\
\hline & & 175 & Van Buren & Low & Yes \\
\hline & & 177 & Warren & Low & Yes \\
\hline & & 179 & Washington & Moderate & Yes \\
\hline & & 181 & Wayne & Low & Yes \\
\hline & & 183 & Weakley & Moderate & No \\
\hline & & 185 & White & Low & Yes \\
\hline & & 187 & Williamson & Low & Yes \\
\hline
\end{tabular}




\begin{tabular}{|l|c|c|c|c|c|}
\hline \multicolumn{5}{|c|}{ Table A-1 - Location and Seismicity Data } & Page A-89 \\
\hline \hline State Code & State & County Code & County Name & Seismicity & Av $<0.15$ \\
\hline
\end{tabular}

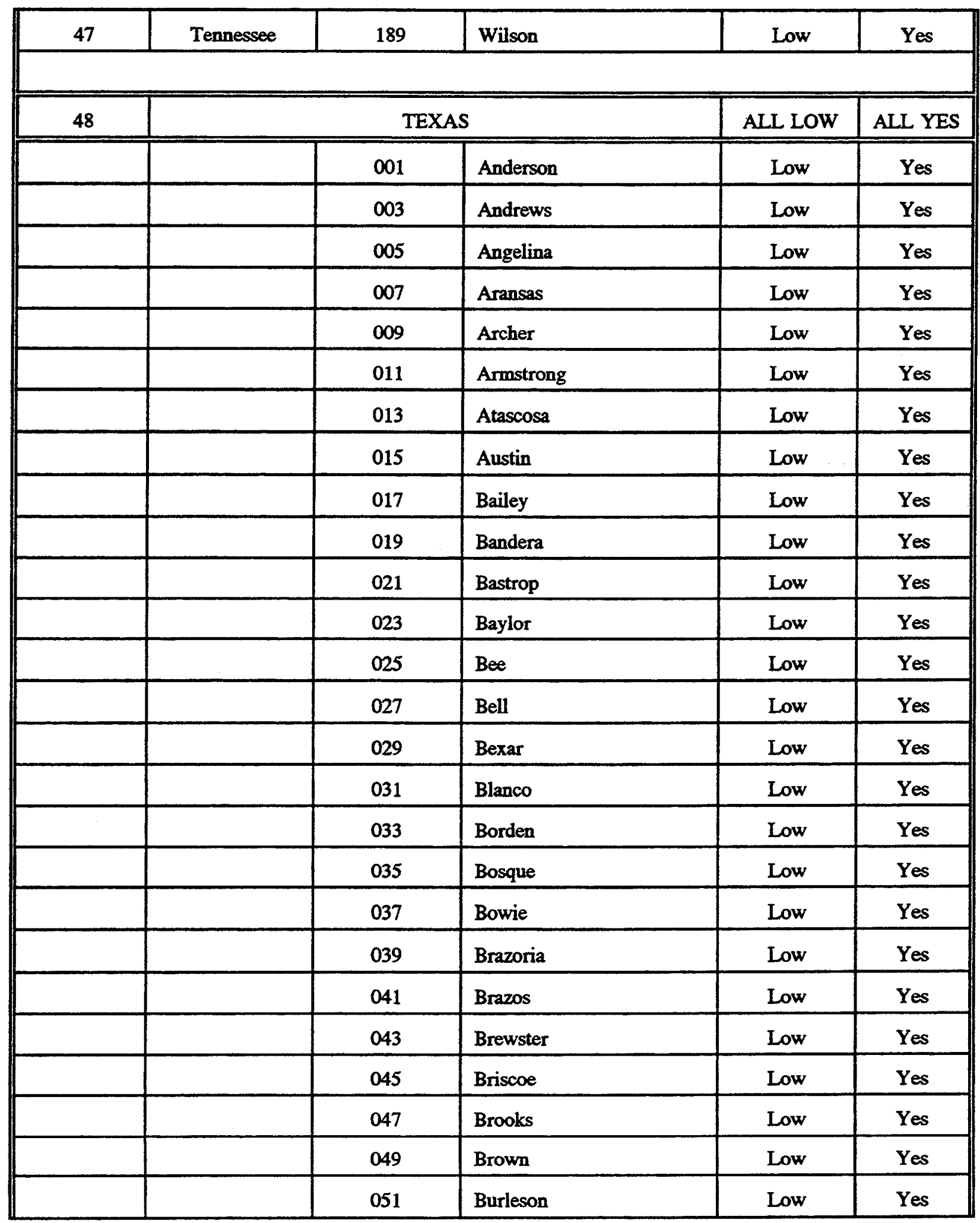


Table A-1 - Location and Seismicity Data

Page A-90

\begin{tabular}{|l|l|l|l|l|l|}
\hline State Code & State & County Code & County Name & Seismicity & $A_{v}<0.15$ \\
\hline
\end{tabular}

\begin{tabular}{|c|c|c|c|c|c|}
\hline 48 & Texas & 053 & Burnet & Low & Yes \\
\hline & & 055 & Caldwell & Low & Yes \\
\hline & & 057 & Calhoun & Low & Yes \\
\hline & & 059 & Callahan & Low & Yes \\
\hline & & 061 & Cameron & Low & Yes \\
\hline & & 063 & Camp & Low & Yes \\
\hline & & 065 & Carson & Low & Yes \\
\hline & & 067 & Cass & Low & Yes \\
\hline & & 069 & Castro & Low & Yes \\
\hline & & 071 & Chambers & Low & Yes \\
\hline & & 073 & Cherokee & Low & Yes \\
\hline & & 075 & Childress & Low & Yes \\
\hline & & 077 & Clay & Low & Yes \\
\hline & & 079 & Cochran & Low & Yes \\
\hline & & 081 & Coke & Low & Yes \\
\hline & & 083 & Coleman & Low & Yes \\
\hline & & 085 & Collin & Low & Yes \\
\hline & & 087 & Collingsworth & Low & Yes \\
\hline & & 089 & Colorado & Low & Yes \\
\hline & & 091 & Comal & Low & Yes \\
\hline & & 093 & Comanche & Low & Yes \\
\hline & & 095 & Concho & Low & Yes \\
\hline & & 097 & Cooke & Low & Yes \\
\hline & & 099 & Coryell & Low & Yes \\
\hline & & 101 & Cottle & Low & Yes \\
\hline & & 103 & Crane & Low & Yes \\
\hline & & 105 & Crockett & Low & Yes \\
\hline & & 107 & Crosby & Low & Yes \\
\hline & & 109 & Culberson & Low & Yes \\
\hline & & 111 & Dallam & Low & Yes \\
\hline
\end{tabular}




\begin{tabular}{|l|c|c|c|c|c|}
\hline \multicolumn{5}{|c|}{ Table A-1 - Location and Seismicity Data } & Page A-91 \\
\hline State Code & State & County Code & County Name & Seismicity & $A_{v}<0.15$ \\
\hline
\end{tabular}

\begin{tabular}{|c|c|c|c|c|c|}
\hline 48 & Texas & 113 & Dallas & Low & Yes \\
\hline & & 115 & Dawson & Low & Yes \\
\hline & & 117 & Deaf Smith & Low & Yes \\
\hline & & 119 & Delta & Low & Yes \\
\hline & & 121 & Denton & Low & Yes \\
\hline & & 123 & De Witt & Low & Yes \\
\hline & & 125 & Dickens & Low & Yes \\
\hline & & 127 & Dimmit & Low & Yes \\
\hline & & 129 & Donley & Low & Yes \\
\hline & & 131 & Duval & Low & Yes \\
\hline & & 133 & Eastland & Low & Yes \\
\hline & & 135 & Ector & Low & Yes \\
\hline & & 137 & Edwards & Low & Yes \\
\hline & & 139 & Ellis & Low & Yes \\
\hline & & 141 & El Paso & Low & Yes \\
\hline & & 143 & Erath & Low & Yes \\
\hline & & 145 & Falls & Low & Yes \\
\hline & & 147 & Fannin & Low & Yes \\
\hline & & 149 & Fayette & Low & Yes \\
\hline & & 151 & Fisher & Low & Yes \\
\hline & & 153 & Floyd & Low & Yes \\
\hline & & 155 & Foard & Low & Yes \\
\hline & & 157 & Fort Bend & Low & Yes \\
\hline & & 159 & Franklin & Low & Yes \\
\hline & & 161 & Freestone & Low & Yes \\
\hline & & 163 & Frio & Low & Yes \\
\hline & & 165 & Gaines & Low & Yes \\
\hline & & 167 & Galveston & Low & Yes \\
\hline & & 169 & Garza & Low & Yes \\
\hline & & 171 & Gillespie & Low & Yes \\
\hline
\end{tabular}


Table A-1 - Location and Seismicity Data

Page A-92

\begin{tabular}{|l|l|l|l|l|l|}
\hline State Code & State & County Code & County Name & Seismicity & $A_{r}<0.15$ \\
\hline
\end{tabular}

\begin{tabular}{|c|c|c|c|c|c|}
\hline 48 & Texas & 173 & Glasscock & Low & Yes \\
\hline & & 175 & Goliad & Low & Yes \\
\hline & & 177 & Gonzales & Low & Yes \\
\hline & & 179 & Gray & Low & Yes \\
\hline & & 181 & Grayson & Low & Yes \\
\hline & & 183 & Gregg & Low & Yes \\
\hline & & 185 & Grimes & Low & Yes \\
\hline & & 187 & Guadalupe & Low & Yes \\
\hline & & 189 & Hale & Low & Yes \\
\hline & & 191 & Hall & Low & Yes \\
\hline & & 193 & Hamilton & Low & Yes \\
\hline & & 195 & Hansford & Low & Yes \\
\hline & & 197 & Hardeman & Low & Yes \\
\hline & & 199 & Hardin & Low & Yes \\
\hline & & 201 & Harris & Low & Yes \\
\hline & & 203 & Harrison & Low & Yes \\
\hline & & 205 & Hartley & Low & Yes \\
\hline & & 207 & Haskell & Low & Yes \\
\hline & & 209 & Hays & Low & Yes \\
\hline & & 211 & Hemphill & Low & Yes \\
\hline & & 213 & Henderson & Low & Yes \\
\hline & & 215 & Hidalgo & Low & Yes \\
\hline & & 217 & Hill & Low & Yes \\
\hline & & 219 & Hockley & Low & Yes \\
\hline & & 221 & Hood & Low & Yes \\
\hline & & 223 & Hopkins & Low & Yes \\
\hline & & 225 & Houston & Low & Yes \\
\hline & & 227 & Howard & Low & Yes \\
\hline & & 229 & Hudspeth & Low & Yes \\
\hline & & 231 & Hunt & Low & Yes \\
\hline
\end{tabular}




\begin{tabular}{||c|c|c|c|c|c|}
\hline \multicolumn{5}{|c|}{ Table A-1 - Location and Seismicity Data } & Page A-93 \\
\hline \hline State Code & State & County Code & County Name & Seismicity & Av $_{\mathbf{v}}<0.15$ \\
\hline
\end{tabular}

\begin{tabular}{|c|c|c|c|c|c|}
\hline 48 & Texas & 233 & Hutchinson & Low & Yes \\
\hline & & 235 & Irion & Low & Yes \\
\hline & & 237 & Jack & Low & Yes \\
\hline & & 239 & Jackson & Low & Yes \\
\hline & & 241 & Jasper & Low & Yes \\
\hline & & 243 & Jeff Davis & Low & Yes \\
\hline & & 245 & Jefferson & Low & Yes \\
\hline & & 247 & Jim Hogg & Low & Yes \\
\hline & & 249 & Jim Wells & Low & Yes \\
\hline & & 251 & Johnson & Low & Yes \\
\hline & & 253 & Jones & Low & Yes \\
\hline & & 255 & Karnes & Low & Yes \\
\hline & & 257 & Kaufman & Low & Yes \\
\hline & & 259 & Kendall & Low & Yes \\
\hline & & 261 & Kenedy & Low & Yes \\
\hline & & 263 & Kent & Low & Yes \\
\hline & & 265 & Kerr & Low & Yes \\
\hline & & 267 & Kimble & Low & Yes \\
\hline & & 269 & King & Low & Yes \\
\hline & & 271 & Kinney & Low & Yes \\
\hline & & 273 & Kleberg & Low & Yes \\
\hline & & 275 & Knox & Low & Yes \\
\hline & & 277 & Lamar & Low & Yes \\
\hline & & 279 & Lamb & Low & Yes \\
\hline & & 281 & Lampasas & Low & Yes \\
\hline & & 283 & La Salle & Low & Yes \\
\hline & & 285 & Lavaca & Low & Yes \\
\hline & & 287 & Lee & Low & Yes \\
\hline & & 289 & Leon & Low & Yes \\
\hline & & 291 & Liberty & Low & Yes \\
\hline
\end{tabular}


Table A-1 - Location and Seismicity Data

Page A-94

\begin{tabular}{|l|l|l|l|l|l|}
\hline State Code & State & County Code & County Name & Seismicity & $A_{\mathrm{v}}<0.15$ \\
\hline
\end{tabular}

\begin{tabular}{|c|c|c|c|c|c|}
\hline 48 & Texas & 293 & Limestone & Low & Yes \\
\hline & & 295 & Lipscomb & Low & Yes \\
\hline & & 297 & Live Oak & Low & Yes \\
\hline & & 299 & Llano & Low & Yes \\
\hline & & 301 & Loving & Low & Yes \\
\hline & & 303 & Lubbock & Low & Yes \\
\hline & & 305 & Lynn & Low & Yes \\
\hline & & 307 & McCulloch & Low & Yes \\
\hline & & 309 & McClennan & Low & Yes \\
\hline & & 311 & McMullen & Low & Yes \\
\hline & & 313 & Madison & Low & Yes \\
\hline & & 315 & Marion & Low & Yes \\
\hline & & 317 & Martin & Low & Yes \\
\hline & & 319 & Mason & Low & Yes \\
\hline & & 321 & Matagorda & Low & Yes \\
\hline & & 323 & Maverick & Low & Yes \\
\hline & & 325 & Medina & Low & Yes \\
\hline & & 327 & Menard & Low & Yes \\
\hline & & 329 & Midland & Low & Yes \\
\hline & & 331 & Milam & Low & Yes \\
\hline & & 333 & Mills & Low & Yes \\
\hline & & 335 & Mitchell & Low & Yes \\
\hline & & 337 & Montague & Low & Yes \\
\hline & & 339 & Montgomery & Low & Yes \\
\hline & & 341 & Moore & Low & Yes \\
\hline & & 343 & Morris & Low & Yes \\
\hline & & 345 & Motley & Low & Yes \\
\hline & & 347 & Nacogdoches & Low & Yes \\
\hline & & 349 & Navarro & Low & Yes \\
\hline & & 351 & Newton & Low & Yes \\
\hline
\end{tabular}




\begin{tabular}{|l|l|l|c|c|c|}
\hline \multicolumn{5}{|c|}{ Table A-1 - Location and Seismicity Data } & Page A-95 \\
\hline \hline State Code & State & County Code & County Name & Seismicity & Av $<0.15$ \\
\hline
\end{tabular}

\begin{tabular}{|c|c|c|c|c|c|}
\hline 48 & Texas & 353 & Nolan & Low & Yes \\
\hline & & 355 & Nueces & Low & Yes \\
\hline & & 357 & Ochiltree & Low & Yes \\
\hline & & 359 & Oldham & Low & Yes \\
\hline & & 361 & Orange & Low & Yes \\
\hline & & 363 & Palo Pinto & Low & Yes \\
\hline & & 365 & Panola & Low & Yes \\
\hline & & 367 & Parker & Low & Yes \\
\hline & & 369 & Parmer & Low & Yes \\
\hline & & 371 & Pecos & Low & Yes \\
\hline & & 373 & Polk & Low & Yes \\
\hline & & 375 & Potter & Low & Yes \\
\hline & & 377 & Presidio & Low & Yes \\
\hline & & 379 & Rains & Low & Yes \\
\hline & & 381 & Randall & Low & Yes \\
\hline & & 383 & Reagan & Low & Yes \\
\hline & & 385 & Real & Low & Yes \\
\hline & & 387 & Red River & Low & Yes \\
\hline & & 389 & Reeves & Low & Yes \\
\hline & & 391 & Refugio & Low & Yes \\
\hline & & 393 & Roberts & Low & Yes \\
\hline & & 395 & Robertson & Low & Yes \\
\hline & & 397 & Rockwall & Low & Yes \\
\hline & & 399 & Runnels & Low & Yes \\
\hline & & 401 & Rusk & Low & Yes \\
\hline & & 403 & Sabine & Low & Yes \\
\hline & & 405 & San Augustine & Low & Yes \\
\hline & & 407 & San Jacinto & Low & Yes \\
\hline & & 409 & San Patricio & Low & Yes \\
\hline & & 411 & San Saba & Low & Yes \\
\hline
\end{tabular}


Table A-1 - Location and Seismicity Data

Page A-96

\begin{tabular}{|l|l|l|l|l|l|}
\hline State Code & State & County Code & County Name & Seismicity & $A_{v}<0.15$ \\
\hline
\end{tabular}

\begin{tabular}{|c|c|c|c|c|c|}
\hline 48 & Texas & 413 & Schleicher & Low & Yes \\
\hline & & 415 & Scurry & Low & Yes \\
\hline & & 417 & Shackelford & Low & Yes \\
\hline & & 419 & Shelby & Low & Yes \\
\hline & & 421 & Sherman & Low & Yes \\
\hline & & 423 & Smith & Low & Yes \\
\hline & & 425 & Somervell & Low & Yes \\
\hline & & 427 & Starr & Low & Yes \\
\hline & & 429 & Stephens & Low & Yes \\
\hline & & 431 & Sterling & Low & Yes \\
\hline & & 433 & Stonewall & Low & Yes \\
\hline & & 435 & Sutton & Low & Yes \\
\hline & & 437 & Swisher & Low & Yes \\
\hline & & 439 & Tarrant & Low & Yes \\
\hline & & 441 & Taylor & Low & Yes \\
\hline & & 443 & Terrell & Low & Yes \\
\hline & & 445 & Terry & Low & Yes \\
\hline & & 447 & Throckmorton & Low & Yes \\
\hline & & 449 & Titus & Low & Yes \\
\hline & & 451 & Tom Green & Low & Yes \\
\hline & & 453 & Travis & Low & Yes \\
\hline & & 455 & Trinity & Low & Yes \\
\hline & & 457 & Tyler & Low & Yes \\
\hline & & 459 & Upshur & Low & Yes \\
\hline & & 461 & Upton & Low & Yes \\
\hline & & 463 & Uvalde & Low & Yes \\
\hline & & 465 & Val Verde & Low & Yes \\
\hline & & 467 & Van Zandt & Low & Yes \\
\hline & & 469 & Victoria & Low & Yes \\
\hline & & 471 & Walker & Low & Yes \\
\hline
\end{tabular}




\begin{tabular}{|l|c|c|c|c|c|}
\hline \multicolumn{5}{|c|}{ Table A-1 - Location and Seismicity Data } & Page A-97 \\
\hline State Code & State & County Code & County Name & Seismicity & Av $_{\mathrm{v}}<0.15$ \\
\hline
\end{tabular}

\begin{tabular}{|c|c|c|c|c|c|}
\hline 48 & Texas & 473 & Waller & Low & Yes \\
\hline & & 475 & Ward & Low & Yes \\
\hline & & 477 & Washington & Low & Yes \\
\hline & & 479 & Webb & Low & Yes \\
\hline & & 481 & Wharton & Low & Yes \\
\hline & & 483 & Wheeler & Low & Yes \\
\hline & & 485 & Wichita & Low & Yes \\
\hline & & 487 & Wilbarger & Low & Yes \\
\hline & & 489 & Willacy & Low & Yes \\
\hline & & 491 & Williamson & Low & Yes \\
\hline & & 493 & Wilson & Low & Yes \\
\hline & & 495 & Winkler & Low & Yes \\
\hline & & 497 & Wise & Low & Yes \\
\hline & & 499 & Wood & Low & Yes \\
\hline & & 501 & Yoakum & Low & Yes \\
\hline & & 503 & Young & Low & Yes \\
\hline & & 505 & Zapata & Low & Yes \\
\hline & & 507 & Zavala & Low & Yes \\
\hline 49 & \multicolumn{3}{|c|}{ UTAH } & MIXED & MIXED \\
\hline & & 001 & Beaver & High & No \\
\hline & & 003 & Box Elder & High & No \\
\hline & & 005 & Cache & High & No \\
\hline & & 007 & Carbon & Moderate & No \\
\hline & & 009 & Daggett & Moderate & Yes \\
\hline & & 011 & Davis & High & No \\
\hline & & 013 & Duchesne & Moderate & No \\
\hline & & 015 & Emery & Moderate & No \\
\hline & & 017 & Garfield & Moderate & No \\
\hline
\end{tabular}


Table A-1 - Location and Seismicity Data

Page A-98

\begin{tabular}{|l|l|l|l|l|l|}
\hline State Code & State & County Code & County Name & Seismicity & $A_{r}<0.15$ \\
\hline
\end{tabular}

\begin{tabular}{|c|c|c|c|c|c|}
\hline 49 & Utah & 019 & Grand & Low & Yes \\
\hline & & 021 & Iron & Moderate & No \\
\hline & & 023 & Juab & High & No \\
\hline & & 025 & Kane & Moderate & Yes \\
\hline & & 027 & Millard & High & No \\
\hline & & 029 & Morgan & High & No \\
\hline & & 031 & Piute & High & No \\
\hline & & 033 & Rich & High & No \\
\hline & & 035 & Salt Lake & High & No \\
\hline & & 037 & San Juan & Low & Yes \\
\hline & & 039 & Sanpete & High & No \\
\hline & & 041 & Sevier & High & No \\
\hline & & 043 & Summit & High & No \\
\hline & & 045 & Tooele & High & No \\
\hline & & 047 & Uintah & Low & Yes \\
\hline & & 049 & Utah & High & No \\
\hline & & 051 & Wasatch & High & No \\
\hline & & 053 & Washington & Moderate & No \\
\hline & & 055 & Wayne & Moderate & No \\
\hline & & 057 & Weber & High & No \\
\hline 50 & \multicolumn{3}{|c|}{ VERMONT } & ALI MOD & ALL YES \\
\hline & & 001 & Addison & Moderate & Yes \\
\hline & & 003 & Bennington & Moderate & Yes \\
\hline & & 005 & Caledonia & Moderate & Yes \\
\hline & & 007 & Chittenden & Moderate & Yes \\
\hline & & 009 & Essex & Moderate & Yes \\
\hline & & 011 & Franklin & Moderate & Yes \\
\hline & & 013 & Grand Isle & Moderate & Yes \\
\hline
\end{tabular}




\begin{tabular}{||c|c|c|c|c|c|}
\hline \multicolumn{5}{|c|}{ Table A-1 - Location and Seismicity Data } & Page A-99 \\
\hline \hline State Code & State & County Code & County Name & Seismicity & Av $_{\mathrm{v}}<0.15$ \\
\hline
\end{tabular}

\begin{tabular}{|c|c|c|c|c|c|}
\hline 50 & Vermont & 015 & Lamoille & Moderate & Yes \\
\hline & & 017 & Orange & Moderate & Yes \\
\hline & & 019 & Orleans & Moderate & Yes \\
\hline & & 021 & Rutland & Moderate & Yes \\
\hline & & 023 & Washington & Moderate & Yes \\
\hline & & 025 & Windham & Moderate & Yes \\
\hline & & 027 & Windsor & Moderate & Yes \\
\hline \multirow[t]{21}{*}{51} & \multicolumn{3}{|c|}{ VIRGINIA } & MIXED & ALL YES \\
\hline & & 001 & Accomack & Low & Yes \\
\hline & & 003 & Albemarle & Low & Yes \\
\hline & & 510 & Alexandria City & Low & Yes \\
\hline & & 005 & Alleghany & Low & Yes \\
\hline & & 007 & Amelia & Low & Yes \\
\hline & & 009 & Amiherst & Low & Yes \\
\hline & & 011 & Appomattox & Low & Yes \\
\hline & & 013 & Arlington & Low & Yes \\
\hline & & 015 & Augusta & Low & Yes \\
\hline & & 017 & Bath & Low & Yes \\
\hline & & 019 & Bedford & Low & Yes \\
\hline & & 515 & Bedford City & Low & Yes \\
\hline & & 021 & Bland & Moderate & Yes \\
\hline & & 023 & Botetourt & Low & Yes \\
\hline & & 520 & Bristol City & Moderate & Yes \\
\hline & & 025 & Brunswick & Low & Yes \\
\hline & & 027 & Buchanan & Moderate & Yes \\
\hline & & 029 & Buckingham & Low & Yes \\
\hline & & 530 & Buena Vista City & Low & Yes \\
\hline & & 031 & Campbell & Low & Yes \\
\hline
\end{tabular}




\begin{tabular}{||c|c|c|c|c|c|}
\hline \multicolumn{5}{|c|}{ Table A-1 - Location and Seismicity Data } & Page A-100 \\
\hline \hline State Code & State & County Code & County Name & Seismicity & A $_{\mathrm{v}}<0.15$ \\
\hline
\end{tabular}

\begin{tabular}{|c|c|c|c|c|c|}
\hline 51 & Virginia & 033 & Caroline & Low & Yes \\
\hline & & 035 & Carroll & Moderate & Yes \\
\hline & & 036 & Charles City & Low & Yes \\
\hline & & 037 & Charlotte & Low & Yes \\
\hline & & 540 & Charlottesville City & Low & Yes \\
\hline & & 550 & Chesapeake City & Low & Yes \\
\hline & & 041 & Chesterfield & Low & Yes \\
\hline & & 043 & Clarke & Low & Yes \\
\hline & & 560 & Clifton Forge City & Moderate & Yes \\
\hline & & 570 & Colonial Heights City & Low & Yes \\
\hline & & 580 & Covington City & Moderate & Yes \\
\hline & & 045 & Craig & Moderate & Yes \\
\hline & & 047 & Culpeper & Low & Yes \\
\hline & & 049 & Cumberland & Low & Yes \\
\hline & & 590 & Danville City & Low & Yes \\
\hline & & 051 & Dickenson & Moderate & Yes \\
\hline & & 053 & Dinwiddie & Low & Yes \\
\hline & & 595 & Emporia City & Low & Yes \\
\hline & & 057 & Essex & Low & Yes \\
\hline 0 & & 059 & Fairfax & Low & Yes \\
\hline & & 600 & Fairfax City & Low & Yes \\
\hline & & 610 & Falls Church City & Low & Yes \\
\hline & & 061 & Fauquier & Low & Yes \\
\hline & & 063 & Floyd & Low & Yes \\
\hline & & 065 & Fluvanna & Moderate & Yes \\
\hline & & 067 & Franklin & Low & Yes \\
\hline & & 620 & Franklin City & Low & Yes \\
\hline & & 069 & Frederick & Low & Yes \\
\hline & & 630 & Fredericksburg City & Low & Yes \\
\hline & & 640 & Galax City & Moderate & Yes \\
\hline
\end{tabular}


Table A-1 - Location and Seismicity Data

Page A-101

\begin{tabular}{|l|l|l|l|l|l|}
\hline State Code & State & County Code & County Name & Seismicity & $\mathrm{A}_{\mathrm{v}}<0.15$ \\
\hline
\end{tabular}

\begin{tabular}{|c|c|c|c|c|c|}
\hline 51 & Virginia & 071 & Giles & Moderate & Yes \\
\hline & & 073 & Gloucester & Low & Yes \\
\hline & & 075 & Goochland & Low & Yes \\
\hline & & 077 & Grayson & Moderate & Yes \\
\hline & & 079 & Greene & Low & Yes \\
\hline & & 081 & Greensville & Low & Yes \\
\hline & & 083 & Halifax & Low & Yes \\
\hline & & 650 & Hampton City & Low & Yes \\
\hline & & 085 & Hanover & Low & Yes \\
\hline & & 660 & Harrisonburg City & Low & Yes \\
\hline & & 087 & Henrico & Low & Yes \\
\hline & & 089 & Henry & Low & Yes \\
\hline & & 091 & Highland & Low & Yes \\
\hline & & 670 & Hopewell City & Low & Yes \\
\hline & & 093 & Isle of Wight & Low & Yes \\
\hline & & 095 & James City & Low & Yes \\
\hline & & 097 & King and Queen & Low & Yes \\
\hline & & 099 & King George & Low & Yes \\
\hline & & 101 & King William & Low & Yes \\
\hline & & 103 & Lancaster & Low & Yes \\
\hline & & 105 & Lee & Moderate & Yes \\
\hline & & 678 & Lexington City & Low & Yes \\
\hline & & 107 & Loudoun & Low & Yes \\
\hline & & 109 & Louisa & Low & Yes \\
\hline & & 111 & Lunenburg & Low & Yes \\
\hline & & 680 & Lynchburg City & Low & Yes \\
\hline & & 113 & Madison & Low & Yes \\
\hline & & 683 & Manassas City & Low & Yes \\
\hline & & 685 & Manassas Park City & Low & Yes \\
\hline & & 690 & Martinsville City & Low & Yes \\
\hline
\end{tabular}




\begin{tabular}{|c|c|c|c|c|c|}
\hline \multicolumn{5}{|c|}{ Table A-1 - Location and Seismicity Data } & \multirow{2}{*}{$\frac{\text { Page A-102 }}{A_{\mathrm{v}}<0.15}$} \\
\hline State Code & State & County Code & County Name & Seismicity & \\
\hline & & 122 & Nansamond & Low & jes \\
\hline \multirow[t]{30}{*}{51} & Virginia & 115 & Mathews & Low & Yes \\
\hline & & 117 & Mecklenburg & Low & Yes \\
\hline & & 119 & Middlesex & Low & Yes \\
\hline & & 121 & Montgomery & Moderate & Yes \\
\hline & & $P_{125}$ & Nelson & Low & Yes \\
\hline & & 127 & New Kent & Low & Yes \\
\hline & & 700 & Newport News City & Low & Yes \\
\hline & & 710 & Norfolk City & Low & Yes \\
\hline & & 131 & Northampton & Low & Yes \\
\hline & & 133 & Northumberland & Low & Yes \\
\hline & & 720 & Norton & Low & Yes \\
\hline & & 135 & Nottoway & Low & Yes \\
\hline & & 137 & Orange & Low & Yes \\
\hline & & 139 & Page & Low & Yes \\
\hline & & 141 & Patrick & Low & Yes \\
\hline & & 730 & Petersburg City & Low & Yes \\
\hline & & 143 & Pittsylvania & Low & Yes \\
\hline & & 735 & Poquoson City & Low & Yes \\
\hline & & 740 & Portsmouth City & Low & Yes \\
\hline & & 145 & Powhatan & Low & Yes \\
\hline & & 147 & Prince Edward & Low & Yes \\
\hline & & 149 & Prince George & Low & Yes \\
\hline & & 153 & Prince William & Low & Yes \\
\hline & & 155 & Pulaski & Low & Yes \\
\hline & & 750 & Radford City & Moderate & Yes \\
\hline & & 157 & Rappahannock & Low & Yes \\
\hline & & 159 & Richmond & Low & Yes \\
\hline & & 760 & Richmond City & Low & Yes \\
\hline & & 161 & Roanoke & Moderate & Yes \\
\hline & & 770 & Roanoke City & Moderate & Yes \\
\hline & & -151 & $\begin{array}{l}\text { Princess Anne } \\
\text { A-102 }\end{array}$ & Low & yes \\
\hline
\end{tabular}




\begin{tabular}{|l|c|c|c|c|c|}
\hline \multicolumn{5}{|c|}{ Table A-1 - Location and Seismicity Data } & Page A-103 \\
\hline \hline State Code & State & County Code & County Name & Seismicity & Av $_{v}<0.15$ \\
\hline
\end{tabular}

\begin{tabular}{|c|c|c|c|c|c|}
\hline 51 & Virginia & 163 & Rockbridge & Low & Yes \\
\hline & & 165 & Rockingham & Low & Yes \\
\hline & & 167 & Russell & Moderate & Yes \\
\hline & & 775 & Salem City & Moderate & Yes \\
\hline & & 169 & Scott & Moderate & Yes \\
\hline & & 171 & Shenandoah & Low & Yes \\
\hline & & 173 & Smyth & Moderate & Yes \\
\hline & & 175 & Southampton & Low & Yes \\
\hline & & 780 & South Boston City & Low & Yes \\
\hline & & 177 & Spotsylvania & Low & Yes \\
\hline & & 179 & Stafford & Low & Yes \\
\hline & & 790 & Staunton City & Low & Yes \\
\hline & & 800 & Suffolk City & Low & Yes \\
\hline & & 181 & Surry & Low & Yes \\
\hline & & 183 & Sussex & Low & Yes \\
\hline & & 185 & Tazewell & Moderate & Yes \\
\hline & & 810 & Virginia Beach City & Low & Yes \\
\hline & & 187 & Warren & Low & Yes \\
\hline & & 191 & Washington & Moderate & Yes \\
\hline & & 820 & Waynesboro City & Low & Yes \\
\hline & & 193 & Westmoreland & Low & Yes \\
\hline & & 830 & Williamsburg City & Low & Yes \\
\hline & & 840 & Winchester City & Low & Yes \\
\hline & & 195 & Wise & Moderate & Yes \\
\hline & & 197 & Wythe & Moderate & Yes \\
\hline & & 199 & York & Low & Yes \\
\hline 53 & \multicolumn{3}{|c|}{ WASHINGTON } & MIXED & MIXED \\
\hline & & 001 & Adams & Moderate & Yes \\
\hline
\end{tabular}




\begin{tabular}{||l|l|l|l|l|l|}
\hline \multicolumn{5}{|c|}{ Table A-1 - Location and Seismicity Data } & Page A-104 \\
\hline \hline State Code & State & County Code & County Name & Seismicity & Av $_{\mathrm{r}}<0.15$ \\
\hline
\end{tabular}

\begin{tabular}{|c|c|c|c|c|c|}
\hline 53 & Washington & 003 & Asotin & Low & Yes \\
\hline & & 005 & Benton & Low & Yes \\
\hline & & 007 & Chelan & High & No \\
\hline & & 009 & Clallam & High & No \\
\hline & & 011 & Clark & Moderate & Yes \\
\hline & & 013 & Columbia & Low & Yes \\
\hline & & 015 & Cowlitz & Moderate & Yes \\
\hline & & 017 & Douglas & Moderate & No \\
\hline & & 019 & Ferry & Moderate & No \\
\hline & & 021 & Franklin & Low & Yes \\
\hline & & 023 & Garfield & Low & Yes \\
\hline & & 025 & Grant & Moderate & Yes \\
\hline & & 027 & Grays Harbour & Moderate & No \\
\hline & & 029 & Island & High & No \\
\hline & & 031 & Jefferson & High & No \\
\hline & & 033 & King & High & No \\
\hline & & 035 & Kitsap & High & No \\
\hline & & 037 & Kittitas & High & No \\
\hline & & 039 & Klickitat & Low & Yes \\
\hline & & 041 & Lewis & Moderate & No \\
\hline & & 043 & Lincoln & Moderate & Yes \\
\hline & & 045 & Mason & High & No \\
\hline & & 047 & Okanogan & High & No \\
\hline & & 049 & Pacific & Moderate & Yes \\
\hline & & 051 & Pend Oreille & Low & Yes \\
\hline & & 053 & Pierce & High & No \\
\hline & & 055 & San Juan & High & No \\
\hline & & 057 & Skagit & High & No \\
\hline & & 059 & Skamania & Moderate & Yes \\
\hline & & 061 & Snohomish & High & No \\
\hline
\end{tabular}




\begin{tabular}{||c|c|c|c|c|c|}
\hline \multicolumn{5}{|c|}{ Table A-1 - Location and Seismicity Data } & Page A-105 \\
\hline State Code & State & County Code & County Name & Seismicity & Av $<0.15$ \\
\hline
\end{tabular}

\begin{tabular}{|c|c|c|c|c|c|}
\hline 53 & Washington & 063 & Spokane & Low & Yes \\
\hline & & 065 & Stevens & Moderate & Yes \\
\hline & & 067 & Thurston & High & No \\
\hline & & 069 & Wahkiakum & Moderate & Yes \\
\hline & & 071 & Walla Walla & Low & Yes \\
\hline & & 073 & Whatcom & High & No \\
\hline & & 075 & Whitman & Low & Yes \\
\hline & & 077 & Yakima & Moderate & No \\
\hline \multirow[t]{20}{*}{54} & \multicolumn{3}{|c|}{ WEST VIRGINIA } & MIXED & ALL YES \\
\hline & & 001 & Barbour & Low & Yes \\
\hline & & 003 & Berkeley & Low & Yes \\
\hline & & 005 & Boone & Low & Yes \\
\hline & & 007 & Braxton & Low & Yes \\
\hline & & 009 & Brooke & Low & Yes \\
\hline & & 011 & Cabell & Low & Yes \\
\hline & & 013 & Calhoun & Low & Yes \\
\hline & & 015 & Clay & Low & Yes \\
\hline & & 017 & Doddridge & Low & Yes \\
\hline & & 019 & Fayette & Low & Yes \\
\hline & & 021 & Gilmer & Low & Yes \\
\hline & & 023 & Grant & Low & Yes \\
\hline & & 025 & Greenbrier & Low & Yes \\
\hline & & 027 & Hampshire & Low & Yes \\
\hline & & 029 & Hancock & Low & Yes \\
\hline & & 031 & Hardy & Low & Yes \\
\hline & & 033 & Harrison & Low & Yes \\
\hline & & 035 & Jackson & Low & Yes \\
\hline & & 037 & Jefferson & Low & Yes \\
\hline
\end{tabular}




\begin{tabular}{|l|c|c|c|c|c|}
\hline \multicolumn{5}{|c|}{ Table A-1 - Location and Seismicity Data } & Page A-106 \\
\hline \hline State Code & State & County Code & County Name & Seismicity & $\mathbf{A}_{v}<0.15$ \\
\hline
\end{tabular}

\begin{tabular}{|c|c|c|c|c|c|}
\hline 54 & West Virginia & 039 & Kanawha & Low & Yes \\
\hline & & 041 & Lewis & Low & Yes \\
\hline & & 043 & Lincoln & Low & Yes \\
\hline & & 045 & Logan & Low & Yes \\
\hline & & 047 & McDowell & Moderate & Yes \\
\hline & & 049 & Marion & Low & Yes \\
\hline & & 051 & Marshall & Low & Yes \\
\hline & & 053 & Mason & Low & Yes \\
\hline & & 055 & Mercer & Moderate & Yes \\
\hline & & 057 & Mineral & Low & Yes \\
\hline & & 059 & Mingo & Low & Yes \\
\hline & & 061 & Monongalia & Low & Yes \\
\hline & & 063 & Monroe & Moderate & Yes \\
\hline & & 065 & Morgan & Low & Yes \\
\hline & & 067 & Nicholas & Low & Yes \\
\hline & & 069 & Ohio & Low & Yes \\
\hline & & 071 & Pendleton & Low & Yes \\
\hline & & 073 & Pleasants & Low & Yes \\
\hline & & 075 & Pocahontas & Low & Yes \\
\hline & & 077 & Preston & Low & Yes \\
\hline & & 079 & Putnam & Low & Yes \\
\hline & & 081 & Raleigh & Low & Yes \\
\hline & & 083 & Randolph & Low & Yes \\
\hline & & 085 & Ritchie & Low & Yes \\
\hline & & 087 & Roane & Low & Yes \\
\hline & & 089 & Summers & Moderate & Yes \\
\hline & & 091 & Taylor & Low & Yes \\
\hline & & 093 & Tucker & Low & Yes \\
\hline & & 095 & Tyler & Low & Yes \\
\hline & & 097 & Upshur & Low & Yes \\
\hline
\end{tabular}




\begin{tabular}{|l|c|c|c|c|c|}
\hline \multicolumn{5}{|c|}{ Table A-1 - Location and Seismicity Data } & Page A-107 \\
\hline \hline State Code & State & County Code & County Name & Seismicity & A $_{\mathbf{v}}<0.15$ \\
\hline
\end{tabular}

\begin{tabular}{|c|c|c|c|c|c|}
\hline 54 & West Virginia & 099 & Wayne & Low & Yes \\
\hline & & 101 & Webster & Low & Yes \\
\hline & & 103 & Wetzel & . Low & Yes \\
\hline & & 105 & Wirt & Low & Yes \\
\hline & & 107 & Wood & Low & Yes \\
\hline & & 109 & Wyoming & Low & Yes \\
\hline \multirow[t]{22}{*}{55} & \multicolumn{3}{|c|}{ WISCONSIN } & ALL LOW & ALL YES \\
\hline & & 001 & Adams & Low & Yes \\
\hline & & 003 & Ashland & Low & Yes \\
\hline & & 005 & Barron & Low & Yes \\
\hline & & 007 & Bayfield & Low & Yes \\
\hline & & 009 & Brown & Low & Yes \\
\hline & & 011 & Buffalo & Low & Yes \\
\hline & & 013 & Burnett & Low & Yes \\
\hline & & 015 & Calumet & Low & Yes \\
\hline & & 017 & Chippewa & Low & Yes \\
\hline & & 019 & Clark & Low & Yes \\
\hline & & 021 & Columbia & Low & Yes \\
\hline & & 023 & Crawford & Low & Yes \\
\hline & & 025 & Dane & Low & Yes \\
\hline & & 027 & Dodge & Low & Yes \\
\hline & & 029 & Door & Low & Yes \\
\hline & & 031 & Douglas & Low & Yes \\
\hline & & 033 & Dunn & Low & Yes \\
\hline & & 035 & Eau Claire & Low & Yes \\
\hline & & 037 & Florence & Low & Yes \\
\hline & & 039 & Fond Du Lac & Low & Yes \\
\hline & & 041 & Forest & Low & Yes \\
\hline
\end{tabular}


Table A-1 - Location and Seismicity Data

Page A-108

\begin{tabular}{|l|l|l|l|l|l|}
\hline State Code & State & County Code & County Name & Seismicity & $\mathbf{A}_{\mathrm{v}}<0.15$ \\
\hline
\end{tabular}

\begin{tabular}{|c|c|c|c|c|c|}
\hline 55 & Wisconsin & 043 & Grant & Low & Yes \\
\hline & & 045 & Green & Low & Yes \\
\hline & & 047 & Green Lake & Low & Yes \\
\hline & & 049 & lowa & Low & Yes \\
\hline & & 051 & Iron & Low & Yes \\
\hline & & 053 & Jackson & Low & Yes \\
\hline & & 055 & Jefferson & Low & Yes \\
\hline & & 057 & Juneau & Low & Yes \\
\hline & & 059 & Kenosha & Low & Yes \\
\hline & & 061 & Kewaunee & Low & Yes \\
\hline & & 063 & La Crosse & Low & Yes \\
\hline & & 065 & Lafayette & Low & Yes \\
\hline & & 067 & Langlade & Low & Yes \\
\hline & & 069 & Lincoln & Low & Yes \\
\hline & & 071 & Manitowoc & Low & Yes \\
\hline & & 073 & Marathon & Low & Yes \\
\hline & & 075 & Marinette & Low & Yes \\
\hline & & 077 & Marquette & Low & Yes \\
\hline & & 078 & Menominee & Low & Yes \\
\hline & & 079 & Milwaukee & Low & Yes \\
\hline & & 081 & Monroe & Low & Yes \\
\hline & & 083 & Oconto & Low & Yes \\
\hline & & 085 & Oneida & Low & Yes \\
\hline & & 087 & Outagamie & Low & Yes \\
\hline & & 089 & Ozaukee & Low & Yes \\
\hline & & 091 & Pepin & Low & Yes \\
\hline & & 093 & Pierce & Low & Yes \\
\hline & & 095 & Polk & Low & Yes \\
\hline & & 097 & Portage & Low & Yes \\
\hline & & 099 & Price & Low & Yes \\
\hline
\end{tabular}




\begin{tabular}{|l|c|c|c|c|c|}
\hline \multicolumn{5}{|c|}{ Table A-1 - Location and Seismicity Data } & Page A-109 \\
\hline \hline State Code & State & County Code & County Name & Seismicity & A $_{\mathrm{v}}<0.15$ \\
\hline
\end{tabular}

\begin{tabular}{|c|c|c|c|c|c|}
\hline 55 & Wisconsin & 101 & Racine & Low & Yes \\
\hline & & 103 & Richland & Low & Yes \\
\hline & & 105 & Rock & Low & Yes \\
\hline & & 107 & Rusk & Low & Yes \\
\hline & & 109 & St Croix & Low & Yes \\
\hline & & 111 & Sauk & Low & Yes \\
\hline & & 113 & Sawyer & Low & Yes \\
\hline & & 115 & Shawano & Low & Yes \\
\hline & & 117 & Sheboygan & Low & Yes \\
\hline & & 119 & Taylor & Low & Yes \\
\hline & & 121 & Trempealeau & Low & Yes \\
\hline & & 123 & Vernon & Low & Yes \\
\hline & & 125 & Vilas & Low & Yes \\
\hline & & 127 & Walworth & Low & Yes \\
\hline & & 129 & Washburn & Low & Yes \\
\hline & & 131 & Washington & Low & Yes \\
\hline & & 133 & Waukesha & Low & Yes \\
\hline & & 135 & Waupaca & Low & Yes \\
\hline & & 137 & Waushara & Low & Yes \\
\hline & & 139 & Winnebago & Low & Yes \\
\hline & & 141 & Wood & Low & Yes \\
\hline 56 & \multicolumn{3}{|c|}{ WYOMING } & MIXED & MIXED \\
\hline & & 001 & Albany & Low & Yes \\
\hline & & 003 & Big Horn & Moderate & Yes \\
\hline & & 005 & Campbell & Low & Yes \\
\hline & & 007 & Carbon & Low & Yes \\
\hline & & 009 & Converse & Low & Yes \\
\hline & & 011 & Crook & Low & Yes \\
\hline
\end{tabular}




\begin{tabular}{|l|l|l|l|l|c|}
\hline \multicolumn{5}{|c|}{ Table A-1 - Location and Seismicity Data } & Page A-110 \\
\hline \hline State Code & State & County Code & County Name & Seismicity & $\mathbf{A}_{v}<0.15$ \\
\hline
\end{tabular}

\begin{tabular}{|c|c|c|c|c|c|}
\hline 56 & Wyoming & 013 & Fremont & High & No \\
\hline & & 015 & Goshen & Low & Yes \\
\hline & & 017 & Hot Springs & Moderate & Yes \\
\hline & & 019 & Johnson & Low & Yes \\
\hline & & 021 & Laramie & Low & Yes \\
\hline & & 023 & Lincoln & High & No \\
\hline & & 025 & Natrona & Low & Yes \\
\hline & & 027 & Niobrara & Low & Yes \\
\hline & & 029 & Park & High & No \\
\hline & & 031 & Platte & Low & Yes \\
\hline & & 033 & Sheridan & Low & Yes \\
\hline & & 035 & Sublette & High & No \\
\hline & & 037 & Sweetwater & Moderate & Yes \\
\hline & & 039 & Teton & High & No \\
\hline & & 041 & Uinta & Moderate & No \\
\hline & & 043 & Washakie & Moderate & Yes \\
\hline & & 045 & Weston & Low & Yes \\
\hline & & 047 & Yellowstone National Park & High & No \\
\hline
\end{tabular}


Table A-2 - Location and Seismicity Data for U.S. Territories and Possessions

Page A-111

\begin{tabular}{|c|c|c|c|}
\hline Territory Code & Territory or Possession & Seismicity & $\mathbf{A}_{\mathbf{v}}<0.15$ \\
\hline
\end{tabular}

\begin{tabular}{|c|l|l|l|}
\hline 81 & American Samoa & High & No \\
\hline 86 & Guam & High & No \\
\hline 92 & Puerto Rico & High & No \\
\hline 93 & Virgin Islands & High & No \\
\hline
\end{tabular}

If you have buildings in a US territory or possession which is not listed here, please contact the ICSSC Technical Secretariat to establish a code number. 
APPENDIX B

OCCUPANCY CATEGORIES 


\section{OCCUPANCY CATEGORIES}

One of the fields which agencies are to report in their electronic database of owned buildings is Occupancy Class. The codes to be used for this reporting are contained in Section 5 of this Handbook in Table 5-3 and are reproduced in that table as follows:

\begin{tabular}{|c|l|}
\hline \multicolumn{2}{|c|}{ Table 5-3 - Occupancy Categories } \\
\hline \hline Code to be Entered & \multicolumn{1}{|c|}{ Occupancy Classification } \\
\hline 10 & Office \\
\hline 14 & Post Office \\
\hline 21 & Hospital \\
\hline 22 & Prison \\
\hline 23 & School \\
\hline 29 & Other Institutional \\
\hline 30 & Housing \\
\hline 40 & Storage \\
\hline 50 & Industrial \\
\hline 60 & Service \\
\hline 70 & Research and Development \\
\hline 80 & All Other \\
\hline
\end{tabular}

These occupancy classes are the same as those used in creating the real-property inventory for annual submission to the General Services Administration (GSA). They have been chosen because many agencies who report regularly to the GSA database already have their buildings classified according to these codes. However, other agencies, including the agencies under the Department of Defense, have their building occupancies classified by different codes which include more than twelve categories.

This Appendix contains a list of Real Property Category codes that are classified as buildings by the Department of Defense in the AR 415-28. These category codes have been grouped under the twelve occupancy codes required for the electronic database reporting effort. This list should serve as a guide for agencies who need to group previously existing building occupancies under the twelve codes listed in Table 5-3. 
OFFICE OCCUPANCY CLASSIFICATION (10)

14110 AIRFIELD OPERATIONS BUIIDING

14112 AVIATION UNIT OPERATIONS BUILDING

14113 ACCESS CONTROL BUILDING

14114 CIDC FIELD OPERATIONS BUILDING

14132 READY BUILDING

14161 EMERGENCY OPERATIONS CENTER (EOC)

14162 SPECIAL COMPARTMENTED INFORMATION FACILITY (SCIF)

14166 DISPATCH BUILDING

14182 BRIGADE HEADQUARTERS BUILDING

14183 BATTALION HEADQUARTERS BUILDING

14185 COMPANY HEADQUARTERS BUILDING

14310 SHIP OPERATIONS BUILDING

15610 CARGO HANDLING OFFICE BUILDING

17140 ARMY RESERVE CENTER BUILDING

17141 ARMED FORCES RESERVE CENTER BUILDING

17142 NATIONAL GUARD/RESERVE CENTER BUILDING

61050 ADMINISTRATIVE FACILITY, GENERAL PURPOSE

61055 WAITING AREA

61075 COURTROOM

62010 UNDERGROUND ADMINISTRATIVE FACILITY

74006 BANK

74023 CREDIT UNION

74033 ARMY COMMUNITY SERVICES CENTER

POST OFFICE OCCUPANCY CLASSIFICATION (14)

73072 POST OFFICE BRANCH

73073 POST OFFICE, MAIN

\section{HOSPITAL OCCUPANCY CLASSIFICATION (21)}

51010 MEDICAL CENTER/HOSPITAL

53020 LABORATORY

53030 MORGUE

53040 VETERINARY FACILITY

53060 MEDICAL WAREHOUSE

53071 AMBULANCE GARAGE

54010 DENTAL CLINIC

55010 TROOP DISPENSARY/HEALTH CLINIC

55050 PHARMACY

61070 RED CROSS BUILDING 


\section{PRISON OCCUPANCY CLASSIFICATION (22)}

73015 CONFINEMENT FACILITY

\section{SCHOOL OCCUPANCY CLASSIFICATION (23)}

14129 TRAINING AIDS CENTER

17112 SIMULATOR BUILDING

17115 BAND TRAINING BUILDING

17119 ORGANIZATIONAL CLASSROOM

17120 GENERAL INSTRUCTION BUILDING

17131 COMPACT ITEM REPAIR INSTRUCTIONAL BUILDING

17132 GENERAL ITEM REPAIR INSTRUCTIONAL BUILDING

17133 VEHICLE MAINTENANCE INSTRUCTIONAL BUILDING

17134 AIRCRAFT MAINTENANCE INSTRUCTIONAL BUILDING

17135 LABORATORY INSTRUCTIONAL BUILDING

17136 AUTOMATION-AIDED INSTRUCTIONAL BUILDING

17137 MATERIAL HANDLING INSTRUCTIONAL BUILDING

17138 LIMITED USE INSTRUCTIONAL BUILDING

17182 MOVING TARGET SIMULATOR BUILDING

61065 TECHNICAL LIBRARY

61080 BATTLE LAB

73018 RELIGIOUS EDUCATION FACILITY

73046 DEPENDENT SCHOOL

74014 CHILD DEVELOPMENT CENTER

74025 ARMY CONTINUING EDUCATION SYSTEM FACILITY

74040 LIBRARY BRANCH

74041 LIBRARY MAIN

\section{OTHER INSTITUTIONAL OCCUPANCY CLASSIFICATION (29)}

13115 INFORMATION SYSTEMS FACILITY

13120 COMMUNICATIONS CENTER

13125 MILITARY AFFILIATE RADIO SYSTEM STATION

13160 TRANSMITTER BUILDING

13170 RECEIVER BUILDING

13175 TELEVIDEO CENTER

13181 TERMINAL EQUIPMENT FACILITY

13310 FLIGHT CONTROL TOWER

13320 NAVIGATION BUILDING, AIR

13710 LIGHTHOUSE

14115 WEATHER STATION

EMPLOYEE CHANGING BUILDING 
SCALE HOUSE

SAFETY SHELTER

INDOOR FIRING RANGE

17122

RANGE OR TARGET HOUSE

17123

RANGE SUPPORT FACILITY

17170

17180

21922

GAS CHAMBER

NATIONAL GUARD ARMORY

ENTOMOLOGY FACILITY

\section{HOUSING OCCUPANCY CLASSIFICATION (30)}

71111 FAMILY HOUSING, GENERAL OFFICER

71112

71113

71114

71115

71116

72111

72114

72115

72120

72170

72181

72360

72410

72411

72510

74032

74036

FAMILY HOUSING, COLONEL

FAMILY HOUSING, LT COLONEL AND MAJOR

FAMILY HOUSING, COMPANY GRADE AND WARRANT OFFICER

FAMILY HOUSING, SENIOR NCO

FAMILY HOUSING, JUNIOR NCO/ENLISTED

ENLISTED UNACCOMPANIED PERSONNEL HOUSING

ENLISTED BARRACKS, ANNUAL TRAINING

ENLISTED BARRACKS, MOBILIZATION

TRANSIENT UNACCOMPANIED PERSONNEL HOUSING

UNACCOMPANIED PERSONNEL HOUSING, SENIOR NCO

TRAINEE BARRACKS

DAY ROOM, DETACHED

UNACCOMPANIED OFFICERS QUARTERS, MILITARY

UNACCOMPANIED OFFICERS QUARTERS, MILITARY TRANSIENT HUTMENT

GUEST HOUSE

RECREATIONAL BILLETS

STORAGE OCCUPANCY CLASSIFICATION (40)

14220 HELIUM STORAGE BUILDING

21113 AIRCRAFT PARTS STORAGE

21445

21470

21865

21870

42104

42107

42110

42120

42150

42160

TANK/AUTOMOTIVE PARTS STORAGE, DEPOT LEVEL

OIL STORAGE BUILDING, NON-DOL/DEH/DPW

OIL STORAGE BUILDING, DOL/DEH/DPW

MAINTENANCE STORAGE, DOL/DEH/DPW

EXPLOSIVE TRANSFER DEPOT LEVEL

STRADLEY, NONATOMIC BLAST RESISTANT, DEPOT LEVEL

FUSE AND DETONATOR MAGAZINE, DEPOT LEVEL

HIGH EXPLOSIVE MAGAZINE, DEPOT LEVEL

SMOKELESS POWDER MAGAZINE, DEPOT LEVEL

42170 SPECIAL WEAPONS MAGAZINE, DEPOT LEVEL GUIDED MISSILE MAGAZINE, DEPOT LEVEL 
42180

42181

42182

42183

42184

42210

42215

42225

42230

42231

42235

42240

42250

42260

42280

42281

42283

42285

42310

42410

43110

43211

43220

44110

44130

44135

44150

44160

44170

44182

44210

44220

44223

44224

44228

44230

44240

44250

44271

71410

71420

72350

74055

IGLOO STORAGE, DEPOT LEVEL

AMMUNITION STOREHOUSE, DEPOT LEVEL SMALL ARMS AMMUNITION MAGAZINE, DEPOT LEVEL GENERAL PURPOSE MAGAZINE, DEPOT LEVEL AMMUNITION HUT, DEPOT LEVEL FUSE AND DETONATOR MAGAZINE, INSTALLATION HIGH EXPLOSIVE MAGAZINE, INSTALLATION SMOKEDRUM STOREHOUSE, INSTALLATION SMALL ARMS AMMUNITION AND PYROTECHNICS MAGAZINE, INSTALLATION

AMMUNTTION STOREHOUSE, INSTALLATION

READY MAGAZINE, INSTALLATION

FIXED AMMUNITION MAGAZINE, INSTALLATION

SPECIAL WEAPONS MAGAZINE, INSTALLATION

GUIDED MISSILE MAGAZINE, INSTALLATION

IGLOO STORAGE, INSTALLATION

AMMUNITION HUT, INSTALLATION

GENERAL PURPOSE MAGAZINE, INSTALLATION

UNIT SMALL ARMS AMMUNITION STORAGE, INSTALLATION

LIQUID PROPELLANT STORAGE, AMMUNITION, BUILDING

BATTERY COLD STORAGE BUILDING

COLD STORAGE FACILITY, DEPOT LEVEL

COLD STORAGE FACILITY, INSTALLATION

MEAT CUTTING PLANT, INSTALLATION

STORAGE FACILITY, GENERAL PURPOSE, DEPOT LEVEL

CONTROLLED HUMIDITY WAREHOUSE, DEPOT LEVEL

HAZARDOUS MATERIAL STORAGE, DEPOT LEVEL

FLAMMABLE MATERIAL STOREHOUSE, DEPOT LEVEL

RADIOACTIVE STORAGE WAREHOUSE, DEPOT LEVEL

UNDERGROUND STORAGE FACILITY, DEPOT LEVEL

VEHICLE STORAGE BUILDING, DEPOT LEVEL

AIRCRAFT PRODUCTION PARTS STORAGE, INSTALLATION

STORAGE FACILITY, GENERAL PURPOSE, INSTALLATION

ARMS BUILDING FOR BATTALION AND ABOVE

DEPLOYMENT STORAGE BUILDING

HAZARDOUS MATERIAL STORAGE BUILDING, INSTALLATION

CONTROLLED HUMIDITY WAREHOUSE, INSTALLATION

FLAMMABLE MATERIAL STOREHOUSE, INSTALLATION

UNDERGROUND STORAGE FACILITY, INSTALLATION

CONSOLIDATED HOUSING FURNITURE STORAGE

GARAGE, FAMILY HOUSING, DETACHED

DETACHED STORAGE BUILDING, FAMILY HOUSING

GARAGE, UPH, DETACHED

EXCHANGE WAREHOUSE 
INDUSTRIAL OCCUPANCY CLASSIFICATION (50)

\section{PRINT PLANT BUILDING}

14121 MISSILE LAUNCHER AND STORAGE BUILDING

14140

CARE AND PRESERVATION SHOP

14150

BOX AND CRATE SHOP

14160

14163

14165

14177

BLOCKING AND BANDING FACILITY

CENTRALIZED WASH BUILDING

FUELING/POL SUPPORT BUILDING

21110

DECONTAMINATION BUILDING

21114

21116

AIRCRAFT MAINTENANCE HANGAR

21117

AIRCRAFT MAINTENANCE BAY

21120

HANGAR SHOP SPACE

21130

AVIONICS MAINTENANCE SHOP, INSTALLATION

21140

AIRCRAFT COMPONENT MAINTENANCE SHOP

AIRCRAFT PAINT SHOP

21210

AIRCRAFT ENGINE TEST FACILITY

21220

21330

21335

GUIDED MISSILE MAINTENANCE FACILITY, DEPOT LEVEL

GUIDED MISSILE LAUNCHER EQUIPMENT SHOP, DEPOT LEVEL

SHIP REPAIR SHOP

21407

SHIP REPAIR FACILITY

21408

NATIONAL GUARD VEHICLE MAINTENANCE SHOP

21409

21410

21411

21412

21413

21414

21415

21416

21417

21435

21440

21458

21465

21510

21512

21520 COMPONENT CLEANING FACILITY

ARMY RESERVE VEHICLE MAINTENANCE SHOP

VEHICLE MAINTENANCE SHOP

REPAIR BAYS, NON-DOL/DEH/DPW

MAINTENANCE STORAGE, NON-DOL/DEH/DPW

ADMINISTRATION AND SHOP CONTROL, NON-DOL/DEH/DPW

GENERAL ITEM REPAIR SHOP, NON-DOL/DEH/DPW

COMPACT ITEM REPAIR SHOP, NON-DOL/DEH/DPW

MISSILE MAINTENANCE FACILITY

VEHICLE PAINT AND PREP SHOP, NON-DOL/DEH/DPW

MAJOR END ITEM REBUILD SHOP, DEPOT LEVEL

COMPONENT REBUILD SHOP, DEPOT LEVEL

STEAM CLEANING BUILDING, DEPOT LEVEL

DRUM RECONDITIONING PLANT, DEPOT LEVEL

SMALL ARMS REPAIR SHOP, DEPOT LEVEL

WEAPON DEMILITARIZATION SHOP, DEPOT LEVEL

21522

21530

21540

21610

21612

21620

LIGHT GUN SHOP, DEPOT LEVEL

WEAPON QUALITY ASSURANCE/CALIBRATION FACILITY, DEPOT LEVEL

HEAVY GUN SHOP, DEPOT LEVEL

SPECIAL WEAPONS SHOP, DEPOT LEVEL

AMMUNITION RENOVATION SHOP, DEPOT LEVEL

AMMUNITION SURVEILLANCE SHOP, DEPOT LEVEL

ROCKET OVERHAUL SHOP, DEPOT LEVEL

21622 EXPLOSIVES RECEIVING/SERVICE FACILITY, DEPOT LEVEL 
21630 AMMUNITION DEMOLITION SHOP, DEPOT LEVEL

21640 DUNNAGE BUILDING, DEPOT LEVEL

21642 COMPONENT CLEANING SHOP, DEPOT LEVEL

21650 AMMUNITION QUALITY ASSURANCE/CALIBRATION FACILITY, DEPOT LEVEL

21710 ELECTRONICS MAINTENANCE SHOP, DEPOT LEVEL

21712 COMMO/ELECTRONICS QUALITY ASSURANCE/CALIBRATION FACILITY, DEPOT LEVEL

21722 COMMUNICATIONS/ELECTRONICS COMPONENT CLEANING SHOP, DEPOT LEVEL

21730 RADAR MAINTENANCE SHOP, DEPOT LEVEL

21740 AVIONICS MAINTENANCE SHOP, DEPOT LEVEL

21835 REPAIR BAYS, DOL/DEH/DPW

21840

RAILROAD EQUIPMENT/ENGINE MAINTENANCE SHOP

21845

21850

21855

21872

21881

21882

21885

21887

21910

21925

22110

22120

22122

22210

22220

22228

22410

22412

22416

22422

22430

22434

22510

22520

22525

22530

22532

22535

22537

22548

ADMINISTRATION AND SHOP CONTROL, DOL/DEH/DPW

BATTERY SHOP

VEHICLE PAINT AND PREP SHOP, DOL/DEH/DPW

QUALITY ASSURANCE/CALIBRATION FACILITY, GENERAL PURPOSE, INSTALLATION

AIRBORNE EQUIPMENT/PARACHUTE REPAIR SHOP

GENERAL ITEM REPAIR SHOP, DOL/DEH/DPW

MAINTENANCE SHOP, GENERAL PURPOSE

COMPACT ITEM REPAIR SHOP, DOL/DEH/DPW

ENGINEERING/HOUSING MAINTENANCE SHOP

ENGINEER MAINTENANCE FACILITY

AIRCRAFT ENGINE ASSEMBLY PLANT

AIRFRAME ASSEMBLY PLANT

AIRCRAFT QUALITY ASSURANCE/CALIBRATION FACILITY

GUIDED MISSILE ASSEMBLY PLANT

GUIDED MISSILE HANDLING AND LAUNCHER PLANT

GUIDED MISSILE QUALITY ASSURANCE/CALIBRATION FACILITY

COMBAT VEHICLE ASSEMBLY PLANT

ENGINE TEST FACILITY

HEAT TREATING SHOP

PLATING SHOP

MACHINE SHOP

TANK/AUTOMOTIVE QUALITY ASSURANCE/CALIBRATION FACILITY

SMALL ARMS PLANT

LIGHT GUN PLANT

FORGE SHOP

HEAVY GUN PLANT

FOUNDRY

WELDING SHOP

MACHINE SHOP, WEAPONS

WEAPONS QUALITY ASSURANCE/CALIBRATION FACILITY, PRODUCTION

22610 BAG CHARGE FILLING PLANT 


$\begin{array}{ll}22612 & \text { ACID MANUFACTURING PLANT } \\ 22614 & \text { LEAD AZIDE MANUFACTURING PLANT } \\ 22616 & \text { EXPLOSIVE MANUFACTURING PLANT } \\ 22618 & \text { CHEMICAL, BIOLOGICAL, RADIOLOGICAL PLANT } \\ 22620 & \text { CASE OVERHAUL AND TANK FACILITY } \\ 22622 & \text { PYROTECHNIC PRODUCTION } \\ 22624 & \text { METAL PARTS PRODUCTION } \\ 22625 & \text { SMALL CALIBER LOADING PLANT (UNDER 40MM) } \\ 22626 & \text { BOMB HIGH EXPLOSIVES FILLING PLANT } \\ 22628 & \text { METAL PARTS LOADING PLANT } \\ 22630 & \text { MINOR CALIBER LOADING PLANT (40-75MM) } \\ 22632 & \text { AMMUNITION FOUNDRY } \\ 22635 & \text { MEDIUM CALIBER LOADING PLANT (76mm-120mm) } \\ 22638 & \text { AMMUNITION QUALITY ASSURANCE/CALIBRATION FACILITY, } \\ & \text { PRODUCTION } \\ 22640 & \text { MAJOR CALIBER LOADING PLANT (OVER 120MM) } \\ 22645 & \text { LARGE CALIBER ROCKET MOTOR LOADING PLANT } \\ 22650 & \text { MEDIUM CALIBER ROCKET MOTOR LOADING PLANT } \\ 22655 & \text { CAST HIGH EXPLOSIVE FILLING PLANT } \\ 22660 & \text { SPECIAL WEAPONS PLANT } \\ 22665 & \text { AMMUNITION WASHOUT FACILITY } \\ 22670 & \text { CASE FILLING PLANT } \\ 22680 & \text { PROPELLANT PLANT } \\ 22810 & \text { LEATHER/TEXTILE/CLOTHING PLANT } \\ 22960 & \text { ICE PLANT } \\ 89111 & \text { POWER PLANT BUILDING } \\ 89112 & \text { ACETYLENE PLANT } \\ 89113 & \text { POWER SUBSTATION/SWITCHING STATION BUILDING } \\ 89115 & \text { ENVIRONMENTAL TEST LABORATORY } \\ 89117 & \text { INERT GAS FACILITY } \\ 89120 & \text { PLANT/UTIIITIES BUILDING } \\ 89121 & \text { HEATING PLANT BUILDING } \\ 89123 & \text { COMPRESSED AIR PLANT } \\ 89126 & \text { REFRIGERATION/AIR-CONDITIONING BUILDING } \\ 89130 & \text { HAZARDOUS BUILDING } \\ 89131 & \text { SEWAGE/WASTE TREATMENT BUILDING } \\ 89132 & \text { OXYGEN PLANT } \\ 89133 & \text { REFUSE AND GARBAGE BUIILING } \\ 89141 & \text { WATER SUPPLY/TREATMENT BUILDING, POTABLE } \\ 89144 & \text { WATER SUPPLY BUILDING, NONPOTABLE } \\ 89148 & \text { WATER STORAGE BUILDING } \\ 89150 & \text { SHREDDER FACILITY } \\ & \end{array}$

\section{SERVICE OCCUPANCY CLASSIFICATION (60)}

71450 TRAILER PARK SERVICE BUILDING 
72210

73010

73013

73016

73021

73022

73028

73030

73032

74012

74013

74020

74021

74046

74047

74048

74050

74051

74053

74056

74058

74060

74062

74064
DINING FACILITY

FIRE STATION

BUS STATION

POLICE/MP STATION

GARRISON BREAD AND PASTRY KITCHEN

MILK PROCESSING PLANT

DRUG AND ALCOHOL ABUSE CENTER

LAUNDRY/DRY CLEANING FACILITY

LAUNDRY/DRY CLEANING PICK-UP POINT

CAFETERIA

CANTEEN

MILITARY CLOTHING SALES STORE

COMMISSARY

CONSOLIDATED OPEN DINING FACILITY

ENLISTED OPEN DINING FACILITY

OFFICER OPEN DINING FACILITY

EXCHANGE BRANCH

EXCHANGE CAFETERIA

EXCHANGE MAIN RETAIL STORE

EXCHANGE SERVICE OUTLET

EXCHANGE CONCESSION

BREAK/LUNCH ROOM

FAST FOOD/SNACK BAR

POST (INSTALLATION) RESTAURANT

RESEARCH AND DEVELOPMENT OCCUPANCY CLASSIFICATION (70)

13131 INFORMATION PROCESSING CENTER

13135 PHOTO LAB

13140 INFORMATION SYSTEMS PROCESSING CENTER

14116 FORENSIC LAB

31010 CHEMISTRY LAB

31015 GREENHOUSE, R\&D

31020 METALLURGY LAB

31030 NUCLEAR PHYSICS AND CHEMICAL LAB

31040 PHYSICS LAB

31050 HUMAN ENGINEERING LAB

31060 MEDICAL RESEARCH LAB

31110 AIRCRAFT AND FLIGHT EQUIPMENT BUILDING

31210 ASTRONAUTICAL AND GEOPHYSICAL BUILDING

31220 GUIDED MISSILE BUILDING

31410 GROUND TRANSPORT EQUIPMENT BUILDING

31510 ORDNANCE BUILDING

31610 CHEMICAL EQUIPMENT AND MATERIAL BUILDING

31620 AMMUNITION/EXPLOSIVES/TOXICS BUILDING

31710 COMMUNICATION EQUIPMENT BUILDING 
DETECTION EQUIPMENT BUILDING

31730

ELECTRICAL EQUIPMENT BUILDING

31740

ELECTRONIC EQUIPMENT BUILDING

31820

PROPULSION SYSTEMS BUILDING

31910

NONMETALLIC MATERIAL FACILITY

31920

LAB AND TEST BUILDING, GENERAL PURPOSE

31930

VIBRATION TEST LAB

32110

PRECISION MACHINE SHOP

37110 RANGE BUILDINGS

\section{ALL OTHER OCCUPANCY CLASSIFICATION (80)}

$\begin{array}{ll}73017 & \text { CHAPEL } \\ 73019 & \text { FAMILY LIFE CENTER } \\ 73050 & \text { AIR RAID/FALLOUT SHELTER } \\ 73056 & \text { SMOKING SHELTER } \\ 73074 & \text { PRIVATELY OWNED VEHICLE INSPECTION } \\ 73075 & \text { SEPARATE TOILET/SHOWER FACILITY } \\ 73080 & \text { CEREMONIAL HALL } \\ 74003 & \text { AUDIO/PHOTO CLUB FACILITY } \\ 74009 & \text { BOAT HOUSE } \\ 74010 & \text { AUDITORIUM, GENERAL PURPOSE } \\ 74011 & \text { BOWLING CENTER } \\ 74022 & \text { SKILL DEVELOPMENT CENTER, NON-AUTOMOTIVE } \\ 74024 & \text { AUTOMOTIVE SKILLS CENTER } \\ 74028 & \text { PHYSICAL FITNESS CENTER } \\ 74029 & \text { GREENHOUSE } \\ 74030 & \text { GOLF CLUB HOUSE } \\ 74031 & \text { GOLF COURSE MAINTENANCE FACILITY } \\ 74049 & \text { RIDING STABLE } \\ 74052 & \text { EXCHANGE AUTOMOTIVE SERVICE STATION } \\ 74054 & \text { EXCHANGE MAINTENANCE SHOP } \\ 74065 & \text { RECREATIONAL EQUIPMENT CHECKOUT } \\ 74066 & \text { YOUTH CENTER } \\ 74068 & \text { RECREATION CENTER } \\ 74070 & \text { INDOOR ROLLER SKATING RINK } \\ 74072 & \text { INDOOR SWIMMING POOL } \\ 74075 & \text { RECREATIONAL SUPPORT FACILITY } \\ 74078 & \text { THRIFT SHOP } \\ 74082 & \text { INDOOR ICE SKATING RINK } \\ 74085 & \text { PRIVATE/ORGANIZATIONAL CLUB FACILITY } \\ 74087 & \text { RECREATION PARK SERVICE BUILDING } \\ 74089 & \text { OUTDOOR POOL SERVICE BUILDING } \\ 76010 & \text { MUSEUM } \\ & \end{array}$

